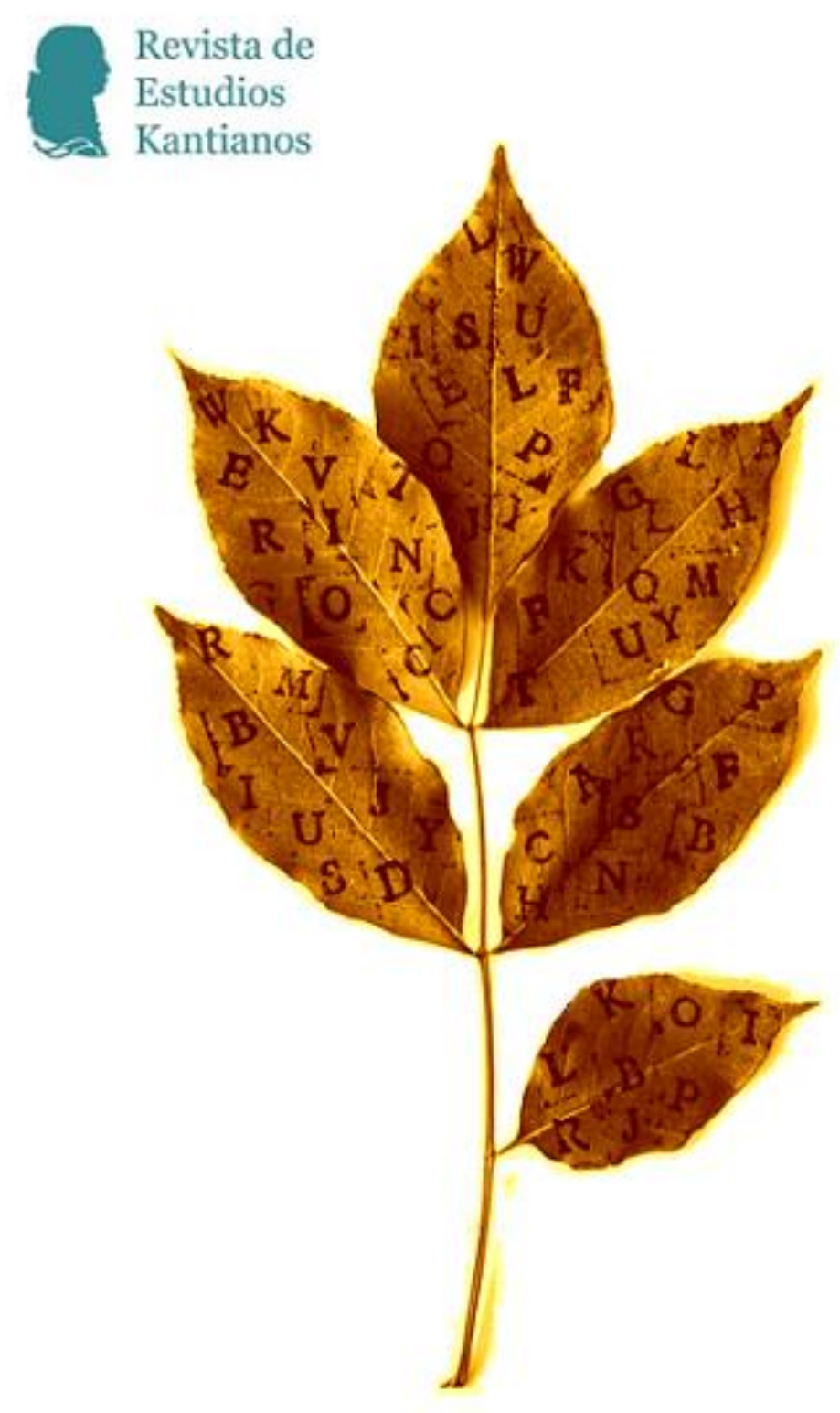




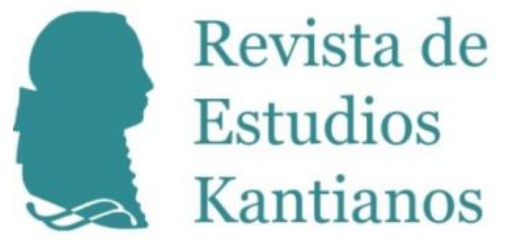




\section{Revista de Estudios Kantianos}

Publicación internacional de la Sociedad de Estudios Kantianos en Lengua Española Internationale Zeitschrift der Gesellschaft für Kant-Studien in Spanischer Sprache

International Journal of the Society of Kantian Studies in the Spanish Language

\section{Dirección}

Fernando Moledo, Fernuniversität in Hagen

fernando.moledo@fernuni-hagen.de

Hernán Pringe, CONICET-Universidad de Buenos Aires/

Universidad Diego Portales, Santiago de Chile

hpringe@gmail.com

\section{Secretario de edición}

Óscar Cubo Ugarte, Universitat de València

oscar.cubo@uv.es

\section{Secretaria de calidad}

Alba Jiménez Rodríguez, Universidad Complutense de Madrid

albjim04@ucm.es

\section{Editores científicos}

Jacinto Rivera de Rosales, UNED, Madrid

Claudia Jáuregui, Universidad de Buenos Aires

Vicente Durán, Pontificia Universidad Javeriana, Bogotá

Julio del Valle, Pontificia Universidad Católica del Perú, Lima

Jesús Conill, Universitat de València

Gustavo Leyva, Universidad Autónoma de México, México D. F.

María Xesús Vázquez Lobeiras, Universidade de Santiago de Compostela

Wilson Herrera, Universidad del Rosario, Bogotá

Pablo Oyarzun, Universidad de Chile, Santiago de Chile

Paula Órdenes Azúa, Universität Heidelberg 


\section{Comité científico}

Juan Arana, Universidad de Sevilla

Reinhardt Brandt, Philipps-Universität Marburg

Mario Caimi, Universidad de Buenos Aires

Monique Castillo, Université de Paris-Est

Adela Cortina, Universitat de València

Bernd Dörflinger, Universität Trier

Norbert Fischer, Universität Eichstätt-Ingolstadt

Miguel Giusti, Pontificia Universidad Católica del Perú

Dulce María Granja, Universidad Nacional Autónoma de México

Christian Hamm, Universidad Federal de Santa María, Brasil

Dietmar Heidemann, Université du Luxembourg

Otfried Höffe, Universität Tübingen

Claudio La Rocca, Università degli Studi di Genova

Juan Manuel Navarro Cordón, Universidad Complutense, Madrid

Carlos Pereda, Universidad Nacional Autónoma de México

Gustavo Pereira, Universidad de la República, Uruguay

Ubirajara Rancan de Azevedo, Universidade Estadual Paulista, Brasil

Margit Ruffing, Johannes Gutenberg-Universität Mainz

Gustavo Sarmiento, Universidad Simón Bolívar, Venezuela

Sergio Sevilla, Universitat de València

Roberto Torretti, Universidad Diego Portales, Santiago de Chile

Violetta Waibel, Universität Wien

Howard Williams, University of Aberystwyth

Allen W. Wood, Indiana University

Diseño, revisión de estilo, corrector y maqueta

Josefa Ros Velasco, Harvard University, Cambridge (MA)

\section{Entidades colaboradoras}

Sociedad de Estudios Kantianos en Lengua Española (SEKLE)

Departament de Filosofia de la Universitat de València

Instituto de Humanidades, Universidad Diego Portales

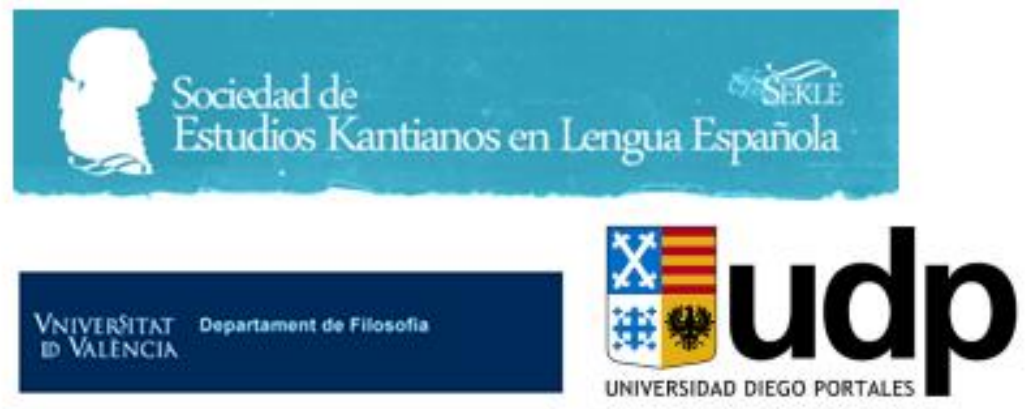




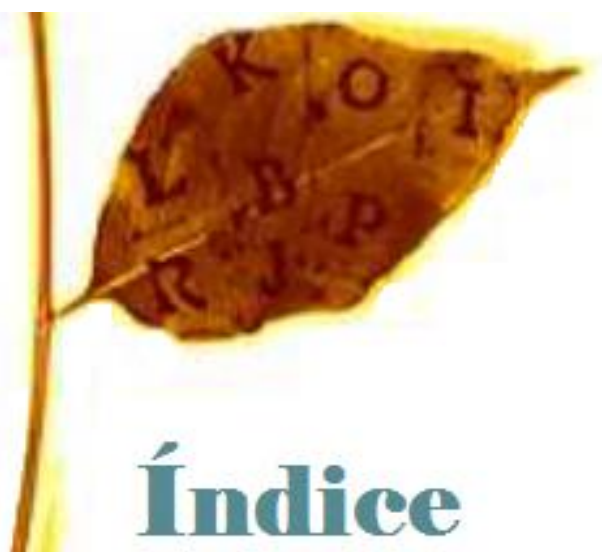

\section{Artículos}

137 ¿Puede la razón práctica ser artificial?

Dieter Schönecker

DOI 10.7203/REK.3.2.13208

149 Invitación al estudio de la aetas kantiana. La filosofía trascendental de Kant a la luz de la crítica de sus coetáneos alemanes

Rogelio Rovira

DOI 10.7203/REK.3.2.13017

175 La virtud de la humildad en la filosofía práctica de Hermann Cohen

Héctor Oscar Arrese Igor

DOI 10.7203/REK.3.2.12665

190 Elastic force in Kant's early works

Stephen Howard

DOI 10.7203/REK.3.2.12780

208 La relación entre autoconciencia pura y existencia en la segunda edición de la Crítica de la razón pura

Alejandra Baehr S.

DOI 10.7203/REK.3.2.12776

\section{Semblanza}

224 Jorge Eugenio Dotti in memoriam

Alberto Mario Damiani

DOI 10.7203/REK.3.2.13208

\section{Recensiones}

227 Miguel Alejandro Herszenbaun: La antinomia de la razón pura en Kant y Hegel. Madrid, Alamanda, 2018, 603 pp. ISBN: 978-84-940-241-9-1. 
Agemir Bavaresco

DOI 10.7203/REK.3.2.13190

229 Adela Cortina: Aporofobia, el rechazo al pobre. Un desafío para la democracia. Barcelona, Paidós, 2017, 196 pp. ISBN: 978-84-493-3338-5.

Pedro Jesús Teruel

DOI 10.7203/REK.3.1.13137

231 Francesco V. Tomassi (comp.): Der Zyklop in der Wissenschaft. Kant und die anthopologia transcendentalis, Archiv für Begriffsgeschichte, 14. Hamburgo, Félix Meiner Verlag, 2018, 207 pp. ISBN: 978-3-7873-3427-8.

Luciana Martínez

DOI 10.7203/REK.3.2.13162

234 Roberto Rodríguez Aramayo: Kant entre la Moral y la Política. Madrid, Alianza, 2018, 309 pp. ISBN: 978-84-9181-309-5.

Alba M. Jiménez Rodríguez

DOI 10.7203/REK.3.2.13150

\section{Novedades editoriales}

237 Immanuel Kant: Crítica de la razón pura. Estudio preliminar, traducción y notas de Mario Caimi. Segunda reimpresión con correcciones del traductor. México, Fondo de Cultura Económica, Universidad Autónoma Metropolitana y Universidad Nacional Autónoma de México, 2018, 734 pp. ISBN: 978-607-16-0119-3.

Mario Caimi

DOI 10.7203/REK.3.2.13125

238 Gustavo Leyva; Álvaro Peláez; Pedro Stepanenko (eds.): Los Rostros de la Razón: Immanuel Kant desde Hispanoamérica. Barcelona, Anthropos Editorial; México,

Universidad Autónoma Metropolitana, 2018, 3 vols., 208 pp. ISBN: 978-84-16421-91-6.

Gustavo Leyva

DOI 10.7203/REK.3.2.13124

\section{Eventos y normas para autores}

239 Leuven Kant Conference 2019: Kant's Transcendental Dialectic

Normas para autores

DOI 10.7203/REK.3.2.13218 


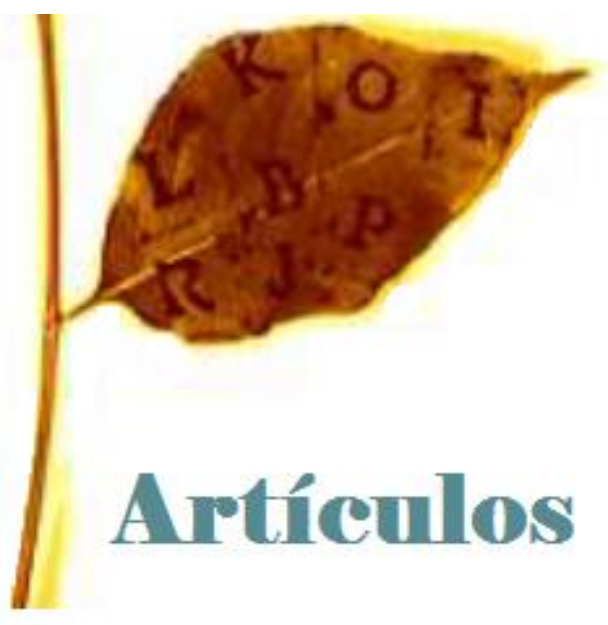




\title{
¿Puede la razón práctica ser artificial?
}

\author{
DIETER SCHÖNECKER ${ }^{2}$
}

\begin{abstract}
Resumen
¿Puede la razón práctica ser artificial? Desde un punto de vista kantiano, la respuesta es claramente negativa: la razón práctica no puede ser artificial. Luego de una observación preliminar acerca de la posibilidad de las máquinas morales kantianas (1.1) y de ciertos aspectos fundamentales acerca del concepto de razón práctica (1.2) e intuicionismo en Kant (1.3), sostendré que, en un modelo kantiano de obligación moral, el sujeto moral (humano) típico tiene, y debe tener, sentimientos morales para poder conocer la validez de la ley moral como un imperativo categórico (1.4). Por medio del argumento del conocimiento en contra del fisicalismo y del funcionalismo, sostendré que las computadoras no tienen sentimientos y, a fortiori, no tienen sentimientos morales; por lo tanto, las computadoras no son sujetos morales (1.5). Esta conclusión se basa en un yo siento kantiano más que en un yo pienso (1.6). A continuación, me ocuparé de dos problemas de ese argumento (2). Concluiré con una analogía (3): así como los planetas no vuelan, las computadoras no sienten.
\end{abstract}

Palabras clave: inteligencia artificial, razón práctica, sentimiento moral, yo pienso vs. yo siento, argumento del conocimiento

\section{Can practical reason be artificial?}

\begin{abstract}
Resumen
Can practical reason be artificial? The answer, from a Kantian point of view, is clearly negative: Practical reason cannot be artificial. After a preliminary remark on the possibility of Kantian moral machines (1.1) and some basics on the concept of practical reason (1.2) and Kant's intuitionism (1.3), I will argue that in a Kantian model of moral obligation, the typical (human) moral subject has moral feelings and must have them in order to cognize the validity of the moral law as a categorical imperative (1.3). Using the knowledge argument against physicalism and functionalism, I shall argue that computers have no feelings and, a fortiori, no moral feelings; therefore, computers are no moral subjects (1.4). This conclusion is based on a Kantian I feel rather than I think (1.5). I will then tackle two problems with this argument (2). I will conclude with an analogy (3): Just as planets do not fly, computers do not feel.
\end{abstract}

Keywords: artificial intelligence, practical reason, moral feelings, I think vs. I feel, knowledge argument

La inteligencia artificial (IA) ha generado una variedad de preguntas morales, jurídicas, económicas, políticas —en suma, preguntas prácticas — que precisan de una respuesta pronto: desde cómo lidiar con autos que se conducen solos hasta la IA como el fin de la raza humana debido a algún tipo de rareza tecnológica. Para solo nombrar un incidente reciente, recordemos la disputa que atañe al Korea Advanced Institute of Science and Technology, que, en una carta abierta, fue acusado por 50 académicos de participar en un programa para desarrollar las así llamadas "máquinas asesinas" (cf. Wakefield 2018). ${ }^{3}$ Dado que la IA, al menos desde estándares filosóficos, es un fenómeno bastante

${ }^{1}$ Traducción: Fiorella Tomassini (UBA-CONICET). Una versión en inglés de este artículo será publicada en Journal of Artificial Intelligence Humanities.

${ }^{2}$ Universidad de Siegen. Contacto: dieter.schoenecker@uni-siegen.de

${ }^{3}$ Quisiera agradecer a los organizadores de The First International Conference on Artificial Intelligence Humanities que tuvo lugar

en la Universidad Chung-Ang (Seúl), el 16 de agosto de 2018. Agradezco especialmente al Prof. Chan Kyu Lee y al Prof. 
reciente, tanto estas preguntas prácticas o problemas así como sus respuestas posibles son bastante novedosas. Nótese, sin embargo, que estas respuestas, a su vez, dependerán de fundamentaciones que lejos están de ser vírgenes o inocentes. En ética aplicada y filosofía política, rápidamente llegamos a preguntas tradicionales y a posiciones que tenemos que discutir tanto a nivel metaético como normativo para ofrecer respuestas plausibles. Por lo tanto, no es sorprendente que en artículos sobre máquinas morales se expongan, por ejemplo, argumentos sobre el viejo y querido utilitarismo (v., e.g., Bonnefon; Shariff; Rahwan 2015).

Sin embargo, aquí las preguntas prácticas o de ética aplicada sobre la IA no son de mi interés. Más bien, la pregunta que trataré aquí pertenece esencialmente a la filosofía de la mente: ¿puede la razón práctica ser artificial? La razón práctica es entendida de la mejor manera, sostengo, como un poder genuino de conocer y querer el bien. Desde un punto de vista kantiano, la respuesta a esa pregunta es claramente negativa: la razón práctica no puede ser artificial. Es tentador pensar que esta respuesta tiene su fundamento en el pensamiento epistemológico de Kant —o bien, como Kant diría, en el pensamiento teórico de que la razón siempre es la razón de alguien -, como por ejemplo que no hay pensar sin alguien que piense o siempre pueda pensar yo pienso. Examinaré esto brevemente, pero me centraré en la filosofía práctica de Kant. También desde este punto de vista práctico, la conclusión de que la razón práctica no puede ser artificial es rápida, sólida e inevitable, pues la razón práctica es libre y las computadoras no lo son. Sin embargo, mi enfoque es diferente: se basa en la idea de que la razón moral está acompañada de sentimientos morales que las computadoras no pueden tener. Luego de una observación preliminar acerca de la posibilidad de las máquinas morales kantianas (1.1) y de ciertos aspectos fundamentales acerca del concepto de razón práctica (1.2) e intuicionismo en Kant (1.3), sostendré que, en un modelo kantiano de obligación moral, el sujeto moral (humano) típico tiene, y debe tener, sentimientos morales para poder conocer la validez de la ley moral como un imperativo categórico (1.4). Por medio del argumento del conocimiento en contra del fisicalismo y del funcionalismo, sostendré que las computadoras no tienen sentimientos y, a fortiori, no tienen sentimientos morales; por lo tanto, las computadoras no son sujetos morales (1.5). Esta conclusión se basa en un yo siento kantiano más que en un yo pienso (1.6). A continuación, me ocuparé de dos problemas de ese argumento (2). Concluiré con una analogía (3): así como los planetas no vuelan, las computadoras no sienten.

\section{El argumento a partir de los sentimientos morales}

Incluso sabiendo solo un poco sobre la filosofía de Kant, es fácil entender un argumento que, si es cierto, descarta claramente la posibilidad de que las computadoras tengan razón práctica. Este es el argumento a partir de la libertad práctica trascendental. Un bosquejo rápido sería el siguiente: la obligación moral presupone la libertad práctica trascendental de la razón práctica. Esta libertad es, hablando negativamente, la independencia de la causalidad natural o determinismo físico. Las computadoras, sin embargo, están determinadas por leyes de la física. Por lo tanto, no pueden ser libres. Pero la razón práctica $-\mathrm{y}$, por consiguiente, el ser humano- es libre, y precisa ser libre para que la moralidad tenga sentido (Kant es un incompatibilista). ${ }^{4}$ Por lo tanto, ninguna computadora puede tener razón práctica. Nótese que incluso en una comprensión no-determinista de la física, e incluso en relación con computadoras cuánticas, este argumento a partir de la libertad sigue valiendo. Pues, la libertad no es solo independencia de causas naturales sino además una facultad positiva, a

Hyeongjoo Kim. Quisiera también expresar mi gratitud a Larissa Berger, al Prof. Dr. Markus Lohrey, a Christian Prust, Elke Schmidt y al Dr. Thomas Sukopp por las discusiones sobre IA.

${ }^{4}$ Kant es un compatibilista solo en el sentido de que la libertad y el determinismo son compatibles, asumiendo la diferencia entre el mundo nouménico y el mundo sensible. Pero esta no es la suposición común utilizada en el debate acerca del compatibilismo e incompatibilismo (cf. Schönecker 2005). 
saber, la facultad de determinarse a uno mismo en un acto autónomo de espontaneidad absoluta, y tal espontaneidad, a diferencia del azar, no es carente de ley.

Por consiguiente, solo con saber un poco de Kant, se puede ver claramente que, al menos desde el punto de vista kantiano, es bastante obvio que una computadora no puede tener razón práctica. Dado que esto es tan obvio, quisiera llamar la atención sobre otro argumento de la filosofía práctica de Kant que usualmente pasa desapercibido; lo llamaré el argumento a partir de los sentimientos morales.

1.1. Una observación premilimar: las máquinas morales kantianas

Una vez, Alan Turing listó un número de cosas que las personas creen que las computadoras nunca serán capaces de hacer; entre ellas, estaba la capacidad de "distinguir el bien del mal". Por supuesto, depende de qué significa "distinguir el bien del mal", pero al menos en relación con el output de ese "distinguir el bien del mal", esa presuposición puede resultar tranquilamente falsa. Desde hace algún tiempo, existen discusiones serias sobre las "máquinas morales" (cf., e.g., Wallach; Allen 2009) y el desarrollo de robots genera preguntas morales que no solo son de interés teórico (o filosófico), por así decirlo, sino que esas preguntas son tratadas de modo bastante práctico. Los algoritmos morales parecen posibles y esos algoritmos no solo, por ejemplo, pueden ayudar a los jueces a tomar decisiones morales, sino que además, en algún sentido muy limitado, pronto tomarán decisiones morales por sí mismos (pensemos tan solo en los así llamados vehículos autónomos). Tal vez sea muy tentador asumir que esas máquinas morales deben estar basadas en algún tipo de razonamiento utilitarista, dado el carácter matemático (y prima facie la facilidad) del cálculo utilitario o hedonista. Sin embargo, dado el aspecto formal del famoso imperativo categórico de Kant y de la idea de universalización, eso podría ser un prejuicio: una computadora también podría ser capaz de realizar un algoritmo moral sobre fundamentos kantianos. Recordemos la idea básica de la así llamada fórmula de la ley natural: supongamos que alguien tiene una máxima, por ejemplo, de que se suicidará si su vida causa irremediablemente, o causará, más sufrimiento que placer. El imperativo categórico obliga a que se pregunte si esa máxima puede ser una ley universal de modo tal que todo aquel que experimente más sufrimiento que placer realmente se suicide. Entonces puede que se dé cuenta de que ello lleva a algún tipo de contradicción. Hubo un largo debate, que aún continúa, sobre cómo entender la contradicción que Kant tiene en mente pero, al menos, en una interpretación de algún modo formal (lógica) de la contradicción envuelta, parece posible una máquina moral kantiana que corra un test de universalización. ${ }^{5}$

\subsection{El concepto de razón práctica en $\mathrm{Kant}^{6}$}

La "razón práctica" es volición buena (pura): «cada cosa de la naturaleza actúa según leyes. Sólo un ser racional tiene la facultad de obrar según la representación de las leyes, es decir, según principios, o [lo que es lo mismo, tiene] una voluntad. Como para la derivación de las acciones a partir de las leyes se requiere razón, entonces la voluntad no es otra cosa que razón práctica» (GMS: 412). ${ }^{7}$ Es importante, sin embargo, diferenciar tres aspectos del concepto de razón práctica o buena voluntad en Kant: la buena voluntad de modo nouménico, la buena voluntad de modo práctico y la voluntad divina. La buena voluntad de modo nouménico es la voluntad autónoma que como tal quiere el bien. Como facultad moral, da la ley moral (el imperativo categórico) para seres imperfectos y, por medio del sentimiento moral, es también una fuerza de motivación. Todos los seres humanos tienen esta

${ }^{5}$ Recordemos el "felicific calculus" de Bentham

${ }^{6}$ Aquí sigo a Schmidt y Schönecker (2017).

${ }^{7}$ Cf. GMS: 427: «la voluntad es pensada como una facultad de determinarse a sí misma, ${ }^{7}$ a obrar en conformidad con la representación de ciertas leyes». Las citas en español de la Fundamentación para la metafísica de las costumbres son tomadas de la traducción de Fernando Moledo (Buenos Aires, Colihue, 2018, en prensa) [Nota de la traductora]. Todas las páginas y número de líneas refieren a la paginación de la Edición Académica. 
voluntad, incluso si se actúa de modo inmoral (cf. GMS: 400, 34-37; 412, 30-35; 440, 7-13; 449, 16 $23 ; 455,7-9$.

La buena voluntad de modo nouménico es la base tanto para la buena voluntad de modo práctico como para la voluntad divina. La buena voluntad de modo práctico es la voluntad que tienen los seres finitos cuando sus voliciones son de hecho morales, es la buena voluntad de modo nouménico considerada como una voluntad que se manifiesta exitosamente en un ser finito contra la influencia de las inclinaciones y los deseos. Para seres imperfectos, actuar moralmente (actuar con una buena voluntad de modo práctico) significa actuar por deber. La buena voluntad de modo nouménico que se manifiesta en una persona sin obstáculos sensoriales (activos) es lo que Kant llama "la voluntad divina", solo pertenece a Dios y a otros seres divinos. Estos seres no tienen inclinaciones y deseos contrarios al bien; «la voluntad cuyas máximas concuerdan necesariamente con las leyes de la autonomía es una voluntad santa, absolutamente buena» (GMS: 439, 28). La buena voluntad de modo nouménico como tal (dejando de lado su incorporación a un ser finito) no puede ser diferenciada de la voluntad divina (dejando de lado su incorporación a un ser infinito). Es una causalidad nouménica: «el ser racional se incluye a sí mismo, como inteligencia, en el mundo inteligible, y llama voluntad a su causalidad, meramente como una causalidad eficiente que pertenece a ese mundo inteligible» (GMS: 453,17, el énfasis es mío). Esta voluntad se identifica luego con la voluntad que es autónoma, i.e. con la autonomía misma, «si nos pensamos como libres nos trasladamos, como miembros, al mundo inteligible, y reconocemos la autonomía de la voluntad, con su consecuencia, la moralidad»(GMS: 453,11, el énfasis es mío). Nótese cómo continúa Kant: «si nos pensamos como obligados, entonces nos consideramos como pertenecientes al mundo sensible y, sin embargo, al mismo tiempo, al mundo inteligible» (GMS: 453,14, el énfasis es mío). Por lo tanto, la voluntad libre es la voluntad nouménica (la razón práctica pura) y la autonomía es su propiedad, y en algunos contextos, esta voluntad es considerada no como la voluntad de un ser humano, que también es parte del mundo sensible, sino solo como una voluntad nouménica: «como mero miembro del mundo inteligible todas mis acciones serían entonces acciones perfectamente conformes al principio de la autonomía de la voluntad pura» (GMS: 453, 25, el énfasis es mío). Es importante tener presente que, como tal, la buena voluntad de modo nouménico no es solo una mera capacidad de actuar moralmente, pues esta voluntad como tal quiere el bien. No obstante, es la buena voluntad de modo nouménico la que capacita al ser humano para actuar moralmente. Por lo tanto, para el ser humano — que es un miembro del mundo nouménico y del mundo sensible - la buena voluntad de modo nouménico es, en efecto, una capacidad. Además, a menos que la autonomía no sea lo mismo que una buena voluntad de modo práctico, un sinvergüenza no sería autónomo —que ciertamente lo es en la medida en que incluso él, de algún modo, quiere ser moralmente bueno, i.e. en la medida en que tiene una buena voluntad de modo nouménico. Retomaremos este punto una vez más.

\subsection{El intuicionismo en Kant}

Probablemente, pronto habrá algoritmos morales por medio de los cuales las computadoras calculen qué hacer en determinadas situaciones moralmente problemáticas, pero ello no significa que actúen en algún sentido sustancial. Muchas veces es sorprendente ver cómo a los defensores de una IA fuerte $^{8}$ les parece obvio que las computadoras «pueden hacer muchas cosas igual o mejor que los seres humanos» (Russell; Norvig 2016: 1022, el énfasis es mío). Pero está claro que tal suposición comete una falacia, dado que realmente la pregunta aquí es si las computadoras pueden hacer cualquier cosa que un ser humano puede hacer cuando se trata de actuar o pensar. De acuerdo con Kant, no hay aquí un "hacer" en sentido estricto. Las acciones humanas, en rigor, no solo son acciones libres. Si están guiadas por la ley moral, están inmersas en sentimientos morales. Las

${ }^{8}$ Por "IA fuerte" me refiero, a los efectos de mis propósitos, a que una computadora podría tener conciencia, una vida interior [qualia] y que realmente piensa del modo en el que nosotros lo hacemos. Una computadora tal no solo imitaría el pensar, y no solo imitaría el pensar moral, sino que realmente pensaría y, por lo tanto, pensaría moralmente. 
computadoras no tienen sentimientos, por lo tanto, no actúan moralmente incluso si toman decisiones de acuerdo con el deber. Consideremos con más detalle esta idea.

Hasta ahora, se considera que Kant defiende, en palabras de Edmund Husserl, «un racionalismo extremo y casi absurdo», un «intelectualismo extremo» que no deja lugar a los sentimientos (1988: 412). Ahora bien, cualquier principiante en una clase introductoria de la ética de Kant aprenderá que él sostiene de manera consistente que la razón solo puede causar acciones por medio de los sentimientos. Los sentimientos, entonces, entran en juego necesariamente ya como fundamentos de determinación (motivación). Sin embargo, es importante notar que, para Kant, los sentimientos cumplen una función mucho más importante. Como hemos visto, Kant traza una línea muy estricta entre los seres divinos y los no divinos. Los seres divinos siempre quieren lo que la buena voluntad quiere, pero esto no es cierto para los seres no divinos, sensorio-racionales. Para ellos, la ley moral es siempre un imperativo categórico que los constriñe. Cito a Kant aquí con más detalle:

\begin{abstract}
Si la razón determina la voluntad indefectiblemente, entonces las acciones de un ser tal, que son reconocidas como objetivamente necesarias, son también necesarias subjetivamente; es decir, la voluntad [de un ser tal] es una facultad de elegir sólo aquello que la razón, independientemente de la inclinación, reconoce como prácticamente necesario, esto es, como bueno. Pero si la razón, sólo por sí misma, no determina la voluntad de manera suficiente, si la voluntad está sometida también a condiciones subjetivas (ciertos resortes impulsores) que no siempre concuerdan con las condiciones objetivas, en una palabra: si la voluntad no es en sí completamente conforme a la razón (que es lo que efectivamente ocurre en los hombres), entonces las acciones que objetivamente son reconocidas como necesarias, subjetivamente son contingentes, y la determinación de una voluntad tal, conforme a leyes objetivas, es constricción; es decir, la relación de las leyes objetivas con una voluntad que no es enteramente buena, es representada como la determinación de la voluntad de un ser racional, bien que por fundamentos de la razón, pero a los cuales esa voluntad, según su naturaleza, no es necesariamente obediente. La representación de un principio objetivo, en tanto que es constrictivo para una voluntad, se llama un mandamiento (de la razón) y la fórmula del mandamiento se llama imperativo. Todos los imperativos son expresados por medio de un deber ser e indican mediante él la relación de una ley objetiva de la razón con una voluntad que, según su cualidad subjetiva, no es determinada necesariamente por esa ley (una constricción) (GMS: 412ss).
\end{abstract}

El paso crucial es ver que la constricción es experimentada por el sentimiento de respeto (que, a su vez, tiene un aspecto negativo y positivo que aquí no puedo tratar, cf. Schadow 2012; Schmidt 2013). Pero este sentimiento no es solamente una suerte de efecto colateral. Dado que por "constricción" Kant se refiere a ninguna otra cosa más que al hecho de que para seres no divinos, sensorio-racionales (como nosotros), la ley es un imperativo, esto es, un deber. La obligación que tiene lugar aquí es experimentada en el sentimiento de respeto. De hecho, la obligación no solo es algo, de algún modo, experimentado sino además conocido por este sentimiento: «aquello que reconozco inmediatamente como ley para mí, lo reconozco con respeto» (GMS: 402, nota al pie). Y es importante ver que la famosa teoría de Kant del "factum de la razón" está directamente relacionada con esta idea (cf. Schönecker 2013ab). En el $\S 7$ de la Crítica de la razón práctica, Kant formula el imperativo categórico. Un poco más adelante, Kant dice que uno podría llamar la «conciencia de esta ley fundamental un factum de la razón» (KpV: 31, 24). La así llamada teoría del factum que explica nuestra percepción del carácter obligatorio de la ley moral es, entre otras cosas, una teoría de la justificación. La idea básica es que no puede haber una deducción del imperativo categórico en ningún sentido normal (deductivo), ${ }^{9}$ pero la realidad objetiva de la ley moral está «no obstante, firmemente establecida por sí misma» (KpV: 47, el énfasis es mío). En nuestra conciencia del

\footnotetext{
9 «Por lo tanto, la realidad objetiva de la ley moral no puede ser probada por ninguna deducción» (KpV: 47, 15).
} 
imperativo categórico, la ley moral es dada inmediatamente en su validez incondicional y obligatoria; en este sentido, la teoría del factum es una teoría de la auto-evidencia moral. Esta conciencia del imperativo categórico, sin embargo, está determinada por el sentimiento de respeto, esto es, la validez incondicional del imperativo categórico está dada en el sentimiento de respeto. Por lo tanto, es por medio del sentimiento de respeto que conocemos la validez o carácter obligatorio de la ley moral. ${ }^{10}$ De esta manera, Kant de ningún modo es un racionalista puro, tal como lo representaban Husserl y otros. Más bien, Kant es un intuicionista ético. Un intuicionista ético es alguien que sostiene la postura de que conocemos la validez de la ley moral (el tú debes moral) no por medio de algún tipo de razonamiento deductivo (inductivo o abductivo) sino por medio de cierto tipo de auto-evidencia, por un sentimiento. Es importante entender esta tesis de manera correcta: de acuerdo con Kant, no es el contenido del imperativo categórico lo que es entendido por el sentimiento de respeto; sabemos qué debemos hacer u omitir por medio de la razón y algún tipo de universalización. Por consiguiente, Kant no es un sentimentalista moral. Además, la ley moral no depende en sí misma del sentimiento moral de respeto para su validez; no es que la ley moral es válida porque tenemos ese sentimiento. De todos modos, lo que sí conocemos mediante el sentimiento de respeto es que debemos actuar moralmente, que la ley moral es categóricamente obligatoria.

\subsection{Un argumento del conocimiento kantiano}

De lo anterior se sigue, sin embargo, que una computadora no puede tener razón práctica. Para ver esto, tenemos que echar un vistazo al así llamado argumento del conocimiento o al argumento a partir del vacío explicativo, expuestos en una u otra versión por Frank Jackson (1982), Joseph Levine (1983) o Thomas Nagel (1974). ${ }^{11}$ Se trata de una historia algo intrincada y aquí solo podemos bosquejar la idea principal. Para nuestro propósito, recordemos la historia de María: pensemos en ella como una científica que sabe todo lo que hay que saber sobre colores y su percepción, excepto que ella, que está encerrada en una habitación con solo libros, TV, etc., en blanco y negro, nunca ha visto ningún objeto que no sea blanco o negro. Un día, sin embargo, deja la habitación y ve realmente algo que, según dice, es rojo. Ahora bien, de acuerdo con el fisicalismo, todo lo que existe son objetos naturales (físicos) que son totalmente descriptos y explicados por medio de la física (y posiblemente por la química, la biología y la neurociencia). Si esto fuera cierto, entonces María no conocería una cualidad nueva - y solo sería una cualidad no-representacional de su percepción o de un dato de la sensació - que todavía no ha conocido porque todo lo que hay que conocer sobre colores desde una perspectiva objetiva, en tercera persona, ella lo sabe. Pero hay algo que ella no sabía antes de dejar la habitación, a saber, cómo es o cómo se siente ver algo rojo, experimentar un cierto quale (como dice la jerga). Por lo tanto, hay algo en el mundo que no es físico, i.e. que no es totalmente descriptible por la física. Este algo es la conciencia teniendo experiencias fenoménicas. Entonces, podríamos saber todo lo que hay que saber sobre los hechos físicos o funcionales que conciernen a un estado mental (como por ejemplo tener la experiencia de que algo sea rojo) y todavía no sabríamos todo sobre el estado mental. Por consiguiente, este estado mental no puede ser idéntico a, o reducido a, aquellos hechos físicos o funcionales. Pero podemos saber todo acerca de cómo está hecha una computadora y cómo funciona. No existe un cómo es ser una computadora y, por lo tanto, a diferencia de los seres para quienes hay una determinada vida interior fenoménica, estar en un estado computacional no significa estar en un estado mental.

Si bien existe cierta disputa sobre qué estados mentales son, o están acompañados por, qualia, es claro que los sentimientos son qualia. Pero entonces el argumento es evidente: a menos que creamos que las computadoras experimentan qualia, no pueden tener razón práctica. En efecto, la razón práctica viene acompañada de constricción práctica a través del sentimiento de respeto. El

${ }^{10}$ Colin, Varner y Zinser (2000: 260) notan que las emociones no solo tienen una función motivacional, sin embargo, no reconocen la función cognitiva con relación a la validez de la ley moral.

${ }^{11}$ Hay algunas diferencias en estos autores, pero asumo que el punto central es el mismo (excepto tal vez en el caso de Levine). 
imperativo categórico no puede ser entendido sin este sentimiento. Puesto que las computadoras no tienen sentimientos, y a fortiori, ningún sentimiento de respeto, no pueden entender el imperativo categórico.

Este es el argumento básico. Desde un punto de vista kantiano, tres puntos más son importantes. Primero, y solo de pasada, debo hacer notar que en su obra tardía (La metafísica de las costumbres) Kant desarrolló de manera ulterior su teoría de los sentimientos morales distinguiendo cuatro tipos de predisposiciones morales y, consecuentemente, cuatro sentimientos morales: el sentimiento moral propiamente dicho, la conciencia, el amor a los seres humanos como amor complacentiae y el respeto por uno mismo (cf. Schönecker 2010). En relación con cada uno de esos sentimientos, Kant resalta que no hay obligación de tenerlos, pues, en primer lugar, tener esos sentimientos es ya una presuposición necesaria para que tenga sentido el concepto mismo de deber. Segundo, para Kant, la razón práctica es la voluntad nouménica que puede tanto conocer como querer el bien, es autónoma, y por lo tanto, una causalidad nouménica. Como he indicado anteriormente, esta es una historia complicada pero los sentimientos morales no pueden ser naturalizados en tanto son producidos por la razón, que tampoco puede ser naturalizada. Por ello, incluso si las computadoras tuvieran sentimientos, no podrían tener el sentimiento de respeto, porque este sentimiento tiene su fuente en la razón, la cual no es una entidad natural (física). Tercero, Kant también entiende los sentimientos como qualia. Por supuesto, este término no fue utilizado por Kant. Pero él entendía claramente el hecho de que los sentimientos tienen un costado fenoménico que no puede ser comprendido por medio de un conocimiento físico sino que debe ser experimentado. El costado fenoménico de los sentimiento es enfatizado por Kant en su teoría de la belleza (cf. Berger 2019). Los sentimientos como tales, dice Kant en la así llamada Primera introducción a la Crítica de la facultad de juzgar, «no pueden de ningún modo ser explicados», más bien «deben ser sentidos, no entendidos» [«Man sieht hier leicht, daß Lust oder Unlust, weil sie keine Erkenntnisarten sind, für sich selbst gar nicht können erklärt werden, und gefühlt, nicht eingesehen werden wollen»] (EEKU: 232). En la misma línea, Kant escribe en la Metafísica de las costumbres que «el placer y el displacer no pueden por sí mismos ser explicados» (MS: 212).

En cualquier caso, la pureza en la razón pura práctica de ningún modo sugiere que no haya sentimientos involucrados. La pureza de la razón práctica consiste en estar libre de consideraciones sobre la felicidad o el amor propio. En los seres humanos, es la razón pura la que se vuelve práctica sobre la fuerza de los sentimientos morales. Entonces, aun cuando una computadora "tome una decisión" (por así decirlo) sobre la base de un algoritmo moral, no tiene idea de lo que es "hacer" (por así decirlo): no comprende en absoluto qué es la ley moral como un imperativo categórico. En la terminología de Kant, una computadora puede realizar acciones (por así decirlo) conforme al deber. Pero ciertamente no puede realizar acciones por deber. Y ciertamente no tiene conciencia o amor propio; a mi modo de ver, una tesis tal ni siquiera es comprensible.

Antes de pasar a dos problemas de esta tesis kantiana, veamos brevemente un posible argumento ulterior, el argumento a partir de la facultad de juzgar. Dada la latitud de muchos deberes éticos, este es obviamente un aspecto importante de la razón práctica. El argumento funciona así: siguiendo a Kant, la facultad de juzgar es la «facultad de pensar el particular como contenido bajo el universal» (KU: 179). Si ya existe una regla, entonces la facultad del juicio es la "facultad de subsumir" algo particular bajo esta regla. Kant llama a esto juicio determinante [bestimmende Urteilskraft]. Si todavía hay una regla que ha de ser encontrada para algo particular que no puede ser subsumido bajo una regla adquirida, entonces Kant lo llama juicio reflexionante [reflektierende Urteilskraft]. Al menos para el juicio determinante, Kant sostiene que no puede haber una regla ulterior. En efecto, si uno «pretendiera mostrar de manera universal cómo se debe subsumir bajo estas reglas, es decir, [cómo se debe] discernir si algo está bajo ellas o no, esto no podría ocurrir de otro modo sino, otra vez, mediante una regla. Pero esta, precisamente por ser una regla, requiere, de 
nuevo, una indicación de la facultad de juzgar; y así se pone de manifiesto que si bien el entendimiento es capaz de instrucción y de equipamiento por medio de reglas, la facultad de juzgar es un talento especial que no puede ser enseñado, son solamente ejercido» (KrV: A133/B172). ${ }^{12}$ Dicho de otro modo: puede haber meta-reglas acerca de cómo y cuándo aplicar reglas, pero so pena de un círculo vicioso o de un número infinito de reglas, debe haber un punto en el cual la facultad de juzgar actúa sin aplicar una regla. Las computadoras, sin embargo, no tienen más que reglas para trabajar, esto es, nada más que algoritmos (y datos, por supuesto, en relación con los cuales son aplicados). Si la facultad de juzgar es la facultad que no sigue reglas, entonces esta facultad no puede ser algo que una computadora pueda tener. La «carencia de la facultad de juzgar», dice Kant, «es lo que propiamente se llama tontería» (KrV: A133/B172); las computadoras, por lo tanto, son tontas. Pero es difícil ver si este argumento realmente puede ser aceptado. La necesidad de algo como la facultad de juzgar se debe al hecho de que no hay una comprobación completa o definición de todos los conceptos posibles y casos a priori de antemano. ${ }^{13}$ Pero si una decisión basada en la facultad de juzgar no está basada en una regla, ¿en qué está basada? Mejor que no esté basada en el azar, porque eso es algo que una computadora puede hacer (seguir la regla de elegir al azar). Uno podría pensar que la facultad de juzgar tiene que ver con algo como las intuiciones, pero las intuiciones, como por ejemplo G. E. Moore las entiende, son distintas y no tienen nada que ver con la facultad de juzgar. Las intuiciones - entendidas de manera amplia como estados mentales (como se entienden en psicología moral) de algún modo inconscientes, fuertes y que rápidamente se ven (juzgan) como verdaderos) - muy bien podrían no ser azarosas sino basadas en alguna ponderación (inconsciente, fuerte, rápida) de los bienes, y una ponderación tal podría seguir reglas. Por consiguiente, no estaría preparado para defender el argumento a partir de la facultad de juzgar.

\subsection{Yo pienso vs. yo siento}

Obviamente, los sujetos morales quieren algo y actúan sobre la base de sus voliciones. Pero también piensan, e incluso si estuviera en discusión cómo el pensamiento, y cuánto de él, está involucrado en sus decisiones morales como tales, no puede estar en discusión que los sujetos morales deban pensar (al menos, en lo que atañe a la cognición del mundo que los rodea en el que quieren y actúan). El conocimiento moral involucra conocimiento no moral sobre el mundo interno y externo. Ahora bien, Kant sostiene célebremente (en la segunda edición de la Crítica de la razón pura) que no hay pensamiento y, por lo tanto, conocimiento, del mundo interno y externo sin la autoconciencia. El yo pienso, dice, «debe poder acompañar todas mis representaciones» (KrV: B131). Qué significa exactamente esto ha sido objeto de dolorosas y largas discusiones entre los especialistas en Kant (cf. Klemme 1996; Rosefeldt 2000). ${ }^{14} \mathrm{La}$ idea básica parece ser que todo pensamiento involucra la síntesis de representaciones como las representaciones de alguien en un juicio, tal que esas representaciones, como el acto de sintetizarlas, pertenecen, y deben pertenecer, ${ }^{15}$ a un yo autoconsciente que siempre puede decir yo pienso (esas representaciones). En cualquier caso, si Kant tiene razón, y si es cierto que una computadora no tiene un yo que piensa, una computadora no piensa, y no puede pensar, y no es inteligente en el modo en que lo son los seres humanos. A lo sumo, entonces, una computadora (IA) puede imitar la inteligencia, y solo en el mejor caso, imitar el pensamiento moral.

No estoy completamente convencido de este argumento. Me parece cierto que los seres humanos (desarrollados) siempre deben poder pensar yo pienso cuando piensan (no que siempre

${ }^{12}$ Las citas en español de la Crítica de la razón pura son tomadas de la traducción de Mario Caimi (Buenos Aires, Colihue, 2007) [Nota de la traductora].

${ }^{13}$ «uno se sirve de ciertas notas solo mientras son suficientes para efectuar distinciones, en cambio, nuevas observaciones suprimen algunas [notas], ponen otras en su lugar; así, pues, el concepto no está nunca encerrado en límites seguros» (cf. KrV: B756).

${ }^{14}$ Un ejemplo de cuán difícil puede ser entender bien la posición de Kant es el libro de Kim sobre el "yo pienso" como una proposición empírica (2017). Para una vista rápida, cf. Kitcher (2005).

${ }^{15}$ Friebe (2005: 53) parece pensar que esta lectura es demasiado fuerte. 
piensan yo pienso, por supuesto). Y si esto es cierto, y es cierto que las computadoras no tienen yo (lo cual pienso que de hecho es cierto), entonces las computadoras no piensan en el modo en el que nosotros lo hacemos. Aún podría estar justificado decir que piensan: si el pensamiento teórico (no práctico) es esencialmente el acto de sintetizar contenido que requiere un centro o unidad por medio de la cual este acto es realizado, entonces es posible entender este centro o unidad como la unidad de control de una computadora. El punto es que este acto de combinar contenido (síntesis) puede no requerir Meinigkeit ni conciencia de sí mismo (apperception, como lo llama Kant), como una forma superior de Meinigkeit, sino solo una unidad de control. Esta unidad no tiene que ser necesariamente consciente de sí misma porque el contenido de (algo como) las percepciones y de (algo como) los pensamientos o proposiciones no requiere de un yo que lo piense e incluso tampoco una forma de Meinigkeit. Kant parece haber sostenido que «todo lo que piensa está constituido de la manera como la sentencia de la conciencia de mí mismo [el yo pienso] lo declara con respecto a mí» (KrV: B404); «no puedo», afirma Kant, «tener la más mínima representación por una experiencia externa, sino solamente por la conciencia de mí mismo» (KrV: B405). En otras palabras: Kant sostiene que el único modo de concebir la posibilidad del pensamiento en algo distinto a los seres humanos está basado en nuestro propio entendimiento de nosotros mismos. Si esto es cierto, no puedo concebir la posibilidad del pensamiento en una computadora sin pensarlo como un pensamiento de un yo. ¿Pero por qué debería ser esto cierto? Esta idea podría ser simplemente una consecuencia del hecho de que todavía no había computadoras. ${ }^{16}$

Entonces puede que quizás exista el pensamiento sin un yo consciente de sí mismo que piensa y sin Meinigkeit. Cuando se trata de sentimientos, sin embargo, necesariamente entramos a un mundo diferente, a saber, al mundo interno. No puede haber sentimientos sin alguien que sienta. Dejando de lado la cuestión de si tenemos que distinguir entre sentimientos en sentido estricto y emociones (como intencionales), decir que existe un estado que podríamos describir, de modo preliminar, como "hay un sentimiento", requiere que exista una instancia a quien corresponda estar en ese estado (de sentir algo). Una vez más, tal vez exista la posibilidad de concebir contenido cognitivo que no requiera alguien para quien, o de quien, sea el contenido, pero esto es incomprensible para el caso de los sentimientos.

\section{Dos problemas del argumento a partir de los sentimientos morales}

Considero que aunque el argumento a partir de los sentimientos morales es fuerte, de todos modos, tiene dos problemas. Primero, ¿qué sucede con las voluntades divinas? Como ya hemos visto, es un elemento importante de la ética de Kant distinguir entre seres divinos y no divinos. Para estos últimos, la ley moral es un imperativo categórico y, por lo tanto, deber y obligación. Para los primeros, no hay obstáculos que la moralidad tenga que superar, ellos tienen una voluntad perfectamente buena. Entonces ¿los seres divinos son en algún sentido máquinas morales? ¿Y no sería cierto que una computadora que siempre siguiera algoritmos morales tendría una voluntad buena perfecta? Bueno, no. Ciertamente, es correcto que un ser divino no puede actuar por deber. ${ }^{17}$ Pero, a diferencia de las computadoras, los seres divinos tienen una voluntad. Las computadoras no tienen voluntad, a fortiori, no quieren nada por la ley moral. La tesis de que las computadoras no tienen voluntad está respaldada por la tesis de que las voliciones son intencionales, ${ }^{18}$ por lo tanto las computadoras no tienen

\footnotetext{
${ }^{16}$ Ciertamente resta la pregunta sobre el modo en el que las computadoras tienen representaciones. Friebe (2005: 61) tiene razón cuando señala que las representaciones [Vorstellungen] como tales son siempre las representaciones de alguien. También podría ser cierto que la propiedad de ser una representación [Meinigkeit] mía no implica necesariamente un yo en sentido estricto. Sin embargo, permanece la pregunta acerca de si el pensamiento debe ser entendido como una operación que involucra representaciones como algo mental.

${ }^{17}$ Tampoco podría tener las cuatro predisposiciones morales.

${ }^{18}$ Por supuesto que todo esto está sumamente en discusión. Recordemos el largo debate actual sobre el argumento la habitación china de Searle. Para un resumen breve y una crítica cf. Gabriel (2018: 95ss).
} 
voluntad. De todos modos, la pregunta acerca de qué significa para una voluntad divina querer y actuar por la ley moral, sin sentimientos morales intermediarios, no es fácil de responder.

El segundo problema con el argumento a partir de los sentimientos morales es simplemente este: ¿las computadoras realmente no pueden tener sentimientos? Esta, también, es una historia larga y complicada y solo puedo bosquejar el problema y una posible solución. El argumento de que las computadoras quizás puedan tener, o que incluso finalmente tienen, sentimientos dice así: sabemos que nosotros tenemos conciencia y sentimientos. Al final del día, no tenemos una historia clara, menos aún comprensible y convincente, que explique cómo esto sucede, cómo realmente puede ser que tengamos una vida interior tal. Sin embargo, si algún tipo de teoría evolutiva naturalista es correcta, sí sabemos que nuestra habilidad de tener eventos mentales se desarrolló a partir de materia inconsciente. Pero si es posible que la mente y sus estados mentales evolucionen de algún modo a partir de la materia, i.e. a partir del cerebro y su encarnación, - y es posible toda vez que asumamos que los estados mentales son reales, a pesar de que puedan o no ser reducidos a estados cerebralesentonces muy bien podría ser posible que la mente y sus estados mentales puedan evolucionar de algún modo a partir de una computadora, entendida también como otro ensamble complejo de materia. Está bien, diría yo. Entonces sí, eso es posible si es posible que la mente evolucione a partir de la materia. Pero por todo lo que sabemos es también muy improbable: solo una única célula biológica es extremadamente compleja, y más aún el cerebro. Por comparación, una computadora es un objeto muy primitivo, no hay más razones para pensar que una computadora tiene una mente que pensar que la tiene una máquina de coser. ${ }^{19}$

\section{Conclusión: submarinos que nadan, planetas que vuelan}

Para concluir, quisiera volver al yo pienso de Kant. El científico en computación Edsger Dijkstra afirmó célebremente que «la cuestión acerca de si las máquinas pueden pensar... es tan relevante como la cuestión acerca de si los submarinos pueden nadar» (Russell; Norvig 2016: 1021), o bien, uno podría agregar, si los aviones pueden volar. Supongo que el punto de Dijkstra es que los submarinos pueden nadar, por supuesto, i.e. moverse a través del agua a pesar del hecho de que no nadan como los peces y que los aviones pueden volar a pesar del hecho de que se mueven a través del aire sin mover las alas hacia arriba y hacia abajo, o como sea. Siguiendo la analogía de Dijkstra, parece sensato sostener que las computadoras piensan a pesar del hecho de que no piensan del modo en el que nosotros lo hacemos; no hay un yo y, sin embargo, piensan. Pero esta analogía entre computadoras que piensan, submarinos que nadan o aviones que vuelan es engañosa. Como siempre, todo depende de cómo se definan las palabras, como "nadar", "volar" o "pensar". Si uno define "nadar" como "moverse a través del agua usando sus miembros, aletas o colas", entonces los submarinos no nadan, pero ¿por qué lo traduciríamos así? Definir una palabra —o explicar qué es para una cosa ser lo que es- presupone de alguna manera reconocer qué es esencial para esa cosa; para hacer eso, sin embargo, uno necesita casos paradigmáticos (cf. Damschen; Schönecker 2019). Ahora bien, uno podría estar de acuerdo — quizás en la línea del funcionalismo- en que las computadoras, sobre la base de determinados inputs, realizan determinadas operaciones que causan determinados outputs y, tomando en consideración solo el output — calcular, jugar al ajedrez, manejar un auto, componer música - uno está tentado a pensar que las computadoras piensan (y también que los seres humanos piensan en el modo en el que lo hacen las computadoras). La pregunta acerca de cómo y por qué medios se nada no es crucial para el concepto de nadar. Pero la diferencia entre un ser que piensa yo pienso, o al menos entre uno que siente yo siento, o experimenta yo quiero, y una

${ }^{19}$ Uno podría también, dicho sea de paso, dar vueltas al asunto y sostener que la existencia de estados mentales prueba que algo está mal con las teorías evolutivas darwinistas. Thomas Nagel, entre otros, ha hecho eso recientemente (2012). Para una visión crítica del realismo moral de Nagel, cf. Schmidt (2018). 
máquina que no tiene tal conciencia de sí es tan enorme que esos términos (pensar, sentir, querer) no deberían usarse para seres que no tienen un yo. Decir que una computadora piensa o siente es como decir que una planeta vuela solo porque se mueve a través del espacio.

Bibliography

$\mathrm{EEKU}=$ Erste Einleitung in die Kritik der Urteilskraft

GMS = Grundlegung zur Metaphysik der Sitten

$\mathrm{KpV}=$ Kritik der praktischen Vernunft

$\mathrm{KrV}=$ Kritik der reinen Vernunft

MS = Metaphysik der Sitten

BERGER, L.: Kants Philosophie des Schönen. Eine kommentarische Interpretation zu den \$§ 1-22 der ,Kritik der Urteilskraft (en prensa), 2019.

BONNEFON, J.-F.; Shariff, A.; Rahwan, I.: “Autonomous Vehicles Need Experimental Ethics: Are we ready for Utilitaran Cars?”, arXiv:1510.03346 [cs.CY] (12/10/2015).

COLIN, A.; VARNER, G.; ZINSER, J.: "Prolegomena to any future artificial moral agent", Journal of Experimental \& Theoretical Artificial Intelligence 12, 3 (2000) 251-261.

DAMSCHEN, G.; SCHÖNECKER, D.: Selbst philosophieren. Ein Methodenbuch, $3^{\mathrm{a}}$ ed., Berlín/Boston, de Gruyter, 2019.

FRIEBE, C.: Theorie des Unbewußten: Eine Deutung der Metapsychologie Freuds aus transzendentalphilosophischer Perspektive, Würzburg, Königshausen \& Neumann, 2005.

GABRIEL, M.: Der Sinn des Denkens, Berlín, Ullstein Verlag, 2018

HUSSERL, E.: "Kritik der Kantischen Ethik," en: Vorlesungen über Ethik und Wertlehre 1908-1914 (Husserliana XXXVIII), Dordrecht/Boston/London, 1988, 402-418.

JACKSON, F.: “Epiphenomenal Qualia”, Philosophical Quarterly 32 (1982) 127-136.

KIM, H.: Zur Empirizität des „Ich denke in Kants Kritik der reinen Vernunft, Würzburg, Königshausen \& Neumann, 2017.

KITCHER, P.: "Ich denke", en WILLASCHEK, M.; STOLZENBERG, J.; MOHR, G.; BACIN, S. (eds.), Kant-Lexikon, 2, Berlín/Boston, de Gruyter, 2015, 1074-1079.

KLEMME, H. F.: Kants Philosophie des Subjekts. Systematische und entwicklungsgeschichtliche Untersuchungen zum Verhältnis von Selbstbewßtsein und Selbsterkenntnis, Hamburg, Meiner Verlag, 1996.

LEVINE, J: "Materialism and Qualia: The Explanatory Gap", Pacific Philosophical Quarterly 64 (1983) 354-361.

MORELAND, J. P.; WILLIAM L. C.: Philosophical Foundations for a Christian Worldview, Illinois, InterVarsity Press, 2003.

NAGEL, T.: "What it is like to be a bat", Philosophical Review 83 (1974) 435-450. 
: Mind and Cosmos: Why the Materialist Neo-Darwinian Conception of Nature is Almost Certainly False, Oxford, Oxford University Press, 2012.

POTHAST, U.: Die Unzulänglichkeit der Freiheitsbeweise. Zu einigen Lehrstücken aus der neueren Geschichte von Philosophie und Recht, Frankfurt, Suhrkamp, 1987.

ROSEFELDT, T.: Das logische Ich. Kant über den Gehalt des Begriffes von sich selbst, Berlín, philo Verlag, 2000.

RUSSEL, S. J.; NORVIG, P.: Artificial Intelligence. A Modern Approach, Londres, Pearson Education Limited, 2016.

SCHADOW, S.: Achtung für das Gesetz: Moral und Motivation bei Kant, Berlín/Boston, de Gruyter, 2012.

SCHMIDT, E. E.: “The Dilemma of Moral Naturalism in Nagel's Mind and Cosmos", Ethical Perspectives 25 (2018) 203-231.

: Kants Begriff der Demütigung in der "Kritik der praktischen Vernunft", Master-Arbeit, Universität Siegen, 2013.

SCHMIDT, E. E.; SCHÖNECKER D.: "Kant's Ground-Thesis. On Dignity and Value in the Groundwork", The Journal of Value Inquiry 52 (2018) 81-95.

SCHÖNECKER, D.: Kants Begriff transzendentaler und praktischer Freiheit. Eine entwicklungsgeschichtliche Studie (en colaboración con Stefanie Buchenau y Desmond Hogan), Berlín, Walter de Gruyter (Kant-Studien Ergänzungshefte), 2005.

: "Kant über Menschenliebe als moralische Gemütsanlage", Archiv für Geschichte der Philosophie (en colaboración con Alexander Cotter, Magdalena Eckes, Sebastian Maly) 2 (2010) 133-175.

: "Das gefühlte Faktum der Vernunft. Skizze einer Interpretation und Verteidigung", Deutsche Zeitschrift für Philosophie 1 (2013a) 91-107.

: "Kant's Moral Intuitionism. The Fact of Reason and Moral Predispositions", Kant Studies Online (2013b) 1-38.

SCHÖNECKER, D.; WOOD, A.: Kant's Groundwork for the Metaphysics of Morals. A Commentary, Cambridge, Harvard University Press, 2015.

ULGEN, O.: "Kantian Ethics in the Age of Artificial Intelligence and Robotics", Questions of International Law, Zoom-in 43 (2017) 59-83.

WAKWFIELD, J.: "South Korean university boycotted over 'killer robots", BBC News (online), 2018, https://www.bbc.com/news/technology-43653648.

WALLACH, W.; ALLEN, C.: Moral machines: Teaching robots right from wrong, Nueva York, Oxford University Press, 2009. 


\title{
Invitación al estudio de la aetas kantiana. La filosofía trascendental de Kant a la luz de la crítica de sus coetáneos alemanes
}

\author{
ROGELIO ROVIRA ${ }^{1}$
}

\begin{abstract}
Resumen
Para mostrar las razones que justifican una invitación al estudio de la recepción de la filosofía trascendental por parte de los pensadores alemanes coetáneos de Kant, en el presente artículo se presenta, primero, un "mapa" de la llamada aetas kantiana en Alemania. Luego se señala el distinto sentido y alcance de las objeciones que se propusieron en esa época contra la nueva filosofía. La invitación se completa con una "guía bibliográfica" que recoge recursos básicos para el estudio de esta precisa fase de la historia del pensamiento.
\end{abstract}

Palabras clave: aetas kantiana, filosofía trascendental, Populärphilosophen.

\section{An Invitation to the Study of the Aetas Kantiana. Kant's transcendental philosophy in light of the criticism of his German contemporaries}

\begin{abstract}
In order to show the reasons justifying an invitation to the study of the reception of transcendental philosophy by Kant's German contemporaries, in this paper a "map" of the so-called aetas kantiana in Germany is firstly presented. Then the different meaning and scope of the objections proposed at that time against the new philosophy is indicated. The invitation is completed by a "bibliographical guide" providing basic resources for the study of this concrete phase of the history of thought.
\end{abstract}

Keywords: Aetas Kantiana, transcendental philosophy, Populärphilosophen.

\begin{abstract}
Un historiador de la aetas kantiana, y acaso el último biógrafo de Kant en nuestros días, Manfred Kühn, señala que el conocimiento de la primera recepción de la filosofía crítica es importante, entre otras razones, porque «la forma en que el pensamiento de Kant se desarrolló entre 1781 y 1800 fue significativamente moldeada por las reacciones de sus contemporáneos». Y añade: «Su concepción madura está determinada, en mucha mayor medida de lo que comúnmente se piensa, por lo que sus contemporáneos de Königsberg y de otros lugares pensaron, dijeron y escribieron» (2006: 630). En lo que sigue me propongo mostrar el alcance y el peso de las razones aducidas por Kühn, y aun añadir a ellas alguna otra nueva, en la forma de una "invitación al estudio de la aetas kantiana". La invitación se ciñe, en particular, al estudio de la filosofía trascendental de Kant (sin atender, por tanto, más que ocasionalmente, a la filosofía moral) a la luz de la crítica de sus coetáneos alemanes (prescindiendo por ello de la recepción de la filosofía crítica en otros ámbitos geográficos).
\end{abstract}

\footnotetext{
${ }^{1}$ Universidad Complutense de Madrid, Facultad de Filosofía. Contacto: rrovira@filos.ucm.es
} 
El atractivo, la conveniencia y la necesidad del estudio al que se invita resultan patentes cuando se tiene ante la vista lo que cabe llamar el "mapa" de la llamada aetas kantiana. Por semejante "mapa" se entiende la descripción, que en este caso ha de ser necesariamente somera y conscientemente incompleta, de los avatares de la época en que vivieron los pensadores coetáneos de Kant que en sus escritos expusieron o discutieron el idealismo trascendental del filósofo de Königsberg. En ese mapa cabe señalar luego el distinto sentido y alcance de las objeciones que los diversos grupos de pensadores coetáneos de Kant propusieron contra la nueva filosofía. El despliegue así logrado de las múltiples cuestiones discutidas y de su distinta trascendencia habrá de justificar, en fin, la importancia y el interés de la investigación de la época que recibe por antonomasia el nombre del filósofo regiomontano. Si con ello el lector se sintiera instado a proseguir el estudio de este periodo del pensamiento, que sitúa la filosofía de Kant a una luz nueva y permite entenderla mejor, el autor habría logrado el modesto, pero necesario, objetivo que se propone. Como apéndice, una breve "guía bibliográfica para el estudio de la aetas kantiana" pondrá en manos del lector interesado algunos recursos básicos para emprender el estudio al que se le invita.

\section{1. "Mapa" de la aetas kantiana en Alemania}

Cabe fijar el inicio de la aetas kantiana, circunscrita, para los fines presentes, al ámbito del pensamiento alemán, en 1782, con la publicación de una de las primeras recensiones de la Crítica de la razón pura y, sin duda, la más famosa de ellas (cf. Duque 1998: 159). Más difícil resulta determinar el límite preciso de su término final, aunque acaso no resulte imprescindible hacerlo. En cualquier caso, es un hecho que los pensadores incluidos en la "edad kantiana" defendieron y criticaron el pensamiento de Kant durante más de dos décadas. Es menester advertir, por tanto, que su actividad se solapa con los inicios del llamado Idealismo alemán, del que, por lo demás, ciertos pensadores seguidores de Kant fueron sus precursores. De este modo, aunque la obra inicial de Fichte sea coetánea de la aetas kantiana y hasta cierto punto heredera de la de alguno de sus representantes, la novedad y la audacia del pensamiento fichteano permiten excluirlo con plena justicia del de los meros epígonos de Kant.

La recepción de la filosofía crítica de Kant en Alemania entre sus coetáneos tiene una historia singular y, en muchos de sus puntos, todavía no bien conocida. Tras las inevitables tergiversaciones que un pensamiento tan innovador no podía por menos que suscitar, pronto los coetáneos compatriotas de Kant se dividieron ante la nueva filosofía. Con cierta simplificación, que tiene, sin embargo, la ventaja de apuntar a lo esencial, los pensadores de la aetas kantiana pueden distribuirse en dos grandes grupos: el de los que vieron en la crítica de la razón propugnada por el filósofo la ocasión de una reforma radical de la filosofía y el de los que consideraron la nueva filosofía como una amenaza para los ideales ilustrados y se opusieron por ello al llamado por el propio Kant "giro corpernicano" del pensar. Consideremos brevemente, por separado, las aportaciones de miembros destacados de cada uno de estos grupos.

1. En el primer grupo, o sea, en el de los que saludaron la oportunidad que brindaba el nuevo giro del pensamiento para emprender una reforma radical de la filosofía, hay que incluir, ante todo, a los primeros partidarios y defensores de la filosofía trascendental. Estos filósofos asumieron las tareas de divulgar el reciente modo de pensar y defenderlo frente a distintas tergiversaciones y diversos ataques y críticas.

De entre estos pensadores cabe citar, en primer lugar, a Johann Friedrich Schultz, profesor de matemáticas en la Universidad de Königsberg y segundo capellán de la corte. Sus Erläuterungen über des Herrn Professor Kant Critik der reinen Vernunft (1784) le convirtieron en el primer expositor y defensor de la filosofía crítica, al menos en la ciudad natal de Kant (cf. Kühn 2006: 643). Kant le profesó gran aprecio intelectual: lo tuvo, en efecto, por «la mejor cabeza filosófica que 
conozco en nuestra región» (Carta a Marcus Herz, 21 de febrero de 1772; Br, AA 10: 133). ${ }^{2}$ Años más tarde, el filósofo no solo reconoció públicamente a Schultz como «el que realmente ha interpretado al menos los puntos centrales de mi sistema de la manera en que quiero que se los interprete», sino que recomendó expresamente el estudio atento de su obra de 1789 Prüfung der Kantische Critik der reinen Vernunft (Carta abierta a Johann August Schlettwein del 29 de mayo de 1797; Br, AA 12: 367-8).

El elenco de los primeros partidarios de la filosofía crítica continúa con el nombre de Carl Christian Erhard Schmid, profesor en Jena, que ya en 1785 dictó lecciones sobre la filosofía de Kant, las cuales dieron lugar más tarde a la publicación de un comentario de la Crítica junto con un diccionario de conceptos kantianos. Su consulta resulta todavía hoy útil: Critik der reinen Vernunft im Grundrisse zu Vorlesungen, nebst einem Wörterbuche zum leichtern Gebrauch der kantischen Schriften (1786).

No cabe olvidar a Friedrich Gottlob Born, profesor en Leipzig, quien, junto a Johann Heinrich Absicht, fundó la revista Neues philosophisches Magazin. La revista, que ya desde su mismo título se dirige contra la fundada por Eberhard, uno de los mayores oponentes, como se verá, del criticismo kantiano, estaba «destinada -según se anuncia en el subtítulo- a explicaciones y aplicaciones del sistema kantiano». Born fue autor de dos libros en defensa de la filosofía de Kant: Versuch über die ersten Gründe der Sinnenlehre (1788) y Versuch über die ursprünglichen Grundlagen des menschlichen Denkens (1791). También tradujo al latín las obras del filósofo, que publicó en cuatro volúmenes entre los años 1796 a 1798 bajo el título de Immanuelis Kantii Opera ad philosophiam criticam.

Asimismo, Ludwig Heinrich Jakob, profesor en Halle, ensayó una refutación de las pruebas de la existencia de Dios propuestas por Mendelssohn desde el punto de vista del criticismo de Kant. Su libro de 1786, sobre el que luego se hablará con más detalle, fue uno de los que iniciaron el "canon" de la larga serie de obras de la nueva filosofía crítica. Christian Gottfried Schütz, de la Universidad de Jena, pasa por ser el primer profesor que expuso públicamente la filosofía de Kant, ya en la temprana fecha de 1784 (cf. Market 1989: 203; Schröpfer 2003: 145-334); fue, además, uno de los editores de la célebre Allgemeine Literatur Zeitung, revista que se destacó en la defensa de las posiciones filosóficas de Kant. Gottlieb Benjamin Jäsche fue también conocido discípulo de Kant. A él le encargó el propio filósofo la redacción y edición de sus lecciones de lógica (Log, AA 09: 1-150).

Es de justicia citar también dentro de este grupo a uno de los grandes comentaristas del pensamiento de Kant, Georg Samuel Albert Mellin, cuyo Encyclopädisches Wörterbuch der Kritischen Philosophie (1797-1803), en seis gruesos volúmenes, sigue siendo todavía hoy una obra de referencia en los estudios de la filosofía crítica.

Muestra del entusiasmo con que algunos recibieron e hicieron suya la nueva filosofía son las siguientes palabras del célebre historiador de la filosofía Wilhelm Gottlieb Tennemann. En el prólogo a su obra en tres volúmenes System der Platonischen Philosophie, comenzada a publicar en 1792, se lee (1792: v):

A partir de la filosofía crítica se alumbra la verdad de que todo sistema de filosofía que le precede contiene algo verdadero, que se funda, sin embargo, en un punto de vista unilateral y se halla mezclado, por tanto, con algo falso. Distinguir lo verdadero de lo falso es una de las muchas ventajas que

${ }^{2}$ Las obras de Kant se citan según la Akademie Ausgabe (AA): Kant's gesammelte Schriften, hrsg. von der Deutschen Akademie der Wissenschften zu Berlin, Berlin, 1902 ss. (En cada caso se indica el volumen y el número de la página, con la sola excepción de las referencias a la Kritik der reinen Vernunft que, como es usual, se cita según la paginación original de la primera y la segunda ediciones, señaladas respectivamente con las letras A y B). Se sigue el sistema de abreviaturas establecido por la KantForschungsstelle de Maguncia. 
proporciona la investigación completa de la facultad de la razón. Puede establecerse, por consiguiente, que cuanta más verdad contiene un sistema, tanto más ha de acercarse a la filosofía crítica; y, a la inversa, cuanto más se acerca a la filosofía crítica, tanto más verdadero ha de ser.

Tennemann publicó en 1812 un manual de historia de la filosofía, su Grundriss der Geschichte der Philosophie für den akademischen Unterricht, traducido luego a varias lenguas, como el francés, el italiano o el inglés, que sigue siendo sumamente útil hoy en día. En él se expone lo que cabría considerar uno de los primeros bosquejos de la aetas kantiana (sobre la historiografía filosófica de Tenneman, cf. Micheli et al. 2015: 838-925).

Pero también en este primer grupo de pensadores hay que incluir a algunos de los críticos más conspicuos de la filosofía crítica de Kant. Hubo, en efecto, pensadores que, asumiendo la novedad del pensar trascendental, trataron de proseguir, de diversos modos, el camino abierto por Kant, buscando incluso mayor radicalidad de la que apreciaron en el fundador de la filosofía crítica. En muchas ocasiones ello no aconteció sin granjearse la desaprobación del maestro.

Sin agotar el elenco de semejantes pensadores, cabe citar entre ellos, sin duda, a Johann Georg Hamann, acaso el primer lector y crítico de la Crítica de la razón pura. Frente al "purismo" de la razón propugnado por Kant, el llamado "Mago del Norte" consideró necesaria una "metacrítica" de la razón que pusiera de relieve la dependencia de la facultad cognoscitiva superior respecto del lenguaje y de la cultura (cf. Berlin 1994; Bayer 2002; Canterla 2008; 2014; Sparling 2011: 57-102; Forster 2012).

Ya en 1787 Friedrich Heinrich Jacobi anticipó una de las objeciones más radicales contra la filosofía trascendental, tratando de mostrar la contradicción que supone la admisión de la "cosa en sí" y su afección sobre los sentidos. En la "Beilage" a su diálogo David Hume über den Glauben, oder Idealismus und Realismus, escribió, en efecto, el célebre dictum según el cual «sin semejante suposición [scl. de la cosa en sí] no puedo entrar en el sistema y con esa suposición no puedo permanecer en él» (1787: 223; cf. Guillermit 2000; Lerussi 2016).

También Karl Leonhard Reinhold merece ser citado entre estos pensadores. Aunque autor de la primera guía para la comprensión de la filosofía de Kant, las Briefe über die Kantische Philosophie, redactadas en 1786 para Der Teuchter Merkur y publicadas como libro en 1790, pronto se convenció Reinhold de que el sistema kantiano adolecía de la falta de un primer principio sobre el que apoyarse. Su discutida propuesta del llamado "principio de conciencia" como fundamento de lo que llamó la "filosofía elemental" [Elementarphilosophie], expuesta en varias de sus obras de los años 1789 a 1791, contribuyó decisivamente al desarrollo de los sucesivos sistemas del Idealismo alemán (cf. Hoyos, 2001a: 23-103; Cruz 2017).

Un lugar destacado en este elenco de críticos debe ocupar asimismo Thomas Wizenmann, que no solo participó en la llamada "polémica del panteísmo" [Pantheismusstreit], sino que criticó por vez primera, con extraordinaria sutileza, el concepto kantiano de "fe racional" [Vernunftglaube]. Esta crítica condujo a Kant a clarificar la doctrina de los postulados en la segunda Crítica (cf. Teruel 2007). Otro tanto es el caso de Johann Gottfried Herder, primer discípulo de Kant, con el que más tarde mantuvo profundos desacuerdos expresados, entre otros escritos, en su obra Eine Metakritik zur Kritik der reinen Vernunft (1799), en la que, siguiendo la estela de Hamann, reivindica la función capital del lenguaje para el pensamiento (cf. Forster 2012).

Con merecida fama ha pasado Gottlob Ernst Schulze, autor del célebre Aenesidemus (1792), como uno de los críticos más radicales de la teoría del conocimiento de Kant y de Reinhold, convirtiéndose así en uno de los originadores del Idealismo alemán (cf. Hoyos 2001a: 105-230). Su crítica escéptica al idealismo trascendental incide en la llamada "aporía de Jacobi". La Crítica de la 
razón pura defiende, en efecto, que las categorías de causa [Ursache] y de realidad [Wirklichkeit] solo pueden aplicarse a las intuiciones sensibles; pero admite a la vez la causalidad y la realidad de las cosas en sí mismas. Por ello escribe Schulze en su Aenesidemus (1792: 264):

\begin{abstract}
Si la deducción trascendental de las categorías que ha proporcionado la crítica de la razón es correcta, entonces es también incorrecto y falso uno de los principios de la crítica de la razón, a saber, que todo conocimiento comienza con la efectividad (Wirksamkeit) de los objetos objetivos (objektiver Gegenstände) sobre nuestro espíritu.
\end{abstract}

Algo análogo sucede con el "criticismo escéptico" de Salomon Maimon. Es verdad que Kant le confesó a su discípulo e interlocutor intelectual Marcus Herz que «ninguno de mis oponentes me ha entendido a mi y a la cuestión principal tan bien [...] como el Sr. Maimon» (Br AA 11: 49). Pero no por ello resulta sencillo disolver las dificultades que este oponente señala en su Versuch über die Transzendentalphilosophie, publicado en 1790, sobre la "cuestión principal" que suscita el dualismo de sensibilidad y entendimiento para la explicación de la posibilidad de la experiencia, ni tampoco es fácil disolver las aporías intrínsecas que este crítico indica en la noción kantiana de "cosa en sí" (cf. Duque 1987: lxxxxv-cxvi; Hoyos 2001b; Bondelli 2004; Herrera 2010; Jiménez 2016; Pachilla 2016).

No debemos dejar de incluir en esta relación, en fin, a Jacob Sigismund Beck, a quien se debe extensas recopilaciones explicativas de la obra de Kant, publicadas, primero, en dos volúmenes en 1793-1794 bajo el título de Erläuternder Auszug aus den kritischen Schriften des Prof. I. Kant, auf Anrathen desselben y completadas luego con un tercer tomo, en 1796, con el título de Einzig mögliche Standpunkt, aus welchem die kritische Philosophie beurteilt werden muss. En esa obra, así como en su Grundriss der kritischen Philosophie, también de 1796, se enfrentó Beck nuevamente al problema de la afección del sujeto por la cosa en sí, proponiendo una solución que abrió paso a los diversos sistemas del Idealismo alemán (cf. Nitzan 2014). Es significativo el modo en que Beck plantea lo que considera el problema fundamental de la Crítica de la razón pura, esto es, el problema de la correspondencia de nuestras representaciones con los objetos o, si se prefiere, el problema de la validez objetiva del conocimiento. Se lee en las primeras páginas del tercer tomo de su obra principal (1796: 8):

\footnotetext{
¿Qué puede ser más maravilloso que la afirmación de que cierto concepto está constantemente en la mente (im Sinne), cuando nuestra facultad cognoscitiva está activa, y que todas nuestras representaciones solo representan algo en la medida en que tratamos con este concepto, y que, sin embargo, este concepto es absolutamente vacío y no tiene ningún objeto? No obstante, así ocurre realmente con el concepto de la relación de nuestras representaciones con los objetos.
}

2. En principio, el segundo grupo aludido, es decir, el formado por los pensadores coetáneos de Kant que vieron en la nueva fundamentación de la filosofía una amenaza para los ideales de la Ilustración y rechazaron, por ello, el idealismo crítico o formal, lo forman en bloque los llamados "filósofos populares" [Populärphilosophen]. Estos filósofos trataron de introducir en Alemania la filosofía de la Ilustración francesa y británica, promoviendo los ideales de la educación pública, la liberación de las supersticiones y la ignorancia y el cultivo del refinamiento en las costumbres. Ideal común de todos ellos fue la preservación de la autoridad de la razón como instancia última sancionadora de las normas morales y las creencias religiosas. Sin pretender que las intenciones de Kant fueran precisamente las de socavar el valor del conocimiento racional, consideraron, sin 
embargo, que su filosofía conducía de hecho a un escepticismo de corte humeano (cf. Beiser 1987: 165-167). Por ello, durante más de dos décadas, atacaron acerbamente la filosofía crítica en numerosos libros, folletos y artículos, muchos de ellos publicados en revistas fundadas con este exclusivo fin (tales como la Philosophische Bibliothek de Feder o el Philosophisches Magazin de Eberhard, al que luego siguió el Philosophisches Archiv). Es menester decir que, en muchos casos, las objeciones planteadas no solo fueron agudas y profundas, sino que en varias ocasiones obligaron a Kant a repensar y reformular su posición o incluso a encargar a algún discípulo la tarea de darles respuesta.

Sin demasiada violencia, los filósofos populares pueden distribuirse en dos conjuntos, según la escuela filosófica principal a la que se adhirieron. Tomando pie precisamente en la distinción que hace el propio Kant de las dos grandes escuelas de pensamiento ante las que la filosofía crítica se erige como radical novedad (cf. $\mathrm{KrV}$, A 854/B 882), cabe decir que hay críticos kantianos empiristas [Empiristen], esto es, seguidores de Locke, y objetores del filósofo de Königsberg que son noologistas [Noologisten], o sea, partidarios de Leibniz.

Entre los filósofos populares de orientación empirista, que negaron, por tanto, la posibilidad de ideas a priori (cf. Sassen 2000), es menester citar, ante todo, a Christian Garve y Johann Georg Feder, autor y editor, respectivamente, de la más famosa reseña de la Crítica de la razón pura, aparecida en el Göttingen Gelehrten Anzeigen, el 19 de enero de 1782. Dos reseñas antecedieron en su publicación a esta más famosa: las que aparecieron anónimamente ya en 1781, en julio en los Frankfurter gelehrte Anzeigen y en diciembre en las Neueste critische Nachrichten [cf. Landau 1991: 3-8]. Es conocida la respuesta que dio Kant (en el "Anhang" de sus Prolegomena y aun en esta obra entera) a la caracterización que se hace en la mencionada recensión del idealismo trascendental como un "sistema de idealismo superior" [System des höhern Idealismus] que no se distingue propiamente del idealismo de Berkeley. No es aventurado pensar que las dolidas palabras con las que Kant comienza sus Prolegómenos tienen presente este reproche: «Hay sabios cuya filosofía propia consiste en la historia de la filosofía (de la antigua y de la moderna); para estos no se han escrito los prolegómenos presentes». La razón de ello es, justamente, que, según estos autores, «no se puede decir nada que no haya sido dicho ya» (Prol, AA 04: 255).

Entre los críticos de Kant pertenecientes a este grupo de pensadores cabe también citar a Johann Christian Lossius. Orientado en la filosofía del sentido común, publicó en 1789 un folleto, hoy apenas conocido, titulado Etwas über Kantsche Philosophie in Hinsicht des Beweises für das Dasein Gottes. Es también obligada la mención de Christoph Meiners, coeditor, con Feder, de la Philosophische Bibliothek, dedicada en gran parte a combatir la filosofía kantiana, y autor de un Grundriss der Seelenlehre en el que expone objeciones a ciertas concepciones de Kant. Figura importante en este grupo es, sin duda, Friedrich Nicolai, editor de la célebre Allgemeine deutsche Bibliothek, uno de los órganos de expresión más importantes de la Ilustración alemana y autor de unos Philosophische Abhandlungen en los que muchas veces confronta su pensamiento con el de Kant. A Hermann Andreas Pistorius se le deben penetrantes reseñas de las obras kantianas, tanto de filosofía teórica como de filosofía moral, que contienen agudas críticas, valoradas incluso por el propio Kant (cf. Gesang 2007; Basaglia 2014).

Christian Gottlieb Selle, médico y filósofo, seguidor del empirismo de Locke, fue autor de varios artículos críticos con la filosofía de Kant publicados en el Berlinische Monatschrift, como su ensayo Versuch eines Beweises, dass es keine reine von der Erfahrung unabhängige Vernunftbegriffe gebe (1784), así como de unos Grundsätze der reinen Philosophie (1788). Al intento emprendido por este pensador de refutar una tesis tan central en la filosofía de Kant como es la de la existencia de los conceptos puros del entendimiento (cf. Motta 2011), le siguió en 1787 la publicación del libro Kantische Denkformen oder Kategorien debido a Gottlob August Tittel, asimismo ferviente partidario del empirismo de Locke y de Feder. En esta obra, Tittel acomete una doble tarea: someter a crítica 
minuciosa no solo la llamada "deducción metafísica", sino también la deducción trascendental de las categorías. Para llevar a cabo la primera tarea, compara la lista aristotélica de las categorías con el elenco de Kant y propone agudas observaciones respecto de la ordenación de los conceptos de la tabla kantiana. Para criticar la justificación kantiana de la validez objetiva de las categorías en su aplicación a la experiencia, examina Tittel, en primer lugar, las características esenciales que Kant atribuye a las categorías (su carácter formal, vacío, su referencia a objetos en general y su independencia originaria respecto de la experiencia) y compara la solución que la filosofía de Locke y la de Kant proponen a la cuestión sobre el "origen de los conceptos humanos" [Ursprung menschlicher Begriffe], tratando de mostrar la superioridad de la respuesta de Locke sobre la de Kant. Poco después, a comienzos de 1789, Karl Leonhard Reinhold publicó una reseña muy negativa de esta obra en la Allgemeine Literatur-Zeitung. Tittel publicó en 1786 su obra Ueber Herrn Kant's Moralreform, a cuya principal objeción contra el formalismo moral respondió Kant en una nota a pie de página del Prólogo de su segunda Crítica.

Dietrich Tiedemann, acaso el más destacado historiador de la filosofía de su época, formó también parte de los críticos empiristas de Kant. En 1785, en tres entregas aparecidas en los Hessische Beyträge zur Gelehrsamkeit und Kunst, publicó la que cabe considerar como la primera recensión fundamental y más extensa de la Crítica de la razón pura, su Ueber die Natur der Metaphysik; zur Prüfung von Hrn Professor Kants Grundsätzen, de más de treinta páginas de extensión. En su detenido análisis de la obra de Kant, para el que se sirve también de los Prolegómenos, Tiedemann niega la validez de la distinción kantiana de los juicios en analíticos y sintéticos. Considera, en efecto, que Kant, al proponerla, distingue dos operaciones: la separación en el pensamiento de diversos predicados pensados conjuntamente y la división de un todo en el pensamiento, que son, sin embargo, dos modos de análisis (cf. 1785: 115). Por lo demás, en la tercera de las entregas de su reseña, Tiedemann defiende la posibilidad de la metafísica oponiéndose precisamente a la pretensión de Kant según la cual a la prueba metafísica de una tesis cabe oponer otra prueba igualmente sólida de la tesis contraria. El examen de los argumentos kantianos le lleva a Tiedemann a considerar que las pruebas ofrecidas de las tesis y de las antítesis respectivas están ellas mismas sujetas a disputa filosófica. De ahí que tras su análisis declare: «De todo lo expuesto se sigue que lo que el señor Kant considera una discordia interna del entendimiento puro, no es una oposición de los conceptos mismos, sino de los conceptos puros y sus imágenes» (1785: 473-474). En los papeles que conforman el Opus postumun, Kant alude varias veces a las posiciones filosóficas de Tiedemann bajo el nombre de "Teeteto", según el título de la obra que el célebre historiador de la filosofía publicó en 1794: Theätet oder über das menschliche Wissen: ein Beytrag zur Vernunftkritik.

Otro importante crítico empirista fue, en fin, Adam Weishaupt, el fundador de los Illuminati, que en 1788 publicó tres tratados polémicos con la filosofía de Kant: Ueber die Kantischen Anschauungen und Erscheinungen, Ueber die Gründe und Gewisheit der Menschlichen Erkenntniss zur Prüfung der Kantischen Critik der reinen Vernunft y Zweifel über die Kantischen Begriffe von Zeit und Raum. La crítica de Weishaupt se basa en última instancia en un escepticismo de corte humeano, según revelan estas significativas palabras de la primera obra citada: «Sabemos, en verdad, que, en virtud de esta subjetividad, así debemos concluir; pero no sabemos cómo se comportará todo esto en el caso de otra subjetividad» (1788a: 64).

Son también numerosos los filósofos populares de orientación racionalista, más fieles, por tanto, a la tradición de Christian Wolff, que por ello admitieron la posibilidad de ideas a priori. Entre ellos hay que citar primeramente a Johann August Eberhard, fundador y editor, como ha quedado dicho, de uno de los órganos más importantes de la crítica racionalista a la filosofía de Kant, el Philosophisches Magazin. En él publicó Eberhard en 1788 sus ataques a la filosofía crítica, negándole originalidad, discutiendo la distinción de los juicios analíticos y sintéticos, recusando la explicación de Kant sobre la posibilidad de los juicios sintéticos a priori y reivindicando, en fin, la filosofía 
leibniziana frente al nuevo modo de pensar. La polémica que Kant mantuvo con este pensador ha sido calificada de «hito (milestone) en la historia de la filosofía crítica», y su famosa respuesta, el escrito de 1790 Über eine Entdeckung, nach der alle neue Kritik der reinen Vernunft durch eine ältere entbehrlich gemacht werden soll (ÜE, AA 08: 185-252) donde responde a los artículos publicados por Eberhard en el primer volumen de su revista (1788-1789), ha sido considerado «una obra maestra de la polémica filosófica» (Beiser 1987: 218-219, 222).

Ante los nuevos ataques de los críticos racionalistas, Kant encargó, con muy precisas instrucciones, a algunos de sus discípulos, como Reinhold o Schultz, que prosiguieran la polémica. Tal es, entre otros, el caso de las críticas de Johann Gebhard Ehrenreich Maaß, profesor en la Facultad de Filosofía de la Universidad de Halle. Además de publicar en 1788 unas Briefe ueber die Antinomie der Vernunft, Maaß dio a la estampa al año siguiente, en el Philosophisches Magazin de Eberhard, un ensayo titulado Ueber den höchsten Grundsatz der synthetischen Urtheile; in Beziehung auf die Theorie von der mathematischen Gewisheit. Entre otros asuntos, en el ensayo Maßß critica la división kantiana de los juicios en analíticos y sintéticos por considerarla meramente relativa, es decir, subjetiva o psicológica. No ha dejado de señalarse que esta reprobación tiene mayor alcance que cualquiera de las que había presentado Eberhard en el primer volumen de su revista, y el propio Eberhard la hizo suya más tarde al proseguir su polémica con Kant (cf. Allison 1973: 42). Como se sabe, el reproche de Maaß ha encontrado, con el correr de los tiempos, amplio eco en buen número de pensadores, como Schleiermacher, Quine o Ayer, acaso ignorantes de este antecedente coetáneo del propio Kant (cf. Gesang 2000). El filósofo no respondió directamente a este ataque, sino que encomendó la tarea de defensa a Johann Schultz. Cumpliendo el encargo, Schultz publicó, en varios números de la Allgemeine Literatur Zeitung de 1790, una recensión del volumen correspondiente del Philosophisches Magazin. La respuesta de Schultz se basa, a lo que parece, en anotaciones y borradores que el propio Kant le envió, y de hecho se encuentra editada entre las obras del filósofo (AA 20: 408-409). Maaß no se quedó callado ante la respuesta de Schultz. En 1791 publicó, también en el Philosophisches Magazin, un nuevo ensayo, titulado Zusätze zu der Abhandlung über den höchsten Grundsatz der synthetischen Urtheile, en el que reitera sus objeciones ante lo que considera una respuesta desacertada e insuficiente.

El año 1788 fue, en verdad, un año crucial en los ataques de los filósofos populares seguidores de Wolff (cf. Beiser 1987: 193). En ese año aparecieron en Leipzig los Fragmentarische Beyträge zur Bestimmung und Deduktion des Begriffs und Grundsatzes der Causalität, und zur Grundlegung der natürlichen Theologie, in Beziehung auf die Kantische Philosophie, debidos a Johann Friedrich Flatt. En ellos, el profesor de la Universidad de Tubinga se opone a la concepción trascendental de la causalidad propugnada por Kant, al defender, en sus propias palabras, «que hay varias deducciones, distintas entre sí, del concepto de causa», pero que «ninguna de las que se está autorizado a tener por válida, ninguna de las que son conformes al fin de una deducción, es completamente independiente de lo empírico» (1788: 89). Asimismo, Johann August Heinrich Ulrich publicó en Jena su Eleuteriologie oder über die Freiheit und Notwendigkeit, obra de la que Christian Jakob Kraus, estudiante de Kant, hizo una reseña basada, según confesión propia, en un breve ensayo de su maestro (cf. Kraus' Recension von Ulrich's Eleutheriologie, editada entre las obras de Kant, AA 08: 451-460). Cabe mencionar también a Johann Christoph Schwab, estrecho colaborador de Eberhard, autor de numerosas contribuciones críticas de la filosofía de Kant en el Philosophisches Magazin, entre ellas una sobre el carácter meramente subjetivo de las categorías kantianas. Recuérdese que Schwab fue el ganador del primer premio del concurso que la Academia Prusiana de Ciencias anunció en 1788 sobre la cuestión de los progresos de la metafísica desde los tiempos de Leibniz y Wolff (cf. Duque 1987: cxvi-clxxii).

Una tesis kantiana que no pasó desde luego inadvertida a los "filósofos populares" de orientación wolffiana fue la afirmación según la cual la prueba cosmológica de la existencia de Dios 
comete una ignoratio elenchi, pues en el fondo se reduce a la prueba ontológica (cf. KrV, A 609/B 637). Estos pensadores vieron atacada así por Kant la originalidad de la prueba a contingentia mundi propuesta por Leibniz y renovada por el propio Wolff. No sorprende por ello que en el año 1789 apareciera en el Philosophisches Magazin un artículo debido al ya citado Flatt titulado Etwas über die Kantische Critik des cosmologischen Beweises für das Daseyn Gottes, cuyo objeto principal es rebatir la mencionada tesis kantiana. Al artículo le siguió un "Zusatz" debido al propio Eberhard en el que, por su parte, trataba de abundar en las razones aducidas por Flatt para rechazar la afirmación de Kant sobre la naturaleza de la prueba cosmológica. Así, pues, la discusión de esta cuestión central de la crítica kantiana de la teología racional, que tanto debate ha suscitado y sigue suscitando entre nuestros contemporáneos, encuentra un claro precedente en los pensadores de la aetas kantiana, lo que es signo inequívoco de la actualidad de las inquietudes de estos filósofos. En este sentido, también es de destacar la crítica que propuso Flatt de la prueba moral de la existencia de Dios, que sigue siendo objeto constante de discusión entre los investigadores kantianos, en su obra publicada en ese mismo año de 1789: Briefe über den moralischen Erkenntnisgrund der Religion überhaupt: und besonders in Beziehung auf die Kantische Philosophie (cf. Mbuyi 2001. Sobre las distintas posturas que los contemporáneos de Kant adoptaron ante los problemas que plantea la teología moral en su encaje en el idealismo trascendental, cf. Gardner 2011).

Caso particular, en fin, entre los críticos racionalistas es el de Ernst Platner, cuyos Philosophische Aphorismen nebst einigen Anleitungen zur philosophischen Geschichte llegaron a convertirse prácticamente en libro de texto en la Universidad de Jena durante la última década del siglo XVIII. Mientras que en sus primeras ediciones (el volumen I se publicó en 1776 y el volumen II en 1782), Platner proponía un sistema filosófico inspirado en el pensamiento leibniziano, a partir de la edición de 1793 propuso una "crítica escéptica" [skeptische Kritik] (1793: § 705, 353), que, aunque acaso inspirada por Kant, supone un serio reproche a la filosofía kantiana.

Si no propiamente entre los Populärphilosophen, merece la pena mencionar como uno de los primeros oponentes de la filosofía crítica de Kant al teólogo jesuita Benedikt Stattler, autor de toda una colección de libros polémicos contra el pensamiento de Kant: los tres volúmenes que conforman su Anti-Kant (1788), Der Anti-Kant im Kurzen (1791), Kurzer Entwurf der unausstehlichen Ungereimtheiten der kantischen Philosophie (1791), Meine noch immer feste Überzeugung von dem vollen Ungrunde der kantischen Philosophie (1794) y, en fin, Wahres Verhältnis der kantischen Philosophie zur christlichen Religion und Moral (1794). Las obras antikantianas de este teólogo tuvieron mucho éxito, hasta el punto de que Conrad Stang, benedictino de Wurzburgo, informó al propio Kant de que «en Munich no cabe pensar en una filosofía crítica, dado que aquí vive y gobierna Stattler» (carta de Conrad Stang a Kant del 2 de octubre de 1796; Br., AA 12: 100). El filósofo, sin embargo, nunca se ocupó de refutar estos ataques.

Pero entre los críticos más egregios de la filosofía de Kant que tampoco cabe incluir propiamente entre los llamados filósofos populares, o al menos hay que situarlo en un lugar eminente entre ellos, hay que citar, sin duda, a Moses Mendelssohn. No parece que hoy en día se haya acabado de reconocer toda la importancia filosófica que tiene esta eminente figura de la Ilustración alemana, al que sus contemporáneos llamaron "el Sócrates de nuestra época". Ciertamente, la importancia filosófica de Mendelssohn no radica en su valiente defensa de los derechos civiles de los judíos como ciudadanos alemanes y en su intento de armonizar el judaísmo con las exigencias de la cultura ilustrada. Tampoco se halla en su meritoria labor como crítico literario y traductor de la Biblia. Ni siquiera su peso filosófico radica únicamente en ser el último gran representante del llamado racionalismo que inaugura Descartes y prosiguen Spinoza, Leibniz y Wolff. Además de por sus valiosas contribuciones en los campos de la estética y de la filosofía política, Mendelssohn, escribe un historiador de esta época filosófica (Bieser 1987: 93), «merece un lugar especial en el seno de la tradición racionalista», porque «fue el más moderno de todos los racionalistas al haber sido 
consciente de la 'crisis de la metafísica', y haber respondido a esa crisis, a la lucha de la metafísica por mantener sus credenciales como ciencia».

Por lo demás, es conocida la admiración que Kant profesaba a Mendelssohn. En los Prolegómenos (AA 04: 262), elogia su estilo literario: «No a todos les es dado escribir [...] tan profundamente y a la vez con tanta elegancia como a Moses Mendelssohn». En la segunda edición de la Crítica de la razón pura, dedica un apartado de los "paralogismos de la razón pura" (B 413) a refutar la prueba de la permanencia del alma que Mendelssohn, ese "penetrante filósofo" [scharfsinniger Philosoph], había propuesto en su Phädon oder über die Unsterblichkeit der Seele. Y vale la pena, en fin, transcribir el juicio que le mereció a Kant la última obra que publicó en vida el filósofo judío, Morgenstunden, oder Vorlesungen über das Dasein Gottes. Confiesa Kant en una carta a su discípulo Christian Gottfried Schütz, a finales de noviembre de 1785 (Br, AA 10: 429):

Si bien en la cuestión principal hay que considerar la obra del digno Mendelssohn como una obra maestra de la ilusión en que cae nuestra razón cuando toma las condiciones subjetivas de su determinación de los objetos en general como condiciones de la posibilidad de estos mismos objetos, ilusión que, ciertamente, no es fácil de presentar en su verdadera naturaleza, ni tampoco liberar exhaustivamente de ella al entendimiento, no obstante esta excelente obra, además de lo que dice de penetrante, nuevo y ejemplarmente claro en el "Conocimiento preliminar de la verdad, la apariencia y el error”, y que muy bien se puede aplicar en toda exposición filosófica, será de utilidad esencial, mediante su segunda parte, para la crítica de la razón humana. [...] Cabe considerar este legado final de una metafísica dogmatizante a la vez como su más perfecto cumplimiento, tanto respecto de la coherencia de su argumentación (kettenförmige Zusammenhang) cuanto respecto de la excepcional claridad de su presentación, y como un monumento, que nunca se devaluará, a la perspicacia de un hombre que conoce y domina toda la fuerza de un modo de conocer que ha hecho suyo, monumento en el que una crítica de la razón, que arroja dudas sobre el feliz progreso de semejante proceder, encuentra un ejemplo permanente para poner a prueba sus principios, con el fin de luego confirmarlos o rechazarlos.

En cualquier caso, el último libro publicado en vida por Mendelssohn encierra una crítica de considerable peso filosófico a posiciones básicas de Kant. Las Horas matinales contienen, en efecto, mucho más que una defensa de la metafísica tradicional. La ocasión de su escritura la dio sin duda la discrepancia que el pensador judío mantenía con Jacobi desde 1783 en torno al espinosismo de Lessing. De ahí que Mendelssohn dedique varios capítulos de su libro a refutar la tesis espinosista según la cual "todo es uno y uno es todo" y a presentar, a la vez, su idea de un "panteísmo purificado" compatible con la religión y la moral. La obra tuvo por ello amplia repercusión, pues constituye un hito en la historia de la célebre "polémica del panteísmo" o "controversia del espinosismo", según los nombres con los que se la conoce. Como es sabido, en el célebre debate participaron luego no pocos pensadores ilustrados, incluyendo al propio Kant, que desarrolló su concepción de "orientarse en el pensamiento" en diálogo con ciertas tesis de Mendelssohn (cf. Kühn 2006: 655-658). Las objeciones que Mendelssohn propone contra la posición de Basedow, que propugnaba un "deber de creer" [Glaubensplicht], alcanzan igualmente, sin embargo, a las posturas de Kant y de Jacobi.

Pero, sobre todo, la ambiciosa empresa que acomete Mendelssohn, en los siete primeros capítulos de su libro, la de «refutar el proyecto de los idealistas» [«das Vorhaben der Idealisten zu widerlegen»] (1875: 55), tiene como principal destinatario el idealismo trascendental de Kant, según advirtió ya, acaso por primera vez, Benno Erdmann en su libro Kant's Kriticismus in der ersten und in der zweiten Auflage der Kritik der reinen Vernunft. Eine historische Untersuchung (1878: 118). No es desatinado pensar, por ello, que, en la llamada "Refutación del idealismo" introducida en la segunda edición de la primera Crítica (B 274-279), Kant haya tratado de minar las bases cartesianas 
en que se apoyan las objeciones de Mendelssohn; e incluso cabe interpretar que en otros pasajes de la segunda edición de la Crítica de la razón pura (como, por ejemplo, la nota en B 422-423 sobre la proposición "yo pienso", incluida en la discusión sobre los paralogismos de la razón pura), Kant haya introducido valiosas puntualizaciones y correcciones justamente para salir al paso de las argumentaciones de Mendelssohn (cf. Dyck 2011; Munk 2011).

Tampoco cabe dejar de mencionar que, en la defensa de la prueba ontológica de la existencia de Dios que Mendelssohn lleva a cabo en el último capítulo de su libro, el filósofo judío responde, una por una, a las objeciones propuestas por Kant en su libro principal para recusar esta demostración de la existencia de Dios. Frente al reproche general de Kant según el cual la prueba anselmiana comete una metábasis eis allo genos al transitar sin más de lo posible a lo real, Mendelssohn, sin citar expresamente la Crítica de la razón pura, muestra que es precisamente la objeción del filósofo de Königsberg la que incurre en el error lógico de la ignoratio elenchi o, si se quiere, de la petitio principii, ya que no tiene en cuenta que el caso único y especialísimo del "ser supremo" [allerhöchsten Wesen] legitima la inferencia de la posibilidad a la realidad (cf. Rovira 2017).

Como la demolición definitiva de la prueba ontológica forma parte esencial del proyecto del idealismo transcendental, pues Kant considera que en el argumento anselmiano se apoyan todas las otras pruebas especulativas de la existencia de Dios posibles en principio, no es extraño el interés del filósofo por esta obra de Mendelssohn. Y no es tampoco sorprendente que, ante la falta de tiempo para «refutar las Horas matinales de Mendelssohn» [«Mendelssohns Morgenstunden zu wiederlegen»], según le confiesa a Ludwig Heinrich Jakob (Br AA 10: 451), haya dejado en manos de este discípulo la respuesta más extensa a la obra del pensador judío. Como ya se ha señalado, en efecto, por indicación de Kant, Ludwig Heinrich Jakob publicó en 1786 su Prüfung der Mendelssohnschen Morgenstunden oder aller spekulativen Beweise für das Daseyn Gottes in Vorlesungen. A esta obra el propio Kant le antepuso un breve ensayo. En el Prólogo de la obra, Jacob declara su propósito con estas palabras (1786: I-II):

Quisiera tan solo confrontar de modo adecuado e imparcial las razones de la antigua escuela a favor de la existencia de Dios, que Mendelssohn ha presentado ciertamente con toda su fuerza, con el juicio kantiano sobre ellas, para ver si el ingenio del señor Mendelssohn ha ganado en la antigua cuestión y si, a través de los nuevos y variados caminos y giros que utiliza, han obtenido realmente las fronteras de la razón más extensión de las que el señor Kant les ha señalado.

No cabe duda, sin embargo, de que, a pesar de su declarada "imparcialidad", Jakob toma partido por Kant. El discípulo, en efecto, reconoce en el mismo Prólogo (1786: II) que «la Crítica de la razón pura anuncia una revolución (Revolution) a toda la filosofía y da a ella un giro completo (eine ganz Wendung)». Por ello, refiriéndose a los logros obtenidos por la filosofía crítica, declara abiertamente que pretende «traer más a la luz los resultados mediante otros giros y posiciones (Wendungen und Stellungen) y dar a la presentación mayor popularidad». La obra de Jacob se convirtió así en una de las primeras obras canónicas de la nueva filosofía crítica.

2. El distinto sentido y alcance de las objeciones contra la filosofía de Kant

El "mapa" de la aetas kantiana trazado en las páginas anteriores, a pesar de su carácter esquemático y de sus múltiples carencias, permite establecer, sin embargo, una conclusión firme. Aunque susceptible de las varias excepciones que afectan inevitablemente a toda generalización, la conclusión puede resultar orientadora para el investigador de la temprana recepción del pensamiento de Kant. Se trata, 
en efecto, de que las objeciones que los coetáneos de Kant de habla germana propusieron contra la nueva filosofía pueden distribuirse en tres grupos radicalmente distintos.

El primer grupo lo forman aquellas objeciones que nacen de tergiversaciones o faltas de comprensión o profundización de la posición filosófica de Kant o de ciertas tesis centrales de su filosofía. Sin duda, ciertas críticas de los "filósofos populares" contra el idealismo trascendental tienen precisamente su raíz en una falta de comprensión de la novedad del pensamiento de Kant. Ejemplos de este tipo de objeciones son la reseña de la Crítica de la razón pura de Garve y Feder y los ataques de Eberhard a la originalidad de la filosofía crítica. Como ya se ha recordado, a todos ellos dio Kant cumplida respuesta y han sido también objeto de valiosos análisis (cf., sobre la reseña de Garve y Feder, Motta 2012; Solé 2016: 10-12 y, sobre el pensamiento de Feder, Nowitzki 2018; sobre la polémica de Kant con Eberhard, Allison 1973; Gram 1980; Gawlina 1986; Duque 1987: xvii-lxiii; La Rocca 2002; Kühn 2006: 638-642; Kertscher 2012). La crítica de Weishaupt merece también citarse entre este tipo de reproches, pues su posición contra la filosofía kantiana «constituye uno de los más claros ejemplos del supuesto psicologista que se refiere a las características empíricas de la facultad cognoscitiva de un ser humano» (Fabbianelli 2016: 15).

Forman también parte de este grupo de objeciones las que surgieron de los propios partidarios y defensores de la filosofía kantiana. Un ejemplo claro de este tipo de críticas es la discusión de Johann Schultz, el que fuera acaso el primer defensor de la filosofía crítica, y el propio Kant sobre el carácter sintético de los juicios de la aritmética. Hay que recordar, en efecto, que Schultz, antes de entregar a la estampa la primera parte de su Prüfung der Kantischen Kritik der reinen Vernunft, sometió su obra al parecer de Kant. En la primitiva versión Schultz negaba la tesis defendida en la Crítica de la razón pura sobre el carácter sintético de los conocimientos aritméticos. Ello obligó a Kant a justificar su posición con nuevas razones, que expuso en una carta del 25 de noviembre de 1788 (Br, AA 10: 554-558) y que lograron que Schultz modificara su concepción de la naturaleza de los juicios aritméticos (cf. Rovira 2011).

Un llamativo caso, no tanto de objeciones al criticismo, cuanto de meras tergiversaciones del pensamiento de Kant en cuestiones esenciales, es el que representa G. F. Born, el meritorio traductor al latín de las obras del filósofo. En su breve ensayo Über den transcendentalen Idealismus, publicado en 1790 en la revista por él fundada precisamente para "explicar" el sistema kantiano, se lee esta sorprendente afirmación (1790: 361-362):

Como los fenómenos, esto es, las representaciones de los objetos externos en nosotros, son modificaciones que no pueden tener a su vez en su base hasta el infinito otras modificaciones por las que fueran causadas, se sigue que las cosas en sí que en último término están en la base de los fenómenos tienen que ser objetos inmutables y constantes, esto es, sustancias.

Pero asimismo, en fin, las objeciones propiamente dichas de esta especie se encuentran en aquellos pensadores que, simpatizantes en principio con el pensamiento de Kant, quisieron ir más allá de los planteamientos de la filosofía crítica. Ejemplo de ello son las objeciones que propuso Herder contra una célebre definición kantiana de lo bello. En su Kalligone (1800: 1. Teil, 2), en efecto, afirma Herder que «Nada puede gustar sin interés» [«Nichts kann ohne Interesse gefallen»]. No es difícil mostrar que esta tesis se apoya en última instancia en la confusión entre el "interés" en sentido psicológico y el "interés” en su significado práctico (cf. Rovira 2013).

El segundo grupo de objeciones contra la filosofía de Kant lo constituyen aquellas que nacen de una supuesta falta de radicalidad de la filosofía crítica o de la presunta advertencia de ciertas inconsecuencias en ella. Se trata de objeciones que se pretenden internas al sistema kantiano. 
Son los reproches que propusieron los que Kant llamó sus «amigos hipercríticos» [«hypercritische Freunde»] (Carta a Tieftrunk del 13 de octubre de 1797; Br, AA 12: 207). Esta expresión, aunque referida expresamente a Fichte y a Reinhold, puede acaso aplicarse también a aquellos pensadores que, apoyándose en el edificio conceptual kantiano, trataron de imprimirle una nueva dirección. Cabe incluir entre estas objeciones, en efecto, no solo la crítica de Reinhold basada en la carencia por parte del idealismo trascendental de un principio sobre el que apoyarse, sino también las que se agrupan bajo la rúbrica de la "polémica sobre el estatuto de la cosa en sí". Por parte de pensadores como Jacobi, Maimon o Schulze se objetó, en efecto, que la concepción de Kant sobre la cosa en sí como causa de la afección sensible está en contradicción tanto con el carácter incognoscible de los noumena como con el único uso legítimo de las categorías reconocido por el idealismo trascendental. Asimismo, Beck trató de ofrecer una nueva y original solución a lo que consideró el problema crítico fundamental, a saber: el de la relación entre la representación y su objeto.

No es de extrañar que semejantes objeciones hayan sido objeto de muchas y valiosas investigaciones (como se puede comprobar consultando el apartado 4 de la "Guía bibliográfica para el estudio de la aetas kantiana" que figura como "Apéndice" del presente artículo). El estudio de estos reproches no solo está justificado por el interés objetivo de los reparos dirigidos contra la filosofía crítica o por la talla intelectual de los filósofos que los propusieron. Estas críticas dieron lugar a la larga serie de sistemas idealistas que conforman el llamado Idealismo alemán y, por esta nueva razón, el conocimiento de ellas resulta imprescindible para comprender una de las épocas más complejas y ricas en ideas de la historia del pensamiento. No cabe olvidar, en efecto, que, aunque la "Doctrina de la Ciencia" tiene su génesis en el intenso diálogo que Fichte mantuvo con el pensamiento de Kant ya desde 1785 (cf. Rohs 1991: 27), el pensador de Jena comenzó sus reflexiones más personales con una confrontación con los escritos de Reinhold, como revelan las extensas anotaciones de finales de 1793 y principios de 1794 que tituló Eigne Meditationen über Elementar-Philosophie (cf. Market 1989: 208; Rohs 1991: 38; Rivera de Rosales 2017: 25).

El tercer grupo de objeciones contra la filosofía de Kant lo constituyen, en fin, aquellas que provienen de las dos principales escuelas de pensamiento frente a las que la filosofía crítica se presenta como una radical novedad. Consideremos brevemente la peculiaridad de estos reproches.

Como es sabido, la Crítica de la razón pura termina con un breve capítulo titulado "Historia de la razón pura". No se trata de un mero complemento erudito de la obra, del que acaso pudiera prescindirse por razones sistemáticas: la historia del uso puro de la razón forma parte, al decir del filósofo, del sistema mismo de la razón pura. Y aunque Kant se limita simplemente en ese capítulo a «echar una rápida mirada, desde un punto de vista meramente trascendental, es decir, partiendo de la razón pura, sobre el conjunto de las producciones anteriores» (KrV, A 852/B 880), el resultado de su breve visión del pasado filosófico resulta en extremo interesante. El pensador de Königsberg traza, en efecto, los rasgos fundamentales de una curiosa historia de la filosofía, en la que las diversas teorías y posiciones se consignan atendiendo a un triple criterio: según el objeto de los conocimientos racionales, los filósofos han sido o sensualistas o intelectualistas; por su parte, a tenor del diverso origen que han asignado a los conocimientos racionales, los pensadores se clasifican en empiristas y en noologistas; y, finalmente, a juzgar por el método con que pretenden obtener los conocimientos racionales, los filósofos son o naturalistas o científicos, y estos últimos, a su vez, o son escépticos o son dogmáticos. Aunque Kant no lo declare expresamente así, cabría decir que con estas distinciones el filósofo tiene ante la vista dos grandes y excluyentes escuelas de pensamiento: la conformada por los filósofos sensualistas y, por ello, empiristas y, al cabo, escépticos; y la constituida por los pensadores intelectualistas y, por ello, noologistas y, al cabo, dogmáticos. Frente a ellas, Kant declara tajante: «Solo queda el camino crítico» [«Der kritische Weg ist allein noch offen»] (KrV, A 856/B 884). 
Como hemos visto, el conjunto de los llamados Populärphilosophen, y, ocupando un puesto singular entre ellos, Moses Mendelssohn, pueden adscribirse sin demasiado forzamiento, aunque con las reservas pertinentes a cada caso, a una u otra de las dos escuelas de pensamiento distinguidas por Kant. No es extraño, por tanto, que estos pensadores vieran en Kant, por usar la célebre expresión de Mendelssohn, al «omnidestructor» [«alles zermalender»] (1785: 3-4) de todo sistema filosófico. Tampoco asombra que, por ello, emprendieran el estudio de la filosofía crítica con el afán de comprobar si en efecto semejante revolución del pensar supera las posiciones filosóficas anteriores. De ahí que muchos de ellos propusieran una serie de objeciones al idealismo trascendental orientadas a mostrar que o bien la crítica de Kant de las tesis heredadas no es acertada o bien que las nuevas propuestas filosóficas incurren en errores filosóficos y no superan las posiciones anteriores.

El estudio de las objeciones de este tercer grupo no solo está justificado por el hecho de que han recibido mucha menos atención por parte de los estudiosos que las que integran el segundo grupo de objeciones. El interés y la importancia de estos reproches radican sobre todo, por una parte, en las características propias de estas objeciones; y, por otra, en el alcance que pretenden. Los reparos aludidos, en efecto, ponen a prueba todas las cuestiones centrales de la filosofía crítica. Dada la radicalidad y la profundidad con que en muchos casos se presentan, Kant no pudo por menos que valorarlas y tenerlas en cuenta en su reflexión, bien respondiendo a ellas directa o indirectamente, bien asumiéndolas en su propio sistema, bien encargando a algunos de sus discípulos que elaboraran una respuesta más amplia a tenor de sus propias indicaciones. Todo ello se comprende bien, puesto que si las objeciones resultaran fundadas, se pondría en entredicho el valor del "camino crítico", esto es, del proyecto filosófico de Kant.

Lejos, pues, de considerar que los mencionados críticos de Kant apenas tuvieron influencia en la historia de la filosofía, y de la filosofía crítica en general (para una crítica de esta concepción, cf. Zande 1995), las dificultades que tanto Mendelssohn cuanto los Populärphilosophen encontraron en la revolución copernicana del filósofo de Königsberg constituyen serias objeciones contra el camino crítico emprendido por Kant y merecen un análisis detenido y una respuesta bien meditada.

\section{Conclusión: Razones del interés del estudio de la aetas kantiana}

De las consideraciones anteriores cabe extraer la siguiente serie de razones que justifican la presente invitación al estudio de la obra de los diversos pensadores que conforman la aetas kantiana.

La primera razón no es otra que el desconocimiento general, patente en las lagunas que se observan en el estado actual de la investigación, de la recepción de la filosofía crítica entre los contemporáneos de Kant. A esta razón se le suma otra segunda de índole pareja: el relativo desconocimiento de la figura y el pensamiento de los propios filósofos coetáneos de Kant que recibieron sus doctrinas de manera más o menos crítica, como es especialmente el caso de Moses Mendelssohn.

A estas razones generales, se le añaden algunas más específicas. Así, sumar nuevas investigaciones a las ya realizadas por diversos estudiosos sobre la obra de los llamados "amigos hipercríticos" de Kant, y del diálogo que mantuvieron con él, sigue siendo imprescindible para lograr una comprensión más cabal de movimientos filosóficos y espirituales posteriores tan importantes como el Idealismo alemán o el Romanticismo. La obra de estos pensadores, entre los que cabe incluir, como se ha visto, no solo a Reinhold y a Fichte, sino a muchos otros, tiene la virtud de sacar a la luz las extraordinarias potencialidades intelectuales del "giro copernicano" de Kant, que acaso permanecieron insospechadas y aun incomprendidas para el mismo que lo propuso.

Pero también el estudio, más desatendido en general por los investigadores kantianos, de las objeciones de los Populärphilosophen coetáneos del filósofo de Königsberg —objeciones nacidas 
de alguna de las dos principales escuelas de pensamiento que la filosofía crítica pretende superar-, así como de las respuestas que Kant mismo o sus discípulos dieron a ellas, ayuda sobremanera a entender la configuración que fue adquiriendo el pensamiento crítico de Kant. La obra de estos pensadores tuvo en este caso la virtud de mostrar en toda su amplitud las dificultades a las que se enfrentaba el proyecto reformador de Kant y las consecuencias, acaso no deseadas por el propio filósofo, a las que podía conducir el camino emprendido. De esta manera, el conocimiento de algunos de los argumentos contenidos en las críticas e interpretaciones que los "filósofos populares" hicieron de la obra de Kant se muestra insustituible para comprender mejor la posición definitiva y la evolución del pensamiento kantiano. $\mathrm{Y}$ no es ganancia menor la que también reporta este conocimiento: las razones esgrimidas contra la nueva filosofía permiten asimismo comprender "la cosa misma" de que se trata, es decir, los problemas metafísicos de gran calado que se discuten. Baste recordar, entre ellos, el problema de la verdad y de la validez objetiva del conocimiento, el papel que desempeña el lenguaje, la dificultad de distinguir el conocimiento analítico del sintético, la cuestión de la existencia de la cosa en sí, de la validez objetiva de la relación causal, del estatuto de las proposiciones de la matemática, de la división del conocimiento en inteligible y en sensible, de la posibilidad de la demostración de la existencia de Dios o del escándalo que supone la existencia de “antinomias" en el seno mismo de la razón.

El estudio, en fin, de los autores alemanes contemporáneos de Kant pone en muchas ocasiones ante nuestros ojos las críticas más perspicaces y mejor construidas que se han dirigido contra la filosofía kantiana. En muchos casos estas críticas superan la audacia de las que han propuesto nuestros contemporáneos. En ocasiones, incluso, son precursoras de las dificultades que se han planteado en tiempos más recientes, y aun en nuestros días, respecto de cuestiones capitales de la filosofía trascendental. Los problemas discutidos en la aetas kantiana siguen teniendo por ello en nuestros días una sorprendente actualidad. De esta manera, tanto para rechazar como para asumir las posiciones kantianas resulta necesario conocer a fondo los argumentos que allegaron los autores alemanes de la época que se conoce con el nombre del filósofo de Königsberg.

\section{Apéndice: Guía bibliográfica para el estudio de la aetas kantiana}

\subsection{Recursos bibliográficos y digitales}

Una completa colección de materiales sobre la historia de la filosofía crítica, aparecida ya en vida de Kant es la siguiente: Hausius, K. G.: Materialien zur Geschichte der critischen Philosophie. In drey Sammlungen. Nebst einer historischen Einleitung zur Geschichte der Kantischen Philosophie, Leipzig, Breitkopf, 1793.

Desde el año 1968, bajo el título de Aetas Kantiana, la editorial belga Culture et Civilisation publica en impresiones anastáticas el corpus de las obras más representativas de los autores de la era kantiana. Han aparecido 375 volúmenes.

Son muchos los libros de los autores de la aetas kantiana que están digitalizados en Google Books (https://books.google.es/) y en Internet Archive (https://archive.org/).

El Kant Research Group de la Universidad de Western Ontario (Canadá) ha creado el Digital Archive of 18th Century German Texts, que facilita el acceso a ediciones digitalizadas de autores coetáneos de Kant: http://publish.uwo.ca/ cdyck5/UWOKRG/digitalarchive.html\#s.

La Biblioteca Universitaria y Estatal de Sajonia-Anhalt ha catalogado y digitalizado su colección de "Zeitschriften des 18. Jahrhunderts", que se puede consultar online: http://digitale.bibliothek.uni-halle.de/vd18p. 
La Universidad de Bielefeld tiene un archivo digitalizado de los "Zeitschriften der Aufklärung”, que puede consultarse on-line: http://ds.ub.uni-bielefeld.de/viewer/.

El portal de Internet journals @ UrMEL, operado por la Universidad de Turingia y la Biblioteca Estatal de Jena (ThULB), ofrece acceso a publicaciones científicas en formato digital. Se encuentran disponibles numerosas revistas históricas y diversos materiales digitalizados: http://zs.thulb.uni-jena.de/content/below/index.xml.

La Digitale Bibliothek de Mecklenburg-Vorpommern ha digitalizado numerosas colecciones de revistas culturales de la época de la Ilustración, que se pueden consultar on-line: http://www.digitale-bibliothek-mv.de/viewer/.

En la Digitale Bibliothek del Münchener DigitalisierungsZentrum (MDZ), así como en la Bayerische StaatsBibliothek (BSB), se encuentran digitalizados muchos libros y colecciones de revistas de la aetas kantiana: https://www.digitale-sammlungen.de/, https://www.bsb-muenchen.de/.

Adickes, E. German Kantian bibliography, Boston, Ginn \& Company, 1895-1896. Este repertorio bibliográfico abarca hasta el año 1804. No llega, por tanto, hasta 1887 , como pretendía su proyecto original. La Parte [1] es reimpresión de The Philosophical Review 9-18, 2,3 (1896) 256; 919, 3, 6 (1894). Las Partes [2]-[3] (p. [253]-623) son reimpresión de Supplement to the The Philosophical Review 1-2 (1895) [253]-623; (1896), respectivamente.

4.2. Obras citadas o aludidas de la aetas kantiana en Alemania

BECK, J. S.: Erläuternder Auszug aus den kritischen Schriften des Prof. I. Kant, auf Anrathen desselben, 2 vols., Riga, bei Johann Friedrich Hartknoch (Aetas kantiana 20), 1793-1794.

: Einzig mögliche Standpunkt, aus welchem die kritische Philosophie beurteilt werden muss, Riga, bei Johann Friedrich Hartknoch, 1796.

: Grundriss der kritischen Philosophie, Halle, Rengersche Buchhandlung (Aetas kantiana 21), 1796

BORN, F. G.: Versuch über die ersten Gründe der Sinnenlehre: zur Prüfung verschiedner, vornämlich der weishauptischen Zweifel über die Kantischen Begriffe von Raum und Zeit, Leipzig, C.K. Klaubarth (Aetas kantiana 38), 1788.

: "Ueber den transcendentalen Idealismus", Neues philosophisches Magazin, Erläuterungen und Anwendungen des Kantischen Systems bestimmt I/3 (1790) 360-371; I/4 (1790) 459. 463.

: Versuch über die ursprünglichen Grundlagen des menschlichen Denkens und die davon abhängigen Schranken unserer Erkentniss, Leipzig, Johann Ambrosius Barth (Aetas kantiana 39), 1791.

: Immanuelis Kantii Opera ad philosophiam criticam. Latine vertit Fredericus Gottlob Born, 4. vols., Leipzig, E. B. Schwickert, 1796-1798.

EBERHARD, J. A.: "Nachricht von dem Zweck und der Einrichtung dieses philosophischen Magazins, nebst einigen Betrachtungen über den gegenwärtigen Zustand der Philosophie in Deutschland", Philosophisches Magazin I/1 (1788), 1-8.

: "Über die Schranken der menschlichen Erkenntniß”, Philosophisches Magazin I/1 (1788) 9-29.

: "Über die logische Wahrheit oder die transcendentale Gültigkeit der mennschlichen Erkenntniß”, Philosophisches Magazin I/2 (1789) 150-174. 
: “An die Herrn Herausgeber der Berlinischen Monathschrift”, Philosophisches Magazin I/2 (1788) 235-241.

: "Weitere Anwendung der Theorie von der logischen Wahrheit oder der transcendentalen Gültigkeit der menschlichen Erkenntniß”, Philosophisches Magazin I/3 (1789) 243-262.

: "Über den wesentlichen Unterschied der Erkenntniß durch die Sinne und durch den Verstand", Philosophisches Magazin, I/3 (1789) 290-306.

: "Über die Unterscheidung der Urtheile in analytische und synthetische", Philosophisches Magazin, I/3 (1789) 307-332.

: "Ausführlichere Erklärung über die Absicht dieses philosophischen Magazins. Veranlaßt durch eine Recension des ersten Stückes desselben in der Allg. Litt. Zeitung", Philosophisches Magazin I/3 (1789) 333-339.

: “Zusatz des Herausgebers”, Philosophisches Magazín II/1 (1789) 106-110. [Al artículo de J. F. Flatt, „Etwas über die Kantische Critik des cosmologischen Beweises für das Daseyn Gottes"].

: “Über den Ursprung der menschlichen Erkenntniß”, Philosophisches Magazin I/4 (1789) 369-405, (Aetas kantiana 63).

FICHTE, J. G.: Eigne Meditationen über ElementarPhilosophie und Practische Philosophie, en FUCHS, E.; LAUTH, R.; GLIWITZKY, H. (eds.): Gesamtausgabe der Bayerischen Akademie der Wissenschaften. Band II, 3, Bad Cannstatt, Frommann-Holzboog, 1964ss., 1793-1794, 21-177.

FLATT, J. F.: Fragmentarische Beyträge zur Bestimmung und Deduktion des Begriffs und Grundsatzes der Causalität, und zur Grundlegung der natürlichen Theologie, in Beziehung auf die Kantische Philosophie, Leipzig, Crusius (Aetas kantiana 73), 1788.

: "Etwas über die Kantische Critik des cosmologischen Beweises für das Daseyn Gottes", Philosophisches Magazín II/1 (1789) 93-106.

: Briefe über den moralischen Erkenntnisgrund der Religion überhaupt: und besonders in Beziehung auf die Kantische Philosophie, Tubinga, Joh. Georg Cottaische Buchhandlung, 1789.

GARVE, C.; FEDER, J. G.: "Critik der reinen Vernunft. Von Imman. Kant. 1781. 856 S. Octav", Zugaben zu den Göttinger Gelehrten Anzeigen 3 (1782) 40-48 (publicado anónimamente).

GARVE, C.: "Kritik der reinen Vernunft, von Immanuel Kant. 1781. 856 S. in 8.", Anhang zu den 3752 Bände der Allgemeine deutsche Bibliothek 2. Abtheilung (1783) 838-862.

HAMANN, J. G.: "Metakritik über den Purismus der Vernunft" (publicada póstumamente), en NADLER, J.: Sämtliche Werke, III. Band, Viena, Thomas-Morus-Presse im Herder-Verlag 1949-1957, 1784, 282-289.

HERDER J. G.: Eine Metakritik zur Kritik der reinen Vernunft, Frácfort/Leipzig, 1799.

: Kalligone. 1. Theil. Vom Angenehmen und Schönen, Leipzig, bei Johann Friedrich Hartknoch, 1800.

JACOBI, F. H.: David Hume über den Glauben, oder Idealismus und Realismus. Ein Gespräch, Breslau, bey Gottl. Loewe, 1787. 
JAKOB, L. H.: Prüfung der Mendelssohnschen Morgenstunden oder aller spekulativen Beweise für das Daseyn Gottes in Vorlesungen. Nebst einer Abhandlung von Herrn Professor Kant, Leipzig, bey Johann Samuel Heinseius (Aetas kantiana 135), 1786.

LOSSIUS, J. C.: Etwas über Kantsche Philosophie in Hinsicht des Beweises für das Dasein Gottes, Erfurt, by Georg Adam Keyser, 1789.

MAAß, J. G.: Briefe ueber die Antinomie der Vernunft, Halle, Franke, 1788.

: "Ueber den höchsten Grundsatz der synthetischen Urtheile; in Beziehung auf die Theorie von der mathematischen Gewisheit", Philosophisches Magazin II/2 (1789) 186-231.

: "Zusätze zu der Abhandlung über den höchsten Grundsatz der synthetischen Urtheile", Philosophisches Magazin IV/2 (1791) 235-253.

MAIMON, S.: Versuch über die Transzendentalphilosophie. Berlin, bei Christian Friedrich Boss und Sohn. (Edición actual: Eingeleitet, herausgegeben, mit Anmerkungen versehen von Florian Ehrensperger, Hamburgo, Meiner Verlag, 2013) (Aetas kantiana 174), 1790.

MEINERS, C.: Grundriss der Seelenlehre, Lemgo, im Verlage der Meyerschen Buchhandlung, 1786.

MELLIN, G. S. A.: Encyclopädisches Wörterbuch der Kritischen Philosophie oder, Versüch einer fasslichen und vollständigen Erklärung der in Kant's kritischen und dogmatischen Schriften enthaltenen Begriffe und Sätze, 6 vols., Jena-Leipzig, bei Friedrich Frommann (Aetas kantiana 175), 1797-1803.

MENDELSSOHN, M.: Phädon oder über die Unsterblichkeit der Seele, Bearbeitet von Fritz Bamberger und Leo Strauss, en MENDELSSOHN, M.: Gesammelte Schriften. Jubiläumsausgabe, vol. 3.1., Berlín, Akademie-Verlag, 1929; Stuttgart-Bad Cannstatt, Frommann-Holzboog, 1971-, 1767.

: Morgenstunden, oder Vorlesungen über das Daseyn Gottes, Bearbeitet von Leo Strauss, en MENDELSSOHN, M.: Gesammelte Schriften. Jubiläumsausgabe, vol. 3.2., Berlin, Akademie-Verlag, 1929-; Stuttgart-Bad Cannstatt, Frommann-Holzboog, 1971-, 1785.

NICOLAI, F.: Philosophische Abhandlungen. Grösstentheils vorgelesen in der Königl. Akademie der Wissenschaften zu Berlin, Berlín-Stettin (Aetas kantiana 200), 1808.

PISTORIUS, H. A.: Kants Vergessener Rezensent, Die Kritik der theoretischen und praktischen Philosophie Kants in fünf frühen Rezensionen von Hermann Andreas Pistorius, Herausgegeben von Bernward Gesang, Hamburgo, Felix Meiner, 2007, 1786-1794.

: "Prüfung der Mendelssohnischen Morgenstunden, oder aller spekulativen Beweise für das Daseyn Gottes in Vorlesungen von Ludwig Heinrich Jakob, Doktor der Philosophie in Halle. Nebst einer Abhandlung von Herrn Professor Kant. Leipzig, bey Heinseius. 1786334 S. 8.", Allgemeine deutsche Bibliothek 82, 2 (1788) 427-470.

PLATNER, E.: Philosophische Aphorismen nebst einigen Anleitungen zur philosophischen Geschichte, 2 vols., Leipzig, im Schwickertschen Verlage (Aetas kantiana 203), 1776, 1782, 1793.

REINHOLD, K. L. Briefe über die Kantische Philosophie, en Der Theutscher Merkur, Erster Brief, Zweyter Brief: August 1786, pp. 99-141; Dritter Brief: Januar 1787, pp. 3.39; Vierter Brief: Februar 1787, pp. 117-142; Fünfter Brief: Mai 1787, pp. 167-185; Sechster Brief: Juli 1787, pp. 67-88; Siebenter Brief: August 1787, pp. 142-165; Achter Brief: September 1787, pp. 247-278. Publicado como libro en Leipzig, bey Georg Joachim Göschen, 1790, vol. I; 1792, vol. II. 
: "Kantische Denkformen oder Kategorien von Gottlob August Tittel", Allgemeine Literatur-Zeitung 10 (1789) 73-76.

: Versuch einer neuen Theorie des menschlichen Vorstellungsvermögens, 1789.

: Beyträge zur Berichtigung bisheriger Missverständnisse der Philosophen, Erster Band, 1790.

: Ueber das Fundament des philosophischen Wissens, 1791.

SCHMID, C. C. E.: Critik der reinen Vernunft im Grundrisse zu Vorlesungen, nebst einem Wörterbuche zum leichtern Gebrauch der kantischen Schriften, Jena (Aetas kantiana 234), 1786.

SCHULTZ, J. F.: Erläuterungen über des Herrn Professor Kant Critik der reinen Vernunft, Königsberg, C. G. Dengel (Aetas kantiana 247), 1784.

: Prüfung der Kantischen Critik der reinen Vernunft, 2 vols., Königsberg, Hartung. Nicolovius, 1792 (Aetas kantiana 248), 1789.

: "Philosophisches Magazins", II/2 (Fortsetzung), Allgemeine Literatur Zeitung 283 (1790) 802-806. (Vid. Kant, AA 20: 408-409).

SCHULZE, G. E.: Aenesidemus oder über die Fundamente der von dem Herrn Professor Reinhold in Jena gelieferten Elementar-Philosophie. Nebst einer Vertheidigung des Skepticismus gegen die Anmassungen der Vernunftkritik, (Anónimo. Sin lugar) (Aetas kantiana 249), 1792.

SCHÜTZ, C. G.: "Moses Mendelssohns Morgenstunden oder Vorlesungen Äuber das Dasein Gottes", Allgemeine Literatur-Zeitung 1 (1786) 1-6; 7 (1786) 49-56.

SCHWAB, J. C.: "Prüfung des Kantischen Beweises von der bloßen Subjectivität der Categorien", Philosophisches Magazin IV/1 (1791) 195-213.

: "Ausführliche Erörterung der von der Königl. Akademie der Wissenschaften zu Berlin für das Jahr 1791 vorgelegten Frage: Welche Fortschritte hat die Metaphysik seit Leibnitzens und Wolffs Zeiten in Deutschland gemacht?", en SCHWAB, J. C.; LEONHARD REINHOLD, K.; ABICHT, J. H.: Preisschriften über die Frage: Welche Fortschritte hat die Metaphysik seit Leibnitzens und Wolffs Zeiten in Deutschland gemacht? Herausgegeben von der Königl, Preuss, Akademie der Wissenschaften, Berlín, bei Friedrich Maurer, 1796.

SELLE, C. G.: "Versuch eines Beweises, dass es keine reine von der Erfahrung unabhängige Vernunftbegriffe gebe", Berlinische Monatschrift 2 (1784) 565-575.

: Grundsätze der reinen Philosophie, Berlín, bei Christian Friedrich Himburg (Aetas kantiana 254), 1788.

STATTLER, B.: Anti-Kant, 2 vols., München, bey Jofeph Rentner, nächst dem schönen Thurme (Aetas kantiana 260), 1788.

: Anhang zum Anti-Kant in einer Widerlegung des Kantischen Grundlegung zur Metaphysik der Sitten, München, bey Jofeph Rentner, nächst dem schönen Thurme (Aetas kantiana 261), 1788.

: Der Anti-Kant im Kurzen: oder kurze vollständige Widerlegung aller vom Herrn Johann Schulz ... im 1. Theile seiner Prüfung vertheidigten entscheidenden Hauptsätze der Kantischen Kritik der reinen Vernunft, Augsburgo, bey Matthäus Rieger (Aetas kantiana 262), 1791. 
: Kurzer Entwurf der unausstehlichen Ungereimtheiten der Kantischen Philosophie: sammt dem Seichtdenken so mancher gutmüthigen Hochschätzer derselben. Hell aufgedecket für jeden gesunden Menschenverstand, und noch mehr für jede auch nur Anfänger im ordentlichen Selbstdenken, München, Joseph Lindauer (Aetas kantiana 264), 1791.

: Meine noch immer feste Ueberzeugung von dem vollen Ungrunde der Kantischen Philosophie, und von dem aus ihrer Aufnahme in christliche Schulen unfehlbar entstehenden äußersten Schaden für Moral und Religion: gegen zween neue Vertheidiger ihrer Gründlichkeit und Unschuld, Landshut, in der Mar, Hagen'schen Buchhandlung (Aetas kantiana 265), 1794.

: Wahres Verhältnis der kantischen Philosophie zur christlichen Religion und Moral nach dem nunmehr redlich gethanen Geständniße selbst des Herrn Kants seiner eifrigsten Anhänger, allen redlichen Christen zum reifen Bedacht, vorgestellet vom Verfasser des Anti-Kants, München, gedruckt bey Joseph Zängl, Stadtbuchdrucker (Aetas kantiana 266), 1794.

TENNEMANN, W. G.: System der Platonischen Philosophie, 1. Band, Leipzig, Johann Ambrosius Barth, 1792.

: Grundriss der Geschichte der Philosophie für den akademischen Unterricht, Leipzig, Johann Ambrosius Barth, 1829 [1812].

TIEDEMANN, D.: "Über die Natur der Metaphysick, zur Prüfung von Herrn Prof. Kants Grundsätzen”, Hessische Beiträge zur Gelehrsamkeit und Kunst 1 (1785) 113-130; 2 (1785) 233-248; 3 (1785) 464-474.

: Theätet oder über das menschliche Wissen: ein Beytrag zur Vernunftkritik, Fráncfort, bey Warrentrapp und Wenner (Aetas kantiana 277), 1794.

TITTEL, G. A.: Ueber Herrn Kant's Moralreform, Fráncfort/Leipzig, bey den Gebrüden Pfähler (Aetas kantiana 285), 1786.

: Kantische Denkformen oder Kategorien, Fráncfort, in der Gebhardischen Buchhandlung (Aetas kantiana 284), 1787.

ULRICH, J. A. H.: Eleuteriologie oder über die Freiheit und Notwendigkeit. Zum Gebrauch der Vorlesungen in den Michaelisferien, Jena, in der Cröterschen Buchhandlung, 1788.

WEISHAUPT, A.: Ueber die Kantischen Anschauungen und Erscheinungen, Nürnberg, in der Grattenauerischen Buchhandlung (Aetas kantiana 299), 1788.

: Ueber die Gründe und Gewisheit der Menschlichen Erkenntniss zur Prüfung der Kantischen Critik der reinen Vernunft, Nürnberg, in der Grattenauerischen Buchhandlung (Aetas kantiana 300), 1788.

: Zweifel über die Kantischen Begriffe von Zeit und Raum, Nürnberg, in der Grattenauerischen Buchhandlung (Aetas kantiana 303), 1788.

WIZENMANN, T.: Die Resultate der Jacobischer und Mendelsohnischen Philosophie kritischs erläutert von einem Freywilligen, Leipzig, bey G. T. Göschen, 1786. (Reproducción fotomecánica en Hildesheim, Gerstenberg Verlag, 1984).

: "An der Herrn Professor Kant vom der Verfasser der Resultate der Jacobischer und Mendelsohnischen Philosophie”, Deutsches Museum 1 (1787) 116-156. (Puede consultarse on-line en los archivos dedicados a los "Zeitschriften derAufklaerung" de la Universidad de Bielefeld: http://ds.ub.uni-bielefeld.de/viewer/). 
4.3. Bibliografía secundaria selecta

ALLISON, H. E.: The Kant-Eberhard Controversy. A Translation together with Supplementary Materials and a Historical-Analytic Introduction of Immanuel Kant's On a Discovery According to which Any New Critique of Pure Reason Has Been Made Superfluous by an Earlier One, Baltimore-Londres, The Johns Hopkins University Press, 1973.

ALTMANN, A.: "Moses Mendelssohn's Proofs for the Existence of God", Mendelssohn-Studien 2 (1975) 9-29.

: Die trostvolle Aufklärung. Studien zur Metaphysik und politischen Theorie Moses Mendelssohns, Stuttgart-Bad Cannstadt, Frommann-Holzboog, 1982.

AMERIKS, K.: Kant and the Fate of Autonomy: Problems in the Appropriation of the Critical Philosophy, Nueva York, Cambridge University Press, 2000.

: Cambridge Companion to Idealism, Cambridge, Cambridge University Press, 2000.

BANHAM, G.; SCHULTING, D.; HEMS, N.: The Bloomsbury Companion to Kant, Londres/Oxford, Bloomsbury Academic, 2015.

BASAGLIA, F.: "Der Einfluss von Hermann Andreas Pistorius auf Kants Argumentation im Paragrafen „Von dem Befugnisse der reinen Vernunft, im praktischen Gebrauche zu einer Erweiterung, die ihr im spekulativen für sich nicht möglich ist“ in der Kritik der praktischen Vernunft", Philosophical Readings 6/1 (2014) 69-75.

BAUMANNS, P.: Kants Philosophie der Erkenntnis. Durchgehender Kommentar zu den Hauptkapiteln der „,Kritik der reinen Vernunft“, Würzburg, Königshausen \& Neumann, 1997.

BAYER, O.: Vernunft ist Sprache: Hamanns Metakritik Kants, Stuttgart-Bad Cannstadt, FrommannHolzboog, 2002.

BECK, L. W.: Early German Philosophy: Kant and His Predecessors, Cambridge/Londres, Harvard University Press, 1969.

BEISER, F. K.: The Fate of Reason. German Philosophy from Kant to Fichte, Cambridge, Harvard University Press, 1987.

BERLIN, I.: The Magus of the North: J.G. Hamann and the Origins of Modern Irrationalism. Edited by Henry Hardy, Nueva York, Farrar, Straus, and Giroux, 1994.

BONDELLI, M.: "Maimon über Kants Beweis syntetischer Urteile a priori“, en DOYÉ, S.; BAUM, M.; HEINZ, M.; RAMEIL, U.; KALETHA, H. (eds.): Metaphysik und Kritik. Festschrift für Manfred Baum zum 65. Geburtstag, Berlín/Nueva York, Walter de Gruter, 2004, 265284.

CANTERLA, C.: "La metacrítica de la razón ilustrada en Hamann”, Daimon 2 (2008) 337-345.

: “La cuestión del nihilismo en J. G. Hamann”, Pensamiento 70 (2014) 577-600.

CIAFARDONE, R.: La Critica della ragion pura nella aetas kantiana. Antologia. 2 vols., L'Aquila/Roma, Japadre, 1987-1990.

CRUZ CRUZ, J.: Conciencia y representación. Una introducción a Reinhold, Pamplona, Eunsa, 2017. 
DAHLSTROM, D. O.: "Verbal Disputes in Mendelssohn's Morgenstunden", en MUNK, R. (ed.): Moses Mendelssohn's Metaphysics and Aesthetics, Dordrecht/Heidelberg/Londres/Nueva York, Springer, 2011, 3-20.

DI BELLA, S.: La storia della filosofia nella aetas kantiana. Teorie e discussioni con appendice di testi, Nápoles, Liguori, 2008.

DI GIOVANNI, G.: "Hume, Jacobi, and Common Sense: An Episode in the Reception of Hume in Germany at the Time of Kant", Kant-Studien 89/1 (1988) 44-58.

: Freedom and Religion in Kant and His Immediate Successors: The Vocation of Humankind, 1774-1800, Nueva York, Cambridge University Press, 2005.

: "The Year 1786 and Die Bestimmung des Menschen, or Popularphilosophie in Crisis", en MUNK, R. (ed.): Moses Mendelssohn's Metaphysics and Aesthetics, Dordrecht/Heidelberg/Londres/Nueva York, Springer, 2011, 217-234.

DUQUE, F.: "Historia y metafísica: el frágil espejo móvil de la razón. Contribución al estudio de la Aetas kantiana: 1790-1797”, en KANT, I.: Los progresos de la Metafísica desde Leibniz y Wolf. Estudio preliminar y traducción de Félix Duque, Madrid, Tecnos, 1987, xvii-ccxxx.

: Historia de la filosofía moderna. La era de la crítica, Madrid, Ediciones Akal, 1988.

DYCK, C. W.: "Turning the Game Against the Idealist: Mendelssohn's Refutation of Idealism in the Morgenstunden and Kant's Replies", en MUNK, R. (ed.): Moses Mendelssohn's Metaphysics and Aesthetics, Dordrecht/Heidelberg/Londres/Nueva York, Springer, 2011, 159-182.

DYCK, C. W.; WUNDERLICH, F. (eds.): Kant and his German Contemporaries, vol. 1: "Logic, Mind, Epistemology, Science and Ethics”, Cambridge, Cambridge University Press, 2018.

ERDMANN, B.: Kant's Kriticismus in der ersten und in der zweiten Auflage der Kritik der reinen Vernunft. Eine historische Untersuchung, Leipzig, Voss., 1878. (Repr. Nachdruck, Hildesheim, H. A. Gerstenberg, 1973).

FABIANELLI, F.: Karl Leonhard Reinhold's Transcendental Psychology, Berlín/Boston, De Gruyter (Reinholdiana vol. 3), 2016.

FALKENSTEIN, L.: “A Double Edged Sword? Kant's Refutation of Mendelssohn's Proof of the Immortality of the Soul and Its Implications for His Theory of Matter", Studies in the History and Philosophy of Science 29A/4 (1998) 561-88.

FORSTER, M. N.: “Kant's Philosophy of Language”, Tijdschrift voor Filosofie 74 (2012) 485-511.

GARDNER, S.: "Kant's Practical Postulates and the Limits of the Critical System", Bulletin of the Hegel Society of Great Britain 63 (2011) 187-215.

GAWLINA, M.: Das Medusenhaupt der Kritik: Die Kontroverse zwischen Immanuel Kant und Johann August Eberhard, Berlín/Nueva York, De Gruyter, 1996.

GESANG, B.: "Die analytisch-synthetisch Dichotomie bei I. Kant und J. G. Maaß. Ein Beitag über die Aktualität der Aetas Kantiana", Archiv für Geschichte der Philosophie 82 (2000) 87101.

: "Einleitung", en: Kants Vergessener Rezensent, Die Kritik der theoretischen und praktischen Philosophie Kants in fünf frühen Rezensionen von Hermann Andreas Pistorius, Hamburgo, Felix Meiner, 2007, VII-XLV. 
GRAM, M. S.: “The Crisis of Syntheticity: The Kant-Eberhard Controversy”, Kant-Studien 71 (1980) $155-180$

GUILLERMIT, L.: "Introduction. Le réalisme de Jacobi”, en JACOBI, F. H.: David Hume et la croyance Idealisme et realisme, introduit, traduit et annoté par Louis Guillermit, París, Vrin, 2000, 15-122.

GUYER, P.: "Mendelssohn and Kant: One Source of the Critical Philosophy", Philosophical Topics, 19 (1991) 119-52.

HARTMANN, N.: Die Philosophie des Deutschen Idealismus: Teil 1: Fichte, Schelling und die Romantik, Berlín, Walter de Gruyter, 1960 2. unveränderte Aufl, 1921.

HENRICH, D.: Between Kant and Hegel: Lectures on German Idealism. Edited by David S. Pacini, Cambridge, Harvard University Press, 2003.

HERRERA, H. E.: "La discusión de Salomon Maimon con el intento de vinculación de sensibilidad y entendimiento en la Crítica de la razón pura de Immanuel Kant", Anuario Filosófico 43 (2010) 561-587.

HOLZHEY, H.: "Popularphilosophie", en RITTER, J.; GRÜNDER, K.; GOTTFRIED, G.: Historisches Wörterbuch der Philosophie, BD. 7, Basilea, Schwabe Verlag, 13 Bände, 1971-2007, 1989, 1093-1099.

HORSTMANN, R-P.: "The Reception of the Critique of Pure Reason in German Idealism", en GUYER, P. (ed.): The Cambridge Companion to Kant's Critique of Pure Reason, Cambridge, Cambridge University Press, 2010, 329-345.

HOYOS, L. E.: El escepticismo y la filosofía trascendental. Estudios sobre el pensamiento alemán a fines del siglo XVII, Bogotá, Universidad Nacional de Colombia-Facultad de Ciencias Humanas, Siglo del Hombre Editores, 2001a.

: “Cosa en sí después de Kant. La solución de Salomon Maimon”, Ideas y Valores 116 (2001b) 43-66.

JAESCHKE, W.; ARNDT, A.: Die Klassische Deutsche Philosophie nach Kant. Systeme der reinen Vernunft und ihre Kritik 1785-1845, München, C. H. Beck, 2012.

JIMÉNEZ, A.: "The Duisburg Nachlaß as a Key to Interpreting Salomon Maimon's Reading of the Transcendental Deduction of Categories", en ORDEN JIMÉNEZ, R. V.; HANNA, R.; LOUDEN, R.; RIVERA DE LOS ROSALES, J.; SÁNCHEZ MADRID, N.: Kant's Shorter Writings. Critical Paths Outside the Critiques, Cambridge, Cambridge Scholars Publishing, 2016, 39-54.

KERTSCHER, H-J.; STÖCKMANN, E.: Ein Antipode Kants? Johann August Eberhard im Spannungsfeld von spätaufklärerischer Philosophie und Theologie, Berlín/Nueva York, Walter de Gruyter, 2012.

KÜHN, M.: Kant. A Biography. Cambridge, Cambridge University Press, 2001.

: "Kant's Critical Philosophy and its Reception - The first five years (1781-1786)", en GUYER, P.: The Cambridge Companion to Kant and Modern Philosophy, Cambridge, Cambridge University Press, 2006, 630-663.

KÜHN, M.; KLEMME, H. F.: The Dictionary of Eighteenth-Century German Philosophers, 3 vols., Londres/Nueva York, Continuum, 2010. 
LA ROCCA, C.: “Introducción”, en KANT, I.: La polémica sobre la Crítica de la Razón Pura (respuesta a Eberhard). Edición y traducción de Mario Caimi, Madrid, Mínimo tránsitoAntonio Machado Libros, 2002, 9-72.

LAFONT, C.: La razón como lenguaje. Una revisión del "giro lingüistico" en la filosofía del lenguaje alemana, Madrid, Visor, 1993.

LANDAU, A.: Rezensionen zur Kantischen Philosophie 1781-1787, Bebra, Albert Landau Verlag, 1991.

LERUSSI, N.: "Sistema e idealismo. Kant frente a Jacobi y Fichte", en LERUSSI, N.; SOLÉ, M. J.: En busca del idealismo. Las transformaciones de un concepto, Buenos Aires, RAGIF Ediciones, 2016, 38-56.

MARKET, O.: "Kant y la recepción de su obra hasta los albores del siglo XX", Anales del Seminario de Historia de la Filosofía 7 (1989) 195-230.

MBUYI, M.: Kants Tübinger Kritiker: die Kritik von Johann Friedrich Flatt an Kants moralischem Argument für die Annahme Gottes, Aachen, Shaker, 2001.

MICHELI, G.; SANTINELLO, G.; BIANCO, B.; LONGO, M.: "Kantianism and the Historiography of Philosophy", en PIAIA, G.; SANTINELlO, G.: Models of the History of Philosophy. Vol. III: The Second Enlightenment and the Kantian Age, Dordrecht/Heidelberg/Nueva York/Londres, Springer, 2015 769-964.

MOTTA, G.: "Evidenzen. Die Abschaffung der Form in Ch. G. Selles Auseinandersetzung mit Kant", Philosophical Readings III.3 (2011) 73-77.

: “„Das Phantom des Berkleyischen Idealisms“. Su alcuni riferimenti a J. G. H. Feder nella Critica della ragion pura”, Studi Kantiani 25 (2012) 59-69.

MUNK, R.: “'What Is the Bond?' The Discussion of Mendelssohn and Kant 1785-1787”, en: Moses Mendelssohn's Metaphysics and Aesthetics, Dordrecht/Heidelberg/Londres/Nueva York, Springer, 2011, 183-202.

NITZAN, L.: Jacob Sigismund Beck's Standpunctslehre and the Kantian Thing-in-itself Debate. The Relation Between a Representation and its Object, Heidelberg/Nueva York/Dordrecht/Londres, Springer, 2014.

NOWITZKI, H-P.; STIENING, G.: Johann Georg Feder (1740-1821). Empirismus und Popularphilosophie zwischen Wolff und Kant, Berlín/Boston, De Gruyter, 2018.

PACHILLA, P.: “¿Escepticismo radical o idealismo absoluto? Maimon en la transición del poskantismo", en LERUSSI, N.; SOLÉ, M. J.: En busca del idealismo. Las transformaciones de un concepto, Buenos Aires, RAGIF Ediciones, 2016, 87-96.

PARDEY, U.: "Über Kants Widerlegung des Mendelssohnschen Beweises der Beharrlichkeit der Seele", Kant-Studien 90/3 (1999) 257-84.

PICHE, C.: "L'espace d'une virgule. Mendelssohn et Kant sur les preuves de l'existence de Dieu", Science et Esprit 64/3 (2012) 395-411.

PIETSCH, L-H.: Topik der Kritik: Die Auseinandersetzung um die Kantische Philosophie (17811788) und ihre Metaphern, Berlín/Nueva York, de Gruyter, 2010.

RIVERA DE ROSALES, J.: "The Methodical Singularity of the First Fichte”, en ROCKMORE, T.; BREAZEALE, D.: Fichte and Transcendental Philosophy, Nueva York, Palgrave Macmillan, 2015, 211-228. 
: Fichte. La libertad es el fundamento del conocimiento y de la moral, Madrid, RBA, 2017.

RIVERA DE ROSALES, J.; MARKET, O.: El inicio del Idealismo alemán, Madrid, Editorial Complutense, 1996.

ROHS, P.: Johann Gottlieb Fichte, München, Beck, 1991.

ROVIRA, R.: “¿Es $7+5=12$ un juicio sintético? Examen de las razones de Kant (y de Schultz)”, en TERUEL, P. J. (ed.): Kant y las ciencias, Madrid, Biblioteca Nueva, 2011, 17-29.

: “Nada puede gustar sin interés'. Las objeciones de Herder contra la definición kantiana de lo bello", Universitas Philosophica XXX, 61 (2013) 131-151.

: "Mendelssohn's Refutation of Kant's Critique of the Ontological Proof", Kant-Studien $108 / 3$ (2017) 401-426.

SANDKÜHLEN, H. J.: Handbuch Deutscher Idealismus, Stuttgart, J. B. Metzler, 2005.

SASSEN, B.: Kant's Early Critics. The Empiricist Critique of the Theorethical Philosophy, Cambridge, Cambridge Univesrity Press, 2000.

: "Kant and Mendelssohn on the Implications of the "I Think", en LENNON, T.; STAINTON, R. (eds.): The Achilles of Rationalist Psychology, Amsterdam/Nueva York, Springer, 2008, 215-234.

: "Reinhold's Critics: Kantian and Anti-Kantian", en DI GIOVANNI, G. (ed.): Karl Leonhard Reinhold and the Enlightenment, Amsterdam/Nueva York, Springer, 2010, 209220.

SCHMIDT, J.: "The Question of Enlightenment: Kant, Mendelssohn, and the Mitwochsgesellschaft", Journal of the History of Ideas 50/2 (1989) 269-91.

SCHRÖPFER, H.: Kants Weg in die Öffentlichkeit: Christian Gottfried Schütz als Wegbereiter der kritischen Philosopie, Stuttgart/Bad Cannstadt, Frommann-Holzboog, 2003.

SEDGWICK, S.: The Reception of Kant's Critical Philosophy: Fichte, Schelling, and Hegel, Cambridge, Cambridge University Press, 2007.

SOLÉ, M. J.: "El idealismo trascendental kantiano y sus primeros críticos", en LERUSSI, N.; SOLÉ, M. J. (eds.): En busca del idealismo. Las transformaciones de un concepto, Buenos Aires, RAGIF Ediciones, 2016, 2-14.

SPARLING, R. A.: Johann Georg Hamann and the Enlightenment Project, Toronto/Buffalo/Londres, University of Toronto Press, 2011.

TERUEL, P. J.: "Una nota a pie de página de la Crítica de la razón práctica. La polémica entre Thomas Wizenmann e Immanuel Kant”, Thémata 38 (2007) 205-224.

TOMASONI, F.: "Kant and Mendelssohn: A Singular Alliance in the Name of Reason", History of European Ideas 30 (2004) 267-294.

: "Mendelssohn's Concept of the Human Soul in Comparison with Those of Georg Friedrich Meier and Kant”, en MUNK, R. (ed.): Moses Mendelssohn's Metaphysics and Aesthetics, Dordrecht/Heidelberg/London/New York, Springer, 2011, 131-157.

UEBERWEGS, F.; FRISCHEISEN-KÖHLER, M.: Grundriß der Geschichte der Philosophie der Neuzeit bis zum Ende des achtzehnten Jahrhunderts, Berlín, Ernst Siegfried Mittler und Sohn, 1914. 
VILLACAÑAS, J. L.: La filosofía del idealismo alemán, 2 vols., Madrid, Síntesis, 2001.

WILLASCHEK, M.; STOLZENBERG, J.; MOHR, G.; BACIN, S. (Hrsg.): Kant-Lexikon. 3 vols., Berlín-Boston, Walter de Gruyter, 2015.

VILLERS, C.: Philosophie de Kant, ou Principes fondamentaux de la philosophie transcendentale, Metz, chez Collignon, 1801.

ZAMMITO, J. H.: Kant, Herder, and the Birth of Anthropology, Chicago, University of Chicago Press, 2002.

ZANDE, J. van der: "In the Image of Cicero: German Philosophy between Wolff and Kant", Journal of the History of Ideas 56/3 (1995) 419-442. 


\title{
La virtud de la humildad en la filosofía práctica de Hermann Cohen
}

\author{
HÉCTOR OSCAR ARRESE IGOR ${ }^{1}$
}

\begin{abstract}
Resumen
Este trabajo apunta a mostrar el rol sistemático de la virtud de la humildad en la ética de Hermann Cohen. Para ello establezco relaciones conceptuales entre las virtudes de la veracidad y la humildad. Por otro lado, exploro la dimensión estética de la humildad, así como su relevancia para el campo de la intersubjetividad. Finalmente considero la función crítica de la humildad en relación con el espacio de lo público político.
\end{abstract}

Palabras clave: Cohen, humildad, neokantismo, socialismo, virtud.

\section{The Virtue of Humility in Hermann Cohen's Practical Philosophy}

\begin{abstract}
In this paper, I aim to show the systematic role played by the virtue of humility in Hermann Cohen's ethics. For that purpose, I establish conceptual relationships between the virtues of humility and veracity. Furthermore, I explore the aesthetic dimension of humility as well as its relevance to the field of intersubjectivity. Finally, I consider the critical function of humility in relationship to the public political space.
\end{abstract}

Keywords: Cohen, humility, Neokantianism, socialism, virtue.

La filosofía de Hermann Cohen fue un hito fundamental en el movimiento de retorno a Kant que tuvo lugar en la segunda mitad del siglo XIX. Cohen articuló un sistema filosófico en línea con su interpretación del pensamiento de Kant, en diálogo con el estado de la ciencia de su tiempo. En el campo de la filosofía práctica, Cohen se propuso elaborar una teoría que no fuera vulnerable a la objeción del psicologismo moral. Esto implica que la ética debe partir de un corpus discursivo científico. Como sostiene Cohen: «toda filosofía está referida al hecho de las ciencias. Esta referencia al hecho de las ciencias vale para nosotros como lo eterno en el sistema de Kant» [«Alle Philosophie ist auf das Faktum von Wissenschaften angewiesen. Diese Anweisung auf das Faktum der Wissenschaften gilt uns als das Ewige in Kants System»] (2002: 65). De este modo, Cohen procura evitar lo que denomina como una ética de la convicción interior [Gesinnungsethik]. Se trata de impedir la fundamentación de los principios de la ética en la observación de los propios estados internos.

En segundo lugar, Cohen tuvo que dar cuenta de la objeción de que la ética kantiana constituiría un mero formalismo sin aplicabilidad práctica. Es en este contexto que Cohen desarrolla su concepción de la virtud, entendida como una serie de disposiciones emocionales que dan estabilidad a la actividad de construir el ideal de un Estado justo. De este modo, Cohen integra la

${ }^{1}$ Centro de Investigaciones Filósóficas, Consejo Nacional de Investigaciones Ciéntificas y Técnicas, Argentina. Contacto: harreseigor@gmail.com 
dimensión interior de la convicción con la realidad histórica en la que el agente debe instanciar el ideal moral. De allí que nuestro filósofo afirme: «la virtud debe tener y conservar sus raíces vivientes en la convicción. Y del mismo modo ella debe atestiguarse por medio de las acciones, que adquieren la apariencia de una substancialidad moral por medio de la continuidad y de un tipo de persistencia» [«Die Tugend muss ihre lebendige Wurzel in der Gesinnung haben und behalten. Und sie muss ebenso sehr durch die Handlungen sich bezeugen, welche durch die Beständigkeit, durch eine Art von Beharrung das Ansehen einer sittlichen Substantialität annehmen»] (2002: 472).

Las virtudes que integran la propuesta de Cohen están divididas en dos categorías. Por un lado, están agrupadas las virtudes de primer grado, que tienen como móvil el afecto del honor [Ehre] y apuntan a poner al individuo en correlación con la comunidad universal de la humanidad. Este grupo está integrado por la veracidad, la valentía y la justicia. Pero Cohen también distingue las virtudes de segundo grado, que están movidas por el amor [die Liebe] y tienen por objeto la realización del ideal moral en el contexto de la comunidad de pertenencia del sujeto. Las virtudes de segundo grado son la humildad y la fidelidad. Finalmente, la virtud de la humanidad integra a las demás virtudes y de este modo completa el sistema pensado por el filósofo de Marburg.

La primera virtud que Cohen tematiza es la veracidad, porque es una disposición moral que habilita la búsqueda del conocimiento necesario para la realización del ideal moral (2002: 500). Se trata tanto del conocimiento del contenido prescriptivo de la moralidad como de los medios para llevarlo a cabo. De allí la importancia que otorga Cohen al derecho universal a la educación, que constituye una piedra fundamental de su propuesta socialista (2002: 503, 505-507). Ahora bien, la virtud de la veracidad y la de la humildad están en una relación íntima en la medida en que se complementan y corrigen mutuamente. La virtud de la humildad es un elemento de suma relevancia para entender la ética de Cohen, en especial porque garantiza el anclaje histórico del ideal moral de la autoconciencia. Por esta razón tiene sentido considerar más en detalle la fundamentación de dicha virtud en el sistema del filósofo neokantiano.

\section{La virtud de la humildad}

La moralidad consiste en una determinada relación que el individuo establece entre la individualidad y la universalidad morales (Cohen 2002: 63). La veracidad es una virtud de primer grado, lo que significa que se dirige al plano de la universalidad moral. Por el contrario, la virtud de la humildad [Bescheidenheit] está movida por el afecto del amor [Liebe], lo que la convierte en una virtud de segundo grado (Cohen 2002: 530). Esto implica que la humildad está orientada a la particularidad histórica en la que actúa el individuo.

La virtud de la humildad oficia de contralor de la veracidad porque limita la ambición de lograr un conocimiento definitivo, completo e incorregible (Cohen 2002: 531-532). Esta relación está expresada gráficamente en la figura de Sócrates. Se trata de una figura bifronte porque, por un lado, encarna el rostro odioso del sileno, que simboliza la ironía y la pequeñez de la humildad. Pero, por el otro, Sócrates representa la divinidad del sabio, en tanto que estableció el método científico, propio de la veracidad (Cohen 2002: 530).

Pero la humildad controla a la veracidad también en lo relativo a la elaboración del juicio moral. La virtud de la veracidad debe velar por la corrección formal del juicio moral; es decir, que debe garantizar su carácter universal. Pero la virtud de la humildad debe ejercer un control sobre la veracidad a fin de que se juzgue la acción pero no se condene moralmente a la persona. La razón de esto es que si la persona llegara a considerar que ella misma es irrecuperable, se privará de continuar su camino hacia el perfeccionamiento moral (Cohen 2002: 533). 
Esta capacidad de autolimitarse a la hora de juzgar moralmente al otro es posible porque la humildad recorre el camino inverso al de la veracidad. Mientras que la virtud de la veracidad y el afecto del honor llevan al yo a verse a sí mismo en el otro, la virtud de la humildad y el afecto del amor nos impulsan a ver al otro en nosotros. Es decir, que la virtud de la humildad nos dispone a juzgarnos en primer lugar a nosotros mismos, a percibir nuestras fragilidades y limitaciones $\mathrm{y}$, con ellas, nuestra finitud. Recién cuando hemos hecho este movimiento podemos transferir este juicio sobre nosotros mismos a los demás. Esto nos pondrá en el camino de la tolerancia y la comprensión del otro. Pero, sobre todo, nos capacita para la moderación [Mässigung] necesaria a fin de elaborar un juicio moral que nos permita desarrollarnos como seres finitos. Como sostiene Cohen, la ética debe estar destinada a los seres humanos y no a los dioses (2002: 533-534).

La moderación del juicio moral sobre el otro surge de tomar en cuenta el contexto en el que tienen lugar la acción y el progreso moral. No se trata de una concepción determinista de la moralidad, en la que el medio ambiente es el único factor explicativo de la acción. Por el contrario, Cohen intenta dar cuenta del 'fundamento y el piso' [Grund und Boden] desde el cual es posible la libertad. Es decir, que la humildad es aquella disposición moral que nos permite tomar en cuenta las condiciones que hacen posible la acción en cada momento. De este modo, la humildad nos preserva de la tentación de caer en una abstracción que nos lleve a negar nuestra finitud constitutiva. Como afirma Cohen: «tú crees empujar y eres empujado. La humildad guía el juicio sobre los empujones, en los que se mueve el ser humano»[«du glaubst zu schieben und du wirst geschoben. Diese Beschiedenheit leitet das Urteil über die Schiebungen, in deben das menschliche Wesen sich bewegt»] (2002: 546).

El afecto del amor se dirige a la particularidad del individuo y las circunstancias específicas de la acción, lo que permite a la virtud de la humildad prestar atención a la fragilidad tanto del agente como de aquellos que están involucrados en la situación de la decisión moral. En este sentido, la humildad nos permite comprender las situaciones en las que el otro o nosotros mismos no podemos cumplir adecuadamente con los mandatos morales de la autoconciencia (Cohen 2002: 544). Por eso, la humildad nos lleva a adoptar una actitud de tolerancia [Duldung]. Pero también es la virtud del cuidado del otro [Schonung], que nos mueve a hacernos cargo de las necesidades y carencias de los demás (Cohen 2002: 532).

Asimismo, la tolerancia que hace posible la humildad es el fundamento de la paciencia. La perseverancia en el camino hacia el logro del ideal moral dota de estabilidad a esta tarea infinita. Esto es así porque tiene un objetivo que nunca podemos alcanzar de modo definitivo, es decir, que opera más bien como un horizonte del desarrollo moral. De este modo, la humildad abre la puerta para la realización histórica de la moralidad (Cohen 2002: 534).

\section{La humildad como una virtud estética}

Como se señaló en la sección anterior, la virtud de la veracidad motiva la búsqueda del conocimiento verdadero. Por su parte, la humildad opera en el ámbito de la exposición del conocimiento obtenido, restringiendo la ambición de ocultar las conclusiones obtenidas detrás de un estilo oscuro e ininteligible. Esta actitud, en realidad, esconde la falta de claridad conceptual de la teoría misma. Suele ocurrir que, dado que el pensador no logró desarrollar una teoría consistente, tampoco puede exponerla de modo diáfano. El autor que cae en este vicio está movido por un sentimiento de exaltación de sí mismo y de menosprecio del lector (Cohen 2002: 535).

Este estilo oscuro y barroco obstaculiza el pensamiento filosófico cuando toma la forma de los aforismos. El estilo aforístico atomiza el pensamiento y lo fragmenta en pequeños trozos, impidiendo de esta manera seguir el decurso de la argumentación. Se trata de un estilo publicitario 
[Reklamestil], es decir, que está destinado a atraer potenciales lectores. Por eso, este estilo exige la inclusión de muchas interjecciones que interrumpen el pensamiento en vez de estimularlo. En este sentido, la virtud de la humildad debe ayudar al pensador a controlar que el decurso de su pensamiento no se interrumpa, sino que pueda extenderse y sostenerse de modo consistente. La ética científica prescribe que el pensador centre la exposición de sus ideas en el eje que brinda el procedimiento de la demostración [Beweisverfahren] (Cohen 2002: 535). Por el contrario, la virtud de la humildad habilita el desarrollo de un estilo filosófico que exprese claramente las convicciones e ideas del filósofo. De este modo, la humildad evita caer en la pretensión de poseer revelaciones geniales que estarían ocultas detrás de un estilo barroco (Cohen 2002: 534-535).

Dado que la exposición científica es un arte en sí mismo, la virtud de la humildad está relacionada también con la estética. En especial, Cohen encuentra el producto de la humildad en aquella forma de prosa poética que está cercana a la exposición científica porque es más bien sobria y no acentúa la expresión de sentimientos individuales (2002: 536). En este marco cobra sentido la afirmación de Jorge Luis Borges: «Es curiosa la suerte del escritor. Al principio es barroco, vanidosamente barroco, y al cabo de los años puede lograr, si son favorables los astros, no la sencillez, que no es nada, sino la modesta y secreta complejidad» (1924a: 858). Pero también pueden citarse aquellos versos suyos en torno a la poesía de Baltasar Gracián (1924b: 881):

\author{
Laberintos, retruécanos, emblemas, \\ Helada y laboriosa nadería, \\ Fue para este jesuita la poesía, \\ Reducida por él a estratagemas. \\ No hubo música en su alma; sólo un vano \\ Herbario de metáforas y argucias \\ Y la veneración de las astucias \\ Y el desdén de lo humano y sobrehumano. \\ No lo movió la antigua voz de Homero \\ Ni esa, de plata y luna, de Virgilio; \\ No vio al fatal Edipo en el exilio \\ $\mathrm{Ni}$ a Cristo que se muere en un madero.
}

Pero el carácter estético de la humildad se evidencia también en el humor. La ironía es la expresión estética de la virtud de la humildad. A diferencia de la sátira, que es la expresión de una concepción pesimista respecto de la perfectibilidad moral de la humanidad, la ironía supone una confianza en la posibilidad de acercarse al ideal normativo (Bergson 2012: 97; Cohen 2002: 359360). El ideal es captado por medio de la ironía de modo negativo, es decir, a partir de lo odioso, ordinario y moralmente bajo. Con las palabras de nuestro autor, la ironía permite el «[...] descubrimiento de lo bueno en un rincón de lo malo» [«die Entdeckung des Guten in einem Winkel des Schlechten»] (2002: 537). El humor pone de manifiesto al bien pero en una dimensión pequeña. De allí la afirmación de Cohen de que en el humor «el llanto es ocultado por la risa» [«das Weinen wird durch das Lachen verheimlicht»] (2002: 537).

La dimensión estética de la humildad se opone a la tesis de la autonomía del arte respecto de la ética. Esto implica que la ética tiene la misión de fundamentar el arte en términos de trabajo moral. En este sentido, Cohen rastrea el espacio que está abierto para el cultivo de la humildad en el arte moderno. Cohen considera que el giro estético de la modernidad está dado por el pasaje desde la poesía épica a la novela. Este pasaje viene dado por el tratamiento irónico de los grandes hechos heroicos [heroische Riesentaten]. Por eso «la poesía épica se convierte en la prosa de la novela» [«die 
Poesie wird die Prosa des Romans»] (Cohen 2002: 537). Esto lleva a Cohen a afirmar que «la novela es el arte de la modernidad» [«der Roman ist die Kunst der neuern Zeit»] (2002: 537).

Hay diferencias fundamentales entre la poesía épica y la novela. En la poesía épica el contenido viene dado por los pueblos que se enfrentan en la lucha y los héroes que representan a cada uno. Por eso, en la poesía épica se relatan más que nada hechos grandiosos y heroicos. En estas hazañas ejemplares la inteligencia deja lugar a la fuerza (Cohen 2002: 537-538). En la novela ocurre lo contrario. Allí, lo cotidiano y la maldad humana son expuestos en su pequeñez [Kleinlichkeit]. El humor genera una actitud benevolente frente a las contradicciones y las propias debilidades y flaquezas. La humildad permite descender de lo grandioso y festivo hacia las pequeñeces de la mezquindad humana. «De este modo la ironía se convierte en humildad» [«Die Ironie wird so zur Bescheidenheit»] (Cohen 2002: 538-539).

Cohen señala que un hito fundamental en este proceso es El Ingenioso Hildalgo Don Quijote de La Mancha (2002: 537). Ante todo, puede señalarse la descripción que hace Cervantes de la figura de Don Quijote, que contrasta fuertemente con sus ambiciones de convertirse en un caballero andante. De este modo comienza la novela:

En un lugar de la Mancha, de cuyo nombre no quiero acordarme, no ha mucho tiempo que vivía un hidalgo de los de lanza en astillero, adarga antigua, rocín flaco y galgo corredor. Una olla de algo más vaca que carnero, salpicón las más noches, duelos y quebrantos los sábados, lentejas los viernes, algún palomino de añadidura los domingos, consumían las tres partes de su hacienda (Cervantes 2015: 27).

También es ilustrativa la escena de aquella noche en que Don Quijote vela las armas en la caballeriza de la posada, en espera de que el dueño de la misma (que él percibe como un 'castellano', es decir, dueño del castillo) lo ordene caballero. En medio de la vela, dos arrieros entran a dar de beber a sus mulas y se ven obligados para ello a sacar de su lugar las armas de Don Quijote, quien los castiga con una buena paliza. En vista de esto, el posadero decide ordenarlo caballero en una ceremonia en la que finge rezar una oración y luego le da un espaldarazo. Recién luego Don Quijote parte en busca de aventuras junto con su caballo Rocinante (Cervantes 2015: 43-47).

Podemos ver el contraste entre la poesía épica y la novela humorística también en el episodio de aquella mañana calurosa de julio en la que Don Quijote sale a buscar aventuras y llega a una posada. Allí Don Quijote se encuentra con dos prostitutas que están de viaje con unos arrieros a Sevilla. Don Quijote se imagina que la posada es un castillo y que las prostitutas son dos damas de la corte. Él se acerca, les pide que no tengan miedo y ellas se ríen en consecuencia. Cuando un cuidador de cerdos toca un cuerno para juntar a los animales, Don Quijote cree que es un heraldo que está anunciando que un caballero llegó al castillo (Cervantes 2015: 36-37). También puede hacerse referencia en este contexto al famoso episodio de los molinos de viento (Cervantes 2015: 75-76).

Como reflexiona Henri Bergson, Don Quijote anda por el mundo como un sonámbulo, confundiendo a las cosas, situaciones y personas que encuentra con las de las novelas de caballería. Es decir, que la causa de sus distracciones se desenvuelve ante nuestros ojos progresivamente y con naturalidad, provocando más aún nuestra risa. Por lo tanto, las distracciones de Don Quijote están unificadas en torno de una idea central. Pero sus desventuras también están vinculadas entre sí, si bien alrededor del modo en que la realidad inevitablemente corrige su sueño (Bergson 2012: 9-11). 


\section{La humildad como descentramiento del yo}

La virtud de la humildad protege al individuo del narcisismo de estar pendiente de sus deseos y frustraciones, porque lo libera del mito de la omnipotencia y perfección del yo. Esta es la actitud del sentimentalismo, que Cohen retrotrae al siglo XVIII. Dado que la virtud de la humildad desarrolla la capacidad de captar la diferencia que existe entre el camino recorrido hasta ahora y el progreso moral que nos resta para acercarnos al ideal, nos permite salir de la preocupación por nuestros estados subjetivos y colocar la mirada en el horizonte de la moralidad. Por esta razón, la virtud de la humildad descentra al individuo (Cohen 2002: 544).

Este descentramiento del yo exige superar posiciones narcisistas tales como la condena moral del otro porque no comparte las propias convicciones morales. Pero la virtud de la humildad no permite solamente moderar los propios juicios científicos o los juicios morales sobre la vida privada de los otros. También está a la base de la construcción de una autoestima fundada en los logros en el camino del propio perfeccionamiento moral. Cohen denomina a este tipo de tarea como un 'trabajo espiritual' [geistige Arbeit]. En este sentido, la virtud de la humildad nos permite evitar construir nuestra autoestima a partir de nuestro éxito en el empleo, la profesión o los negocios, lo que es denominado por Cohen como 'sentimiento de sí' [Selbstgefühl] (2002: 534). Cohen es claramente sensible al predominio de una moral burguesa basada en la búsqueda de riquezas y de status socioeconómico.

La virtud de la humildad permite solucionar el conflicto que se presenta a quien vela por la justicia y, en consecuencia, se ve obligado a elaborar juicios morales sin tomar en cuenta a la persona a quien acusa. Es el caso del juez, a quien le corresponde practicar esta virtud de la humildad para poder moderar sus juicios sobre el delincuente. Es decir, que la sentencia del delincuente debe dejar abierta la posibilidad de su perfeccionamiento moral permanente (Cohen 2002: 372). Del mismo modo, el delincuente debe practicar la virtud de la humildad para poder retomar el camino de la moralidad (Cohen 2002: 532).

En este punto Cohen se opone a la concepción intelectualista del derecho penal según la cual el criminal habría cometido un crimen porque le habría faltado el conocimiento adecuado de las circunstancias de su acción (2002: 358, 366-369). En este marco conceptual de referencia, el ladrón cometería su crimen por falta de una conciencia clara del daño que produce al otro. Contra esta concepción, Cohen sostiene la necesidad de incorporar la cooperación del afecto en la acción criminal, a fin de poder imputar correctamente al acusado (2002: 359).

De este modo, se abre la puerta al ejercicio de la autorresponsabilidad del delincuente. Por esta razón, Cohen se opone resueltamente al concepto del mal moral entendido como un destino del delincuente, del que no podría liberarse trabajando en pro de su perfeccionamiento. Cohen sostiene que esta idea del mal moral es producto de una forma de pensamiento mítico que es contrario al ejercicio de la razón práctica $(2002: 363,367)$. Se trata de un fatalismo determinista que está llamado a superarse gracias al ejercicio de la virtud de la humildad.

A la hora de juzgar un crimen debemos distinguir entre el acto [Tat] y la acción [Handlung]. El acto es la dimensión externa y observable de la acción del criminal que puede ser tipificada por la ley y que debe ser castigada con la pena prevista. Pero, desde el punto de vista moral, el crimen es una acción en tanto que escapa al castigo penal, si bien es el objeto del juicio moral que realizamos respecto de la persona del criminal o que este último hace sobre sí mismo. En este sentido, la virtud de la humildad nos lleva a confiar en la capacidad del criminal para retomar el camino del progreso moral que lo lleva a acercarse al ideal.

La razón de esto es que el Estado está fundado en un contrato implícito entre todos los ciudadanos; una de cuyas cláusulas fundamentales es el cumplimiento de la ley. Cada ciudadano 
puede realizarse como persona moral únicamente en la medida en que cumple con las condiciones del contrato mencionado, dado que solo de esta manera puede participar en la comunidad moral que se instancia en el Estado de derecho, denominada por Cohen como autoconciencia (2002: 249; Günther 1971: 196; Winter 1980: 292; Görland 1912: 241, 244-245). Por otro lado, la autoconciencia tiene realidad moral únicamente si todos los ciudadanos participan en la toma de decisiones del Estado, dado que es una comunidad intersubjetiva. De este modo, si un ciudadano ha dejado de participar de la red de acuerdos que constituyen la autoconciencia, entonces se impone una instancia en la que dicho ciudadano pueda iniciar un proceso de reconciliación con la comunidad.

Cohen establece una relación íntima entre el derecho y la ética de modo tal que entiende la filosofía moral como una filosofía del derecho (2002: 225; Schmid 1993: 58; Müller 1994: 125-129). Dado que el Estado es idéntico al sistema de los derechos, la ética deviene en una teoría del Estado (Cohen 2002: 33). Ahora bien, esta relación íntima entre lo moral y lo jurídico-político exige una concepción de la sentencia y la pena en la que haya un lugar para que el criminal pueda recorrer el proceso de regreso al camino hacia el ideal moral (Cohen 2002: 375). Este espacio está habilitado por la virtud de la humildad. De este modo, el criminal reconoce subjetivamente el derecho en la medida en que cumple la pena pero asumiendo la culpa. Esto significa que el criminal debe aceptar que ha transgredido el derecho y se ha separado de la comunidad moral de la autoconciencia (Cohen 2002: 377).

Gracias a la expiación de la pena el sentenciado pierde progresivamente su condición de criminal. Pero también, en la medida en que reconozca y acepte su lugar en la construcción de la autoconciencia moral, se convertirá en un hombre nuevo (Cohen 2002: 378). Por esta razón, Cohen se opone a aquella concepción del justo castigo en términos de restitución del equilibrio roto por el crimen, es decir, como una forma de venganza (2002: 379, 385-386).

La satisfacción de necesidad de justicia es secundaria desde el punto de vista moral. En consecuencia, Cohen considera inaceptable la pena de muerte porque interrumpe el camino hacia el perfeccionamiento moral. Pero, al atentar contra la autoconservación del sujeto, se daña simultáneamente a la autoconciencia dado que esta comunidad necesita de la participación de todos los ciudadanos (Cohen 2002: 382). De este modo, el cumplimiento de la pena tiene sentido si el Estado cuida de la satisfacción de las necesidades básicas del criminal, de modo tal de respetar su dignidad (Cohen 2002: 385). Solo a partir de esta condición es posible que el ciudadano pueda llegar a comprenderse como un elemento fundamental de la realización de la autoconciencia moral de la comunidad. En este sentido, Cohen puso las bases del socialismo alemán en su vertiente socialdemócrata (Holzhey 1994; Van der Linden 1988; 1994; 1998). Esto exige el rechazo de la concepción del castigo como un modo de proteger a la sociedad del peligro representado por el criminal (Cohen 2002: 386). En caso contrario, podría legitimarse el asco moral frente al criminal y su estigmatización. Por eso, Cohen sostiene que la auto-conservación del ciudadano es el alfa y el omega de la cultura y, en tanto que tal, el fundamento de toda tarea moral (2002: 387).

La virtud de la humildad tiene también repercusiones para la vida civil porque exige la discreción en el juicio sobre las acciones de los demás ciudadanos. En la antigüedad, la función acusatoria correspondía a cualquier ciudadano dado que se vivía en el marco de una democracia directa. Pero en la actualidad esta atribución está reservada al fiscal, que es quien tiene la obligación de acusar a un sospechoso de haber cometido un crimen. A lo sumo, el ciudadano debe brindar información respecto de las acciones de otros ciudadanos si se lo llama a declarar como testigo en un juicio (Cohen 2002: 546).

La virtud de la humildad debe llevar al ciudadano a separar su juicio moral sobre cada situación injusta respecto de su juicio sobre los responsables de la misma. La razón de muchos de los conflictos entre los ciudadanos tiene que ver con el celo que la mayoría tiene respecto del objetivo 
común de hacer respetar el derecho. Por eso, es necesario moderar el propio juicio para hacer posible la cooperación social indispensable para el logro de dicho objetivo común (Cohen 2002: 547). La virtud de la humildad también oficia de guía para resolver aquellos conflictos relativos a cuestiones públicas en los que está involucrado el autointerés. En estos casos, la virtud de la humildad exige llevar el debate al campo de las ideas, moderando la búsqueda del propio interés en aras del bien común (Cohen 2002: 547).

\section{La humildad como ejercicio del pensamiento crítico}

La virtud de la humildad permite utilizar la ironía, si bien no en el sentido en que lo hacen quienes buscan defender el empoderamiento del superhombre, para que pueda usar su fuerza sin escrúpulos. Por el contrario, la ironía permite limitar y restringir los intentos de pensar la autoconciencia como una forma de comunidad que se expande o se levanta sobre otras comunidades. De este modo, la autoconciencia continúa estando al servicio de la comunidad humana (Cohen 2002: 530-531).

El ejercicio de la ironía es importante para la humildad porque esta es la virtud del escepticismo. Pero no se trata de un escepticismo sofístico que desprecia a la razón y la ciencia. Por el contrario, el escepticismo es un primer momento motivador que debe dar lugar a una actitud crítica. El carácter crítico de la investigación filosófica permite poner en evidencia los límites del conocimiento y aquellos problemas que deben ser replanteados. De este modo, la virtud de la humildad evita el dogmatismo de quien cree hallarse en posesión de la verdad (Cohen 2002: 531).

Cohen aspira a la construcción de un sistema filosófico que integre la ética y la lógica. Esto significa que existe una relación intrínseca entre los fundamentos filosóficos de la ciencia matemático-natural y aquellos de la ciencia del derecho, objetos de la lógica y la ética, respectivamente. Este vínculo está corporizado en el pensamiento de Sócrates, en el que están unificados el método crítico de la ciencia y el conocimiento de sí mismo, en tanto que mandato moral (Cohen 2002: 83). Ahora bien, cabría preguntarse en qué consiste dicho vínculo sistemático entre la filosofía teórica y la práctica.

La lógica y la ética se integran porque comparten el mismo método de fundamentación de sus respectivos corpus de discurso científico (Cohen 2002: 85, 87-88). Este método implica la revisión y autocrítica constante de la actividad de fundamentación. Por esta razón, la ética nunca puede establecer un contenido substantivo definitivo y completo, sino que está en una búsqueda constante de acercarse al ideal moral. En este contexto, Cohen retoma la famosa parábola de los anillos de Gottlob Ephraim Lessing.

Según esta narración, un hombre había recibido como regalo un anillo con una piedra de ópalo que reflejaba muchos colores y hacía agradable ante Dios a quien lo llevara. Este hombre pasó el anillo al hijo que más quería y pidió a este último que hiciera lo propio en su debido momento. De este modo, quien recibiera el anillo se convertiría en el jefe de la familia. Luego de pasar varias generaciones, el anillo llegó a estar en propiedad de un descendiente de aquel hombre, quien resultó tener tres hijos y quererlos a todos por igual. Por esa razón no podía decidirse a quién dejar el anillo. De modo tal que mandó a hacer dos copias idénticas del mismo, haciendo imposible distinguir el anillo auténtico. Una vez que este hombre hubo muerto, se apersonaron los tres hijos, cada uno con su anillo, con la finalidad de convertirse en jefes de la familia. Pero no lograron su objetivo, dado que no pudieron probar que su anillo era el genuino. Los tres hermanos alegaban haber recibido el anillo directamente de su padre, quien les habría asegurado que era el original. El juez no pudo decidir la cuestión. Por eso el juez pidió a los hijos que vivan con el mismo amor libre de prejuicios de su padre, quien los amó a todos por igual, dado que les dio el mismo anillo (Lessing 2004: 63-69). 
Cohen rescata de este relato la idea de que no existe una verdad absoluta y definitiva, sino que el conocimiento debe consistir en una búsqueda constante de la verdad (2002: 91). Lessing apela efectivamente a despertar una actitud crítica en el lector a fin de motivar un respeto por la pluralidad de doctrinas y concepciones religiosas (Nisbet 2013: 578). Esta concepción del conocimiento como la actividad misma de la fundamentación implica el deber que tiene el científico de estar dispuesto siempre a revisar sus conclusiones. Cohen interpreta en este sentido la teoría plátonica de las Ideas. ${ }^{2}$ Por eso el conocimiento tiene siempre un carácter hipotético y provisorio.

Esto implica, en primer lugar, que el método de la pureza debe poner en cuestión lo dado, es decir, el prejuicio de que las relaciones intersubjetivas y políticas tienen una legitimidad intrínseca (Cohen 2002: 93). Por esta razón, Cohen considera que la ética de Aristóteles es una forma de oportunismo, en la medida en que supone sin más que la estructura estamental de la polis es moralmente incuestionable. Contra esta concepción conservadora de la moral, Cohen rescata la tradición iniciada por Rousseau, quien tuvo la valentía de tomar distancia frente a la configuración de las relaciones sociales y políticas de su tiempo, a fin de elaborar una teoría crítica (2002: 94).

Asimismo, el método de la pureza tiene consecuencias importantes para el tratamiento del problema del sujeto. Por un lado, esto significa la liberación del concepto dogmático de un alma dada previamente a la reflexión moral que limitaría el contenido prescriptivo de la misma. Pero también se ponen en cuestión las concepciones de la naturaleza humana desarrolladas en el seno de tradiciones ideológicas o religiosas. Presuponer sin más la validez de estas construcciones antropológicas conllevaría una forma de paternalismo ejercido sobre la razón, limitando su autonomía moral (Cohen 2002: 96)

Pero la forma de paternalismo de la razón que Cohen rechaza de modo más enérgico es la 'teonomía' (2002: 334; Dreyer 1985; Schmid 1993: 209-233). Es una posición que busca fundamentar la validez de los mandatos morales a partir de la revelación de la voluntad divina en las escrituras sagradas (Cohen 2002: 332). Dado que se trata siempre de una revelación divina en el marco de una religión determinada, la teonomía desencadena necesariamente la intolerancia y el enfrentamiento con las demás confesiones, incluso hasta llegar a las guerras de religión (Cohen 2002: 333-334).

Cohen sostiene que el ideal moral no puede instanciarse de modo completo en ninguna formación social o política con realidad histórica efectiva. La razón de esto reside en que el ideal moral es una serie de normas a cumplir que configura una estructura prescriptiva trascendente a lo dado (Schmid 1993: 72-73; Lisser 1922: 56-57). En consecuencia, el ideal moral es pensado como una tarea infinita que nunca es completada del todo (Cohen 2002: 258). Esta concepción abstracta del ideal moral pone a la teoría frente a la objeción de que se trataría de una propuesta meramente normativa, por lo que no sería aplicable al terreno de la política.

A fin de responder a esta objeción, Cohen distingue entre el sentido negativo y el positivo del método de la pureza. El primero corresponde al carácter trascendente del ideal respecto de la historia. Pero el sentido positivo de la pureza exige tomar en cuenta a los ciudadanos de carne y hueso a fin de establecer la correlación entre el individuo y la universalidad, que es la característica de la ética (Cohen 2002: 130, 391, 436). De allí las siguientes palabras de Cohen: «La voluntad natural no es la voluntad pura. El hombre natural no es el hombre puro. El yo empírico no es el yo puro. Pero, si no hubiera ningún hombre natural con una voluntad natural y una autoconciencia natural, entonces el método de la pureza no podría ni siquiera empezar; no tendría ningún sentido en absoluto» [«Der natürliche Wille ist nicht der reine Wille. Der natürliche Mensch ist nicht der reine Mensch. Das empirische Ich ist nicht das reine Ich. Aber wenn es keinen natürlichen Menschen mit natürlichem

${ }^{2}$ Cohen 2002: 97; 2005: 5-7, 13, 15 ss., 20 ss., 65, 87 ss., 94-96, 102, 111, 211 ss., 216, 247, 303, 311-313, 316, 326, 344, 374, 376, 379, 394, 400, 407, 445, 457-460, 482-485, 500, 502 ss., 528, 595; Lembeck, 1994: 89-100. 
Willen und natürlichem Selbstbewusstsein gäbe, so könnte die Methode der Reinheit nicht anfangen; sie hätte schlechterdings keinen Sinn»] (2002: 436-437).

\section{La humildad como una virtud para el espacio de lo público}

El ideal moral es una tarea infinita que, sin embargo, debe adquirir realidad histórica, como se argumentó en la sección anterior. Es en este punto en el que la virtud de la humildad adquiere relevancia para la praxis política efectiva. Para materializar la aplicabilidad del ideal moral en la historia, la virtud de la humildad dispone al agente a hacer un uso crítico de su razón a la hora de intervenir en las relaciones político-sociales. En este sentido, Cohen es deudor de una tradición que se remonta al menos hasta John Milton.

En el contexto de una grave crisis política que llevó al derrocamiento y la ejecución de Carlos I, en 1649, Milton desarrolló una propuesta filosófico-política centrada en el ejercicio crítico de la razón para el espacio público. En los años previos a la caída de Carlos I, Milton publicó sus primeros tratados sobre esta cuestión, en especial aquellos dedicados a las problemáticas del divorcio y la política educativa (Milton 1959 ; 1959b). Pero es en Areopagitica donde Milton desarrolló una defensa robusta de la libertad de expresión como condición del uso crítico de la razón en asuntos públicos. El contexto político de esta teoría viene dado por la exigencia de que el gobernante y sus funcionarios rindan cuenta al pueblo de sus acciones (Milton 2014a: 141). Esta condición opera como reaseguro del carácter representativo del poder (Milton 2014a: 163; Kahn 1995; Skinner 2004: 289).

Areopagitica es el resultado de la reacción de Milton contra el Licensing Act, una ley promulgada en 1643 en la que se establecía el requisito de la aprobación de un organismo público para poder publicar un libro (Milton 2014b: 101). De allí la afirmación contundente de Milton de que «[...] quien destruye un buen libro, mata a la razón misma $[\ldots] »[«[\ldots]$ who detroyes a good Booke, kills reason it selfe ...]»] (2014b: 103). Si dejamos la difusión de las ideas en manos de los censores suponemos que estos funcionarios son infalibles, lo que contradice la experiencia histórica secular (Milton 2014b: 113). Dado que los seres humanos somos falibles por naturaleza, el examen de los argumentos a favor o en contra de determinada virtud o de cierto vicio, o también de la verdad o falsedad de determinada tesis, nos brinda una ayuda indispensable para el desarrollo crítico de nuestra razón (Milton 2014b: 111-112). La censura previa de los libros también es una falta de respeto al público, dado que se trata de una forma de paternalismo, porque se cree que el público es tan tonto como para cambiar de opinión únicamente por leer un panfleto. Además, presupone que el censor debe llevar por las narices al público, indicándole lo que debe creer (Milton 2014b: 123-124).

El rechazo de esta forma de paternalismo es un eje fundamental también de la idea kantiana de la Ilustración, en el contexto del reinado de Federico II de Prusia (WA, AA 08: 40). Kant reclama superar la minoría de edad [Unmündigkeit], en su texto "Respuesta a la pregunta: ¿Qué es la Ilustración?". Se trata de atreverse a usar el propio entendimiento sin ser guiado por otra persona (WA, AA 08: 35). Esta minoría de edad tiene que ver con nuestro miedo y nuestra pereza para pensar por nosotros mismos, pero también con una educación basada en la repetición de meras fórmulas y reglas mecánicas (WA, AA 08: 35-36).

Kant considera que el uso público de la razón tiene lugar sobre todo en el espacio de intercambio entre los académicos y los intelectuales. Se trata de un espacio de comunicación no dominado o libre de coacción. Esto hace posible que el autor pueda comunicar sus ideas y que sus lectores u oyentes puedan testear la consistencia de sus argumentos (WA, AA 08: 37). Sin embargo, Kant concibe a la Ilustración como un cambio cultural que solo puede darse progresivamente dado que involucra la autocrítica necesaria para deshacerse de prejuicios profundamente arraigados (WA, AA 08: 36). 
La propuesta kantiana tiene repercusiones de peso para el diseño institucional del Estado, sobre todo en lo relativo al respeto por la libertad de expresión (WA, AA 08: 40). Esto también tiene consecuencias a la hora de determinar las relaciones de las diversas Facultades en el seno de la universidad. Esta cuestión lleva a Kant a postular un conflicto inevitable entre las Facultades superiores (la de Teología, la de Derecho y la de Medicina) y la Facultad inferior, que es la de Filosofía (SF, AA 07: 23). Las Facultades superiores transmiten contenidos de interés directo para el gobierno, dado que influyen en la vida del pueblo (SF, AA 07: 21-22). Por el contrario, la Facultad inferior tiene a su cargo la búsqueda de la verdad (SF, AA 07: 27-28). Por esta razón, la Facultad de Filosofía debe gozar de una libertad de investigación especialmente protegida (SF, AA 07: 18-20).

En este contexto institucional, la función de la filosofía es desmentir y criticar la pretensión que pueden tener los profesionales formados en las Facultades superiores de convertirse en taumaturgos frente al pueblo. El pueblo tiene la tendencia natural a esforzarse lo menos posible sin utilizar su razón a fin de satisfacer sus inclinaciones. Por eso, busca líderes con propuestas mágicas de solucionarlo todo de modo rápido y sin sacrificios. Por ejemplo, se tiende a creer que, cumpliendo con ciertos rituales, uno puede salvarse de ser condenado eternamente por ciertos pecados, sin tener que trabajar por el propio perfeccionamiento moral. De este modo, se produce un litigio ilegítimo entre la Facultad de Filosofía y las Facultades superiores, dado que estas tienden a limitar la influencia de aquella para poder mantener controlado al pueblo (SF, AA 07: 31-32).

Como se ha sostenido más arriba, las Facultades superiores deben transmitir determinadas doctrinas por mandato del gobierno. Sin embargo, dado que la razón humana no es infalible, dichas doctrinas deben ser sometidas al examen de la razón. Justamente, la Facultad de Filosofía tiene la responsabilidad de velar por el rigor y el apego a la verdad en las investigaciones de las Facultades superiores. Esto originará un conflicto inevitable pero legítimo, dado que tiene que ver con las funciones de cada una de las Facultades (SF, AA 07: 32).

Este conflicto entre las Facultades no puede resolverse de modo amistoso, sino que debe hacerse por medio de la sentencia pronunciada por el tribunal de la razón. La filosofía tiene la función de exponer públicamente la verdad. Este conflicto nunca terminará porque el gobierno siempre buscará garantizarse la influencia sobre el pueblo. Esto implica que las Facultades superiores no renunciarán nunca a su pretensión de dominio sobre el pueblo, por lo que la Facultad de Filosofía tiene que reservarse la custodia de la verdad. La Facultad de Filosofía tiene la obligación entonces de estar atenta a este peligro que siempre acecha (SF, AA 07: 33).

La concepción de la humildad desarrollada por Cohen conlleva el uso crítico de la razón en el ámbito de lo público, en línea con las propuestas mencionadas. Por ejemplo, la virtud de la humildad debe contrarrestar la práctica de construir héroes ficticios para usarlos como estandartes en los enfrentamientos entre los partidos políticos. Este cultivo de la heroicidad [Heroentum] es un obstáculo en el camino de la autoconciencia moral, porque la lucha facciosa entre los partidos atenta contra la construcción de la comunidad política (Cohen 2002: 539). La crítica de Cohen al culto a los héroes está dirigida principalmente contra la teoría de Thomas Carlyle (Cohen 2002: 542; Carlyle 2013: 21-195).

La humildad religiosa, presente por ejemplo en los libros proféticos, tiene un carácter moralmente aceptable. Sin embargo, la humildad religiosa pertenece también al culto a los héroes de la fe, que tienen este rasgo entre otros. Esto hace que se pierda el carácter moral de la humildad religiosa, dado que queda sumida en el culto a los grandes hombres. Por eso, Cohen prefiere la ironía antes que la humildad religiosa (2002: 539). El culto a los héroes también está presente en la literatura, porque muchos autores se presentan como genios cuando en realidad son meros pedantes. O se ubican en una genealogía que llega hasta Homero, siendo artistas mediocres (Cohen 2002: 539540). 
En el ámbito de la moralidad también está presente el culto al héroe bajo la forma del genio moral o de aquellas personas que encarnan de modo perfecto el ideal moral. Esto implica volver al pensamiento mítico, dado que se supone que el ideal moral podría llegar a ser cumplido absolutamente en algún momento de la historia. Contra esto, Cohen plantea la necesidad de retomar el camino de la autoconciencia moral, que es el ideal moral entendido como una tarea infinita (2002: 540). En relación al culto a los héroes morales, Cohen impugna el principio de la perfección moral [Vollkommenheit]. Se trata de un criterio que destruye la vida moral misma, porque anula la búsqueda del acercamiento infinito al ideal moral. Es una ilusión mítica que niega y desconoce la fragilidad humana (Cohen 2002: 540-541).

La idea de que puede lograrse la perfección moral tiene una fuerza importante porque es aceptada masivamente y tiene también su apoyo en la autoestima positiva de quien cree haberla logrado. La virtud de la humildad nos permite renunciar a esta ilusión de la perfección moral (Cohen 2002: 541). Desde este punto de vista, no puede aceptarse tampoco la idea de una perfección estética en sí misma que sea independiente de toda consideración moral. La ética y la estética están unidas en el sistema filosófico de Cohen, lo que implica que cada una tiene su autonomía pero a la vez es dependiente de la otra. Por esa razón, el arte siempre está incompleto y la virtud de la humildad es una virtud también estética (Cohen 2002: 541).

Ahora bien, la crítica al culto a los héroes no significa que no debamos estar agradecidos por los servicios que han brindado a la humanidad quienes propiciaron grandes avances, tales como los fundadores de las grandes religiones, Kant, el pintor Miguel Angel o Beethoven. Sin embargo, no debemos adorarlos como héroes, sino valorar críticamente su aporte y aprovecharlo para el progreso de la cultura humana. Es decir, que no está reñido el reconocimiento de la grandeza de espíritu [Grosse des Geistes] de estas personas con la admisión de sus debilidades y flaquezas. Esto nos permite un conocimiento científico de sus figuras, con lo que la virtud de la humildad trabaja aquí junto con la de la veracidad (Cohen 2002: 542-543).

La preferencia por las grandes personalidades parece inocua. Sin embargo, habilita el culto a la raza más refinada y evolucionada. El racismo contradice la ley fundamental de la moralidad porque niega el respeto debido a cada persona en tanto que integrante de la humanidad. El racismo solo puede ser contrarrestado por medio de la virtud de la humildad, dado que la ciencia e incluso la religión pueden llegar a justificarlo (Cohen 2002: 543). La locura del racismo hace imposible la convivencia de los pueblos en un marco de legalidad y de paz. Por esa razón, la virtud de la humildad tiene un carácter eminentemente político. Solo a partir de la virtud de la humildad puede fundamentarse el ideal de una federación de Estados [Staatenbund]. La virtud de la humildad se potencia gracias al amor por la humanidad, mientras que al racismo lo alimenta la misantropía (Cohen 2002: 543).

Como señalan algunos intérpretes, Cohen habría defendido la idea de un Estado democrático de derecho basado en el sufragio universal, entre otras razones para garantizar la inclusión de las minorías, entre las cuales se contaba claramente el pueblo judío (Holzhey 1993: 27 28; Schmid 1993: 77; Winter 1980: 333-334; Lübbe 1994: 234; 1987: 240; Schwarzschild 1994: 216). Cohen, hijo del cantor de la sinagoga de Coswig, había constatado en primera persona el crecimiento del antisemitismo en Alemania. Eran varias las organizaciones que vertebraban el movimiento antisemita, entre ellas el Chistlichsoziale Partei, la Verein deutscher Studenten, etc. (Geismann 1993: 370; Sieg 1994: 154). Incluso Cohen participó en calidad de perito en un juicio iniciado por el rabino Leo Munk contra el docente Ferdinand Fenner, quien había afirmado que el Talmud legitimaba moralmente la traición a los cristianos (Palmer 2006). Frente a esta ola creciente, Cohen asumió la defensa de la identidad judía y su aporte a la cultura alemana. En este contexto, Cohen centró su argumentación en el carácter itinerante del pueblo judío que lo libera de cualquier identificación con 
toda idiosincrasia y, a su vez, le permite integrarse a las diferentes culturas sin problemas (Wiedebach 1997: 35).

Pero es en su conferencia "Germanidad y Judaísmo", pronunciada hacia 1915, en donde Cohen desarrolla su posición contra el antisemitismo. Dicha conferencia, pronunciada en plena guerra, estaba dirigida contra los antisemitas que fustigaban a los judíos que morían en las trincheras (Cohen 1924: 292-293). Pero también Cohen polemizó allí con los sionistas, que abogaban por una separación tajante entre los judíos y los alemanes (1924: 291, 299-301). El movimiento argumentativo de Cohen consiste en determinar puntos en común entre el proceso de construcción de la identidad alemana y la judía. En este sentido, Cohen destaca la influencia del judaísmo en la reforma luterana, en especial en su tesis del carácter decisivo del tribunal de la conciencia a la hora de formar las convicciones religiosas (1924: 242-243). La Ilustración alemana debe también su idea de la autonomía moral al concepto de la pureza del alma en tanto que capacidad de juicio crítico (Cohen 1924: 245). De estos argumentos, Cohen concluye que los judíos están vinculados por obligaciones de piedad tanto con Alemania como con la patria de la que fueron expulsados (1924: 274). Esta exigencia levantada contra los sionistas tiene como contrapartida el reclamo para con el Estado alemán de la inclusión de los judíos como ciudadanos de pleno derecho. En este sentido, Cohen intentó aplicar la virtud de la humildad para lograr un avance hacia una Alemania más democrática y tolerante frente a los tiempos oscuros que se avecinaban.

\section{Bibliografía}

BERGSON, H.: Le Rire. Essai sur la signification du comique, París, Presses Universitaires de France, 2012.

BORGES, J. L.: "Prólogo", en: Obras Completas, Buenos Aires, Emecé Editores, 1974a.

: "Baltasar Gracián”, en Obras Completas, Buenos Aires, Emecé Editores, 1974b.

CARLYLE, T.: On Heroes, Hero-Worship and the Heroic in History, New Haven/Londres, Yale University Press, 2013.

COHEN, H.: "Deutschtum und Judentum", en: Hermann Cohens Jüdische Schriften, 2, Berlín, Schwetschke \& Sohn, 1924.

: "Ethik des reinen Willens", en: Herman Cohen. Werke, 7, Hildesheim/Zurich/Nueva York, Georg Olms Verlag, 2002.

: "Logik der reinen Erkenntnis", en: Herman Cohen. Werke, 6, Hildesheim/Zurich/Nueva York, Georg Olms Verlag, 2005.

DE CERVANTES SAAVEDRA, M.: "El Ingenioso Hidalgo Don Quijote de La Mancha", en: Don Quijote de La Mancha, Barcelona, Real Academia Española, Asociación de Academias de la Lengua Española, 2015.

DREYER, M.: Die Idee Gottes im Werk Hermann Cohens, Königstein, Verlag Anton Hain Meisenheim GmbH, 1985.

GEISMANN, G.: "Der Berliner Antisemitimusstreit und die Abdankung der rechtlich-praktischen Vernunft", Kant-Studien 83 (1993) 369-380.

GÖRLAND, A.: "Hermann Cohens systematische Arbeit im Dienste des kritischen Idealismus", Kant-Studien 17 (1912) 222-251.

GÜNTER, H.: System und Fortschritt im Denken Hermann Cohens, Colonia, Dissertation, 1971. 
HOLZHEY, H.: "Hermann Cohen: der Philosoph in Auseinandersetzung mit dem politischen und gesellschaftlichen Probleme seiner Zeit", en BRANDT, R.; ORLIK, F. (eds.): Philosophisches Denken - Politisches Wirken. Hermann Cohens Kolloquium Marburg 1992, Hildesheim/Zurich/Nueva York, Georg Olms Verlag, 1993.

: Ethischer Sozialismus, Fráncfort, Suhrkamp, 1994.

KAHN, V.: "The metaphorical contract in Milton's Tenure of Kings and Magistrates", en SKINNER, Q.; ARMITAGE, D.; HIMY, A. (eds.): Milton and Republicanism, Cambridge, Cambridge University Press, 1995.

KANT, I.: "Beantwortung der Frage: Was ist Aufklärung?", en Kants Gesammelte Schriften, herausgegeben von der Preussischen Akademie der Wissenschaften, Berlín, 1902 ss.

: "Der Streit der Facultäten in drei Abschnitten", en Kants Gesammelte Schriften, herausgegeben von der Preussischen Akademie der Wissenschaften, Berlín, 1902 ss.

LEMBECK, K.-H.: Platon in Marburg, Würzburg/Könighausen, Neumann, 1994.

LESSING, G. E.: Nathan der Weise, Husum/Nordsee, HusumDruck- und Verlaggesellschaft, 2004.

LISSER, K.: Der Begriff des Rechts bei Kant. Mit einem Anhang über Cohen und Görland, Berlín, Verlag von Reuter \& Reichard, 1922.

LÜBBE, H.: "Neukantianische Sozialismus", en OLLIG, H.-L. (ed.): Materialen zur Neukantianismus Diskussion, Darmstadt, Wissenschaftliche Buchgesellschaft, 1987.

: "Die politische Theorie des Neukantianismus und des Marxismus", en HOLZHEY, H. (ed.): Auslegungen. Band 4. Hermann Cohen, Fráncfort/Berlín/Berna/Nueva York/París/Viena, Peter Lang, 1994.

MILTON, J.: "Doctrine and Discipline of Divorce", en: The Complete Prose Works of John Milton. Volume II: 1643-1648, New Haven, Yale University Press, 1959a.

: Of Education, The Complete Prose Works of John Milton. Volume II: 1643-1648, New Haven, Yale University Press, $1959 \mathrm{~b}$.

: "The Tenure of Kings and Magistrates", en: Areopagitica and Other Writings, Londres, Penguin Group, 2014a.

:Areopagitica, en: Areopagitica and Other Writings, Londres, Penguin Group, 2014b.

MÜLLER, C.: Die Rechtsphilosophie des Marburguer Neukantianismus. Naturrecht und Rechtpositivismus in der Auseinandersetzung zwischen Hermann Cohen, Rudolf Stammler und Paul Natorp, Tubinga, J.C.B. Mohr (Paul Siebeck), 1994.

NISBET, H. B.: Gotthold Ephraim Lessing. His Life, Works and Thoughts, Oxford, Oxford University Press, 2013.

PALMER, G.: "Judaism as a ,method' with Hermann Cohen and Franz Rosenzweig", en GIBBS, R. (eds.): Hermann Cohen's Ethics, Leiden-Boston, Brill, 2006.

SCHMID, P.: Ethik als Hermeneutik. Systematische Untersuchungen zu Hermann Cohens Rechts und Tugendlehre, Würzburg, Könighausen \& Neumann, 1993.

SCHWARZSCHILD, S.: “The Democratic Socialism of Hermann Cohen”, en HOLZHEY, H. (ed.): Auslegungen. Band 4. Hermann Cohen, Fráncfort/Berlín/Berna/Nueva York/París/Viena, Peter Lang, 1994. 
SKINNER, Q.: "John Milton and the politics of slavery", en: Vision of Politics. Vol. 2: Renaissance Virtues, Cambridge, Cambridge University Press, 2004.

SIEG, U.: Aufstieg und Niedergang des Marburger Neukantianismus. Die Geschichte einer philosophischen Schulgemeinschaft, Würzburg, Könighausen \& Neumann, 1994.

VAN DER LINDEN, H.: Kantian Ethics and Socialism, Indianapolis/Cambridge, Hackett Publishing Company, 1988.

: "Cohens sozialistische Rekonstruktion der Ethik Kants", en HOLZHEY, H. (ed.): Ethischer Sozialismus, Fráncfort, Suhrkamp, 1994.

: “A Kantian Defense of Enterprise Democracy”, en KELLER, J.; AXINN, S. (eds.): Autonomy and Community. Readings in Contemporary Kantian Social Philosophy, Nueva York, State University of New York Press, 1998.

WIEDEBACH, H.: Die Bedeutung der Nationalität für Hermann Cohen, Hildesheim/Zurich/Nueva York, Georg Olms Verlag, 1997.

WINTER, E.: Ethik und Rechtswissenschaft. Eine historisch-systematische Untersuchung zur EthikKonzeption des Marburger Neukantismus im Werke Hermann Cohens, Berlín, Duncker \& Humblot, 1980 


\title{
Elastic force in Kant's early works
}

\author{
STEPHEN HOWARD ${ }^{1}$
}

\begin{abstract}
This paper argues that the notion of elastic force is an important and overlooked thread running through a number of Kant's writings from 1754 to 1764 . After presenting the historical context, I argue that the key aspects of Kant's early understanding of physical elasticity can be found in On Fire (1755) and show how Kant attempts to explain a wide range of phenomena through elasticity. On my account, one aim of his account of physical monads is provide metaphysical grounds for elastic phenomena. Finally, I examine Kant's hints that minds can be understood through an analogy with elastic physical phenomena.
\end{abstract}

Keywords: Kant, precritical period, natural philosophy, On Fire, elasticity

\section{La fuerza elástica en los primeros trabajos de Kant}

\begin{abstract}
Resumen
Este artículo defiende que la noción de fuerza elástica es un importante hilo conductor que se ha pasado por alto en un número de escritos kantianos desde 1754 a 1764. Tras presentar el contexto histórico, explicaré que los aspectos cruciales de la temprana comprensión kantiana de la elasticidad física se encuentra en On Fire (1755), y mostraré cómo Kant trata de explicar una gran cantidad de fenómenos a través de la elasticidad. A mi juicio, uno de los objetivos de su reflexión sobre las mónadas físicas es el de facilitar la base para los fenómenos elásticos. Finalmente, examinaré la sugerencia de Kant de que las mentes pueden ser entendidas a través de una analogía con los fenómenos físicos elásticos.
\end{abstract}

Palabras clave: Kant, periodo pre-crítico, filosofía natural, On Fire, elasticidad

Introduction

Between 1754 and 1764, Kant wrote on a remarkably wide range of topics for very diverse audiences. In the local Königsberg weekly newspaper, which primarily published small adverts for buying, selling and borrowing goods, Kant serialised essays on the rotation and age of the earth and on the causes of earthquakes. ${ }^{2} \mathrm{He}$ issued pamphlets, advertising his lectures, on other natural-philosophical topics and on logic. The subjects of books Kant published over the decade include a "Newtonian" account of the formation and constitution of the universe, the possible grounds of the proof of God, and the introduction of negative magnitudes into philosophy. ${ }^{3} \mathrm{He}$ wrote three Latin works to meet formal requirements at the University of Königsberg, on the nature of fire, metaphysical principles of cognition, and physical monads. Kant submitted an essay to the Berlin Academy prize competition on

${ }^{1}$ ICUB, University of Bucharest / University of Leuven. Contacto: stephen.howard@ kuleuven.be

2 These essays appeared in the Wochentliche Königsbergische Frag- und Anzeigungs-Nachrichten in 1754, nos. 23-24 and 32-37 and 1756, nos. 4-5 and 15-16. My citations of Kant's works generally follow the Cambridge edition, modified where I consider necessary. Translations of other foreign-language primary and secondary texts, if no translation is listed in the bibliography, are my own.

${ }^{3}$ In addition, Kant published the Observations on the Feeling of the Beautiful and the Sublime (1764), a short book in a primarily anthropological vein that I will not discuss here. 
the methods of metaphysics and mathematics, which resulted, in 1764, in his first publication outside Königsberg.

Commentators have often considered whether any common thread runs through this apparently eccentric assortment of early works. Michael Friedman and Martin Schönfeld propose a narrative that unifies the precritical period, according to which Kant attempts to fuse the results of Newtonian natural science with metaphysical foundations that fundamentally transform aspects of Leibnizian-Wolffian metaphysics (Friedman 1992: 1-52; Schönfeld 2000). ${ }^{4}$ This usefully highlights Kant's early interest in natural philosophy, to which he dedicated more published pages than to metaphysics in 1754-1764. However, Friedman's and Schönfeld's broad narrative of Kant's early "Newtonianism" risks obscuring themes that run through the early works but fit less easily into the opposed paradigms of Newtonian physics and Leibnizian-Wolffian metaphysics, as typically understood.

This paper will trace one such theme through Kant's early writings. It is striking how often in these works Kant refers to elasticity or elastic force [Elastizität, elastische Kraft or Federkraft] or uses examples of elastic phenomena. Kant conceives of air as a fundamentally elastic medium, and its elasticity is key to his accounts of fire, winds and the sun. His explanations of earthquakes present the earth, like the sun, as self-active from within. The Physical Monadology (1756) concludes with an account of the metaphysical basis of elastic media. Kant even toys with presenting minds as analogous with elastic physical phenomena. I will present an account of Kant's writings from 17541764 that shows the significant role that Kant accords to elastic force for explaining a diverse range of phenomena. A central text for understanding Kant's early interest in elasticity is, on my account, his short Latin dissertation Meditationum quarundam de igne succincta delineatio (1755, hereafter On Fire).

The paper is divided into six sections. Section 1 provides a brief overview of how elastic force has been treated in the literature on Kant's precritical natural-philosophical works. Sections 2 and 3 set out what I take to be the most important natural-philosophical context for On Fire and Kant's early discussions of elastic force. This is, firstly, seventeenth-century experimental work on the elastic "spring of the air" (section 2) and the debates on whether Leibniz's principle of equipollence is transgressed by the phenomenon of fire (section 3). Section 4 presents Kant's 1755 account of fire, which I consider key to understanding Kant's broad conception of elastic force: I show that it has the structure of what Kant will later call "relative spontaneity". In section 5, I discuss how Kant attempts to explain various physical phenomena through elastic force in subsequent works of 1754-1764. This culminates in another little-known text, a 1764 review of a book by Johann Esaias Silberschlag, which gives a sense of how Kant thought the explanatory function of physical elasticity could be raised to the "heights of metaphysics" in order to explain various physical phenomena. Finally, section 6 turns to Kant's short-lived account of spontaneous mental activity as analogous with the spontaneity of elastic physical phenomena. Although Kant would soon thereafter (in 1766) reject such an analogy between physical and mental spontaneous forces, the passages reveal an intriguing aspect of Kant's early interest in physical elasticity and relative spontaneity.

\section{Elastic force in scholarship on Kant's early natural philosophy}

The literature on Kant's early writings has not emphasised Kant's early concern with elasticity. Schönfeld makes merely passing references to elastic force in his account of Kant's precritical period (see Schönfeld 2000: 47, 84-5, 112, 169). He dismisses On Fire as "neither scientifically sound nor philosophically important” (Schönfeld 2000: 84). For a study that reflects Kant's regular references to

${ }^{4}$ I discuss aspects of Friedman's more nuanced later account below. 
physical elasticity, we must go back to Erich Adickes' magnum opus on Kant's natural-scientific writings, Kant als Naturforscher (1924/25). However, despite noting the many points at which Kant refers to elastic phenomena, ${ }^{5}$ Adickes does not discuss elasticity as a recurrent theme in Kant's early works. We can turn briefly to Adickes' study to see that his oversight is due to a presupposition guiding his account of Kant's natural science, a presupposition that still informs some current scholarship.

The second volume of Kant als Naturforscher dedicates two hundred pages to Kant's "general ether theory" and specific phenomena including heat, fire, light and magnetism (Adickes 1925: 3-205). Although Kant considers the ether to be an elastic medium, Adickes explicitly discusses elasticity only in relation to "the problem of elasticity" (1925: 140). The "problem" is here the strictly natural-scientific one of explaining how physical bodies can be elastic. ${ }^{6}$ In his long discussion of $\mathrm{On}$ Fire, which notes the role of the elastic matter of fire, Adickes includes a discussion of theories of elastic phenomena among Kant's contemporaries, and foregrounds the question of whether they can be mechanically explained. Most natural scientists took elastic force to be a derivative cause, which was in general explained mechanically; Musschenbroek fought against the mechanical theory, but offered no alternative, claiming there was not enough empirical data to determine the issue (Adickes 1925: 37). For Adickes, Kant's "Theorie der Elastizität", if it had been fully realised, was a "hermaphrodite" [Zwitterbildung], eclectically combining these earlier views (1925: 38).

Whilst revealing that Kant consistently discusses heat, air and fire in terms of elasticity in his early works, then, Adickes reduces Kant's discussions to the question of whether the phenomena of elastic bodies can be explained on a broadly mechanical basis through an ether theory (1925: 1412). He fails to note that Kant's regular references to elasticity are not restricted to the attempt to explain elastic bodies, but instead appear in reflections on a wide range of topics, including air, fire, the sun, monads and even minds. Adickes overlooks the breadth of Kant's conception of elasticity arguably because the central question of Kant als Naturforscher is whether Kant is a Naturwissenschaftler or a Naturphilosopher (1924: 5). Adickes argues that Kant should be considered a natural philosopher, and although he says some positive things about this approach, ${ }^{7}$ he generally judges Kant harshly for not being a natural scientist, particularly for failing to sharply determine concepts, which is the "conditio sine qua non" of the method of mathematical physics (1924: 25). ${ }^{8}$ It is certainly true that the concept of elasticity that appears in Kant's early writings does not meet the standards of clarity of nineteenth-century mathematical physics. Nevertheless, it is in this broader natural-philosophical, not natural-scientific, sense that Kant employs the term in 1754-64. I will contend that Kant's early interest in elasticity deserves attention on its own terms, rather than being dismissed as unscientific or subsumed under the question of the existence or non-existence of the ether. $^{9}$

${ }^{5}$ For example, alongside his account of Kant's ether theory, Adickes discusses the role that elastic air and the elastic force of fire plays in Kant's description of the sun in the Universal Natural History, and notes that Kant's theory of winds is based on a conception of air as a sea of elastic matter possessing a Federkraft (1925: 276, 329).

${ }^{6}$ Adickes draws on the distinctions that Kant makes in the later Metaphysical Foundations of Natural Science (1786) between expansive elasticity (a body returning to its original size after compression) and attractive elasticity (a body returning to its original size after being stretched) (1925: 141; see MAN AA 04: 529-30). The explanation of these elastic phenomena in the General Remark to the Dynamics chapter of the Metaphysical Foundations is a narrow problem in comparison to the way Kant uses the term in his early works.

${ }^{7}$ As a natural philosopher, Adickes affirms that Kant had a "deductive and architectonic-constructive mind", an "extraordinary force of synthesis" and a "capacity to discover similarities, inner connections" among apparently disparate things (1924: 40, 51).

8 "Because [Kant] did not think in clear formulae, his thoughts often wandered aimlessly here and there, commingling completely different things without consciousness of their variety. Thus emerged, in place of the distinct determinateness of true natura science, in which one knows without anything further what is meant, an unclear vagueness [unklare Verschwommenheit]" (Adickes 1924: 29). See Adickes' criticism of Kant's ambiguous use of the term "moment" (1924: 29). His conclusion stresses Kant's "great terminological indeterminacy", which even extends "to the termini technici of mechanics (like moment, force and so on)" (1924: 483).

${ }^{9}$ It seems to be an anachronistic, nineteenth-century scientific perspective that leads Adickes to subsume Kant's various discussions of elastic phenomena to the question of an "ether theory". At the time Adickes wrote Kant als Naturforscher, the 
Adickes' approach persists in some recent scholarship. Having claimed that On Fire is neither scientifically nor philosophically significant, Schönfeld states that it is only of interest in relation to "the question which it raises about Kant's Newtonian conversion [...] How was it possible for Kant to be a Newtonian and to endorse the ether?" (2000: 84). Schönfeld is interested in the Latin dissertation on fire only insofar as it aligns with his narrative of Kant's Newtonianism, and he is thus drawn, like Adickes, to read On Fire only in terms of whether Kant supported the ether theory.

Two recent studies that take seriously Kant's early interest in elasticity are by Michela Massimi, and Massimi and Silvia De Bianchi. Massimi provides an innovative account of the influence of a tradition of "speculative Newtonian experimentalism" on Kant's works of 1755, an influence that does not primarily stem from the Newton of the Principia, but rather "the much more controversial Newton of the Opticks, who ruminated on chemistry and on the possible ethermechanism behind chemical phenomena" (2011: 541). This reaches Kant, on Massimi's account, via the Leiden school (including 's Gravesande, Musschenbroek and Boerhaave) and, particularly, Stephen Hales (2011: 536). These experimental Newtonian chemists and life scientists "dealt with the matter of fire, wondered about the elasticity of air, and believed in an ethereal fluid as the repository of repulsive force (interchangeably with air)" (Massimi 2011: 541). I will discuss Hales, as a particularly important influence on Kant, in section 2.

Massimi and Bianchi claim, with reference to works published before and after the period that I will consider - namely, Thoughts on the True Estimation of Living Forces (1747) and the Metaphysical Foundations of Natural Science (1786) - that "a central aspect of Kant's view of nature" is that "the natural power that bodies would possess in their state of rest - which would explain both their ability to resist penetration by other bodies and their ability to cause motion in other bodies - is nothing but some primordial elasticity" (2013: 488). On their account, Kant sought to identify the physical cause of primordial elasticity over the years following the True Estimation: "Kant embarked on a journey to investigate the physical cause of elasticity in air (particularly through the experiments of Stephen Hales on vegetable and animal fermentations) as well as in some primordial fine cosmic matter (in Universal Natural History)" (2013: 488). In what follows, I will build on these suggestive but brief indications in the papers by Massimi and Bianchi to provide an account of Kant's reflections on elasticity in 1754-64. ${ }^{10}$

Friedman's commentary on the Metaphysical Foundations contains a section on "matter as an originally fluid and elastic medium" that argues, like Massimi and Bianchi, for a connection between Kant's early interest in elasticity and the matter theory of the Metaphysical Foundations. Friedman notes the significance of On Fire for Kant's early account of elastic media (2013: 134-6, 140). He identifies a break between 1756 and 1786 in Kant's move from the Physical Monadology's conception of an original elasticity located in discrete force-centres, to the account in the Metaphysical Foundations of matter as an elastic continuum in which all the parts of space occupied by matter exert expansive force (2013: 138-42). My discussion will not here extend to the Metaphysical Foundations as I consider Kant's early reflections on elastic forces worthy of close attention in their own right.

notion of ether had fairly recently been experimentally and theoretically disproved by Michelson and Morley and Einstein. Adickes' focus on Kant's affirmation of the ether - a key example of a pseudoscientific notion at the time he was writing - may well be an attempt to support his central claim that Kant had a philosophical, not a natural-scientific disposition (1924: vi, 4-5).

${ }^{10}$ Excepting a brief discussion in section 3, I will set aside True Estimation and its concern with the proper calculation of the results of elastic and inelastic physical collisions. For more on elastic force in True Estimation, see Howard (forthcoming). 
2. The elastic force of the air in eighteenth-century natural philosophy

Christian Wolff's textbooks and dictionaries of the physical and mathematical sciences show the broad conception of elastic force that was common in the period. Elasticity was considered not only a property of bodies that can be stretched or compressed but a property of a broader class of physical phenomena including, most notably, the air. In his 1716 Mathematisches Lexicon, Wolff defines elastic force as the force of a body to strive to expand, and to actually expand when resistance is removed from it. ${ }^{11}$ Alongside this corporeal elasticity, the entry points to the significance of the term for the science of "aerometrie". Wolff states that elasticity is one of the primary properties of air and thus the basis of many effects in nature. Wolff's early Aerometrie elementa (1709) examines experiments on air pressure and provides a similar definition of elastic force. ${ }^{12}$ The Anfangs-Gründe aller Mathematischen Wissenschafften (1710) and the abbreviated Auszug (1717), which Kant used as his textbooks for the mathematics and mechanics lectures that he taught from 1755 to 1763, discuss the elastische or ausdehnende Kraft der Luft in the aerometrie chapters (Wolff 1710: 885; 1717: 266). Johann Georg Walch's Philosophisches Lexicon (1726) follows the definition in Wolff's Mathematisches Lexicon almost to the letter, but adds more detail on experimental results (1726: 703$5)$.

Both Wolff and Walch refer to Otto de Guericke's experimental work with air pumps, and Wolff's Deutsche Experimentalphysik (1727) devotes over 350 pages to air-pumps, the properties and effects of the air, and the air concealed in bodies (Wolff 1727: 107-460). Kant had a direct interest in this experimental tradition. He owned Boyle's Opera varia (1677), which contained a Latin translation of the New Experiments Physico-Mechanical, Touching the Spring of the Air (1660) (see Warda 1922: 33). Boyle's treatise takes it as a matter of fact that "the air hath a notable elastical power" (1772: 44). A more obscure source, highlighted by Hans-Joachim Waschkies, is the German translation of Guilleame Amontons' Von einigen Eigenschaften der Luft (1748), a study of properties of the air and the thermometer, which Kant cites in preparatory work for On Fire. The translator's introduction to Amontons' book states that "one should imagine the air as if compounded of innumerable small springs [Federn] furnished with an expansive force" (see Waschkies 1994: 171).

Stephen Hales' Vegetable Staticks (1727) is a particularly significant source for Kant's reflections on elastic force. Kant owned the 1748 German translation, and refers to it in no less than five works of $1754-1756 .{ }^{13}$ Hales' book is a compendium of his experiments, through which he attempts something like a Newtonian physics of the "force of the Sap" and the way that plants "imbibe and perspire" moisture (Hales 1727: iii, ii; see also 358). Having found that plants absorb a lot of air, Hales is led to dedicate by far the largest chapter of Vegetable Staticks to an "analysis of the air" with a particular focus on its elastic nature (Hales 1727: iv; 155-317). He writes in the preface that

there is diffused thro' all natural, mutually attracting bodies, a large proportion of particles, which, as [...] Sir Isaac Newton observes, are capable of being thrown off from dense bodies by heat or fermentation into a vigourously elastick and permanently repelling state: And also of returning by fermentation and sometimes without it, into dense bodies; It is by this amphibious property of the air, that the main and principle operations of Nature are carried on (Hales 1727: v).

\footnotetext{
11 "Elater, vis elastica, die elastische Kraft ist die Kraft eines Körpers, dadurch er sich weiter auszudehnen trachtet, auch würcklich ausdehnet, wenn der Wiederstand gehoben wird" (Wolff 1716: 577).

12 "Elater est vis, qua corpus compressum cessante, vi comprimente ad eam reducitur molem, quam ante compressionem obtinuerat, aut certe ad majorem ea, quam in statu compressionis habuerat" (Wolff 1709: 8).

${ }^{13}$ See Warda 1922: 28. Kant refers to Hales in FEV, AA 01: 208; NTH, AA 01: 326; DI, AA 01: 381; PND, AA 01: 407-8; GNVE, AA 01: 457. Martin Carrier seems mistaken to claim that “[o]ffenbar sind Kant die Experimente Hales' und die durch diese eingeleitete vermehrte Gewichtung der Repulsion im Newtonianismus unbekannt" (Carrier 1990: 172n11). Waschkies emphasises the importance of Hales for On Fire (1994: 172-3, 191-2).
} 
The "amphibious property" of the air is the fact that it has an expansive elasticity but can nevertheless be compressed by fermentation or heat into a fixed state (see also Hales 1727: 315). Hales' regular references to Newton are almost always, as in this passage, to Newton's more speculative remarks on the forces of particles and the ether in the Opticks (see Massimi 2011). Whereas Newton limits his discussion of "elastick force" to the Queries of that work ([1730] 1952: Query 21, 352; see also Query $31,387,395-396)$, Hales makes elastic air central to his account because he considers it the vehicle for nature's "main and principle operations". Hales concludes that as air, "found so manifestly to abound in almost all natural bodies", is "so operative and active a principle in every chymical operation" that we might "with good reason adopt this now fixt, now volatile Proteus among the chymical principles, and that a very active one" (1727: 315-316). Kant had such an interest in this tradition of experimental research into the elasticity of air that he had his own "Elaterometer" built, with which he (unsuccessfully) sought to conduct his own experiments. ${ }^{14}$

\section{Fire and Leibniz's principle of equipollence}

A further important context for Kant's claims in On Fire is the debates around fire in relation to Leibniz's principle of equipollence. This principle, which Leibniz introduced in 1676, states that in any causal series the entire effect must be equal to the full cause (see Mercer 2004: 434-435; Lærke 2015: 123-130). It was in Leibniz's view a "law of nature" that should lead to progress in physics and in his new science of dynamics (Antognazza 2009: 173-174, 249-250). ${ }^{15}$ The phenomenon of fire seems to threaten the principle, as Leibniz acknowledged in a letter to Malebranche, published in the Nouvelles de la république des lettres in July 1687: "[i]t is true that in composite things a small change can sometimes bring about a great effect. So a small spark, for example, which falls into a large mass of gunpowder can demolish an entire city". Leibniz's letter does not clarify the issue, merely stating that this can be "explained by [his] general principles" (Leibniz 1989b: 353).

The problem of whether fire transgresses the principle of equipollence inspired the Paris Academy of Science's 1738 essay prize on La nature et la propagation de feu, among the winners of which was Euler (see Adickes 1922: 334; 1925: 67-68). In his contribution, Euler argues that fire is the result of an external force freeing the highly subtle, elastic matter of fire that is compressed inside the tiny parts of bodies (Euler 1752: 5-21; see Adickes 1922: 336-337). ${ }^{16}$ Euler distinguishes the matter of fire from the ether or the matter of light: the former is much finer and more elastic. The matter of fire is explosively freed from its bounds, and it flings the particles of the part of the body in all directions like projectiles. The matter of fire bursts out with ever-greater strength, triggering the same process in other tiny parts of the body (Adickes 1922: 336-337). In this way Euler seeks to account for the apparent imbalance between cause and effect in the case of fire, through an internal, spontaneous process that is merely initiated by an external force.

\footnotetext{
${ }^{14}$ Kant's friend and early biographer Wasianski describes in detail the construction and failings of this device. It is called an "Elektrometer" in the printed version of Wasianski 1804. However, Adickes points out that the term is changed throughout by Wasianski in his personal copy to the term "Elaterometer" (1924: 8n1). This fits Wasianski's description of it as an "air-elasticitymeter" [Elastizitätmesser der Luft]. Wasianski notes that Kant had the Elaterometer made around ten years before Wasianski began to assist Kant (Wasianski 1804: 249). This could either refer to the early 1760s or the late 1780s: Wasianski first assisted Kant as his amanuensis around 1773-4, then became his daily helper in 1799 after Kant was forced to dismiss his servant Lampe (Wasianski 1804: 195).

${ }^{15}$ For the claims about the "law of nature" and its utility for physics and dynamics, see the letter to Bayle of 9 January 1687. quoted by Antognazza, and the "Preliminary specimen" to the Dynamica de Potentia et Legibus Naturae Corporeae (1689/91) in Leibniz 1989a: 106.

${ }^{16}$ Boyle has a similar account in New Experiments, touching the Relation betwixt Flame and Air (1672), which was translated in the Opera varia that Kant owned. See Massimi 2011: 533n68.
} 
Kant's familiarity with Leibniz's principle of equipollence is evident in his first work, Thoughts on the True Estimation of Living Forces (1747). ${ }^{17}$ In the third chapter, Kant introduces "vivification" as an attempt to explain what happens when bodies change from possessing potential moving force (dead force) to actual moving force (living force). Without entering into the complexities of Kant's discussion we can note that, on his account, bodies with living force can sustain their own motion indefinitely on the basis of their "inner striving" (GSK, AA 01: 143-144). Living force is thus for Kant an internal, self-active force that grounds a body's motion. Kant then provides a complex account of vivification, in which a body infinitesimally accumulates "elements" of immanent striving. ${ }^{18}$ What is important for our purposes is that a body with living force "does not get this force from the external cause that had set the body in motion, but rather that, after the external trigger [Anreizung], this force has its source in the body's inner natural force itself" (GSK, AA 01: 148, my emphasis). Kant here attempts to ensure that the principle of equipollence is not transgressed when the force of a body shifts from dead to living force. He does so by claiming that the external force is not a cause but merely a "trigger", and that the living force springs from forces internal to the body. ${ }^{19}$ Indeed, in his first work Kant is consistently concerned with adhering to Leibniz's "great law of mechanics that effectus quilibet aequipollet viribus causae plenae [any effect has the same power as the forces of its complete cause]" (GSK, AA 01: 106). ${ }^{20}$

\section{Elasticity and equipollence in On Fire}

These two contexts - experimentally-based conceptions of the elastic force of the air and the debates on whether fire transgresses the principle of equipollence - are key to Kant's claims in his short Latin dissertation, On Fire, submitted to the Albertina in Königsberg in 1755. The treatise seeks to explain the nature of fire on the basis of a fundamental elastic matter. ${ }^{21}$ Kant claims that "every body consisting of solid parts is held together by some elastic matter [materia [...] elastica] as the bond of its unity" (DI, AA 01: 375). This elastic matter connects particles in a body and is the intermediary through which particles press or pull upon each other. ${ }^{22}$ Kant seeks to prove that "this elastic matter, which is present between the elementary parts of a fluid body, is nothing other than the matter of heat [materiam caloris]" (DI, AA 01: 372). By extension, the matter of heat is the matter of fire (DI, AA 01: 376). The matter of heat or fire is glossed further as "the ether (the matter of light) compressed by a strong attractive (adhesive) force of bodies into their interstices" (DI, AA 01: 377). The elastic matter of fire is thus the ether, held by attractive forces between particles of a body.

Kant's account is similar to that of Euler's Paris Academy prize essay in depicting an elastic matter of fire bound between tiny parts of a body. Given Kant's esteem for Euler, it is highly likely

\footnotetext{
${ }^{17}$ Kant's first book attempts to resolve the vis viva controversy between Cartesians and Leibnizians about the proper measure of force in physical collisions. On the Cartesian view, force should be measured by the product of the quantity of matter and the velocity: in modern notation, $m v$. For the Leibnizians, force is the quantity of matter times the square of the velocity: $m v^{2}$. Leibniz named the Cartesian measure, $m v$, "dead force", and his own measure, $m v^{2}$, "living force". For a detailed account, see Schönfeld 2000: 17-35.

${ }^{18}$ Kant outlines his theory of vivification in $\$ \$ 117-124$ (GSK, AA 01: 141-148).

${ }^{19}$ Earlier in the work Kant carefully distinguishes triggering or occasioning from causality: "Although this exertion of mechanical force $[\ldots]$ has been triggered $[$ veranlaßt] by the force transferred into body $B$, it still is not an effect $[$ Wirkung] of this force. We must very carefully avoid the conflation of these two aspects. [...] [T] he motion that is produced is not the real effect of force, which actually only occasioned it, and consequently it can still be greater than this motion without violating the fundamental law of mechanics" (my emphasis; GSK, AA 01: 103).

${ }^{20}$ Massimi and Bianchi show that Mairan's dispute with Du Châtelet and the former's view that "springiness [ressort] is a true machine of nature" inform Kant's concern in True Estimation with elasticity and the Leibnizian principle of equipollence (2013 488-490). In my view, Massimi and Bianchi's claim that Mairan's position is a "critique of the Leibnizian principle" underestimates the extent to which Leibniz himself posited elasticity as the ground of the self-movement of bodies, as they partly acknowledge (2013: 491, 490n56); see Howard (forthcoming).

${ }^{21}$ For the historical background to what Adickes calls the "Stoff- oder Substantialitätstheorie" of heat, which contrasts with the "Vibrations- oder Bewegungstheorie" that later became dominant, see Adickes 1922: 329-51.

${ }^{22}$ Propositions IV and V characterise this elastic matter through the laws of physical elastic bodies. On Kant's atomism in this text, see note 43 below.
} 
that he read the latter's prize-winning essay. ${ }^{23}$ It is in direct contrast to Euler, however, that Kant equates the matter of fire with the ether or matter of light. ${ }^{24} \mathrm{He}$ provides three justifications for this: firstly, that dense bodies attract light, bodies always collide with the matter of light, and the matter of light is elastic and so can be compressed into the interstices of bodies; secondly, that there is a correlation between the capacities of bodies to refract light and to absorb heat; and thirdly, that the transparency of glass might indicate that it contains a large quantity of the matter of light, which could result from the long burning process by which it is produced (DI, AA 01: 377-8). Kant's justifications refer to the authority of Newton, through two references to the Opticks, and Euler, through a reference to his Nova theoria lucis et colorum (1746), in order to defend a view that runs counter to Euler's own account of fire. ${ }^{25}$

Kant diverges further from Euler by linking fire to the conceptions of elastic air discussed above. Vapours are important to Kant's account: these "particles torn from the surface of fluids" possess the "remarkable and peculiar property" that the particles "strongly repel each other" (DI, AA 01:379-80). This means that "it is the nature of vapours [...] to show elastic force" (DI, AA 01:382). Air is such an elastic vapour, reduced to the "maximum subtlety" or the greatest distance between particles, and with a "strong elasticity" (DI, AA 01: 382). Kant defines flame as the ignition of vapour, which frees the elastic matter of heat from the interstitial attractive forces of bodies: "[f]lame is [...] vapour brought to that degree of fire that it flashes with light and goes out only when there is insufficient fuel" (DI, AA 01: 383). This fuel is oil, "which, by virtue of its elastic motion [motui elastico], serves as its most active principle" (DI, AA 01: 383). Kant is yet further from Euler in his account of the ignition of vapour and the function of oil: Euler considers the matter of heat, once freed from its bounds within the body, to be sufficient to explain fire. Oil plays a dual role in Kant's treatise: he proposes that it is "the bond, as it were the glue, of concrete bodies, indeed the true magnet of etherial matter which holds all bodies together"; ${ }^{26}$ and, once the body is ignited and the matter of heat escapes, oil fuels the body's flame (DI, AA 01:377).

A key aspect of Kant's account of fire, which he does adopt from Euler, is the idea that elastic repulsive forces overcome the attractive, interstitial forces of bodies when the body is ignited. But Kant's description is more complex as he contends that the matter of fire escapes from its bounds between the body's particles and greatly expands in the form of vapour. This ignited elastic vapour, with the elastic motion of the oil that serves as fuel, produces the phenomenon of flame.

Like Leibniz and the contributors to the Paris Academy of Science's 1738 essay prize, Kant is concerned with the question of whether fire transgresses the principle of equipollence, because a small spark can lead to a great conflagration: "at first glance this phenomenon appears opposed to the basic law of mechanics that the effect is always equal to the cause" (DI, AA 01: 383-4). However, he adds:

One should not wonder that the effects of a little cause should be so immensely great, for the spring of the confined ether, when freed in this manner from the bonds of attraction, surpasses the effect; and one recognizes that the kindling [sollicitationem] [of fire in another body] by a small flame is not, properly speaking, the cause [of these great effects]; they depend upon the attraction of oil, the subtile division

${ }^{23}$ For Kant's esteem for Euler, see for example his letter to him of 1749, not included in the Academy edition: Kant 1999: 45-46.

${ }^{24}$ Friedman points out that Kant refers to Euler's wave theory of light when equating the matter of heat with the ether (DI, AA 01:

378; Friedman 2013: 135n51). Friedman does not however note that Euler distinguishes the matter of heat from the ether in his prize essay on fire.

${ }^{25}$ On the references to Newton and Euler, see the editors' notes in Kant 2012: 713n10-12. Kant's references to Newton may well be based on Hales 1727: 300 .

${ }^{26} \mathrm{DI}$, AA 01: 382. Kant follows the contemporary view that the active principle of oil is acid, which he also calls, with reference to Hales, a "salty principle" (DI, AA 01: 381) 
of its enclosed matter giving occasion for its liberation with great violence [semet magna violentia expediendi copiam fecit] (DI, AA 01: 384, my emphasis).

The cause of fire on Kant's account is not merely the spark that ignites it. It is also the attractive force that holds the matter of heat between the particles, and the elastic force that seeks to escape these bonds. If these forces, invisibly operative within the body at rest, are taken into account, then the cause and effect are equal in the case of fire, and Leibniz's metaphysical principle is not transgressed. It is the inner forces of a combustible body, and particularly the elastic force or "spring of the confined ether", that explains how the effect appears to exceed the cause, in the case of the fire that develops from a small spark.

We can note that Kant's explanation of how fire conforms to the principle of equipollence proceeds by ascribing a spontaneous quality to flammable bodies that can be called "relative spontaneity". The distinction between absolute and relative spontaneity, which is now a commonplace in the literature, is drawn in Kant's metaphysics lectures of the late 1770s (V-Met-L1/Pölitz, AA 28: 267-270). ${ }^{27}$ Absolute spontaneity is unconditioned - "self-activity from an inner principle according to the power of free choice" - whereas relative spontaneity [spontaneitas secundum quid or spontaneitas automatica] is self-causality but "under a condition". A thing with relative spontaneity "moves itself according to an inner principle", but "the inner principle [is] determined by an external principle" (V-Met-L1/Pölitz, AA 28: 267). Kant's usual example is "a turnspit, which, when once it is wound up, also accomplishes its movements of itself" (KpV, AA 05: 97; see also V-Met-L1/Pölitz, AA 28: 267). The air, the matter of heat and other "spring-like" physical phenomena are spontaneous in this relative sense, as they require an external impetus, but, in order to make up the full cause of the resulting effect, an internal activity must be added to this external one.

As a natural-philosophical account of fire, the Latin treatise was a mixed success, even for its time. ${ }^{28}$ What is important for our purposes is the explanatory role of elastic force in the treatise. ${ }^{29}$ The elastic force in On Fire is not the strict notion of elasticity as used in modern physics, which designates the capacity of physical bodies to return to their original shape after being stretched or compressed. Rather, the 1755 dissertation conceives of elastic force as a broader property of the matter of heat, the ether, vapours and air. Furthermore, the notion of elastic force provides a basis for Kant to explain how there can be natural reactions in which the effect appears to be greater than the cause, without this transgressing the principle of equipollence. The next section will examine how, over the decade following On Fire, Kant extended the explanatory scope of the notion of elastic force to various other natural phenomena.

\section{Elastic forces of various physical phenomena in Kant's works of 1754-1764}

Almost simultaneously with the submission of his Latin dissertation on fire, Kant published the Universal Natural History and Theory of the Heavens (1755). This ambitious cosmogony and cosmology seeks to explain the formation and structure of the universe on the basis of Newtonian mechanical principles. The opening chapters describe the first formation of matter, planets, moons and comets. Chapter seven is followed by a supplement, titled "General Theory and History of the

${ }^{27}$ Wilfred Sellars was among the first to foreground relative spontaneity in Kant: Sellars 1970: 23. See also Allison 1990: 60-64; Sgarbi 2012.

${ }_{28}^{28}$ See Adickes' critical evaluation in Adickes 1925: 1-77, particularly 10-15, 21-25, 34-36, 59-60, 69-77.

${ }^{29}$ In emphasising elastic force I diverge from Adickes and Jeffrey Edwards who foreground the concept of the ether in their accounts of De igne. I consider that it is elasticity, as the defining property of the ether or the matter of heat or fire, that is most important to the treatise's argument. I discuss Adickes' position in the Introduction, above; Edwards foregrounds the ether due to its significance for the "ether proofs" of the Opus postumum and Edwards' central notion of a material transcendental condition. See Edwards 2000: 117-118. 
Sun in General". Kant considers why the "middle point of the attraction" in a planetary system has to be a "fiery body" (NTH, AA 01: 323). He ascribes to the sun's fire the same characteristics that earthly fire possesses in the Latin dissertation: it "is active out of itself instead of diminishing or exhausting itself by transference [...] [it] thereby acquires more strength and fierceness and thus requires only material and feeding for its maintenance in order to continue on and on" (NTH, AA 01: 325 , my emphasis). The fire of the sun is fed by the "elastic force of the liquid element of air" (NTH, AA 01: 326). As with On Fire, Kant bases his explanation on elastic forces inside the body, in this case the sun. ${ }^{30}$ Kant discusses the concern that the sun will use up the air that surrounds it, and he speculates that the sun contains deep chasms or caverns, in which air is locked and periodically released to stoke the sun's fire, and "matters [...] like saltpetre" inside the sun's caverns that "are inexhaustibly productive of elastic air" (NTH, AA 01:326). In this picture, the sun is a self-active source of heat at the centre of the planetary system, driven by the elastic nature of air.

In 1756 Kant published three essays on earthquakes, in response to the Lisbon earthquake of November 1755. This event is famous for spurring thinkers, notably Voltaire, to question the philosophical doctrine of optimism; but Kant's contributions display his interest in elastic forces and spontaneous activity in nature. He locates the source of earthquakes in "subterranean conflagrations" (GNVE, AA 01: 445), or the "fire of the subterranean vaults" (FBZE, AA 01: 465). The second essay ruminates on the "beneficial effects from this subterranean fire", one of which is the gentle warming of the earth from within, the other being that volcanos provide "a certain active principle, volatile salts [...] [and] an immeasurable amount of sulphurous vapours", which "enter into the composition of plants, to move and develop them" (GNVE, AA 01: 447f). The earth, like the sun of the Universal Natural History and again drawing on On Fire's account of fire, is spontaneously active from within. $^{31}$

A similar idea appears in Kant's 1754 essay on the question of whether the earth is aging. Kant considers four possible opinions on the reason for the earth's aging, and guards against too hastily rejecting the fourth: that "the ever-effective force, which, as it were, constitutes the life of nature, and which, although imperceptible to the eye, is active in all generation and the economy of all three realms of nature, gradually becomes exhausted" (FEV, AA 01:211). This would be a "subtle though universally active matter which, in the products of nature, constitutes the active principle" and Kant contends that this is "not so opposed to sound natural science and observation as one might think" (FEV, AA 01: 211). This active principle is evident in the spiritus rector of the chemists and the "volatile acid [...] which constitutes the active principle in most kinds of salts, the essential part of sulphur and the leading principle of the combustible element of fire", which the second earthquake essay claimed to be provided by volcanos to the advantage of plants (FEV, AA 01:212). ${ }^{32}$ Although Kant does not here refer to elastic force, the "active principle" of fire is precisely the elastic matter of the 1755 Latin dissertation.

In extending his reflections on fire to various other physical phenomena, Kant echoes aspects of Du Châtelet's entry to the 1738 Paris Academy competition. ${ }^{33}$ Kant's specific account of

\footnotetext{
${ }^{30}$ Kant's explanation of the sun is far removed from Wolff's. Wolff considers sunbeams not to be warm themselves, and to only heat bodies on earth by merely setting in motion the matter of heat that is already present in the body. Wolff makes a sharp distinction between the matter of light, which emanates from the sun, and the matter of heat (a distinction that Euler retains in his Dissertatio de igne, as noted above). Kant does not follow this in the works of 1755. See Wolff 1723: 193-5.

${ }^{31}$ Waschkies notes that a relation between the elasticity of air, fire and earthquakes is already proposed by Guilleame Amontons (1994: 171-172).

${ }^{32}$ Kant goes on to call this active principle the "Proteus of nature": he may well be drawing on Hales, who writes of air, after his discussion of its elasticity: "may we not with good reason adopt this now fixt, now volatile Proteus among the chymical principles, and that a very active one, as well as acid sulphur [...]?" (Hales 1727: 316).

${ }^{33} \mathrm{Du}$ Châtelet's contribution was published alongside those of Euler, Lozeran du Fiesc, Crequy, and Voltaire in the Recueil of 1752. Kant does not refer to Du Châtelet's essay in On Fire - nor does he refer to Euler's prize-winning entry - but, as True Estimation reveals, he was well aware of her work (see GSK, AA 01: 67-68, 92, 124, 128, 130-133).
} 
fire does not seem to have been influenced by Du Châtelet's essay on its nature and propagation, ${ }^{34}$ but his claims about the sun and the earth are similar to her broader speculative claims about fire. Du Châtelet claims that there is a "central fire" in every body and every point in space: "this fire contained in the bosom of all bodies vivifies them, animates them, fertilises them, maintains the motion between their parts, and prevents them from condensing entirely" (1752: 167). Fire is thus "a spirit of life that animates [matter]" (Du Châtelet 1752: 113).

In the context of Kant's interest in broadly elastic phenomena in 1754-55, we can reread the Physical Monadology (1756) as an attempt to provide a metaphysical basis for physical elasticity. The work develops Baumgarten's notion of a monad as a physical point, to depict monads as dynamical spheres of activity. On the basis of fundamental repulsive force and a corresponding attractive force, Kant explores various properties of physical bodies. ${ }^{35}$ The final proposition of the text is that "[t]he elements of a body, even when they are posited on their own, possess a perfect elastic force which is different in different things; and they constitute a medium which is, in itself and without the admixture of a vacuum, primitively elastic" (MoPh, AA 01: 486). The elements or physical monads that make up all bodies are elastic, and they constitute an elastic medium.

Whilst there is a great difference between the atomism of On Fire and the dynamic physical monadology of 1756, in both cases Kant seeks to conceptualise an elasticity at a fundamental level of bodies. ${ }^{36}$ The corollary to Proposition XIII states that elements can "be compressed, and they constitute bodies which can also be compressed [...] This is the origin of the bodies or media which are elastic. And among such bodies one may already legitimately include aether, that is to say, the matter of fire" (MoPh, AA 01: 487). Kant seeks to explain elasticity, not in the narrow sense of elastic physical bodies but as a broad notion that includes the ether or matter of fire of the Latin dissertation. The Physical Monadology can therefore be considered an attempt to provide a metaphysical basis for the spontaneous elastic force of the various physical phenomena addressed in Kant's essays of the period. ${ }^{37}$

An idea of the way that Kant might have hoped to ground natural-scientific knowledge on his physical monadology can be gleaned from his Review of Silberschlag's work: Theory of the fireball that appeared on 23 July 1762, published in the Königsbergsche Gelehrte und Politische Zeitung in 1764. On Kant's account, Silberschlag has an account of corporeal substances that echoes Kant's own physical monadology: "the presence of corporeal substances in space is actually a sphere of activity that has a dynamical sphere and a centre point" (AA 08:450). Silberschlag seeks to establish this, according to Kant, "[t] $]$ hrough reasons that seem very significant but insufficiently developed" (AA 08:450). Kant summarises the physical phenomena that Silberschlag seeks to explain on the basis of his dynamical conception of physical substance:

\footnotetext{
${ }^{34}$ Du Châtelet takes positions that Kant will oppose: she claims that heat and light are independent of one another (1752: 119), implies that fire can be equated with heat when discussing the fire contained by the "spirit of wine" and by water (1752: 114), gives a very different account of the emergence of fire (1752: 122), and claims that fire is not the cause of elasticity but destroys it (1752: 142)

${ }^{35}$ Proposition IX thereby explains contact; X, determinate volume; XI, mass or inertial force; and XII, differences in density.

${ }^{36}$ On Kant's shift in early 1756 from an atomistic to a dynamic conception of matter, see Adickes 1924: 162-163; 1925: 9-10.

${ }^{37}$ This overlooked aim of the Physical Monadology does not replace but rather supplements what are more commonly taken to be the work's aims. Kant seeks to contribute to the early eighteenth-century debates around the possibility of physical monads on a methodological level, by reconciling the geometrical understanding of space, as infinitely divisible, with the monadological doctrine of indivisible simple substances (MoPh, AA 01: 475). Eric Watkins notes that an easily-overlooked aspect of Kant's "official solution" to the problem of physical monads is that he is "trying to articulate in a detailed way how the spatial and physical properties of bodies are supposed to be derived from (metaphysical) forces" (2005: 110, 112). Beyond Watkins' discussion, which is tied to his general concern with causality, I propose that we take seriously that the Physical Monadology concludes with the physical property of elasticity. Friedman makes a similar point when he argues that the "striking corollary" with which the Physical Monadology ends implies that "Kant intends the metaphysical theory of 1756 to fit together smoothly with the physical theory of $1755 "(2013: 137)$
} 
From the differences between these spheres and the forces that act in them, he derives elasticity, density, the oscillation of the air and the aether, the tone, the light, colours and warmth, and similarly also the attraction of matters, according to the [specific] differences of the substances. All of this is applied to air and its changes [...] (AA 08:450).

In addition, Silberschlag seeks to explain mists, fog, clouds, and rain, and divides the regions of air, from lowest to highest: the dust atmosphere, the watery atmosphere, "then the phlegmatic and phosphorescent atmosphere, which contains oily, resinous and rubbery parts, and is the workshop of shooting stars, fireballs, and fiery meteors", and "finally, the spiritual atmosphere [...] in which the very extensive fiery air, such as the Northern Lights, is produced" (AA 08:450). ${ }^{38}$ The phenomena that Silberschlag explains are physical, but Kant nevertheless notes approvingly that, in a manner "unusual for natural scientists", Silberschlag "feels compelled to take a path into the heights of metaphysics" (AA 08:450). We can take Kant's enthusiasm for Silberschlag's treatise to indicate its proximity to Kant's own ambitions at this time: the elucidation of many phenomena through the forces underpinning physical elasticity. ${ }^{39}$

There is therefore a common thread running through the apparently heterogeneous and eccentric works of 1754-1764, which has not been recognised in the literature. Kant is consistently concerned with the explanation of physical phenomena on the basis of elastic forces, drawing on experimental research into the properties of air and applying the theory of fire set out in his short Latin dissertation. Kant explains the phenomena of the sun and of earthquakes alike on the basis of the elastic forces of air. He approves of Silberschlag's attempt to explain the full range of atmospheric phenomena on the basis of the dynamic forces of elements. From this perspective, the Physical Monadology can be understood as an attempt to ground elastic forces in the more fundamental forces of physical monads. In each case, Kant is concerned with the basis of a relative spontaneity in nature, in which hidden forces inside bodies allow us to explain how effects can exceed their apparent causes without transgressing the principle of equipollence.

\section{From physical elastic forces to mental spontaneity}

This is not, however, the end of the story. In passages in works of 1755 and 1763, Kant draws an intriguing connection between this conception of elastic force and the activities of minds, which he at this point understands on broadly Leibnizian lines. Kant will not retain this position after 1766, but it is nevertheless a noteworthy moment in the development of his thought.

The New Elucidation of the First Principles of Metaphysical Cognition (1755) brings together physical and mental forces in what at first sight is a very different context: an exploration of the principle of sufficient reason, or as Kant calls it after Crusius, the determining ground (see Watkins 2005: 112-113). At the end of section two Kant argues that the principle entails that the "quantity of absolute reality in the world" (PND, AA 01:407) is unchanging, because there is nothing in an effect that was not in its cause. This is defended through an example of a collision between two elastic bodies; as with the Physical Monadology, we can consider Kant's interest in these metaphysical questions to be in part motivated by a desire to explain elastic physical phenomena. Kant notes that these very elastic phenomena might be taken to disprove the principle of the

${ }^{38} \mathrm{Kant}$ had already used the notion of elasticity to explain atmospheric phenomena in the notes on the winds that advertised his 1756 summer semester lectures: the earth's atmosphere is depicted as "a sea of fluid, elastic material" (TW, AA 01: 491). The preface to the Universal Natural History similarly presents winds as a result of a property of the air: it moves "through its elasticity and mass" between warmer and cooler regions (NTH, AA 01: 224).

${ }^{39}$ Watkins notes in his editorial introduction that "[w]hile it is uncertain exactly what motivated Kant to respond to this work in this way, the review is clearly positive" (Kant 2012: 409): my account offers a reason for Kant's positive review. 
conservation of absolute reality, because "[v]ery frequently we see enormous forces issue from an infinitely small initiating cause", such as the explosion of gunpowder or the burning of forests as a result of a tiny spark. Kant repeats the explanation we have seen in other early works:

\begin{abstract}
In these cases, however, the efficient cause of the enormous forces is a cause which lies hidden within the structure of bodies. I refer, namely, to the elastic matter either of air, as in the case of gunpowder (according to the experiments of Hales), or of the igneous matter, as is the case with all inflammable bodies whatever. The efficient cause is, in these cases, unleashed [manifestatur], rather than produced, by the tiny stimulus. Elastic forces which are compressed together are stored within; and if these forces are stimulated just a little, they will release forces which are proportionate to the reciprocal pressure exercised in attraction and repulsion (PND, AA 01:407-408).
\end{abstract}

Again, the calculus of cause and effect must take into account the immanent elastic forces that require only a small stimulation to explode out of the attractive forces that constrain them.

Kant now goes further when seeking to forestall a second objection: that our mental capacities could transgress the law of the conservation of absolute reality in the world:

\begin{abstract}
Certainly the forces exercised by spirits and the perpetual advances of these forces to higher perfections seem not to be governed by this law. But they are, in my opinion at least, nonetheless subject to [it]. Without doubt, the infinite perception of the entire universe, which is always internally present to the soul, albeit only obscurely, already contains within itself all the reality which must inhere in the thoughts, which are later to be illuminated in a stronger light (PND, AA 01:408).
\end{abstract}

Kant presents the conservation principle as governing both physical elastic forces and the infinite but obscure forces of the soul. The view that mental forces contain the "infinite perception of the entire universe [...] albeit only obscurely" is recognisably that of Leibniz's Monadologie (1714). For Leibniz, a mind, a higher-order monad, is a "perpetual living mirror of the universe", which "represents the whole universe" but only in a confused or obscure manner. ${ }^{40}$ Kant's Leibnizian account of minds depicts mental forces as structurally equivalent to physical ones: in both cases, a huge effect can be triggered from a tiny cause, due to dormant, potential internal forces.

The same claim appears in Attempt to Introduce the Concept of Negative Magnitudes into Philosophy (1763). The work presents a philosophical notion of a negative magnitude, on the basis of a distinction between logical and real opposition. Whereas a logical opposition results in "nothing at all", a real opposition yields "something" (NG, AA 02: 171). One of Kant's examples of a real opposition is taken from physics. A body at rest can be considered a result of real opposition in two ways: a moving body meeting an equal and opposite force results in rest (NG, AA 02: 171); and determinate bodies are themselves constituted through an equilibrium of attractive and repulsive forces (NG, AA 02: 199). Kant contends that conceiving of such real oppositions as negative magnitudes reveals the value of introducing this mathematical notion into philosophy. ${ }^{41}$

${ }^{40}$ Monadologie $\$ 56, \S 62$, in Leibniz 1989a: 220-21. Published translations of the Monadologie had been available in German since 1720 and Latin since 1721.

${ }_{41}$ Specifically, Kant provides examples from four domains of philosophy in which negative magnitudes can assist our understanding: i) the dynamical conception of material substance as in the Physical Monadology: the "true force" of repulsion, which grounds the impenetrability of bodies, as "negative attraction" (2:179-180); ii) psychology: pleasure as a "positive ground" that cancels pleasure, hence "negative pleasure" (2:180-182); iii) moral philosophy: vice as "negative virtue" (2:182-184); iv) natural science: coldness as negative heat, with warming and cooling explained by the "real passage of the elemental fire", where 
As in the New Elucidation, Kant broadens his discussion from physics to psychology, noting that the concept of a philosophical negative magnitude "can be extended far beyond the limits of the material world" (NG, AA 02: 199). ${ }^{42}$ His example is that of a man of learning in a moment of relaxation, who, asked generally to share his knowledge with you, will say that his mind is presently empty: "[b]ut stimulate him by asking him a question or expressing a view of your own, and his learning will reveal itself in a series of activities" (NG, AA 02: 199). The state of mental inactivity is just like the state of rest of a body: it is not a contradiction or logical negation; rather mental activity and counteracting relaxation are two opposed forces, and the former can be stimulated to overcome the latter. ${ }^{43}$ Kant then returns to the analogy between the relative spontaneous forces in fire, or here gunpowder, and the activities of minds:

Thus it is with the thunder which, invented by art for our destruction and carefully preserved in the arsenal of a prince ready for a future war, lies in menacing silence until, touched by a treacherous spark, it explodes in lightening and lays waste to everything around it. Tensed springs [Spannfedern], constantly ready to explode, lay dormant within it, the prisoners of powerful forces of attraction, waiting to be released by the stimulus [Reiz] of a spark of fire. There is something imposing and, it seems to me, profoundly true in this thought of Leibniz: the soul embraces the whole universe with its faculty of representation, though only an infinitesimally tiny part of these representations is clear. [...] The force of thought possessed by the soul must contain the real grounds of all concepts, in so far as they are supposed to arise in a natural fashion within the soul (NG, AA 02: 199).

More explicitly than in the New Elucidation, Kant draws an analogy between the spontaneous force of fire's elastic matter and mental forces. In this 1763 text, Kant contends that Leibniz's notion of a faculty of obscure representations is "profoundly true", insofar as the real grounds of all concepts are already present in the soul, and mental stimulation can trigger the illumination of obscure representations. Like elastic physical phenomena, minds possess a relative spontaneity, in that internal forces can be unleashed by a minor stimulus.

Kant will go on to reject both Leibniz's account of the faculty of obscure representations, and the possibility of knowledge of the mind through an analogy with physical forces. Both shifts are evident in Dreams of a Spirit-Seer (1766). In a footnote, Kant gives a much more circumspect account of the Leibnizian "faculty of obscure representations": rather than affirming this conception as "profoundly true", Kant says only that if philosophers reject Leibniz's view, it is incumbent on them to provide an alternative account of the inner ground of external relations. Kant states that he himself "cannot specify in what that inner activity consists", and so by 1766 has taken an agnostic stance towards Leibniz's doctrine of the faculty of obscure representations (TG, AA 02: 328). ${ }^{44}$ Furthermore, Kant denies that our knowledge of physical forces can increase our understanding of mental activity: he states that it is natural that soul-body community is incomprehensible, because

the latter is a "subtle and elastic fluid" set in motion by attractive force (2:184-188). Kant's first and fourth examples draw on interests familiar from his texts of the 1750s.

${ }^{42}$ Earlier Kant writes, "in what concerns the cancellation of an existing something, there can be no difference between the accidents of mental natures [geistigen Naturen] and the consequences of effective forces [wirksamer Kräfte] in the physical world" (NG, AA 02: 191).

${ }^{43}$ The only commentator, to my knowledge, to emphasise that the forces of Negativen Größen are psychological as well as physical is Zinkin 2012: 397-414. I do not however follow Zinkin's presentation of negative magnitudes as themselves forces; rather, I take Kant to introduce negative magnitudes as conceptual tools for conceiving of forces, both of physical bodies and minds

${ }^{44}$ Kant's agnostic position will develop, by 1770 , into a dismissal of what he calls the Leibnizian-Wolffian philosophy's "merely logical" distinction between sensibility as confused cognition and the understanding as distinct cognition. See MSI, AA 02: 394f; $\mathrm{KrV}, \mathrm{A} 44 / \mathrm{B} 61-2$ 
"our concepts of outer actions are derived from matter, and always connected with the conditions of pressure or impact, which do not occur here" (TG, AA 02: 328). ${ }^{45}$

By 1766, then, Kant rejects both the analogy between physical elasticity and mental spontaneity, and any straightforwardly Leibnizian account of the latter. Nevertheless, his explorations of this analogy in 1755 and 1763 reveal the extent of his enthusiasm for the explanatory potential of elastic force at this time. The passages show that Kant reflected on at least an analogical connection between the elastic matter, with which he explained diverse physical phenomena in his naturalphilosophical works of the 1750s and 1760s and which I propose he sought to metaphysically ground on his physical monadology, and the relative spontaneity of minds, understood on Leibnizian lines. If, as commentators have argued, Kant continues to ascribe a relative spontaneity to the understanding in the Critique of Pure Reason (Sellars 1971: 23-25; Ameriks 1991; Sgarbi 2012: 60), it is instructive to see that in the 1750s and early 1760 s his ascription of relative spontaneity to the mind appears in the context of an analogy between Leibniz's faculty of obscure representations and the relative spontaneity of elastic matter, air and fire.

\section{Conclusion}

The period of 1754-64 sees Kant explore elasticity and elastic forces in an increasingly broad sense. On my account, On Fire provides an important insight into how Kant considered the elastic matter of air and fire to be connected. This provides the basis for the explanation of various physical phenomena in other texts of the decade. The Physical Monadology can be read as an attempt to provide a dynamic metaphysical ground for elasticity. On my account, Kant's review of Silberschlag indicates Kant's ambitions to extend the physical monadology to the "heights of metaphysics". But whilst Silberschlag's metaphysical heights remain within the realm of physics, the New Elucidation and Negative Magnitudes explore a yet-more metaphysical extension of the explanatory potential of physical spontaneity. Kant suggests in these works that the mind, understood on Leibnizian lines as possessing an infinite but predominantly obscure Vorstellungskraft, can be compared to the potential force contained in the elastic matter of fire. Although he will reject the use of such analogies in 1766, the passages in Kant's works of 1755 and 1763 give an intriguing insight into how he was then exploring a common relative spontaneity in the physical and psychological domains.

In closing, we can return to the comparison with Adickes' Kant als Naturforscher that was introduced in section 1. Regarding elastic force in Kant's early works, Adickes discusses only how Kant's view fits into contemporaneous debates around the cause of elasticity in physical bodies and the question of whether this should be explained by a notion of the ether. I hope to have shown that, regardless of the later developments in Kant's discussions of elasticity in the critical period or the significance of the ether-concept for his final drafts, in 1754-64 Kant is interested in elasticity as a means of explaining the increase in force that occurs in immanent self-activity without transgressing the principle of equipollence.

In this regard, Adickes' question of whether Kant should be considered a Naturwissenschaftler or a Naturphilosopher is still relevant. No commentator today would argue that Kant is a natural scientist in the modern sense; nor would anyone judge Kant's failure to achieve natural-scientific standards of rigour as harshly as Adickes does. Nevertheless, current scholarship could emphasise even further that Kant's early writings on nature are natural-philosophical works.

${ }^{45}$ The Mrongovius lecture notes (1782-1783) make this point explicit: "[a]1l efforts are ... in vain that want to make the faculties of the soul distinct through bodily intuition. We find not the slightest analogy between thinking and matter" (V-Met/Mron AA 29: 904). 
This entails that the distinction between Kant's "theoretical" and "natural-scientific" writings dissolves, enabling a deeper appreciation of Kant's multifaceted early philosophy. ${ }^{46}$

\section{Bibliography}

Primary works

DU CHÂTELET, É.: Dissertation sur la Nature et la Propagation du Feu, in: Académie Royale des Sciences: Recueil des pièces qui ont remporté les prix de l'Académie Royale des Sciences, depuis leurs fondation jusqu'à présent. Tome quatrième, contenant les pièces depuis 1738 jusqu'en 1740, Paris, 1752, 87-170. http://iris.univ-lille1.fr/handle/1908/1247.

BOYLE, T.: "New Experiments Physico-Mechanical, touching the Spring of the Air", in: BIRCH, T.: The Works of the Honourable Robert Boyle, $2^{\text {nd }}$ ed., 6 vols, Vol. 1, London, J. \& F. Rivington, 1772, 1-117.

EULER, L.: Dissertatio de igne, in qua eius natura et proprietates explicantur, in: Académie Royale des Sciences, Recueil des pièces qui ont remporté les prix de l'Académie Royale des Sciences, depuis leurs fondation jusqu'à présent. Tome quatrième, contenant les pièces depuis 1738 jusqu'en 1740, Paris, 1752, 5-21. http://iris.univ-lille1.fr/handle/1908/1247.

HALES, S.: Vegetable Staticks: or, an Account of some Statical Experiments on the Sap in Vegetables: being an essay towards a Natural History of Vegetation. Also a Specimen of an attempt to analyse the air, by a great variety of chymio-statical experiments; which were read at several meetings before the Royal Society, London, W. and J. Innys, and T. Woodward, 1727.

KANT, I.: Correspondence, ed. and trans. ZWEIG, A., Cambridge, Cambridge University Press, 1999.

: Natural Science, ed. WATKINS, E., Cambridge, Cambridge University Press, 2012.

LEIBNIZ, G. W.: Philosophical Essays, ed. and trans. ARIEW, R.; GARBER, D., Indianapolis, Hackett, 1989a.

: Philosophical Papers and Letters, ed. and trans. LOEMKER, L. E., $2^{\text {nd }}$ edition, Dordrecht, Kluwer, 1989b.

NEWTON, I.: Opticks, or a Treatise of the Reflections, Refractions, Inflections and Colours of Light, $4^{\text {th }}$ ed. [1730], New York, Dover, 1952.

WALCH, J. G.: Philosophisches Lexicon, Leipzig, 1726.

WASIANSKI, E. A. C.: Immanuel Kant in seinen letzten Lebensjahren, Königsberg, 1804; reprinted in GROSS, F.: Immanuel Kant: Sein Leben in Darstellungen von Zeitgenossen, Darmstadt, WBG, 1993, 189-271.

WOLFF, C.: Aërometriae Elementa, Leipzig, 1709; reprinted in Gesammelte Werke [GW] II.37, Hildesheim, Olms, 1981.

: Anfangs-Gründe aller Mathematischen Wissenschafften, Halle, 1710, 4 vols; reprinted in GW I.12-15, Hildesheim, Olms, 1999.

${ }^{46}$ For helpful comments on earlier versions of this paper, I would like to thank Karin de Boer, the participants of the 2017 Leu ven Kant Conference, and the reviewers for the Revista. Completion of the paper was supported by a fellowship at the Research Institute of the University of Bucharest (ICUB). 
: Mathematisches Lexicon, Leipzig, 1716; reprinted in GW I.11, Hildesheim, Olms, 1978.

: Auszug aus den Anfangs-Gründen aller Mathematischen Wissenschaften, Halle, 1717; reprinted in $G W$ I.25, Hildesheim, Olms, 2009.

: Vernünffige Gedancken Von den Würckungen der Natur, Halle, 1723; reprinted in GW I.6. Hildesheim, Olms, 1981.

: Allerhand Nützliche Versuche, Dadurch Zu genauer Erkäntniß Der Natur und Kunst Der Weg gebähnet wird Teil 1. Halle, 1727; reprinted in GW I.20.1, Hildesheim, Olms, 107-460.

Secondary works

ADICKES, E.: “Zur Lehre von der Wärme von Fr. Bacon bis Kant”, Kant-Studien 27 (1922) 328-368.

: Kant als Naturforscher, vol. 1, Berlin, de Gruyter, 1924.

: Kant als Naturforscher, vol. 2, Berlin, de Gruyter, 1925.

ALLISON, H. E.: Kant's Theory of Freedom, Cambridge, Cambridge University Press, 1990.

AMERIKS, K.: "Kant on Spontaneity: Some New Data", in FUNK, G.: Akten des Siebenten Internationalen Kant-Kongresses, Bonn, Bouvier, 1991, 469-79.

ANTOGNAZZA, M. R.: Leibniz: An Intellectual Biography, Cambridge, Cambridge University Press, 2009.

CARRIER, M.: "Kants Theorie der Materie und ihre Wirkung auf die zeitgenössische Chemie", Kant Studien 81 (1990) 170-210.

EDWARDS, J.: Substance, Force, and the Possibility of Knowledge: On Kant's Philosophy of Nature, Berkeley, University of California Press, 2000.

FRIEDMAN, M.: Kant and the Exact Sciences, Cambridge, Harvard University Press, 1992.

: Kant's Construction of Nature: A Reading of the Metaphysical Foundations of Natural Science, Cambridge, Cambridge University Press, 2013.

HOWARD, S.: "Modes of cognition, proto-transcendentalism and force in Kant's Living Forces", in WAIBEL, V. L.; RUFFING, M.: Akten des 12. Internationalen Kant-Kongresses ,Natur und Freiheit' in Wien vom 21.-25. September 2015, forthcoming.

LÆRKE, M.: "Leibniz on the Principle of Equipollence and Spinoza's Causal Axiom", Leibniz Society Review 25 (2015) 123-130.

MASSIMI, M.: "Kant's dynamical theory of matter in 1755, and its debt to speculative Newtonian experimentalism", Studies in History and Philosophy of Science 42 (2011),525-543.

MASSIMI, M.; BIANCHI, S. D.: "Cartesian echoes in Kant's philosophy of nature", Studies in History and Philosophy of Science 44 (2013) 481-492.

MERCER, C.: Leibniz's Metaphysics: Its Origins and Development, Cambridge, Cambridge University Press, 2004.

SCHÖNFELD, M.: The Philosophy of the Young Kant: The Precritical Project, Oxford: Oxford University Press, 2000.

SELLARS, W.: “...this I or He or It (The thing) which thinks...”, Proceedings of the American Philosophical Association 44 (1970) 5-31. 
SGARBI, M.: Kant on Spontaneity, London, Bloomsbury, 2012.

WARDA, A.: Immanuel Kants Bücher, Berlin, Martin Breslauer, 1922.

WATKINS, E.: Kant and the Metaphysics of Causality, Cambridge, Cambridge University Press, 2005.

WASCHKIES, H-J.: "Ein Entwurf zu Kants Dissertation De igne (Loses Blatt Dorpat/Tarta)", in BRANDT, R.; STARK, W.: Autographen, Dokumente und Berichte. Zu Edition, Amtsgeschäften und Werk Immanuel Kant, Hamburg, 1994, 158-196.

ZINKIN, M.: “Kant on Negative Magnitudes”, Kant-Studien 103, 4 (2012) 397-414. 


\title{
La relación entre autoconciencia pura y existencia en la segunda edición de la Crítica de la razón pura ${ }^{1}$
}

\author{
ALEJANDRA BAEHR S.2
}

\begin{abstract}
Resumen
El presente trabajo tiene por objetivo dilucidar el sentido que Kant le confiere a la relación entre apercepción pura y existencia en los textos añadidos a la segunda edición de la Crítica de la razón pura ${ }^{3}$ (1787). Se defenderá que a partir de la interconexión dinámica entre la materia y la forma del pensar se puede comprender que el sentido de la existencia que Kant relaciona con la apercepción pura en la $K r V$ (B) refiere a la posición relativa que ocupa la existencia del sujeto pensante en relación con la posición absoluta que ocupa un genuino objeto de conocimiento.
\end{abstract}

Palabras clave: Autoconsciencia, existencia, materia, forma, posición.

\section{The relationship between pure self-consciousness and existence in the second edition of the Critique of pure reason}

\begin{abstract}
This paper attempts to clarify the sense that Kant wants to give to the relationship between pure apperception and existence in the added texts to the second edition of the Critique of pure reason (1787). I will support the idea that from the dynamic interconnection between matter and form of thought, it is possible to understand that the sense of the existence that Kant links to pure apperception in the $\operatorname{KrV}(\mathrm{B})$ has to do with the relative position of the existence of the thinking subject with regard to the absolute position of a genuine object of knowledge.
\end{abstract}

Keywords: Self-consciousness, existence, matter, form, position.

La crítica kantiana a la doctrina racional del alma o 'yo pensante' desarrollada en el capítulo de los Paralogismos de la razón pura es ciertamente devastadora. Las pretensiones cognoscitivas de la razón pura pronto se ven frustradas al establecerse la imposibilidad de auto-objetivar el 'yo pensante'. Sin embargo, el error en la doctrina racional del alma se funda en un particular tipo de ilusión, una ilusión trascendental. ${ }^{4}$ Arraigada en la naturaleza misma de la razón, la ilusión trascendental resulta inevitable para quien (como el psicólogo racionalista) ignora los sentidos en los que podemos referirnos al 'yo pensante', a saber: como expresión de la necesaria unidad de la conciencia en la

${ }^{1}$ Artículo ganador de la 2da. edición del Premio Kant panta jóvenes investigadores en lengua española, otorgado por la SEKLE. ${ }^{2}$ Becaria CONICYT-PFCHA/Doctorado Nacional/2017-21171378. Contacto: abaehr@alumnos.uahurtado.cl

${ }^{3}$ En lo que sigue, para referirme a esta obra emplearé la abreviatura $\mathrm{KrV}$. Las obras de Immanuel Kant se citan según la paginación de la Akademie Ausgabe; en particular, para la Crítica de la razón pura, según la paginación de la primera edición, 1781 (A), y de la segunda, 1787 (B). Para todas las demás obras de este autor se usan las siglas AA, seguidas del número de volumen y la página.

${ }^{4}$ Cabe destacar que este tipo de ilusión es natural. Esto se debe a que la manera en que razonamos nos conduce inevitablemente a referirnos al alma como si esta fuera una sustancia a la que podemos atribuir predicados. Más aún, desde esta perspectiva se advierte que la causa de que caigamos una y otra vez en esta ilusión trascendental se debe a que la única manera en que podemos referirnos a las cosas (fuera de nosotros) es por medio del juicio y, en consecuencia, comparte la estructura de este. Así, resulta 'natural' la confusión que nos lleva a referirnos a las ideas de la razón como si estas fueran auténticos objetos de conocimiento, aun cuando ellas no encuentren fundamento alguno en la intuición. Para un análisis detallado del asunto, véase Grier (2001). 
apercepción pura ('yo trascendental'), como autoconciencia empírica ('yo empírico'), i.e. determinada temporalmente y, por último, como noúmeno o cosa en sí. ${ }^{5}$

De esta manera, el psicólogo racionalista considera el 'yo trascendental' como si fuera el 'yo nouménico o en sí', aplicándole categorías que, para el idealismo trascendental, solo poseen significación en el plano empírico (cf. Jáuregui 2008: 125). En otras palabras, el error en la inferencia del psicólogo racionalista consiste básicamente en poner bajo una categoría (la de substancia, por ejemplo) —que debe referir necesariamente a una intuición — una representación meramente intelectual, a saber, la representación 'yo pienso' como producto de la espontaneidad del entendimiento y por medio de la cual se expresa la actividad determinante que este ejecuta sobre lo múltiple dado a la intuición. Sin embargo, la actividad pura del pensamiento no puede ella misma constituirse como un auténtico objeto de conocimiento. En efecto, la crítica kantiana a los paralogismos de la psicología racional radica precisamente en que del hecho de que todas mis representaciones deban referir a la unidad trascendental de la conciencia no se sigue el conocimiento de ningún sujeto concreto al que pueda atribuirsele estas representaciones (i.e. los pensamientos) al modo de accidentes de una sustancia. La representación de la unidad trascendental de la conciencia es una condición de posibilidad del conocimiento de objetos, en la medida en que proporciona la (x) vacía a la que deben referir todas mis representaciones. Por consiguiente, el 'yo pienso', entendido como apercepción trascendental, no es ni una intuición ni un concepto, sino la mera forma de la conciencia (A382), la cual debe poder acompañar a todas mis representaciones.

Ahora bien, la complejidad de los pasajes donde se puede encontrar la concepción kantiana del 'yo pensante' y la autoconciencia en la primera edición de la $\operatorname{KrV}$ (A) suscitaron controversia ya entre sus contemporáneos, en particular a partir de la objeción planteada por Herman Andreas Pistorius. De acuerdo con Norman K. Smith ${ }^{6}$ (2003: 305), la objeción de Pistorius al idealismo trascendental kantiano consiste en establecer que, al referir los fenómenos externos a una conciencia interna que, a su vez, es ella misma fenoménica, Kant estaría reduciendo tanto al 'yo' como al objeto de conocimiento a una mera ilusión [Schein]. De ahí que para evitar la acusación de Pistorius sobre un idealismo no deseado por parte de Kant, era preciso que este aclarara el vínculo entre el 'yo pienso' de la apercepción pura y la existencia.

En vista de lo anterior, algunos comentaristas (Smith 2003: 323; Howell 1992: 193) sostienen que la respuesta kantiana a la objeción de Pistorius consiste en afirmar que a través del 'yo pienso', en cuanto representación puramente intelectual, tiene lugar un tipo de conciencia no fenoménica de nuestra existencia. En este sentido, la objeción planteada por Pistorius permite comprender la relación que Kant establece en la segunda edición (B) de la $K r V$ entre el 'yo pienso' de la apercepción pura y la existencia ${ }^{7}$ particularmente en lo que respecta a los pasajes añadidos a la Deducción trascendental (B) y al capítulo de los Paralogismos (B).

\footnotetext{
${ }^{5}$ Lo que Kant pretende destacar al referirse al 'yo en sí mismo' o a la 'idea de alma' es el carácter indeterminado de la misma, puesto que al exceder los límites de la experiencia posible no contamos con un concepto del entendimiento que nos permita determinarla in concreto. De esta manera, el término 'noúmeno' comparte de igual forma este sentido, oponiéndose a aquello que sí podemos determinar por medio de las categorías, a saber: los fenómenos. De ahí que aquello que es 'en sí', lo 'nouménico' o la 'idea' excede los límites de la experiencia posible y, en consecuencia, resulta incognoscible para nosotros.

${ }^{6}$ Siguiendo a K. Smith (2003: 323), Kant habría sentido la necesidad de responder a la objeción de Pistorius en la segunda edición de la $K r V$, lo cual ocurre, entre otras referencias, en no menos de siete ocasiones (BXXXIX, 67-8, 70, 157-8, 276-8, 422 n., 427-9).

${ }^{7}$ Recientemente, algunos especialistas tales como Ameriks (2006), Melnick (2009), Kumar (2016), Rosales (2015) y Klemme (2016) han abordado el problema de la relación entre el 'yo pienso' y la existencia, retomando así la tradición hermenéutica instaurada por Hartmann, Wundt y Heimsoeth (1924), quienes vieron a Kant como un metafísico preocupado, en primer lugar, por el carácter y la existencia del 'yo', el mundo y Dios (Paton 1957; Ando 1974). No obstante, la influencia ejercida por la escuela neokantiana de Marburgo desde finales del siglo XIX (Cohen, Natorp, Cassirer) determinó en gran medida el interés de los especialistas alemanes por la fundamentación kantiana de la ciencia natural. De ahí que comenzara a considerarse a Kant como un pensador cuya intención primaria habría consistido en sustituir la infructuosa especulación metafísica por una teoría de conocimiento. Efectivamente, la motivación principal que guía la investigación kantiana, en lo que respecta a la determinación de las fuentes, el alcance y los límites del conocimiento en la $K r V$, es el problema acerca de la posibilidad o imposibilidad de la metafísica. En este sentido, me parece que, tal como el primer grupo de autores ha observado, la empresa crítica que Kant
} 
En lo que sigue, pretendo mostrar que el sentido de la particular relación que Kant establece entre apercepción pura y existencia debe comprenderse a partir de la interconexión dinámica entre la materia y la forma del pensar. Con este propósito, comenzaré por realizar un análisis de los pasajes de la $K r V$ (B) en donde Kant vincula al 'yo pienso' de la apercepción pura con una existencia, particularmente: i) el $\$ 25$ de la Deducción trascendental; así como también ii) algunos de los pasajes añadidos al capítulo de los Paralogismos (B423 nota). Luego, presentaré iii) una interpretación de la afirmación kantiana según la cual la proposición 'yo pienso' es, en rigor, una proposición empírica (B423 nota). Más tarde, me referiré a la categoría de existencia en la sección dedicada a los Postulados del pensamiento empírico con el fin de esclarecer los pasajes analizados en los apartados (1) y (2). Por último, iv) presentaré algunas consideraciones generales acerca del sentido de la existencia que Kant relaciona con la apercepción pura en (B) y que en mi interpretación refiere a la posición relativa que ocupa la existencia del sujeto pensante en relación con la posición absoluta que ocupa un genuino objeto de conocimiento.

\section{Apercepción pura y existencia en el §25 de la Deducción trascendental (B)}

Dentro de los pasajes de la Deducción que Kant reescribe se observan lugares donde la reflexión kantiana vuelve sobre el tipo de autoconciencia que supone la unidad originaria de la apercepción trascendental. En este contexto, resulta fundamental para Kant esclarecer posibles malentendidos ${ }^{8}$ acerca de los principios a priori que hacen posible la deducción de las categorías. Dicho de otra forma, lo que interesa a Kant aquí es establecer el principio supremo de todo el uso del entendimiento, a saber, el principio de la unidad sintética originaria de la conciencia en la apercepción pura (A117). ${ }^{9}$ El principio supremo del entendimiento, al igual que el principio supremo de la posibilidad de toda intuición con respecto a la sensibilidad (espacio y tiempo), es una condición formal de la experiencia ( $\$ 17 \mathrm{DTB}$ ); esto es, un conocimiento sintético a priori del que se pueden deducir las categorías ${ }^{10}$. Ambos principios supremos — de la sensibilidad y del entendimiento- son condiciones trascendentales de la posibilidad de la experiencia. Sin embargo, el carácter meramente formal del principio de la apercepción trascendental ha hecho que al lector de la segunda edición (B) le llame la atención la relación que Kant establece entre el tipo de autoconciencia que dicho principio supone y la propia existencia, esto es, la existencia de $m i$ 'yo pensante' en cada caso. Al respecto Kant sostiene:

desarrolla en la Dialéctica no debe ser considerada como la expresión de un rechazo absoluto a la necesidad de abordar las problemáticas clásicas planteadas por la metafísica tradicional, sino como el establecimiento de una delimitación necesaria del alcance de las pretensiones cognoscitivas de la razón pura. De esta forma, la limitación del ámbito del conocimiento objetivo constituye un momento necesario para toda reflexión posterior que pretenda instalar a la metafísica en el camino de la ciencia, puesto que permite comprender que el ámbito en el que la razón pura puede abordar, legítimamente, los asuntos a los que por naturaleza tiende (alma, Dios y mundo) es el ámbito práctico.

${ }^{8} \mathrm{Al}$ referirse a los cambios realizados en la segunda edición de la $\mathrm{KrV}(\mathrm{B})$, Kant sostiene: «Pero en la exposición hay todavía mucho que hacer, y en esto he intentado, con esta edición, mejoras que tienen por finalidad remediar, ya la mala comprensión de la "Estética", especialmente la del concepto de tiempo; ya la oscuridad de la deducción de los conceptos puros del entendimiento; ya la presunta carencia de evidencia suficiente en las pruebas de los principios del entendimiento puro; ya, por fin, la mala interpretación de los paralogismos que preceden a la psicología racional [...]» (Prólogo B, XXXIX).

${ }^{9}$ Se trata, pues, de establecer la necesidad de reunir la multiplicidad de representaciones dadas a la intuición bajo la unidad trascendental de la apercepción, puesto que solo con referencia a ella es posible enlazar el múltiple dado a la sensibilidad como perteneciente a una y la misma conciencia. En este sentido, Kant distingue entre la unidad sintética y la unidad analítica de la conciencia. Así, «[...] esta integral identidad de la apercepción de un múltiple dado en la intuición contiene una síntesis de las representaciones, y sólo mediante la conciencia de esa síntesis es posible. Pues la conciencia empírica que acompaña a diversas representaciones es, en sí, dispersa y sin referencia a la identidad del sujeto. Por tanto, esa referencia no ocurre con sólo que yo acompañe con conciencia cada representación, sino [que para ella se requiere] que yo añada una [representación] a la otra y que sea consciente de la síntesis de ellas. Por consiguiente, sólo porque puedo enlazar en una conciencia un múltiple de representaciones dadas, es posible que me represente la identidad de la conciencia en esas representaciones; es decir, la unidad analítica de la apercepción sólo es posible bajo la presuposición de alguna [unidad] sintética» (B133).

${ }^{10}$ En otras palabras, a partir del principio supremo del entendimiento (la unidad suprema de la conciencia) es posible mostrar la legitimidad del uso de las categorías para referirnos a fenómenos de la experiencia. 
En cambio, en la síntesis trascendental de lo múltiple de las representaciones en general, y por tanto, en la unidad sintética originaria de la apercepción, tengo conciencia de mí mismo, no como me aparezco a mí [mismo], ni como, en mí mismo, soy, sino sólo [tengo conciencia de] que soy. Esta representación es un pensar, no un intuir. Ahora bien, como para el conocimiento de nosotros mismos, además de la acción de pensar que lleva a la unidad de la apercepción lo múltiple de toda intuición posible, se requiere también una determinada especie de intuición, por la cual ese múltiple es dado, entonces mi propia existencia no es, por cierto, fenómeno (y menos aún apariencia ilusoria), pero la determinación de mi existencia // sólo puede ocurrir de acuerdo a la forma del sentido interno, según la manera particular como es dado en la intuición interna lo múltiple que yo enlazo; y por consiguiente no tengo, según esto, conocimiento alguno de mí mismo, tal y como soy, sino meramente tal como aparezco a mí mismo $(\$ 25, \mathrm{~B} 157-8)$

En el contexto inmediato de este pasaje Kant está empeñado en establecer que la distinción fenómeno-noúmeno debe también aplicarse en relación con la posibilidad de conocernos a nosotros mismos. En este sentido, el 'yo pienso' de la apercepción pura es una representación puramente intelectual que supone un tipo peculiar de autoconciencia, a saber, conciencia de que el 'yo' que piensa, a su vez, es. Sin embargo, para poder conocerme a mí mismo necesito una intuición determinada de mi existencia, la cual solo puede darse temporalmente y, por consiguiente, no puedo conocerme a mí mismo tal y como soy, sino solo como fenómeno.

Ahora bien, aun cuando Kant advierte que la determinación de la existencia solo es posible en el tiempo, esto es, en el sentido interno, esto no significa que mi propia existencia como algo que piensa sea un mero fenómeno y, en ningún caso, una apariencia ilusoria como la que conduce a la razón más allá de los límites de la experiencia posible. En efecto, Kant desarrolla esta diferencia en una nota al pasaje comentado más arriba. Allí señala que:

El Yo pienso expresa el acto de determinar mi existencia. Por consiguiente, la existencia es ya dada por ello, pero la manera en la que tengo que determinar, es decir, [la manera] como tengo que poner en mí mismo lo múltiple que a ella pertenece, no está dada con ello. Para ello se requiere intuición de sí mismo, en cuyo fundamento está una forma dada a priori, es decir, el tiempo, [forma] que es sensible y pertenece a la receptividad de lo determinable. Pero si no poseo además // otra intuición de mí mismo, que antes del acto de determinar suministre lo determinante en mí (sólo de cuya espontaneidad tengo conciencia), tal como el tiempo [suministra] lo determinable, entonces no puedo determinar mi existencia (como [existencia] de un ente espontáneo), sino sólo me represento la espontaneidad de mi pensar, es decir, del determinar; y mi existencia sigue siendo determinable sólo sensiblemente, es decir, como la existencia de un fenómeno. Pero esa espontaneidad hace que me llame a mí mismo inteligencia.

La espontaneidad del entendimiento produce la representación intelectual 'yo pienso', por medio de la cual se expresa la actividad determinante de la apercepción pura. Sin embargo, la posibilidad del conocimiento requiere tanto de un elemento sensible como de uno intelectual. Para conocerme a mí mismo no basta con la mera representación de la espontaneidad de mi pensamiento; esto quiere decir que en el 'yo pienso' puro lo que me represento es solo la actividad determinante de mi pensamiento. En cambio, para conocerme a mí mismo, necesito de una intuición sensible que suministre el material determinable requerido para el conocimiento objetivo que, en este caso, es necesariamente una representación temporal. En otras palabras, para que haya conocimiento y se ejecute la actividad del pensamiento es necesario que algo me sea dado en la intuición, cuya forma general es el tiempo (A34/B50). 
En este sentido, la reflexión en torno a la actividad determinante de la apercepción pura y el material determinable del sentido interno señala el camino para el nuevo punto de partida que adoptará Kant para analizar el enunciado 'yo pienso' en la segunda edición del capítulo de los Paralogismos (B), a saber: la identidad de los enunciados 'yo pienso' y 'yo existo'.

\section{Existencia y autoconciencia pura en los Paralogismos (B)}

En la segunda versión de los Paralogismos (B) Kant ensaya una alternativa analítica a la doctrina cartesiana del cogito. El resultado del ensayo propuesto por Kant como alternativa al silogismo que se adjudica a Descartes es una tabla analítica de los juicios que podemos inferir legítimamente ${ }^{11}$ a partir del 'yo pienso' y donde, al igual que en el §25 (DTB) citado más arriba, la existencia se encuentra ya supuesta en dicha representación.

En general, ambas ediciones de la $K r V$ arriban a consecuencias similares acerca de la doctrina tradicional del alma. En ambos casos la principal lección que podemos extraer de los Paralogismos guarda relación con la imposibilidad de acceder a un conocimiento de lo suprasensible, i.e. de lo que el alma es en sí misma. Sin embargo, esto no es todo. Tanto en la edición (A) como en la (B), aunque siguiendo una estrategia distinta, Kant es enfático al admitir que podemos establecer ciertas conclusiones válidas a partir de la proposición 'yo pienso', esto es, tomando el mismo punto de partida adoptado por el psicólogo racional, pero con un sentido y alcance epistemológico cuidadosamente delimitado.

En relación con la estrategia analítica que Kant adopta en (B), cabe destacar que el error del psicólogo racional se identifica aquí con el resultado de una confusión entre juicios sintéticos y analíticos. En este sentido, el error de la psicología racionalista consiste en tratar las proposiciones analíticas sobre el 'yo pensante' como proposiciones sintéticas a priori (B417). En efecto, Kant describe esta alternativa analítica de proceder y sus resultados señalando que:

Si, en cambio, seguimos el proceder analítico, según el cual el Yo pienso, como una proposición que en sí misma encierra una existencia, sirve de fundamento, como dado, y por tanto, [sirve de fundamento] la modalidad, y si descomponemos [a esa proposición] para conocer su contenido, es decir, [para saber] si acaso este Yo determina sólo por este medio su existencia en el espacio o en el tiempo, y cómo lo hace, entonces las proposiciones de la doctrina racional del alma no comenzarían por el concepto de un ente pensante en general, sino por una realidad efectiva (Wirklichkeit), ${ }^{12}$ y a partir de la manera como ésta fuese pensada, luego que hubiera sido apartado todo lo que en ella es empírico, se deduciría lo que corresponde a un ente pensante en general, como muestra la tabla siguiente.

(1) Yo pienso

(2) Como sujeto,

(3) Como sujeto simple,

(4) Como sujeto idéntico en todo mi pensar (B418-9).

En este pasaje Kant admite la validez de estas cuatro proposiciones analíticas en la medida en que el punto de partida, i.e., la representación de la actividad determinante de mi pensamiento, encierra ya en su fundamento una existencia. En este sentido, el fundamento de la validez de estas proposiciones analíticas no es el concepto de un ente pensante en general (como para el racionalista), sino una realidad efectiva [Wirklichkeit], de la que se ha apartado todo lo empíricamente determinado

${ }^{11}$ Para una exposición sumaria de las principales diferencias entre las estrategias argumentativas de la primera (A) y la segunda (B) versión de los Paralogismos, véase Thiel (2006)

${ }^{12}$ Los paréntesis aquí son míos. 
en ella. No obstante, aun cuando la representación intelectual 'yo pienso' expresa el acto de determinar mi existencia, esto no significa que pueda determinar mi existencia en el tiempo solo a partir de dicha actividad. Para poder determinar mi existencia en el tiempo necesito de una intuición determinada. Sin embargo, como intentaré mostrar en el siguiente apartado, aun cuando no contamos con una intuición determinada de nosotros mismos, Kant sí admite que a través de la apercepción trascendental tenemos acceso a una sensación empírica indeterminada de nuestra propia existencia.

De esta manera, si seguimos el razonamiento alternativo propuesto por Kant $\mathrm{y}$, tal como expresa la tabla analítica, consideramos que en (2) «el concepto de un sujeto aquí está tomado de manera meramente lógica, y queda indeterminado, si ha de entenderse con él una sustancia o no» (B420), entonces el problema acerca de la existencia que acompaña a la representación intelectual 'yo pienso' se reduce al modo en el que debo determinar mi existencia. En otras palabras, en (1) mi existencia se considera como dada y, por tanto, puedo establecer legítimamente que 'yo existo pensando'. No obstante, de lo anterior no se sigue que yo deba necesariamente, como habría pensado Descartes, existir como una sustancia simple e indivisible.

En este contexto, me parece que a partir de las consideraciones precedentes (apartados 1 y 2) es posible establecer que aun cuando la apercepción trascendental es caracterizada como un requerimiento formal necesario para la posibilidad de la experiencia en general, Kant advierte la necesidad de explicitar en la segunda edición (B) de la $K r V$ el particular tipo de autoconciencia supuesto en el principio de la unidad necesaria de la conciencia en la apercepción pura. Si aislamos la actividad determinante ejecutada por la apercepción trascendental o pura, entonces la estamos considerando como una mera condición formal de la experiencia de objetos, esto es, una mera función lógica del pensar en general. Sin embargo, si la consideramos en su efectividad ('yo existo pensando'), entonces esta ya no puede considerarse como una mera función lógica ${ }^{13}$ (B430). En efecto, Kant advierte la necesidad de que la apercepción trascendental suponga, a su vez, una realidad efectiva (B419) que ejecute la actividad determinante del pensamiento. En este sentido, la conciencia de la síntesis de mis representaciones en la unidad sintética originaria de la apercepción trascendental encierra en sí misma la conciencia de que ‘yo soy’ (\$25).

3. Una interpretación de la afirmación kantiana según la cual la proposición 'yo pienso' es, en rigor, una proposición empírica (B420, nota a B423)

De acuerdo a lo establecido a partir del proceder analítico que Kant ensaya en (B419) podemos establecer legítimamente la validez de la proposición 'yo existo pensando'. Sin embargo, queda por determinar en qué sentido debemos comprender la afirmación kantiana según la cual dicha proposición es una proposición empírica (B420). Kant explica el asunto afirmando que la proposición 'yo pienso' «contiene la determinabilidad de mi existencia meramente con respecto a mis representaciones en el tiempo» (B420). Por esto puede sostenerse que la proposición 'yo pienso' contiene en sí la proposición 'yo existo'. No obstante, no parece tan claro en qué sentido una representación meramente intelectual, a saber, el 'yo pienso', que expresa la actividad determinante de mi pensamiento, puede dar lugar a una proposición empírica. La explicación que Kant ofrece la encontramos en una enigmática nota añadida en la segunda edición del capítulo de los Paralogismos (B). Allí Kant sostiene que:

\footnotetext{
${ }^{13}$ En palabras de Ameriks (2006: 60): «[...] even though the thought of an I can also be understood as the thought of a function that is present in all thought (the function of synthesis), the I that is spoken of here is not being characterized as a mere function or abstraction. Kant stresses that it exists, it has 'being' as an actual element in all the particular apperceptions that I can carry out or consider, and so it is there in the minimal determinate truth that each of them is really had by an I: 'it is no mere logical function but determines the subject in respect of existence' (B 430)».
} 
El Yo pienso es, como ya se dijo, una proposición empírica, y contiene en sí la proposición Yo existo. Pero no puedo decir: todo lo que piensa, existe; pues en ese caso la propiedad de pensar haría, de todos los entes que la poseen, entes necesarios. Por eso mi existencia tampoco puede considerarse como deducida de la proposición Yo pienso, como creyó Cartesius (porque, en caso contrario, debería preceder la premisa mayor: todo lo que piensa, existe), sino que es idéntica a ella.

[Esta proposición] expresa una intuición empírica indeterminada, es decir, [una] percepción (Wahrnehmung) (y por tanto prueba que // en el fundamento de esta proposición existencial hay ya una sensación (Empfindung), que, en consecuencia, pertenece a la sensibilidad), pero precede a la experiencia que ha de determinar, por medio de la categoría, el objeto de la percepción, con respecto al tiempo; y la existencia no es todavía aquí una categoría; [una categoría] como tal, no se refiere a un objeto dado de manera indeterminada, sino sólo a uno del que se tiene un concepto, y del que se quiere saber si además, fuera de este concepto, está puesto, o no. Una percepción indeterminada significa aquí algo real (etwas Reales) que ha sido dado, pero sólo [dado] al pensar en general, y por tanto, no [dado] como fenómeno, ni tampoco como cosa en sí misma (noumenon), sino como algo que efectivamente existe (was in der That existirt), y que es designado como tal en la proposición Yo pienso. Pues hay que notar que si la proposición: Yo pienso, la he llamado empírica, no quiero decir que el Yo, en esa proposición, sea una representación empírica; es más bien una [representación] puramente intelectual porque pertenece al pensar en general. Pero sin alguna representación empírica que suministre la materia para el pensar, el acto Yo pienso no tendría lugar, y lo empírico es solamente la condición de aplicación, o del uso, de la facultad intelectual pura (B423 nota).

En este pasaje Kant establece con precisión su postura frente la doctrina cartesiana del cogito. El problema con el silogismo que Kant atribuye a Descartes consiste en el hecho de que al considerar la proposición singular 'yo pienso' como una proposición universal en la premisa mayor (todo lo que piensa existe), Descartes estaría derivando la existencia (en la conclusión 'yo existo') a partir de un mero pensamiento. En efecto, tal y como sostiene Rosales:

Kant distingue con esto entre la existencia y la posibilidad, es decir: la esencia del yo, lo que este es. El "yo pienso", según su mera posibilidad, i.e., tomado problemáticamente (cfr. A347/B405), refiere a la mera forma de la conciencia que debe poder acompañar a todas mis representaciones (2015: 323-324).

De esta manera, Kant se distancia del racionalismo cartesiano al distinguir así la esencia y la existencia y evitar de este modo derivar la existencia del cogito, esto es, a partir de un mero pensamiento. Cuando Kant habla acerca del 'yo pienso' como la mera forma de la conciencia (A383) que debe poder acompañar todas mis representaciones se está refiriendo a una condición formal de la posibilidad de la experiencia en general y, en consecuencia, pertenece universalmente a todo sujeto que piensa. En este contexto, el 'yo pienso' es tomado problemáticamente y, como advierte Longuenesse (2008: 25), lo complejo aquí consiste en que, al derivar la existencia de una representación intelectual, Descartes estaría considerando al enunciado 'yo pienso' como una afirmación, cuyo contenido se vuelve verdadero en cada acto asertivo individual y es realmente conocido por el agente del acto referido por el 'yo'. Para Kant, en cambio, el particular tipo de autoconciencia que supone el 'yo pienso' en la apercepción pura no debe entenderse como un peculiar tipo de intuición determinada del 'yo'.

Ahora bien, tal y como Kant advierte en la nota (B423), la existencia de la que se está hablando aquí no es la de la categoría. La categoría de existencia requiere una intuición empírica determinada para su aplicación. En otras palabras, para que el entendimiento pueda desempeñar su función cognoscitiva y determinar objetos por medio de la categoría de existencia, se requiere a su 
vez de un material sensible provisto por la sensibilidad. ${ }^{14}$ Sin embargo, en el caso del alma como supuesto objeto del sentido interno, no tengo acceso a ninguna intuición temporal determinada de mi existencia, sino solo al material meramente determinable constituido por la sucesión temporal de mis representaciones en el sentido interno. De esta manera, la relación entre un material determinable (la sucesión de mis representaciones en el sentido interno) y una actividad determinante (la actividad del pensar) constituye un elemento central en la caracterización de la alternativa que Kant propone frente a la concepción tradicional del alma. ${ }^{15}$

Por consiguiente, debemos distinguir, por un lado, cuando Kant habla acerca de la representación intelectual 'yo pienso', en cuanto condición formal de la posibilidad de la experiencia en general, esto es, como una representación que debe pertenecer universalmente a todo sujeto pensante, y, por otro lado, cuando Kant discute la identidad de los enunciados 'yo pienso' y ‘yo existo' en la nota citada más arriba (B423), puesto que en esta nota no se está refiriendo ya a una mera condición formal de la experiencia en general, sino al particular tipo de autoconciencia que supone la unidad originaria de la apercepción trascendental en su efectividad, a saber, «conciencia de mí mismo, no como me aparezco a mí [mismo], ni como, en mí mismo, soy, sino sólo [tengo conciencia de] que soy» (\$25). En este último sentido, el 'yo pienso' es una proposición empírica que contiene en sí la proposición 'yo existo'. Sin embargo, esta representación intelectual que contiene la determinabilidad de mi existencia con respecto a mis representaciones en el tiempo, no me proporciona una intuición determinada de mi existencia, sino solo una intuición empírica indeterminada, i.e., la intuición indeterminada de algo que efectivamente existe.

En este contexto, cabe preguntarse qué significa el hecho de que los juicios 'yo pienso' y ‘yo existo' sean idénticos. Más aún, ¿por qué debemos suponer que el 'yo pienso', que expresa el acto de determinar mi existencia, debe encerrar en sí una existencia? En este sentido, me parece fundamental volver sobre el final de la nota a B423: «Pero sin alguna representación empírica que suministre la materia para el pensar, el acto Yo pienso no tendría lugar, y lo empírico es solamente la condición de aplicación, o del uso, de la facultad intelectual pura».

Ciertamente, en este pasaje Kant centra su atención en establecer la necesidad de que una cierta intuición empírica se sitúe en la base de la representación 'yo pienso'. Esto quiere decir que para que el acto de determinar mi existencia, expresado en el 'yo pienso', tenga lugar, entonces, es necesario suponer, a su vez, una cierta representación empírica que le proporcione la materia al pensar. En este sentido, la «intuición empírica indeterminada», expresada en la proposición 'yo pienso', constituye una «condición material de la posibilidad de la experiencia» (Rosales 2015: 321). Esta 'condición material' a la que refiere Rosales pone de manifiesto un aspecto central de la doctrina kantiana del 'yo pensante', puesto que expresa, por así decirlo, la necesaria orientación de la actividad del pensamiento hacia la sensibilidad en general, en cuanto 'material' para la ejecución de dicha actividad.

En efecto, ya al comienzo del capítulo de los Paralogismos —en ambas ediciones—, Kant advierte al lector sobre esta necesaria referencia del pensar a la percepción en general, esto es, a algo dado efectivamente al pensar. Al respecto señala que:

No hay que dejarse detener por [el hecho de] que yo, en esta proposición que expresa la percepción de mí mismo, tenga una experiencia interna, // y que por tanto la doctrina racional del alma, edificada

\footnotetext{
${ }^{14}$ Volveré sobre este asunto en el apartado (3.1).

${ }^{15}$ En efecto, debemos recordar que «la teoría kantiana de la subjetividad se apoya en conceptos de la tradición aristotélicoescolástica, como materia, forma y acto» (Rosales 2015: 321). Para una interpretación hylemorfista de la concepción kantiana del alma, véase Aquila (1997).
} 
sobre ella, no sea nunca pura, sino que esté, en parte, fundada en un principio empírico. Pues esa percepción interna no es nada más que la mera apercepción: Yo pienso; la cual incluso hace posible todos los conceptos trascendentales, en los cuales se dice: Yo pienso la sustancia, la causa, etc. Pues la experiencia interna en general, y su posibilidad, o la de la percepción en general y su relación con otra percepción, sin que sea dada empíricamente ninguna determinación ni diferencia particular en ellas, no puede ser considerada como conocimiento empírico, sino que debe ser considerada como conocimiento de lo empírico en general, y forma parte de la investigación de la posibilidad de toda experiencia, [investigación] que es ciertamente trascendental (A343/B401).

En este sentido, la investigación trascendental llevada al ámbito del 'yo pensante' descubre la necesidad de suponer un fundamento empírico, aunque indeterminado, para la apercepción originaria. Esto se debe a que la conciencia efectivamente real [Wirklich] de la actividad determinante desarrollada por el pensamiento sobre la percepción en general, esto es, «sin que sea dada empíricamente ninguna determinación ni diferencia particular en ellas», le confiere al 'yo' el carácter de algo existente (cf. Rosales 2015: 321).

Con esto, lo que Kant quiere poner de manifiesto al discutir el 'carácter empírico' de la proposición 'yo pienso' es simplemente que la proposición 'yo pienso' implica que algo es dado al pensamiento, a saber, la sucesión de mis representaciones en el sentido interno. Y, en este sentido, la proposición 'yo pienso' expresa una percepción indeterminada en la medida en que pone de manifiesto la necesaria relación entre la actividad determinante del pensamiento y la sensibilidad en general, como su materia. En otras palabras, el sentido interno proporciona el material determinable necesario (pero no suficiente) para que la actividad del pensamiento pueda efectivamente realizarse, dando lugar a la representación 'yo pienso'. Así pues, el 'yo pienso' es ciertamente una representación puramente intelectual, resultado de la apercepción pura, pero supone, o implica, la relación con algo dado a la sensibilidad en general.

La clave de la cuestión radica en cómo hemos de interpretar esta 'intuición empírica indeterminada'. En este sentido, me parece que lo que Kant quiere mostrar es que la intuición o percepción empírica indeterminada de nuestra existencia, que se encuentra a la base de la apercepción pura, constituye la expresión de la necesaria referencia de la actividad del pensamiento a una percepción posible en general. Esta última se constituye a partir del material determinable dado al sentido interno, i.e. la sucesión meramente subjetiva de mis representaciones dadas bajo la forma pura que es el tiempo, para la ejecución de la actividad determinante del entendimiento. Lo que me afecta es mi propia existencia en cuanto actividad de un sujeto determinante; actividad que, por lo demás, no determina aún el material determinable dado al sentido interno como lo haría si estuviera orientada por una categoría. En efecto, en los pasajes añadidos a la Estética trascendental en (B) Kant afirma que:

[...], aquello que, como representación, puede preceder a toda acción de pensar algo cualquiera, es la intuición; y si ella no contiene nada más que relaciones, [es] la forma de la intuición, la cual, como no representa nada, salvo en la medida en que algo es puesto en la mente, no puede ser otra cosa que la manera como la mente es afectada por su propia actividad, a saber, por este // poner las representaciones de ella, y por tanto, por sí misma; es decir, [no puede ser otra cosa que] un sentido interno, según su forma (B67).

En este sentido, la 'auto-afección' que describe aquí Kant es la responsable de provocar la sensación indeterminada de la propia existencia efectiva como sujeto pensante. Cabe desatacar que, por una parte, la sensación que en este caso tengo de mi propia existencia en cuanto sujeto pensante, 
si bien es efectiva [Wirklich], es, sin embargo, indeterminada (meramente subjetiva). Por otra parte, 'la materia propiamente dicha' con la que ocupamos nuestra mente son representaciones espaciales. Esto quiere decir que en el sentido interno lo que tengo es una serie sucesiva de representaciones espaciales (de los sentidos externos) que aún no han sido puestas en un ordenamiento temporal objetivo por medio de una categoría que oriente a la imaginación en la determinación del sentido interno. Esto explica por qué la sensación de la propia existencia en la apercepción pura es indeterminada. En este sentido, la relevancia que adquiere la referencia necesaria de la actividad del pensamiento a una percepción posible en general (al sentido interno) radica precisamente en poner de manifiesto el hecho de que para que yo pueda tener una sensación indeterminada de mi existencia como sujeto pensante, algo debe afectar mi sensibilidad y, en este caso, lo que me afecta es la existencia de mi propia actividad sintética ejecutada en virtud del material dado al sentido interno, material que en rigor se constituye a partir de representaciones espaciales, i.e. algo otro distinto de mí. Solo en la medida en que un genuino objeto de conocimiento (espacial) afecte mi sensibilidad puede entonces ejecutarse la actividad de mi pensamiento, cuya consecuencia es la sensación indeterminada de mi propia existencia.

Por consiguiente, los enunciados 'yo pienso' y ‘yo existo' pueden ser idénticos sin que con ello nos veamos obligados a considerar al 'yo pienso' de la apercepción pura como una representación empírica. Por el contrario, el 'yo pienso', que expresa la necesaria unidad de la conciencia en la apercepción pura, constituye un tipo de representación puramente intelectual que contiene en sí la conciencia de que soy, de que existo. De ahí que el 'yo pienso' que Kant está identificando aquí con una existencia, que por lo demás permanece absolutamente indeterminada, ${ }^{16}$ no pueda ser el 'yo empírico', puesto que la existencia en este caso no es, propiamente, la categoría de existencia. Como se verá en el siguiente apartado, la existencia en cuestión precede a la experiencia y, por tanto, a toda posible determinación temporal.

En este contexto, me parece relevante llamar la atención sobre un pasaje de Prolegómenos (1783) donde Kant advierte que:

Si la representación de la apercepción, el yo, fuese un concepto mediante el cual se pensase alguna cosa, entonces podría ser usado también como predicado de otras cosas, o contendría en sí tales predicados. Pero el yo no es más que el sentimiento de una existencia (Gefühll eines Daseins), sin el más mínimo concepto y es sólo la representación de aquello con lo cual todo pensar está en relación (relationae accidentis) (AA, IV: 334 nota).

En este pasaje Kant expresa la necesaria referencia de la actividad del pensamiento a una percepción en general por medio de la expresión 'el sentimiento de una existencia'. Esto quiere decir que la actividad de la apercepción pura, expresada en el 'yo pienso', implica una referencia a una cierta intuición sensible, i.e., el sentimiento de una existencia. Cabe destacar que el término que Kant utiliza aquí para referirse al 'sentimiento de una existencia' es la palabra alemana Gefühl, mientras que en los Paralogismos (B423 n.) utiliza el término Empfindung para referirse a esta sensación indeterminada de la existencia. Ambos términos refieren a una representación meramente 'subjetiva'. Así pues, en el caso de Gefühl el término refiere a una representación siempre subjetiva que expresa el modo en que somos afectados, sin implicar con ello la referencia cognoscitiva a un objeto. El término Empfindung, a su vez, es definido en (A320/B376) como «una percepción que se refiere solamente al sujeto, como modificación del estado de él» y, en este sentido, debe distinguirse de «una percepción objetiva», esto es, del conocimiento.

${ }^{16}$ Para una detallada exposición acerca del sentimiento de una existencia y el sentido de los términos Empfindung y Gefühl, véase Kumar (2016). 


\subsection{La categoría de existencia en los Postulados (A219/B266)}

El contexto inmediato de la problemática relativa a la categoría de existencia desarrollada en los Postulados corresponde al sistema de todos los principios del entendimiento puro. El sistema de los principios constituye un conjunto de juicios sintéticos a priori derivados de las categorías, atendiendo a las condiciones sensibles de su aplicación. De ahí que pueda considerárselo como un canon para la facultad de juzgar. Esta última es la encargada de subsumir el material sensible dado a la intuición bajo las reglas del entendimiento o categorías. En este sentido, la facultad de juzgar debe discernir si algo está o no bajo una regla dada. Cabe señalar que lo que interesa aquí a Kant no es el caso particular de aplicación de la regla, sino la condición de todo caso.

En este sentido, los principios del entendimiento puro se dividen, al igual que las categorías, en dos grandes grupos según el tipo de evidencia que suponen. Kant distingue entre principios matemáticos y principios dinámicos (A161-2/B200-1); los principios matemáticos poseen una evidencia intuitiva, i.e. inmediata; los principios dinámicos, en cambio, en la medida en que poseen una evidencia discursiva, i.e. mediata, rigen también la determinación a priori de todos los fenómenos, pero lo hacen solo regulativamente.

No obstante la función regulativa de los principios dinámicos, estos rigen a priori «sin menoscabo de su certeza [Gewißheit] con respecto a la experiencia en general» (A161-2/B200-1). En efecto, los principios dinámicos son universales y necesarios, aunque solo subjetivamente (de acuerdo con la estructura de un intelecto finito como el nuestro) y, en este sentido, de su función regulativa no se sigue que sean meramente contingentes. Por el contrario, son necesarios, pero hipotéticamente necesarios. De esta manera, quisiera llamar la atención sobre el hecho de que para Kant no habría lugar a una necesidad absoluta, sino solo hipotética, en la medida en que «las reglas de la interconexión empírica de los fenómenos demuestran mediatamente la existencia efectiva» de objetos de la experiencia (B274). Esto pone de manifiesto los matices que adquiere la posición kantiana frente a la doctrina cartesiana del cogito, según la cual debemos juzgar como dudosa la inferencia acerca de la efectiva realidad del mundo externo.

Ahora bien, tanto las categorías de modalidad, como las de relación son categorías dinámicas. En este contexto, Kant distingue entre una modalidad lógica (general) y una modalidad trascendental (formal). ${ }^{17}$ La modalidad lógica refiere a la analiticidad de los juicios, esto es, a la ausencia de contradicción. Sin embargo, para el idealismo trascendental kantiano, la mera ausencia de contradicción no garantiza un conocimiento sintético a priori. La modalidad trascendental, en cambio, debe considerar siempre la referencia de nuestros conceptos a fenómenos de la experiencia. Además, Kant afirma que, sumado su carácter regulativo, las categorías de modalidad se caracterizan a su vez por no contribuir en nada a la determinación del objeto (sujeto del juicio), ya que no proporcionan ninguna nueva determinación de este (como predicado del objeto).

Así pues, los Postulados del pensamiento empírico en general ofrecen una definición de las categorías de modalidad en su uso empírico y, de esta forma, distinguen el ámbito del mero pensamiento del ámbito del conocimiento objetivo. Este punto es de central importancia para la comprensión del sentido que Kant le otorga a la 'intuición empírica indeterminada' que viene ya dada junto con la actividad determinante de la apercepción pura y que desarrolla, como se mostró antes, en la nota a B423.

En primer lugar, tal como se señaló antes, Kant culpa a Descartes de inferir, a partir del mero concepto problemático que tenemos del 'yo pensante', la existencia efectiva de una substancia

${ }^{17}$ Kant está pensando aquí en la tradición leibniziana que pretendía poder determinar la realidad efectiva de un objeto a partir de la determinación completa de su concepto. En efecto, en el contexto de la Dialéctica trascendental Kant (A571) se refiere específicamente al sentido que adquieren las categorías modales de posibilidad y realidad efectiva (ser), en el marco de una lógica trascendental. 
permanente en el tiempo. En este contexto, debe distinguirse cuidadosamente la categoría de Realidad [Realität], de la categoría de existencia efectiva [Wirklichkeit]. Mientras que la primera es una categoría de cualidad (determinaciones positivas del objeto, predicados posibles no-contradictorios entre sí), la segunda es de modalidad. De ahí que para el idealismo trascendental kantiano no podamos derivar la existencia del cogito a partir de un mero concepto problemático, esto es, de lo meramente pensado en ausencia de sensación.

En segundo lugar, los Postulados del pensamiento empírico en general son proposiciones prácticas que no contienen nada más que la síntesis a través de la cual nos damos un objeto y producimos su concepto. En este sentido, la aplicación de categorías modales a fenómenos - como en el caso de la existencia efectiva - requiere siempre de la mediación de un esquema trascendental que sensibilice la categoría. En efecto, Kant define los esquemas como determinaciones trascendentales del tiempo [Zeitbestimmung], en cuanto forma general de todos los fenómenos (A139/B178). ${ }^{18}$

En consecuencia, para la aplicación de categorías modales a fenómenos de la experiencia resulta necesario que la sensación sea acogida en el tiempo en general (cualquiera: futuro o pasado), o bien en un tiempo determinado. En el caso de la categoría de existencia efectiva, su aplicación requiere necesariamente que la sensación sea acogida en un tiempo determinado. Esto quiere decir que para poder juzgar la existencia efectiva de un objeto, la imaginación trascendental debe ejecutar un particular tipo de síntesis a priori (síntesis speciosa) sobre el múltiple sucesivo de mis representaciones dado al sentido interno. Dicho de otra manera, la imaginación trascendental —en cuanto facultad mediadora entre sensibilidad y entendimiento - produce un esquema que le permite unificar el múltiple sensible de mis representaciones dadas al sentido interno y, así, volverlo compatible con la unidad de la apercepción. Así pues, la síntesis trascendental de la imaginación no se realiza al azar; por el contrario, se realiza siguiendo una regla precisa determinada en cada caso por la categoría. En este sentido, el esquema trascendental — orientado por la categoría - proporciona las instrucciones según las cuales ha de determinarse el tiempo, esto es, el múltiple de mis representaciones en el sentido interno.

Lo dicho con anterioridad supone, en primer lugar, que algo sea dado al sentido interno, el cual, de acuerdo con (B67), se constituye principalmente a partir de representaciones de objetos en el espacio. En segundo lugar, si la sensación provocada por el objeto —en la medida en que somos afectados por él- es acogida en un tiempo determinado, entonces, el objeto que me afecta es un objeto efectivamente existente. Esto quiere decir que su existencia no depende de mi pensamiento, ni del concepto que yo tenga de dicho objeto. En efecto, la existencia en un tiempo determinado (A1456/B184-5) es el esquema trascendental de la existencia efectiva, la que en cuanto categoría dinámica, no constituye una nota esencial del concepto de un objeto «[...] sino, la posición absoluta del objeto mismo, en cuanto independiente de su concepto y del pensamiento correspondiente, posición fundada en la sensación del objeto» (Rosales 2015: 324). Por esta razón, la existencia efectiva no puede ser nunca anticipada como querrían los racionalistas de cuño leibniziano. Si digo que un objeto es efectivamente real, entonces estoy diciendo que algo está puesto en un tiempo determinado, lo que supone que la sensibilidad haya acogido una cierta sensación y la imaginación trascendental haya determinado el sentido interno según una regla (la categoría de existencia efectiva).

En efecto, ya al final de la nota a B423, Kant señala: «[una categoría], como tal, no se refiere a un objeto dado de manera indeterminada, sino sólo a uno del que se tiene un concepto, y del que se quiere saber si fuera de ese concepto está puesto o no». En este sentido, continúa Kant:

${ }^{18}$ La Zeitbestimmung puede entenderse como ejercida en el tiempo o como si la determinación fuera ella misma temporal. Me parece que la determinación en cuanto actividad espontánea debe efectuarse siempre sobre un material sensible que, en este caso, lo proporciona el tiempo como forma pura de todos los fenómenos en general y, en este sentido, la determinación se efectúa en o sobre el tiempo y no en el trascurso o fluir del tiempo. Para un análisis detallado de la problemática vinculada al capítulo del Esquematismo trascendental, véase Moledo (2011) 
Una percepción indeterminada significa aquí algo real que ha sido dado, pero sólo [dado] al pensar en general, y por tanto, no [dado] como fenómeno, ni tampoco como sosa en sí misma (noumenon), sino como algo que efectivamente existe (als Etwas, was in der Tat existiert), ${ }^{19}$ y que es designado como tal en la proposición Yo pienso (B423).

Esto quiere decir que si lo que expresa la categoría de existencia efectiva (en cuanto categoría de modalidad) es la relación de un objeto de la experiencia con la facultad cognoscitiva (A219/B266), ya que su esquema «[contiene y hace representar] el tiempo mismo, como el correlato de la determinación de un objeto» (A145/B184), entonces lo que la 'intuición empírica indeterminada' de mi existencia pone de manifiesto es «[...] the setting of the subject as a necessary, albeit insufficient, condition of Knowledge» (Caimi 2014: 94).

Por consiguiente, puede sostenerse que la existencia a la que refiere la 'intuición empírica indeterminada' de mi existencia refiere a la posición relativa que ocupa mi propia existencia como sujeto pensante respecto de un genuino objeto de conocimiento, cuya existencia, en cambio, ocupa una posición absoluta. Dicho de otra manera, la existencia del sujeto pensante ocupa una posición que es siempre relativa a la posición absoluta ocupada por la existencia de un genuino objeto de conocimiento. En este sentido, la representación que puedo hacerme de la posición relativa que ocupa mi existencia en relación con la posición absoluta del objeto es de carácter meramente subjetivo, puesto que la sensación que tiene a su base no se encuentra determinada según una regla objetiva, esto es, según una categoría. No obstante, lo anterior no implica que deba considerar mi propia existencia como el producto de una mera ilusión (como habría pensado Pistorius). Por el contrario, me parece que lo que Kant quiere destacar es que el modo indeterminado en que el sentido interno es afectado por mi propia actividad sintética tiene como consecuencia una sensación también indeterminada de mi propia existencia. En este sentido, el 'yo pienso' de la apercepción pura tiene en su fundamento una existencia considerada como la existencia de algo que de hecho existe [als Etwas, was in der Tat existiert], aun cuando no pueda saber de qué modo debo determinar mi existencia en el tiempo.

Así pues, el análisis de las categorías de modalidad desarrollado en los Postulados permite esclarecer en qué sentido podemos juzgar la propia existencia como algo efectivamente real que precede a la experiencia. Debemos, pues, suponer (juzgar como hipotéticamente necesaria) la existencia efectiva del sujeto pensante en la medida en que es precisamente su propia actividad sintética la que afecta al sentido interno, provocando con ello una sensación indeterminada. En otras palabras, para orientarnos en el pensamiento debemos suponer tanto la existencia efectiva de un objeto de la experiencia, cuya representación es acogida en el sentido interno, como mi propia existencia efectiva en cuanto sujeto pensante. Esta última, como se ha intentado mostrar, no corresponde a la categoría modal de existencia efectiva, sino solo a la posición que como sujeto ocupo respecto de un objeto de la experiencia. De ahí que la relación con algo otro distinto de mí (un genuino objeto de conocimiento) como condición necesaria para la autoconciencia constituya un aspecto central de la teoría kantiana, puesto que pone en evidencia el carácter no-reflexivo del modelo kantiano de la autoconciencia (cf. Klemme 2016). Por cierto, distinto es el caso cuando caemos presa de una ilusión trascendental y nos consideramos a nosotros mismos como objetos de conocimiento, cuestión que, como Kant explica en el capítulo de los Paralogismos, es el producto de un error causado por una razón que no ha sido refrenada por la crítica.

${ }^{19}$ Los paréntesis aquí son míos. 


\section{Algunas consideraciones generales en torno a la presente interpretación}

A partir de las consideraciones precedentes es posible establecer que aun cuando la apercepción trascendental es caracterizada como un requerimiento formal necesario para la posibilidad de la experiencia en general, Kant advierte la necesidad de explicitar, en la segunda edición (B) de la $\mathrm{KrV}$, el particular tipo de autoconciencia supuesto en el principio de la unidad necesaria de la conciencia en la apercepción pura. Si aislamos la actividad determinante ejecutada por la apercepción trascendental o pura, entonces la estamos considerando como una mera condición formal de la experiencia de objetos, esto es, una mera función lógica del pensar en general. Sin embargo, si la consideramos en su efectividad ('yo existo pensando'), entonces esta ya no puede considerarse como una mera función lógica (B430).

Los pasajes analizados en este trabajo no consideran el 'yo pienso' de la apercepción pura como concepto problemático (meramente posible), sino en su efectividad o ejecución. Es en este sentido en el que Kant sostiene que el 'yo pienso' es una proposición empírica que contiene en sí la proposición 'yo existo'. Sin embargo, esta representación intelectual que contiene la determinabilidad de mi existencia con respecto a mis representaciones en el tiempo no me proporciona una intuición determinada de mi existencia (que me permita aplicar categorías), sino únicamente una intuición empírica indeterminada, i.e., la intuición indeterminada de algo que efectivamente existe (B423 N.).

Como se ha intentado mostrar, la clave de la cuestión radica en cómo hemos de interpretar esta 'intuición empírica indeterminada' a la que Kant refiere en su enigmática nota a los Paralogismos (B). En este contexto, me parece que lo que Kant quiere poner de manifiesto es que la intuición o percepción empírica indeterminada de nuestra existencia, y que se encuentra a la base de la apercepción pura, constituye la expresión de la necesaria referencia de la actividad del pensamiento a una percepción posible en general y, por tanto, a una receptividad que acoja dichas percepciones (el sentido interno). Así pues, es mi propia actividad sintética ejecutada sobre material dado al sentido interno (que en rigor se constituye a partir de representaciones espaciales, i.e. algo otro distinto de mí) la que tiene como consecuencia una sensación indeterminada de mi existencia como sujeto pensante. En otras palabras, la existencia a la que refiere la 'intuición empírica indeterminada' es la posición relativa que ocupa mi propia existencia respecto de la posición que ocupa la existencia de un genuino objeto de la experiencia.

Ahora bien, la representación intelectual que contiene la determinabilidad de mi existencia con respecto a la sucesión de mis representaciones en el tiempo (lo determinable en mí) no me proporciona una intuición determinada de mi existencia y, por tanto, no es suficiente para el conocimiento. Sin embargo, la particular relación que Kant establece entre apercepción pura y existencia en (B) se esclarece si la comprendemos a partir de la interconexión dinámica entre la materia y la forma del pensar. Esto se debe a que cuando se ejecuta la actividad del pensamiento, lo que ocurre es que ponemos el múltiple sucesivo del sentido interno bajo la unidad necesaria de la conciencia en la apercepción trascendental y, al hacerlo, tenemos una sensación indeterminada de nosotros mismos que no es todavía una conciencia empírica y tampoco una intuición intelectual. En este sentido, solo en la medida en que un genuino objeto de conocimiento (espacial) afecte a mi sensibilidad puede entonces ejecutarse la actividad sintética del pensamiento, que pone el múltiple dado al sentido interno bajo la unidad de la apercepción trascendental y cuya consecuencia es la sensación indeterminada de mi propia existencia.

Por último, resulta relevante señalar que el caso que nos convoca no constituye un caso de auto-conocimiento en ningún sentido, puesto que aquí la actividad del entendimiento no se dirige al sentido interno con el propósito de conocerse a sí mismo como sujeto determinante. Si este fuera el caso, estaríamos considerando (como el psicólogo racionalista) al 'yo pensante' como si fuera un genuino objeto de conocimiento, cuestión que Kant rechaza. De lo que se trata es más bien de que la 
actividad determinante del entendimiento — considerada en su efectividad — se dirige al múltiple del sentido interno sin una regla o categoría que oriente a la imaginación y que, por tanto, le permita determinar el múltiple de manera objetiva. Por esta razón la sensación indeterminada que tengo de mi existencia como sujeto pensante es previa a la experiencia, la que, por su parte, ha de poder ser determinada por medio de las categorías. De ahí que la existencia en cuestión no pueda identificarse con la categoría modal de existencia efectiva.

\section{Bibliografía}

Traducciones utilizadas de las obras de Kant

KANT, I.: Crítica de la razón pura, edición bilingüe, traducción, notas y estudio introductorio de Mario Caimi, México DF, Fondo de Cultura Económica, 2009.

: Prolegómenos a toda metafísica futura que haya de poder presentarse como ciencia, edición bilingüe, traducción de Mario Caimi, Madrid, Ediciones Istmo, 1999.

Bibliografía secundaria

AMERIKS, K.: Kant and the historical turn: Philosophy as critical investigation, Oxford, Oxford University Press, 2006.

ANDO, T.: Metaphysics. A Critical Survey of its Meaning, Dordrecht, Springer, 1974.

AQUILA, R.: "Self as Matter and Form: some reflections on Kant's view of the Soul", en KLEMME, D.; ZÖLLER, G. (eds.): Figuring the Self: subject, absolute, and others in classic German Philosophy, New York, State University of New York Press, 1997.

CAIMI, M.: “Kant's B Deduction”, Cambridge Scholars Publishing (2014) 94-99.

GRIER, M.: Kant's doctrine of transcendental illusion, Cambridge, Cambridge University Press, 2001.

HOWELL, R.: Kant's transcendental deduction: an analysis of main themes in his critical philosophy, Dordrecht/Boston/London, Kluwer Academic Publishers, 1992.

JÁUREGUI, C.: Sentido interno y subjetividad: Un análisis del problema del autoconocimiento en la filosofía trascendental de Kant, Buenos Aires, Prometeo Libros, 2008.

KLEMME, H.: “'El yo propiamente tal' (I. Kant) o el 'originario ser sí mismo' (D. Heinrich). Algunas características del concepto kantiano de autoconciencia", Revista de Estudios kantianos (2016) 113-125.

KUMAR, A.: "Transcendental Self and the Feeling of Existence", Con-Textos Kantianos. International Journal of Philosophy (2016) 90-121.

LONGUENESSE, B.: "Kant's 'I think' versus Descartes' 'I am a thing that thinks"”, en GARBER, D.; LONGUENESSE, B. (eds.): Kant and the Early Moderns, New Jersey, Princeton University Press, 2008

MELNICK, A.: Kant's Theory of the self, New York, Roudledge University, 2009.

MOLEDO, F.: "Función sistemática y naturaleza del esquematismo trascendental", Ágora: Papeles de Filosofía (2011) 163-185.

PATON, H. J.: "Book review: Studien zur Philosophie Immanuel Kants by Heinz Heimsoeth", The Philosophical Quarterly (1957) 380-381. 
ROSALES, A.: "La teoría de la apercepción en el capítulo de los paralogismos", en JÁUREGUI, C.; MOLEDO, F.; PRINGE, H.; THISED, M. (eds.): Crítica y Metafísica: Homenaje a Mario Caimi, Zürich/New York, Georg Olms Verlag Hildesheim, 2015.

SMITH, K.: A Commentary to Kant's Critique of Pure Reason, New York, Palgrave Macmillan, 2008.

THIEL, U.: "The critique of rational psychology", en BIRD, G. (eds.): A companion to Kant, Oxford, Willey Blackwell Publishing, 2006. 


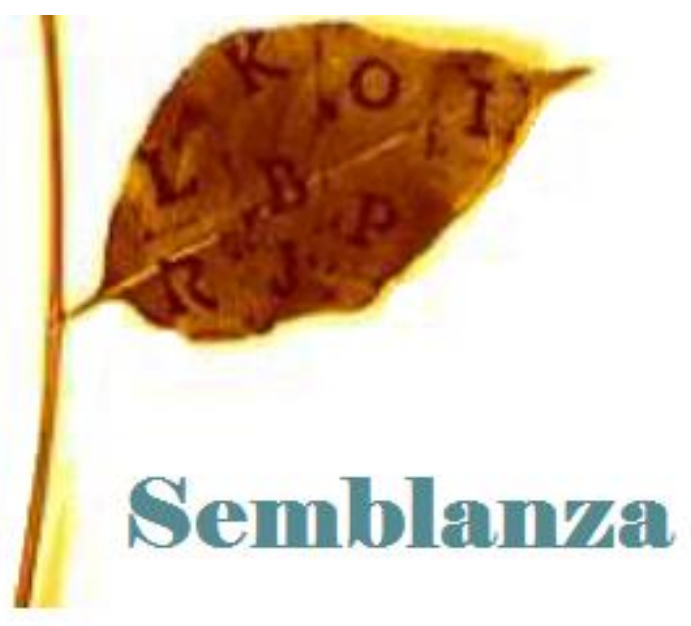




\title{
Jorge Eugenio Dotti in memoriam
}

\author{
ALBERTO MARIO DAMIANI ${ }^{1}$
}

El 21 de marzo de 2018 falleció en Chile el profesor Jorge Eugenio Dotti. El profesor Dotti llevó adelante una carrera prolífica y de excelente calidad a través de su desempeño como docente de grado y posgrado y como Investigador del CONICET, alcanzando el reconocimiento de la comunidad académica nacional e internacional. La profusa formación de recursos humanos realizada en el área de la filosofía política hace que lo recordemos con gratitud todos los que fuimos sus discípulos.

Quisiera comenzar esta semblanza mencionando algunos aspectos de su vasta trayectoria académica. El profesor Dotti estudió Filosofía en la Facultad de Filosofía y Letras de la Universidad de Buenos Aires (UBA) y en la Facoltà di Lettere e Filosofia de la Università degli Studi di Roma, donde se doctoró en 1975 con la tesis Logica e politica nella filosofia del diritto di Hegel, dirigida por Lucio Colletti. Fue miembro de la Carrera del Investigador Científico del Consejo Nacional de Investigaciones Científicas y Técnicas (CONICET) desde 1981, donde llegó a la categoría más alta de Investigador Superior.

Su carrera docente comenzó en la mencionada Facultad de Filosofía y Letras de la Universidad de Buenos Aires en 1975, donde se desempeñó como jefe de trabajos prácticos en las asignaturas de Filosofía Contemporánea, Gnoseología y Metafísica. A partir de 1980 fue Profesor Adjunto (interino) de Gnoseología y desde 1986 a 1993 Profesor Adjunto ordinario de la misma asignatura. De 1986 a 1988, fue Profesor Asociado interino de Filosofía Política. En 1988 fue nombrado Profesor Titular ordinario y desde 2008 trabajó como Profesor Titular plenario y luego como Profesor Consulto de Filosofía Política en la UBA. Asimismo, ha sido profesor en distintas universidades argentinas.

En el exterior se desempeñó como profesor invitado [Gastprofessor] en la Universidad Johannes Gutenberg de Mainz (1981), en la Universidade Federal do Rio Grande do Sul (1995), en la Universidad de Köln (1996, 2005-2006, 2011, 2014) y en la Universitat de Barcelona (2000). Al momento de su fallecimiento se estaba desempeñando como Profesor Invitado permanente en la Universidad Diego Portales de Chile. Sus investigaciones en el exterior fueron financiadas por el Servicio Alemán de Intercambio Académico (DAAD), la Friedrich Ebert Stiftung, la Universidade Federal do Rio Grande do Sul (Porto Alegre) y por el Programa René H. Thalmann de la Universidad de Buenos Aires.

Escribió los libros El mundo de Juan Jacobo Rousseau (Buenos Aires, 1980, 1991), Dialéctica y derecho. El proyecto ético-político hegeliano (Buenos Aires, 1983), Las vetas del texto. Una lectura filosófica de Alberdi, los positivistas, Juan B. Justo (Buenos Aires, 1990, 2011), La letra gótica: recepción de Kant en Argentina, desde el romanticismo hasta el treinta (Buenos Aires, 1992), Carl Schmitt en Argentina (Rosario, 2000) y alrededor de un centenar de artículos académicos, que vieron la luz en revistas y volúmenes colectivos nacionales e internacionales con referato. Además, publicó numerosos artículos de crítica cultural, reseñas, estudios críticos, presentaciones, obras de difusión y traducciones.

\footnotetext{
${ }^{1}$ Universidad de Buenos Aires, Facultad de Filosofía y Letras. Contacto: damial@ filo.uba.ar
} 
Sus publicaciones han tenido un alto impacto sobre la comunidad científica internacional, siendo comentadas y reseñadas en revistas especializadas de gran prestigio, tales como Revue philosophique de la France et de l'étranger, Concordia. Internationale Zeitschrift für Philosophie, Cuadernos Hispanoamericanos, Archives de Philosophie, Studi Kantiani, Kant-Studien, Revista Internacional de Filosofía Política, Behemoth y Res Publica. Asimismo, sus trabajos son citados, desde hace décadas, en numerosos artículos y libros locales e internacionales de su especialidad.

Desde 2001 fue Editor y Director de Deus Mortalis. Cuaderno de Filosofía Política, importante revista filosófica en la que algunos de sus discípulos seguimos trabajando. Fue miembro del Comitato Internazionale de la revista Filosofia politica (Bologna). Miembro del Consejo Científico Internacional de las revistas Anales de Historia de la Filosofía (Madrid) y Res Publica (Madrid). Miembro del Consejo Internacional de las revistas Problemata (UFPB, Brasil) y Tempo da Ciência. Revista de Ciencias Sociais e Humanas (Unioeste Paraná, Brasil) y de Signos Filosóficos (México). Miembro del Consejo Consultivo de las revistas Cuadernos Filosóficos (Universidad Nacional de Rosario), Revista de Ciencias Sociales (Universidad Nacional de Quilmes), Enfoques (UA, Entre Ríos). Miembro del Consejo Asesor y del Consejo de Redacción de la revista Punto de Vista (Buenos Aires). Desde 1985 hasta 2002, fue Miembro del Consejo de Redacción de la revista Espacios de crítica y producción, de la Facultad de Filosofía y Letras de la UBA.

Participó en más de ciento treinta eventos académicos, en muchos de ellos como invitado especial a cargo de conferencias, tanto en el ámbito nacional como internacional. Dirigió numerosos proyectos de investigación, en el marco de los cuales formó y dirigió a un gran número de becarios, tesistas de licenciatura, maestría y doctorado, así como a investigadores en el CONICET y en distintas universidades nacionales. Asimismo, llevó adelante una profusa tarea como evaluador de diferentes instituciones científicas nacionales e internacionales e integró jurados de tesis y de concursos docentes en diversas universidades. En nuestra facultad se desempeñó también como Director de la Sección de Estudios de Filosofía Política y Social del Instituto de Filosofía, como Miembro de la Comisión de Posdoctorado y como Director de la Maestría de Filosofía Política.

También fue miembro del Centro de Estudios Filosóficos de la Academia Nacional de Ciencias de la República Argentina, del Centro de Estudios Éticos de la Facultad de Filosofía y Letras de la UBA, de la Forschungsstelle für Ibero-amerikanische Philosophie de la Universidad de Köln, de la Asociación de Estudios Hobbesianos, de la Sociedade Hegel Brasileira, del Comité Científico de la Biblioteca Immanuel Kant (México) y del Grupo de Investigación y Discusión Filosófica Internacional (GIDFI), con sedes en México y Alemania.

Obtuvo el Premio Bernardo Houssay al Investigador Joven, CONICET (1987); el Premio Antorchas en Filosofía, Fundación Antorchas (1997); el Premio Fundación Konex en Ciencia Política (2006); la Distinción por Excelencia Académica, Universidad de Buenos Aires (2007); el Premio Fundación Konex en Ensayo Filosófico (2014); el Premio Konex de Platino (2014); la Distinción por Excelencia Académica, Universidad de Buenos Aires (2015), y el Premio Bernardo Houssay Trayectoria en Humanidades, Ministerio de Ciencia y Tecnología - CONICET (2016). En 2015 fue nombrado profesor Emérito de la Facultad Latinoamericana de Ciencias Sociales (FLACSO, Buenos Aires).

Sin pretensión de exhaustividad, menciono a continuación algunas de las importantes contribuciones del profesor Dotti a la Kant-Forschung: "Quid iuris und quid facti", Akten des Internationalen Kant-Kongress (Bonn, 1981); "El tiempo en Kant: de la Disertación a la Crítica", Escritos de Filosofía 2 (1984); "Kant: crítica y modernidad", Punto de Vista 23 (1985); "La distinción kantiana entre juicios de percepción y de experiencia: problemas y sugestiones”, Diálogos 51, 2 (1988); "Die Einwürfe der "einsehenden Männer", Proceedings of the Sixth International Kant Congress (Washington, 1989); "El juicio como apriori epistemológico", Revista Latinoamericana de 
Filosofía 16, 3 (1990); "La libertad del Juicio: epistemología y política a la luz de la tercera Crítica", Filosofía, política y estética en la Crítica del Juicio de Kant (Lima, 1990); "Das Signifikanzaprinzip und die Unterscheidung zwischen Denken und Erkennen in der Deduktion der Kategorien", Die goldene Regel der Kritik. Festschrift für Hans Radermacher (Frankfurt, 1990); "El Opus Postumum de Kant en la lectura de Vittorio Mathieu", Cuadernos de Ética 9 (1990); "Die epistemologische Freiheit”, Akten des Internationalen Kant-Kongress (Bonn-Berlín, 1991); “Acción, decisión y espacio público: Kant y Hannah Arendt", Racionalidade e Ação. Antecedes e evolução atual da Filosofía Prática Alemá (Porto Alegre 1992); "Hannah Arendt y la Crítica del Juicio", Homenaje a Kant (Buenos Aires, 1993); "Buchsprechung: María D. Granja Castro, Kant: de la crítica a la filosofía de la Religión”, Kant-Studien 90, 2 (1999); “Observaciones sobre Kant y el liberalismo”, Araucaria 7, 13 (2005).

El profesor Dotti también tradujo textos de Kant al español, por ejemplo, Deducción trascendental de las categorías. Versión de 1781. Dos cartas a Markus Herz (Buenos Aires, 1996) y "Respuesta a la pregunta: ¿Qué es el iluminismo?”, Espacios (1986). Asimismo, publicó algunos trabajos sobre la recepción de Kant en la cultura argentina, por ejemplo: "La recepción de Kant en la Argentina (1837-1930)”, Anuario de Filosofía Jurídica y Social 4 (1984); Realismo fantastico. Gioco di specchi su Swedenborg, Kant, Borges (Nápoles, 1986); "Die Anfänge der Kantrezeption in Argentinien", Kant in der Hispanidad (Frankfurt, 1986); "La figura de Kant en las ideas argentinas del siglo XIX", Ethik in Deutschland und Lateinamerika heute (Frankfurt, 1987) y el libro ya mencionado: La letra gótica: recepción de Kant en Argentina, desde el romanticismo hasta el treinta (Buenos Aires, 1992).

Quienes tuvimos la suerte de conocerlo como profesor y colega lo recordaremos siempre como un modelo a imitar, por varios motivos. El primero es la pasión por el pensamiento filosófico, que trasmitía en sus clases y en sus textos. Esa pasión venía siempre canalizada en un cauce de rigurosidad argumentativa y de un cuidado estilo expresivo. La defensa de sus ideas carecía de fisuras; pero no avasallaba al interlocutor con sus posiciones, sino que siempre dejaba un lugar para que el oponente presentara sus objeciones y réplicas. En segundo lugar, era un pluralista consumado, tanto en la dirección de su cátedra como en la de los grupos de investigación, así como en la selección de los tesistas y becarios que orientaba. Nunca le impuso sus convicciones a ningún discípulo. Quienes lo rodeábamos cultivamos tradiciones de pensamiento muy distintas, pero todos aprendíamos de él a ser docentes e investigadores. No era una convivencia pacífica, ni un desinterés ecléctico, ni un diálogo inofensivo lo que orientaba su pluralismo académico. Lo animaba, en cambio, la convicción profunda de que solo mediante la confrontación abierta de argumentos rigurosos se puede producir algo valioso en filosofía. Por último, su sentido del humor, inteligente y discreto, que le servía, según me confesó una vez, como un secreto criterio de selección de sus interlocutores.

Se tomaba muy en serio su profesión, tal como lo atestigua en una nota publicada hace algunos años bajo el título " OObra como si el formulario para tu proyecto pudiera valer cual ley universal!", Cuadernos filosóficos 1 (2014). En defensa del rigor y de la responsabilidad de quien se dedica al estudio de una disciplina filosófica, alertaba en esa nota contra tres peligros que es necesario evitar a toda costa: el disciplinamiento cientificista, el acartonamiento academicista y la banalidad diletante. Sin duda, contra esos peligros nos protegió su magisterio a todos los que nos sentimos en deuda con su trabajo. 


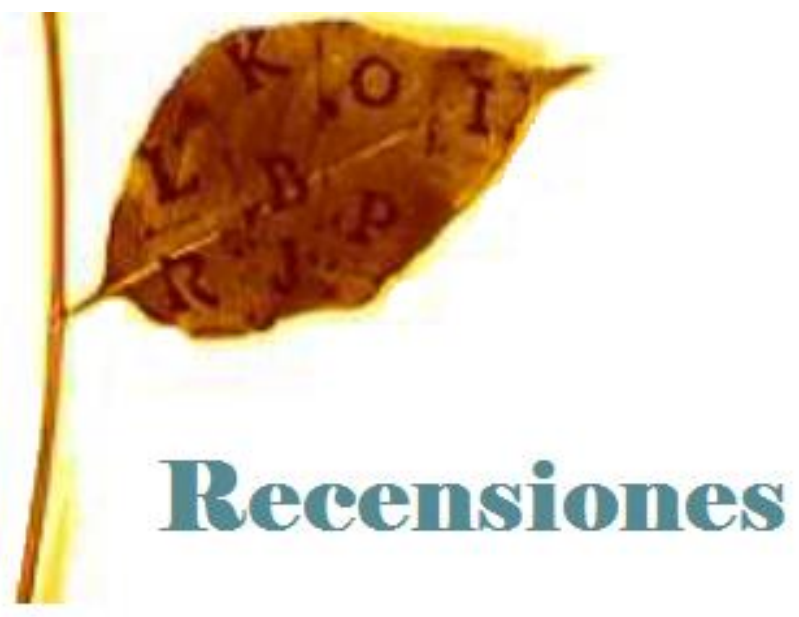




\title{
Miguel Alejandro Herszenbaun: La antinomia de la razón pura en Kant y Hegel. Madrid, Alamanda, 2018, 603 pp. ISBN: 978-84-940-241-9-1.
}

\author{
AGEMIR BAVARESCO
}

O livro de Miguel Alejandro Herszenbaun é uma pesquisa minuciosa e sistemática sobre um tema relevante do idealismo alemão, isto é, a legitimidade epistemológica do uso da razão conforme é tratada pela Crítica da Razão Pura kantiana. O autor trata da antinomia da razão de Kant e da recepção que Hegel fez das antinomias para critica-las e reconstruí-las numa dimensão dialéticoespeculativa. A pesquisa de Herszenbaun limita-se ao estudo das antinomias matemáticas. Ele contextualiza o tema no momento atual, classificando a bibliografia segundo dois enfoques: o histórico e o sistemático.

A antinomia da razão pura é estudada por Hegel em várias de suas obras, porém, é na Ciência da Lógica que aparece o estudo mais profundo. Para o autor trata-se de uma abordagem geral e integral. A abordagem geral é considerada externa, isto é, a partir de fora da filosofia kantiana, enquanto que a abordagem integral faz um estudo das antinomias matemáticas.

A pesquisa tem dois objetivos: primeiramente, fazer um estudo sistemático da antinomia da razão pura como é apresentada por Kant na Crítica da Razão Pura explicitando os elementos lógicotranscendentais; em segundo lugar, apresentar a interpretação hegeliana da antinomia kantiana a partir da Ciência da Lógica, Enciclopédia das ciências filosóficas e as Lições da história da filosofia.

O livro é composto de quatro capítulos. Os capítulos 1, 2 e 3 apresentam uma leitura sistemática da antinomia da razão pura. O capítulo 1: "A dialética transcendental e a antinomia da razão pura" (44) trata da formação da antinomia da razão pura. Aqui é descrita a "dialética transcendental" e a faculdade da razão pura, a ilusão transcendental e a solução para eliminar a sua contradição.

No capítulo 2: "A primeira antinomia da razão pura" (241) e no capítulo 3: "A segunda antinomia da razão pura (350), o autor analisa cada uma das provas e o estudo das categorias para a formação das ideias cosmológicas.

O autor abordará apenas as antinomias matemáticas, pois, são estas que Hegel trabalha detalhadamente na Doutrina do Ser, elaborando uma crítica interna das provas e propondo uma reelaboração dialético-especulativa das mesmas. Por isso, «sólo con respecto a éstas podemos ver el desarrollo íntegro de la estrategia de apropiación que Hegel impulsa» (43).

O capítulo 4 “A apropriação hegeliana da antinomia da razão pura” (464) apresenta, especificamente, a leitura hegeliana da antinomia kantiana na Ciência da Lógica. Aqui o autor apresenta «las dos estratégias de abordaje que Hegel implementa para interpretar y criticar la antinomia kantiana (una crítica interna combinada con una crítica externa)» (43). Depois deste capítulo o livro tem um Epílogo "Algumas conclusões e uma proposta de futuras linhas de investigação" (578), em que se pode encontrar um resumo das principais conclusões da pesquisa e desafios para o futuro.

\footnotetext{
${ }^{1}$ Pontifícia Universidade Católica do Rio Grande do Sul (PUCRS). Contacto: abavaresco@ pucrs.br
} 
O autor faz uma pesquisa exaustiva sobre a antinomia kantiana, reconstruindo as teses kantianas e relacionando-as com a crítica hegeliana. O livro tem o mérito de apresentar o debate atual sobre o tema e o autor sabe tomar posição em meio a esse contexto.

Segundo nossa opinião, cabe lembrar que para Hegel a lógica que apresenta a verdadeira natureza das coisas é a lógica da contradição. Uma das críticas de Hegel é o não reconhecimento do aspecto ontológico das antinomias por Kant, que ficou no resultado negativo do caráter incognoscível do em-si das coisas e não penetrou no conhecimento da significação verdadeira e positiva das antinomias. Hegel rejeita o caráter meramente subjetivo que Kant aplica à dialética, pois toma a contradição como algo que ocorre no âmbito do sujeito que pretende conhecer a totalidade e o incondicionado, e não na própria realidade.

Para Hegel a antinomia é encontrada em todos os tipos de objetos, em toda e qualquer representação, conceito e ideia, pois não há nada em lugar nenhum em que a contradição, isto é, a determinação oposta, não possa e não deva ser exposta. O idealismo transcendental de Kant deixa subsistir a contradição, sob a compreensão de que a contradição não é a essência objetiva das coisas, atribuindo as antinomias à subjetividade e não à realidade mesma. Assim, a contradição não é resolvida, ela subsiste depois como antes. Hegel reconstrói, porém, o princípio de não-contradição, pensando a contradição como imanente a todo movimento lógico-ontológico. 


\title{
Adela Cortina: Aporofobia, el rechazo al pobre. Un desafío para la democracia. Barcelona, Paidós, 2017, 196 pp. ISBN: 978-84-493-3338-5.
}

\author{
PEDRO JESÚS TERUEL ${ }^{1}$
}

Kant acababa de publicar la Fundamentación de la metafísica de las costumbres (1785) cuando Mozart comenzaba a componer Las bodas de Fígaro. La ópera concluye con una escena en la que los protagonistas, enzarzados en equívocos y desamores a lo largo de la trama, desatan el nudo por medio del arte más difícil y humano: el perdón. El sevillano conde de Almaviva pide perdón a su esposa Rosina por las veleidades con que la ha herido; ella le perdona. Refiriéndose, en la memorable fantasía teatral de Peter Shaffer, a esa escena, Salieri evoca cómo entonces, sobre la audiencia que asistía a la representación en el teatro, se derramó una completa absolución, una reconciliación perfecta.

La obra que nos ocupa trata, justamente, de las condiciones que posibilitan la reconciliación. No solo entre individuos, sino también en el seno de las sociedades y frente a un conflicto que no por invisible resulta menos real. Su invisibilidad da pie a uno de los aciertos del volumen, por el que sin duda será recordado: nombrar para rescatar del olvido. El neologismo 'aporofobia', que Cortina acuñó en 1995 en un artículo en El país, está construido a partir del griego siguiendo un patrón clásico (de Áporo7, 'pobre' y fobéw, 'infundir miedo o temor'). Da cabida a diversas manifestaciones de un fenómeno subyacente, a saber: el rechazo a aquéllos que, aparentemente, no están en condiciones de aportar nada en la lógica del beneficio mutuo. A esta categoría pertenecen no solo los pobres — noción que cobija realidades heterogéneas, cuya identificación depende de parámetros relativos - sino también, entre otros, los extranjeros e inmigrantes.

Hay en el volumen dos operaciones intelectuales que desbrozan el camino a su vertiente propositiva. La primera se ubica en el marco de la argumentación antropológica, cultural, sociológica y económica. Desde este punto de vista se muestra cómo la aporofobia se halla enraizada no solo en la lógica del consumo propia de las sociedades neocapitalistas sino en la evolución misma del cerebro humano. También desde aquí se exponen las razones que llevan a afirmar cómo, a diferencia de lo que se supone, el pobre tiene mucho que aportar al entramado de beneficios mutuos que vertebran una sociedad; el fomento de la igualdad constituye, desde la perspectiva económica, un poderoso factor de estabilidad y progreso. En todo ello, la autora navega con pericia por diversos ámbitos y exhibe un sólido conocimiento de la actualidad mundial.

La segunda operación intelectual a la que me refería tiene que ver con la transición al orden, propiamente filosófico, de la argumentación ética. En esta encrucijada, Kant juega un papel decisivo. La exhortación a ayudar al pobre —en las múltiples figuras que éste adopta: el hambriento, el extranjero, el perseguido - atraviesa como una admonición profética la historia de la cultura, desde la mentalidad griega y romana, pasando por las categorías bíblicas, hasta llegar al Renacimiento. Es más: se podría decir — argumenta Cortina — que enlaza con pautas filogenéticas muy anteriores y que somos, hemos sido siempre, homo oeconomicus y homo reciprocans al mismo tiempo. Ahora bien: que, más allá del compromiso individual, la cura hacia los necesitados haya de ser adoptada por las instituciones constituye una ganancia relativamente reciente.

${ }^{1}$ Universitat de València. Contacto: pedro.teruel@uv.es 
Fue el valenciano Luis Vives quien llamó la atención sobre esta vertiente de la cura. Lo hizo en un tratado seminal: De subventione pauperum (1526). Iniciaba así un movimiento que, pasando por la primera Ilustración, conduciría a los avances de la segunda mitad del siglo XX y a un proyecto ambicioso y radical, planteado en 2015 por Naciones Unidas como primero de los Objetivos del Desarrollo Sostenible: erradicar la pobreza.

La transición del punto de vista individual al institucional lleva aparejado el paso de la noción de deber a la de derecho: hay un derecho a empoderarse en orden a poder realizar los proyectos que se tenga razones para valorar. Cortina argumenta esa transición remitiéndose —more hegeliano - a la co-pertenencia constitutiva: somos en un diálogo, que fundamenta la alianza previa a todo contrato social. Que tal diálogo entrañe derechos, cuya fuerza haya de substanciarse en instituciones, se sigue de un principio que vertebra el volumen: el ser humano tiene dignidad y no solo precio. La formulación del imperativo categórico que vincula Humanidad y fin (AA 04: 429, 1012) hace las veces de interfaz que conecta la lógica de la alianza con su traducción a propuestas de acción política. Desgranadas entre las páginas 141 y 148, esas propuestas constituyen el precipitado de una argumentación que en varios sentidos brota de la filosofía práctica de Kant.

Decía Voltaire, en carta a D'Alembert de 1766, que no se puede hacer una revolución con libros largos. Podemos imaginarnos que un razonamiento similar subyace a este volumen. Aspectos como la fundamentación filosófica de la compasión, que ocupa un lugar central pero no desarrollado, dejan a quien lee con ganas de saber más. En este sentido vale la pena abordar este libro como pieza de un vasto proyecto intelectual.

Hoy catedrática emérita del departamento de Filosofía de la Universidad de Valencia, Adela Cortina ha desplegado un itinerario arraigado en su interés por la filosofía kantiana: fue en 1976 que defendió su Tesis doctoral, publicada bajo el título Dios en la filosofía trascendental de Kant (1981). Sus inquietudes en el ámbito de la filosofía práctica — ligadas a sus trabajos con Karl-Otto Apel— le llevaron a abordar los desafíos que caracterizan la configuración de las sociedades democráticas. En esta estela se sitúan obras como Ética mínima (1986), Alianza y contrato (2001) o Ética de la razón cordial (2007). Recientemente, y junto con Jesús Conill, ha dirigido una serie de proyectos de investigación, financiados por el Ministerio de Economía y Competitividad del Gobierno de España, relacionados con la neurofilosofía práctica. Tales intereses, solo aparentemente centrífugos, confluyen en la presente obra.

Aporofobia. El rechazo al pobre ha recibido una acogida entusiasta. A la inclusión del término en el Diccionario de la Real Academia Española han seguido numerosos galardones: desde la elección como "palabra del año" por la Fundación del Español Urgente hasta el premio de la Crítica Literaria valenciana. Todo ello testimonia una conciencia creciente y que los tiempos, en su paulatina modificación de la mirada hacia la pobreza, maduran poco a poco para una revolución solidaria. Contribuir a ella es el gran mérito de este libro. Y es que trabajar por un horizonte de reconocimiento mutuo constituye uno de los mayores servicios que se le puede prestar a la Humanidad: es un ejercicio de reconciliación. 


\section{Francesco V. Tomassi (comp.): Der Zyklop in der Wissenschaft. Kant und die anthopologia transcendentalis, Archiv für Begriffsgeschichte, 14. Hamburgo, Félix Meiner Verlag, 2018, 207 pp. ISBN: 978-3-7873-3427-8.}

\section{LUCIANA MARTÍNEZ}

El libro que aquí se reseña es una compilación de artículos dedicados a estudiar el contenido de la reflexión 903, que se encuentra publicada en AA 15: 394s. Adickes consideró que esta anotación fue escrita entre 1776 y 1778. En ella se presentan dos nociones que son analizadas en los artículos incluidos en el libro aquí reseñado. Esas nociones son: i) la del científico como cíclope, ii) la de la antropología transcendental. El científico-cíclope es aquel que tiene la mirada puesta solamente en el objeto de su ciencia, sin atender críticamente a la índole de sus facultades de conocimiento. Asimismo, esa mirada unitaria parece estar vinculada al aislamiento, es decir, al egoísmo científico. A aquel autoconocimiento del intelecto parece estar referida, por su parte, la antropología transcendental.

El primer capítulo, escrito por Francesco Tomassi, se titula "Die anthropologia transcendentalis. Das Rätsel eines kantischen Paradoxons”. En primer lugar, el autor establece, centrándose en las fuentes pero recorriendo también la literatura sobre el tema, el carácter empírico de la antropología kantiana. Sin embargo, en una reflexión, la R903, Kant se refiere a la "antropología transcendental". Aunque Tomassi reconozca que este término aparece una sola vez en el corpus kantiano, advierte empero que parece tener un contenido significativo importante. El capítulo de Tomassi procura exhibir los motivos de la relevancia de la reflexión para los estudios kantianos. Constituye un estudio detallado de aquella expresión y de la reflexión en la que aparece, que se demora en el significado de los términos, recorre las fuentes e indaga en aspectos de interés, tales como la datación de la anotación y el sentido que, de acuerdo con ella, pueda tener el término "transcendental".

El segundo capítulo, de Norbert Hinske, se titula "Gibt es bei Kant eine tranzscendentale Anthropologie?". En este capítulo se presenta otra interpretación histórica de esa reflexión. En primer lugar, Hinske recuerda que el legado de Kant contiene una antropología pragmática, pero no una antropología transcendental. Luego, explica la diferencia entre la antropología pragmática y la moral, considerando que ambas disciplinas eran enseñadas por Kant en la universidad. En la segunda sección de su capítulo, Hinske se demora en la datación de la reflexión e inscribe la noción de una "antropología transcendental" en el contexto de la emergencia de una nueva concepción de la filosofía, que es la del proyecto crítico.

"Kant's Anthropology: (Mostly) Empirical Not Transcendental" es la contribución de Robert Louden. Este autor considera que Kant no ha desarrollado una antropología transcendental y que, antes bien, la antropología kantiana puede ser interpretada como un conjunto de observaciones sobre la vida cotidiana. Su argumentación incluye un recorrido minucioso de las fuentes, que muestra que esa disciplina se caracteriza principal, si bien no únicamente, como empírica. Y Louden señala que una ciencia empírica no puede ser transcendental. El autor, de hecho, analiza también el uso del término "transcendental" a lo largo del corpus kantiano, y muestra que ese término se opone constantemente a lo empírico. Además, estudia los textos kantianos de filosofía transcendental y

${ }^{1}$ CONICET, UNR, UBA. Contacto: luciana.mtnz@ gmail.com 
muestra que en ellos no hay una antropología, en la medida en que la investigación transcendental trasciende el ámbito de la experiencia meramente humana. Por último, Lauden se ocupa de la pregunta "¿Qué es el hombre?” y muestra que la filosofía involucra una investigación que es más amplia que ella. A la luz de tales investigaciones, el autor ofrece un comentario de R903 que no concede el desarrollo de una antropología transcendental, sino que inscribe la investigación antropológica en el seno de una filosofía mundana, que no es de índole transcendental.

El artículo de Anselmo Aportone, "Von der anthropologia transscendentalis zur >formalen Anthropologie‘ der Kritik", exhibe un análisis de R903 en el marco de una interpretación sistemática del proyecto crítico. Su propuesta involucra una consideración de este proyecto como una forma de autoconocimiento formal, no empírico, del hombre. En este sentido, según él, la filosofía transcendental puede ser considerada como una antropología formal. Ciertamente, el término "antropología transcendental", presente en la mentada reflexión, parece involucrar un oxímoron. Sin embargo, este carácter empírico de los contenidos de esta disciplina no torna inconcebible una investigación formal del hombre.

El artículo de Clemens Schwaiger se titula "Kants Antiegoismus. Wurzeln und Motive". En esta contribución se analiza la doctrina del egoísmo. En primer término, el autor se demora en la recepción kantiana de las doctrinas de Wolff y de Meier. Luego, analiza las fuentes sobre antropología y, especialmente, la R903. En esta reflexión se analiza y se objeta un tipo de egoísmo que no ha recibido tanta atención y que Schwaiger describe en detalle: el egoísmo de la ciencia.

El capítulo escrito por Jean-François Goubet tiene como título "Der wunderliche Zyklop des Professor Kant. Technische Bildung, Schranken der Erkenntnis und Sinn für Perspektive beim Gelehrten". En él, encontramos una exégesis de las fuentes que procura exhibir la génesis de la figura monstruosa del cíclope y el significado que tiene para Kant. El autor investiga el tratamiento del cíclope en la literatura previa y analiza la selección de rasgos que caracterizan el uso de ella en la argumentación kantiana.

El texto de Alexei N. Krouglov se titula “Tetens' Lehre von der menschlichen Natur als positives und negatives Beispiel für die Anthropologie Kants". La propuesta de este autor consiste en considerar los vínculos posibles entre la R903, datada por Adickes entre 1776 y 1778, y el texto Philosophische Versuche über die menschliche Natur und ihre Entwicklung, publicado por Tetens en 1777. Krouglov analiza el libro de Tetens y procura algunos indicios acerca de la naturaleza de la "antropología transcendental" que se menciona en la reflexión estudiada.

El texto "Kants Anthropologie in Spiegelung und Gegenspiegelung bei Karl Heinrich Ludwig Pölitz. Die Umformung der kritischen Philosophie zum tranzscendentalen Idealismus auf dem Weg ihrer Aneignung" es la contribución de Christoph Böhr. Este autor comenta la vida intelectual de Pölitz y su contribución para el legado kantiano. El capítulo incluye un análisis del pensamiento de Pölitz y de la incidencia de ese pensamiento en la recepción y la trasmisión de las enseñanzas de Kant.

Gualtiero Lorini escribió "Anthropologie und empirische Psychologie bei Kant: Diskontinuität oder Entwicklung?". En este artículo se analizan las relaciones entre antropología, psicología empírica, metafísica y lógica, de acuerdo con las fuentes kantianas. A partir del análisis de esas relaciones, Lorini investiga qué puede ser y cuáles son las características de una antropología transcendental.

La contribución de Nuria Sánchez Madrid se titula "Anthropologia transcendentalis: die Selbstkenntnis der Vernunft und die antinomische Grundlage der Reflexion bei Kant". El punto de partida de la autora es la imagen del cíclope y su significado en relación con el concepto de la antropología transcendental. Para ella, a un científico-cíclope se contrapone el sujeto reflexionante. 
Por esta razón, la autora analiza la noción crítica de la reflexión. En este capítulo se analiza, en otras palabras, el significado que puede tener una antropología transcendental en el contexto de la filosofía transcendental kantiana. Para la autora, esa antropología se diferencia de la antropología pragmática e involucra aspectos emocionales de la investigación de nuestras facultades.

El capítulo de Marianinna Failla se titula "Das Wohlwollen bei Kant. Zu einer neuen Anthropologie". En este texto se propone una interpretación en clave práctica de la metáfora del cíclope y una revisión del egoísmo de la acción. Frente a este egoísmo se presenta la doctrina de la benevolencia. La autora recorre esta doctrina e identifica en ella una estructura de tres momentos. Su investigación conduce a una concepción antropológica de una sociedad solidaria, que es compatible con la filosofía práctica de Kant.

El capítulo de Ricardo Pozzo se titula “The Nature of Kant's Anthropology Lectures in Königsberg Fifteen Years Later”. Este texto constituye una introducción interesante para el estudio de las lecciones de antropología. En primer término, Pozzo presenta las ideas principales que se discuten en la literatura sobre estas lecciones. Luego, especifica el estatus, que el autor denomina "no científico", de ellas en la Universidad de Königsberg. Por último, examina la noción que Kant tenía de la antropología y la relación entre aquella y la filosofía transcendental.

El capítulo de Mirella Capozzi, "The Relevance of Anthropology for Kant's Logic", distingue dos periodos en el tratamiento de las relaciones entre la psicología empírica/antropología y la lógica. En el periodo precrítico aquella ciencia es fundamental para la lógica. En el periodo crítico, en cambio, Kant separa la psicología de la lógica y señala que solo la lógica aplicada necesita la psicología. La tesis de Capozzi, empero, es que ciertos contenidos de la antropología son relevantes en la investigación lógica. A lo largo del artículo encontramos un tratamiento minucioso de las anotaciones de la lógica kantiana, por medio del cual Capozzi exhibe las relaciones entre las dos ciencias. Las indicaciones precríticas indican una fundación de la investigación lógica en la mente del sujeto que piensa. Ya con la emergencia del criticismo, en cambio, buscar las leyes lógicas en la naturaleza de la mente se presenta como un error procedimental. La lógica proporciona un hilo conductor para la metafísica futura. Ella misma no puede, pues, apoyarse en la metafísica disponible, o en una ciencia empírica como la psicología. Sin embargo, la investigación antropológica proporciona conocimientos útiles para la lógica que el artículo de Capozzi reseña.

Por último, el capítulo escrito por Irene Kajon se titula "From anthropologia transcendentalis to the Question on the Transcendental. Thinking of God in Kant's Opus Postumum". Este capítulo tiene cuatro secciones. En la primera la autora analiza el significado de "antropología transcendental" en el contexto de R903. Luego, estudia la noción de "transcendental" y su relación con la antropología. En tercer término, se ocupa de la relación entre la antropología y el pensamiento religioso de aquello que obstaculiza la civilización y los procesos morales. Por último, se demora en el tratamiento de este tema en el Opus Postumum.

La variedad de temas tratados en estos capítulos da cuenta de la interconexión sistemática de los contenidos de la filosofía kantiana, por un lado, y de la riqueza que puede alcanzar la investigación de esa filosofía, por el otro. Diversos en sus contenidos, todos ellos proporcionan investigaciones valiosas, rigurosas y precisas. El libro, centrado en una anotación marginal precrítica, se presenta como una fuente ineludible para los investigadores de la filosofía de Immanuel Kant. 


\title{
Roberto Rodríguez Aramayo: Kant entre la Moral y la Política. Madrid, Alianza, 2018, 309 pp. ISBN: 978-84-9181-309-5.
}

\author{
ALBA M. JIMÉNEZ RODRÍGUEZ ${ }^{1}$
}

Los más recientes rumbos de la Kant-Forschung parecen apuntar al hecho de que la filosofía kantiana, como la Tebas de cien puertas, abre innumerables flancos de su andamiaje conceptual tanto práctico como teórico a una interpretación estrictamente política. Bajo esa intuición, Kant: entre la moral y la política ofrece un recorrido exhaustivo por los principales loci de la filosofía práctica de Kant y un diálogo fértil y novedoso entre algunas de sus tesis sobre ciertas formas y estructuras de raíz política y el pensamiento de autores como Platón, Spinoza, Rousseau o Diderot.

Platón, a pesar su concepción del rey filósofo, tan poco propicia al contenido de ese fragmento de Hacia la Paz Perpetua conocido como el "Artículo Secreto", nos habla — de modo más afín al vocabulario kantiano- de "ideas", las cuales funcionan como arquetipos para la razón práctica; Spinoza aparece en escena como héroe moral; Rousseau como aquel que despierta a Kant del sueño apolítico y Diderot como el responsable de su concepción global de la política. Partiendo de este recorrido, el autor enfrenta los problemas prácticos kantianos más relevantes a las exigencias de nuestra época previniendo convenientemente contra los abusos, excesos, distorsiones y peticiones de cuenta ilegítimas a las que la filosofía de Kant se ha visto sometida no pocas veces. El libro está estructurado en dos partes fundamentales. En la primera se abordan las principales tesis de la filosofía kantiana bajo dos presupuestos que funcionan como hilo conductor de todo el trabajo: el primado de la razón práctica y la aceptación de la existencia de una filosofía política en Kant, inexorablemente vinculada a su filosofía moral e independiente de la filosofía de la historia, de la filosofía de la religión o de la filosofía del derecho. En efecto, una de las tesis fuertes del libro consiste en afirmar, en la línea de autoras como Onora O’Oneill, la existencia de una filosofía política en Kant que se presenta incluso como condición de posibilidad de una realización plena de la dimensión moral. En la segunda parte los problemas prácticos abordados se tornan en herramienta para proyectar una ontología crítica del presente en diálogo con algunos de los representantes de la Ilustración cuyos planteamientos tuvieron una repercusión más directa en el pensamiento kantiano. A lo largo de todo el libro late una clara preocupación por dilucidar las relaciones entre religión, filosofía de la historia y moral. La posición del autor al respecto se condensa en la idea de que la ética kantiana precisa de su conexión con una historia filosófica si no quiere quedar ciega, tal como las intuiciones que no son subsumidas bajo conceptos y, simultáneamente, la filosofía de la historia requiere la presuposición de una Anwendung, nunca cumplida por completo, que se extendería asintóticamente orientada por la idea regulativa del Bien Supremo.

Los temas abordados son innumerables: la posibilidad de una interpretación utilitarista espuria del imperativo kantiano; la lectura kantiana de la Revolución Francesa; la mentira como problema moral; la crítica al eudemonismo; el papel del sentimiento como Triebfedern de las acciones; Dios como razón práctica legisladora o hipótesis heurística de la explicación mecánica de los fenómenos; la genealogía de la felicidad; la diferencia entre imperativos morales y consilia; la oposición entre libertad y causalidad; la idea de imputación; la crítica a los estoicos o la noción de

\footnotetext{
${ }^{1}$ Universidad Complutense de Madrid. Contacto: albjim04@ucm.es
} 
insociable sociabilidad, en la que el autor reconoce un claro precedente en el concepto de mano invisible de Adam Smith.

Como cabe esperar de un autor con una dilatada experiencia en el ámbito de la investigación sobre Kant, el libro puede resultar de gran interés para especialistas en la filosofía kantiana en la medida en que se proponen algunas tesis fuertes sobre ciertos tópicos de su filosofía moral y se trazan puentes con ciertas claves secretas de su diseño práctico. Quizás sorprenda más al lector que este trabajo puede resultar, seguramente sin pretenderlo, un perfecto manual para cualquier estudiante de Grado o Postgrado que quiera conocer con rigor los pilares de la filosofía práctica kantiana. Por lo demás, su extrema claridad y su redacción directa permitirían también a un lector no familiarizado con la literatura kantiana especializada acceder al núcleo de los grandes nudos de la filosofía de Kant.

El libro pone de relevancia la importancia que la figura del contrato social rousseauniana adopta en la filosofía kantiana. En efecto, su filosofía práctica difícilmente puede entenderse sin su peculiar corrección del contractualismo clásico, el cual había desplegado una interpretación de sí mismo en clave utilitarista. El postulado del derecho público kantiano que obliga a pasar del estado de naturaleza al estado civil se construye sobre una noción del contrato que, a diferencia de todos los anteriores, no depende de ninguna justificación empírica, sino que representa la condición para la deducción apagójica del estado civil. Pactum societatis, por tanto, entendido como fin en sí mismo. Asimismo, el autor reconoce en el eudemonismo, o en el papel desempeñado por la fe en la filosofía moral, otros tantos puntos de encuentro entre ambos filósofos. La lectura de Rousseau propiciará el giro del discípulo de Martin Knutzen, preocupado fundamentalmente por los meandros naturales del cielo estrellado, al Kant de la ley moral y la teoría de la sociedad.

Una de las características más notables de la presente obra consiste en que permite superar algunos prejuicios muy arraigados sobre la filosofía moral de Kant como la acusación de rigorismo o la crítica extendida por Schopenhauer, según la cual la concepción del sumo bien acabaría por incluir subrepticiamente una justificación teológica de la ética. La atención a la interpretación schopenhaueriana de Kant, a la que no siempre se ha hecho justicia, es otro de los aciertos del libro. En efecto, a nuestro juicio, una relectura atenta de Die beiden Grundprobleme der Ethik podría resultar de gran utilidad para analizar una de las fuentes más prolijas del desprecio a la filosofía moral de Kant; por ejemplo, en lo que atañe al supuesto origen teológico de conceptos típicamente kantianos como el de obligación, deber, respeto, dignidad o ley. Una versión algo gruesa de los argumentos schopenhauerianos ha destilado sin duda algo de la cosmovisión omnipresente en nuestra actualidad y que el propio autor hace objeto de crítica a propósito de su reflexión final sobre el valor de las humanidades, la cual tiene como consecuencia directa la derogación más absoluta de toda vocación deontologista. Sin duda, una de las lanzas del pragmatismo más ramplón consiste precisamente en repetir como un mantra la idea de que a todos ojos es evidente que el deber, en última instancia, no puede sino estar motivado por una expectativa soterrada de un interés o premio ulterior (ya sea este terreno o ultraterreno, sensible o suprasensible). Concepción esta nada alejada de la crítica de Schopenhauer al concepto de deber incondicionado. En este sentido, el mundo no solo es voluntad (previa a la razón) y representación, sino que es $m i$ voluntad y $m i$ representación, de manera que bajo el imperativo categórico siempre acecha el móvil del egoísmo como condición última de toda posibilidad de universalización de las leyes morales. El Dios guillotinado por la primera crítica y resucitado por la segunda, según las palabras de Heine, se disuelve invirtiendo las relaciones entre religión y moral en las lecciones de filosofía moral anotadas por su alumno Mrongovius, donde se pone de manifiesto muy a las claras que la religión desempeña un papel meramente ancilar como Triebfeder de la moral, pues si la moral estuviera al servicio de la religión o basara sus preceptos en esta, sus leyes morales devendrían a juicio de Kant en meros estatuta. 
La figura de Spinoza evocada en la tercera crítica servirá a Kant para ejemplificar al hombre íntegro que, precisamente por no creer en Dios, obra bien al margen de la expectativa de recibir ninguna recompensa por sus buenas acciones. Por otra parte, su falta de esperanza en una transformación moral del mundo representa el contraejemplo perfecto de la Tugendlehre kantiana merced a la cual, según la lógica de la profecía que se cumple a sí misma, la creencia en la posibilidad de un mundo mejor es condición necesaria para albergar la disposición adecuada para promover dicha transformación. La recuperación de esta vuelta a Spinoza conecta con una de las propuestas más audaces, presentada ya en otras obras anteriores del autor, como es la formulación de una suerte de "imperativo elpidológico" que complementaría a las ya clásicas formulaciones del imperativo categórico. En este sentido, a mi modo de ver, y como he defendido en otros contextos, a las dos formulaciones del imperativo mencionadas por el autor (la fórmula de la universalización nomológica y la fórmula de los medios-fines o "imperativo de la disidencia") cabría sumarle las siguientes: la fórmula cosmopolita, la comunitaria, la contractual, la jurídica, la penal y la de la publicidad.

Entre el pensamiento de Rousseau y de Kant —rastreando, entre otras, ciertas afinidades electivas entre la Profesión de fe de un Vicario saboyano y La Religión dentro de los límites de la mera razón - el autor establece correlaciones muy significativas: ambos son pensadores preocupados por la desigualdad social; conceden gran importancia a la pedagogía; critican los privilegios hereditarios; vinculan de modo inextricable la política y la moral y, lo más importante a mi juicio, conciben la libertad como autocoacción.

Por lo demás, en el libro quedan abiertas líneas de investigación muy fecundas, fundamentalmente recogidas en una coda sobre las emociones políticas y sus antecedentes y raíces en otros pensadores de la Ilustración que concedieron un lugar a las mismas mucho más importante de lo que cabría suponer de inicio. Frente a estudios como los de Philipp Blom o Jonathan Israel, el libro nos ofrece una revisión de la distinción ya consagrada entre una Ilustración moderada y una Ilustración radical — de la que el diálogo con Spinoza sería su gozne- en la que se recupera la importancia del papel que desempeñaron algunos representantes del flanco moderado de la Ilustración. La revisión de este tópico permite al autor, en la estela de autores como Jean Ferrari, Simone Goyard-Fabre, Georg Cavallar o Pauline Kleingeld, reconstruir la influencia que pudieron ejercer en Kant la lectura de las contribuciones anónimas de Diderot a la Historia de Indias o de algunos artículos de la Enciclopedia como aquel en el que el ilustrado francés reivindica la figura del ecléctico como la del filósofo que "se atreve a pensar por sí mismo". A juicio del autor, la versión tardía del anticolonialismo y del cosmopolitismo, la hospitalidad o la tesis del derecho del primer ocupante, deberían mucho a la repercusión indirecta que la lectura de Diderot ejerció sobre Kant. Otros aspectos como sus posiciones respectivas ante las revoluciones americana y francesa serían asimismo signo inequívoco de mutua afinidad.

La consideración política de las tesis de Kant se cifra también en un diagnóstico final sobre las instituciones, las universidades públicas regidas por el imperativo económico de la transferencia o el papel de las humanidades en la sociedad donde, con honesta heterodoxia, se reivindica una peculiar forma de militancia para la filosofía que, merced a su genuina condición crítica, se presenta independiente de toda instancia de poder o facción política, como seguramente habría sostenido el Kant que todavía reivindica a la filosofía como el ala izquierda del parlamento de la ciencia. 


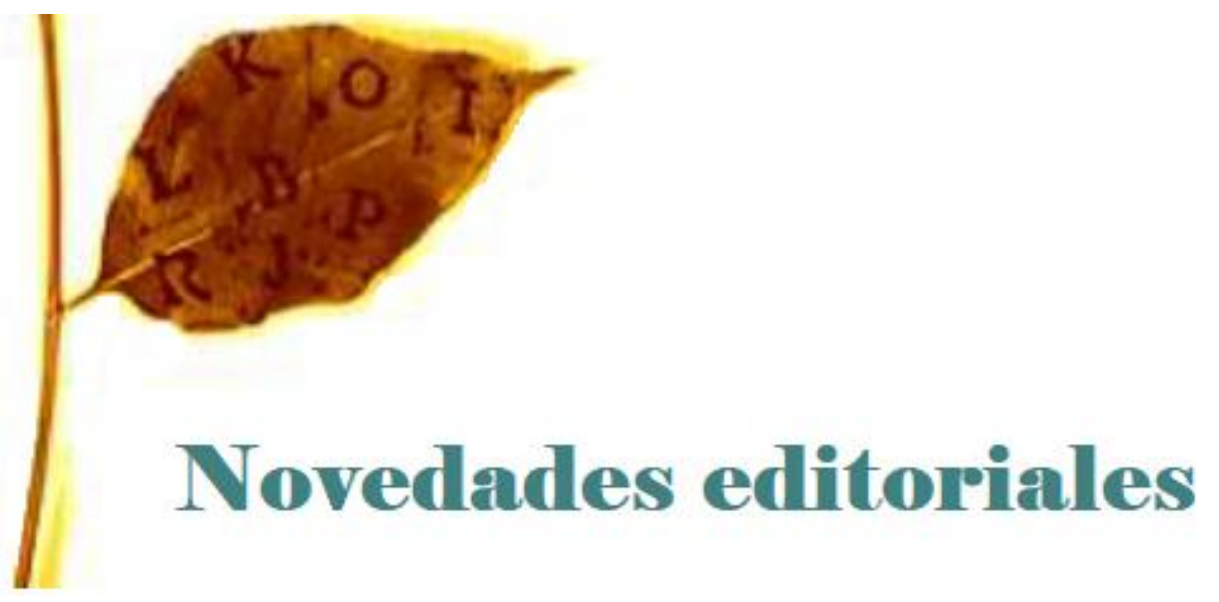


Immanuel Kant: Crítica de la razón pura. Estudio preliminar, traducción y notas de Mario Caimi. Segunda reimpresión con correcciones del traductor. México, Fondo de Cultura Económica, Universidad Autónoma Metropolitana y Universidad Nacional Autónoma de México, 2018, 734 pp. ISBN: 978-60716-0119-3.

MARIO CAIMI ${ }^{1}$

Quizá sea una característica propia de la traducción de los grandes textos clásicos el estar sujeta a incesante corrección y perfeccionamiento, de acuerdo con el avance de la comprensión de ellos. La obra de Kant, y especialmente la Crítica de la razón pura, es objeto de estudio desde hace más de dos siglos. Nuevas interpretaciones se apoyan en las precedentes, las profundizan o las corrigen, abriendo así perspectivas siempre nuevas y cada vez más ricas. También las traducciones de las obras kantianas recorren este camino de perfeccionamiento incesante. Esto se comprueba ahora en esta segunda reimpresión de la primera Crítica. Se ha perfeccionado en ella la selección de los términos (la discutible traducción del verbo erweitern y sus derivados ha sido sustituida por el más exacto "ampliar" y sus derivados) y, gracias a los progresos de la interpretación, se ha modificado la versión de algunas frases, cambiándola por otra más ajustada al pensamiento del autor. También se ha corregido algún erratum.

La presentación editorial es impecable. El libro contiene, como en la versión anterior, los índices confeccionados por Esteban Amador, Mariela Paolucci y Marcos Thisted, y la tabla de correspondencias de traducción de términos de Dulce María Granja, María de Jesús Gallardo, Ernesto Aguilar y Óscar Palancares. Es oportuno agradecer este esfuerzo de las editoriales responsables, que brindan ahora una mejor versión de una de las obras cumbres de la filosofía.

${ }^{1}$ CONICET / Universidad de Buenos Aires, Facultad de Filosofía y Letras. Contacto: mcaimi3@yahoo.com 


\title{
Gustavo Leyva; Álvaro Peláez; Pedro Stepanenko (eds.): Los Rostros de la Razón: Immanuel Kant desde Hispanoamérica. Barcelona, Anthropos Editorial; México, Universidad Autónoma Metropolitana, 2018, 3 vols., 208 pp. ISBN: 978-84-16421-91-6.
}

\author{
GuSTAVO LEYVA ${ }^{1}$
}

Prácticamente desde su publicación en lengua alemana la obra de Immanuel Kant y su pensamiento se convirtieron en una referencia central en la discusión filosófica. Así, la obra de Kant ha sido leída, interpretada, desarrollada y discutida en forma incesante en los últimos dos siglos en el marco de diversas tradiciones, vertientes y disciplinas: en la filosofía anglosajona y en la continental lo mismo que en la iberoamericana, sea en el ámbito de la epistemología o en el de la ética, la estética, la filosofía del derecho, la filosofía política, la filosofía de la historia y la filosofía de la religión. Ello concierne, y retomamos aquí la distinción establecida por Norbert Hinske, a la filología y a la investigación kantianas lo mismo que al kantianismo. La primera —esto es, la filología kantianase ocupa del establecimiento y de la fijación de los textos originales kantianos; la segunda — es decir, la investigación kantiana - se propone investigar preguntas en torno a la biografía, el desarrollo intelectual, el comentario a los textos, la historia de las fuentes y conceptos del pensamiento kantiano; finalmente, el tercero - el kantianismo - se comprende como una propuesta filosófica sistemática en torno a preguntas tanto de la filosofía teórica como de la filosofía práctica al igual que de la estética, la filosofía de la historia y la filosofía de la religión. Todas estas dimensiones han sido incorporadas en los tres volúmenes que ahora presentamos al lector bajo el título general de Los rostros de la razón: Immanuel Kant desde Hispanoamérica. En ellos se recogen una serie de aportaciones centrales de algunos de los investigadores y estudiosos más destacados del pensamiento de Kant en lengua española. A fin de ofrecer una visión más clara tanto del pensamiento de Kant como de la estructura de este libro, éste ha sido dividido en tres volúmenes: el primero de ellos está dedicado a la Filosofía Teórica; el segundo, a la Filosofía Moral, Política y del Derecho y, finalmente, el tercero, lo hemos consagrado a la Filosofía de la Religión, de la Historia y Crítica de la Facultad de Juzgar: Estética y Teleología.

\footnotetext{
${ }^{1}$ Universidad Autónoma Metropolitana, México D. F. Contacto: leyv@xanum.uam.mx
} 


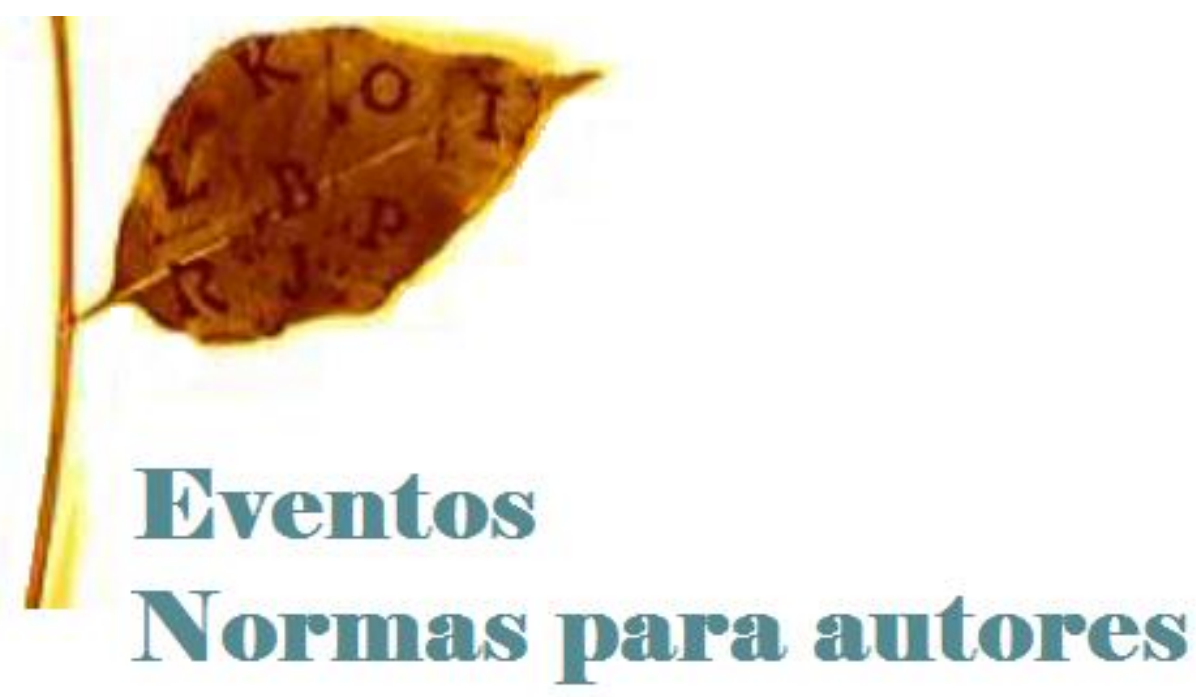




\title{
LEUVEN KANT CONFERENCE 2019: KANT'S TRANSCENDENTAL DIALECTIC
}

\author{
May 23-24, 2019 \\ KU Leuven, Belgium
}

\section{Call for papers}

The Leuven Research Group in Classical German Philosophy (LCGP) invites submissions of abstracts for the yearly Leuven Kant Conference.

The upcoming edition of the Leuven Kant Conference differs from preceding ones in two respects. We will not make a distinction between keynote speakers and participants selected on the basis of their abstracts, and we intend the conference to provide a space for open exchange between established scholars, early career researchers, and PhD students. Moreover, the conference will be devoted to a specific topic: Kant's Transcendental Dialectic.

Kant famously claimed in a letter to Garve that he was awoken from his dogmatic slumber by his identification of the antinomy of pure reason, which he took to represent 'the scandal of the ostensible contradiction of reason with itself'. In this sense, the Critique of Pure Reason can be said to owe its impetus to the critique of metaphysics carried out in Transcendental Dialectic, more specifically, its analysis of the 'natural and unavoidable illusion' that emerges in attempts to obtain a priori knowledge of the soul, the world as such, and God. However, the section was all-but ignored by many early commentators. Following in the wake of the monographs by Wood, Ameriks, and Grier, more recent studies provide valuably focused accounts of specific parts and aspects of the text. However, they often do not connect Kant's various claims in the Dialectic and tend to ignore the systematic place of the Dialectic in Kant's theoretical philosophy.

We invite proposals on any aspect of the Transcendental Dialectic of Kant's Critique of Pure Reason. Given the wide scope of this division of the work, we do not plan to include papers on the Dialectic chapters of the second and third Critiques, the reception of Kant's Dialectic by postKantians, or the notion of dialectic in philosophers other than Kant.

Topics may include (but are not limited to):

- The arguments in the Transcendental Dialectic

- Kant's notion of dialectic in general

- The aim and nature of Kant's engagement with former metaphysics in the Transcendental Dialectic

- Kant's interlocutors and the immediate historical context of the Transcendental Dialectic

- The unity or disunity of the Transcendental Dialectic's chapters: the Paralogisms, Antinomies and Ideal

- Transcendental illusion

- Kant's account of phenomena and noumena in relation to the Transcendental Dialectic

- Kant's conception of the ideas of reason

- The relation between the Appendix and the main part of the Transcendental Dialectic

- The relation between Kant's pre-critical works and the Transcendental Dialectic 
Abstracts (no more than 500 words) should be sent in word format, as attachment, to leuvenkantconference@kuleuven.be up to January 14, 2019. Abstracts, including the title, should be prepared for double-blind review by removing any identification details. The author's name, paper title, institutional position and affiliation, as well as contact information, should be included in the body of the email.

Notification of acceptance by February 10, 2019. Presentation time will be 25 minutes +20 minutes for discussion. We offer limited travel grants to $\mathrm{PhD}$ students without funding of their own. Registration for the conference consists of $10 €$ fee (including coffee and lunch breaks, without conference dinner) or $55 €$ (including coffee and lunch breaks, with conference dinner). Speakers pay $35 €$ (coffee, lunch breaks and conference dinner included). Registration is free for KU Leuven students and staff members.

More information:

http://hiw.kuleuven.be/leuvenkantconference

Practical information (travel and accomodation):

https://hiw.kuleuven.be/cmprpc/events/leuvenkantconference/practical

Organizers:

Karin de Boer (KU Leuven)

Henny Blomme (KU Leuven)

Stephen Howard (KU Leuven).

Leuven Kant Conference Committee:

Karin de Boer (KU Leuven)

Arnaud Pelletier (Université Libre de Bruxelles)

Simon Truwant (KU Leuven)

Dennis Vanden Auweele (KU Leuven)

\section{KU LEUVEN}

\section{INSTITUTE OF PHILOSOPHY}




\section{Normas para autores/as}

La revista publica trabajos redactados en lengua castellana, alemana, inglesa y portuguesa y referidos a cualquiera de los ámbitos relativos a la filosofía kantiana o en los que la presencia de esta tenga una relevancia significativa. Las contribuciones deben ser originales y su extensión no podrá superar los 80.000 caracteres con espacios. Las reseñas no excederán los 16.000 caracteres con espacios.

\section{Encabezamiento}

El texto será precedido por título (Times New Roman, 14 puntos), un resumen (máx. 100 palabras, Times New Roman, 7 puntos) y hasta cinco palabras clave (Times New Roman, 7 puntos, separadas por comas), tanto en la lengua propia del artículo como en inglés (si la lengua empleada en el trabajo es el castellano) o en castellano (si el trabajo está redactado en inglés, alemán o portugués).

\section{$\underline{\text { 2. Estilo }}$}

\subsection{Cuerpo de texto}

Los textos serán redactados en Times New Roman, 9 puntos, interlineado múltiple 1,15, con espaciado posterior de 6 puntos, con párrafos justificados y sangrados $(1,25 \mathrm{~cm})$ en primera línea siempre que no se trate del párrafo que da comienzo a una sección.

\subsection{Citas}

Las referencias relativas a una cita textual aparecerán en cuerpo de texto, indicando entre paréntesis autor y año seguido de dos puntos y número de página, según el modelo:

...tal y como indica el naturalista inglés (Darwin 1871: 32).. / ...tal y como indica el naturalista inglés Darwin (1871: 32)... / «...todo apuntaba en esa dirección» (Autor1; Autor2; Autor3 2018: 15) / «...todo apuntaba en esa dirección» (Autor1 et al. 2018: 15) / Autor et al. (2018) ha explicado que «...todo apuntaba en esa dirección» (15).

Ello no excluye que se abra una reflexión complementaria, si así se estima oportuno, en nota a pie de página, a 7 puntos, Times New Roman. Cuando se indique que parte de la cita ha sido omitida se emplearán tres puntos entre corchetes [...]. Si la cita es en lengua distinta a la del artículo, se tratará de buscar su traducción en alguna edición en castellano y se añadirá entre corchetes la cita en la lengua original (en caso de que no se disponga de una traducción, el autor indicará que la misma ha sido elaborada por él mismo mediante la abreviatura a. trad., o bien en una nota a pie de página si todas las traducciones son propias); por ejemplo

«...todo apuntaba a dicha interpretación» [«...All leads us in that direction»] (Autor 2017: 18; 1995: 20) / «...todo apuntaba a dicha interpretación» (a. trad.) [«...All leads us in that direction»] (Autor 1995: 20) 
Cuando las citas textuales superen los 4 renglones se colocarán aparte, a 8 puntos, en un párrafo justificado y sangrado en primera lína a $1,25 \mathrm{~cm}$.

Citaciones kantianas

En el caso de obras de Kant, en cuerpo de texto y nota se aludirá a ellas empleando las abreviaturas establecidas por la Kant-Forschungsstelle de Maguncia. Las abreviaturas se hallan publicadas en su página web (http://www.kant.uni-mainz.de/), pestaña 'Kant-Studien', sección 'Hinweise für Autoren'.

\subsection{Apartados}

Los encabezados de los apartados y subapartados se indicarán mediante la siguiente numeración: 1, 1.1, 1.1.1... etc., sin cursiva ni negrita, a Times New Roman, 9 puntos. La enumeración de listados empleará los indicativos i), ii), iii) etc. Cada apartado irá separado del anterior por un espacio en blanco.

2.4. Uso de las comillas, guiones, corchetes y cursiva

Comillas bajas, latinas, españolas o angulares («»): para citas textuales, ej. «todo apuntaba en esa dirección».

Comillas altas o inglesas (“"): para títulos de artículos, capítulos de libro, noticias, posts, entradas en una web, entradas en enciclopedia, título de ponencia..., ej. En el tercer capítulo "La verdad y la mentira" / Así lo demostró en su artículo "La recepción de los colores".

Comillas simples (' ’): para añadir énfasis a una palabra o expresión, ej. Esa 'verdad' era muy relativa.

Corchetes ([ ]): para la traducción de palabras extranjeras, ej. Cuando Heidegger habla de Stimmung [estado de ánimo], está refiriéndose a...

Cursiva: reservada para palabras o expresiones en lengua distinta a la del manuscrito, así como para títulos de libro, revistas, periódicos, películas, páginas web, blogs, congresos..., ej. Así lo describe Kant en la Crítica de la razón pura / La noticia apareció en El país / La revista Evolutionary Anthropology se encargó de la publicación... / Como apunta la autora en su web Ver para creer...

\subsection{Notas a pie}

Los números indicativos de las notas a pie de página (que en ningún caso se colocarán al final del documento, sino al final de cada página) deben encontrarse después de los signos de puntuación.

\subsection{Referencias bibliográficas}

Las referencias bibliográficas completas aparecerán al final de la contribución, en un apartado ad hoc bajo el título Bibliografía o Referencias, según corresponda, por orden alfabético aplicado a los apellidos de los autores. En el caso de que varias publicaciones del mismo autor coincidan en el mismo año, se las distinguirá con letras (1999a, 1999b).

Citas de libros

MORENO, Juan: Los retos actuales del darwinismo. ¿Una teoría en crisis?, Madrid, Síntesis, 2008.

DARWIN, C.: The Descent of Man and Selection in Relation to Sex, Londres, John Murray, 1871, 1882 ( $2^{\mathrm{a}}$ ed.).

: El origen del hombre y la selección en relación al sexo, traducción de Julián Aguirre, Madrid, EDAF, 2006. 
Capítulos de libro

KINSBOURNE, Marcel: "Integrated field theory of consciousness", en MARCEL, A.; BISIACH, E. (eds.): Consciousness in Contemporary Science, Oxford, Oxford University Press, 1988, 35-78.

ROS VELASCO, J.: "Introduction", en: Feminism. Past, Present, and Future Perspectives, Nueva York, Nova, 2017, 1-16.

Artículos

TINBERGEN, Nikolaas: "On aims and methods of Ethology", Zeitschrift für Tierpsychologie 20 (1963) 410-433.

MARTIN, S.: "Recepciones de la despersonalización”, Retos 12, 3 (2015) 103-115.

Recursos de internet

LEMOS RODRÍGUEZ, R.: "Conoce los beneficios del aburrimiento", La mente es maravillosa (Web), 2015, https://lamenteesmaravillosa.com/conoce-los-beneficios-del-aburrimiento/.

CAMPOS DÍEZ, Abigail: "Cómo vencer al aburrimiento sin moverse del sofá”, El país (online), 2015, https://elpais.com/elpais/2015/02/19/buenavida/1424345312_592437.html.

FLORES, Y.: “Aburrido. ¿Qué hacer contra el aburrimiento?”, El blog de Yes (Blog), 2017, http://www.elblogdeyes.com/aburrido-que-hacer-contra-el-aburrimiento/.

ARCHILA, Arturo: "El aburrimiento", Youtube (Clip de video), 2016, https://www.youtube.com/watch?v=0NXrkHpIFn4.

\section{Revisión}

Cada autor/a revisará detenidamente que de su envío haya sido eliminado cualquier indicio que pudiera denotar su identidad. En el caso de que se aluda a publicaciones propias, se sustituirá todos los datos por la indicación [Datos eliminados para favorecer la anonimidad del envío]. Del mismo modo, se cuidará de que el documento no contenga información sobre la autoría en sus propiedades informáticas.

\section{Envío}

Los trabajos deberán ser enviados a través de la plataforma virtual:

https://ojs.uv.es/index.php/REK/

Es aconsejable que los autores revisen los artículos publicados previamente para una mejor adaptación a las normas de estilo o que usen la plantilla disponible en la web de la revista. 


\section{Instructions for contributors}

The journal publishes papers in Spanish, German, English, and Portuguese, dealing with Kantian philosophy or with issues raised in it. Contributions must be original and should not exceed 25 pages (80,000 characters with spaces). Reviews should not exceed 5 pages ( 16,000 characters with spaces).

\section{Heading}

The text will be headed by title (Times New Roman, 14 points), abstract (max. 100 words, Times New Roman, 7 points) and keywords (max. 5, Times New Roman, 7 points, separated by commas) in both the language in which the work is written and English (if written in Spanish) or Spanish (if written in English, German, or Portuguese).

\section{Style}

\subsection{Body text}

The text will be written in Times New Roman, 9 points, multiple spacing 1,15, line spacing after 6 points, justified paragraphs, first line intended $(1,25 \mathrm{~cm})$, as long as it is not the paragraph with which the section starts.

\subsection{Quotes}

The textual quotes will appear in the text self, by referring to author and year followed by colon and page number. For example:

...so as pointed out by the British naturalist (Darwin 1871: 32)... / ...as so pointed by the British naturalist Darwin (1871: 32) / «....all leads us to that direction» (Autor1; Autor2; Autor3 2018: 15) / «... all leads us to that direction » (Autor1 et al. 2018: 15) / Autor et al. (2018) explained that all leads us to that direction» (15).

If considered suitable, a further discussion in a footnote is not excluded ( 7 points, Times New Roman). To indicate that a part of the quoted text has been omitted three points will be used in brackets [...]. If the quote is in a different language, the author should look for a translation, adding the original quote in brackets. If no translation is available, the author will indicate that it has been drawn up by himself by the abbreviation a. trans. or in a footnote if all translations have been made by the author.

«...All leads us in that direction» [«...todo apuntaba a dicha interpretación»] (Autor 2017: 18; 1995: 20) / «...All leads us in that direction» (a. trans.) [«...todo apuntaba a dicha interpretación»] (Autor 1995: 20)

When quotations exceed 4 lines will be placed apart, 8 points, in a justified paragraph and $1,25 \mathrm{~cm}$. 


\section{Kantian quotes}

The citation of Kantian texts will employ the abbreviations established by the Kant-Forschungsstelle Mainz (see website http://www.kant.uni-mainz.de/, 'Kant-Studien', section 'Hinweise für Autoren').

\subsection{Sub-headings}

The headings of the sections and subsections shall be indicated by the following numbers: $1,1.1$, 1.1.1., etc., without italics nor bold, Times New Roman, 9 points. To enumerate the elements of a list: i), ii), iii), etc. Each sub-heading will be separated from the previous by a space.

\subsection{Quotation marks and italics}

Angled quotes («»): literary quotes, e.g. «all leds us in that direction».

Inverted commas (“"): titles of papers, book chapters, news, posts, communications... e.g. In the third chapter "The truth and the lie" / That was pointed in his paper "Color perception".

Single quotes (' '): to add emphasis to a word or expression, e.g. This 'truth' is relative.

Brackets ([ ]): to translate words in other language, e.g. Heidegger is talking about the Stimmung $[\operatorname{mood}] \ldots$

Italics: to foreign words and titles of books, journals, diaries, movies, websites, blogs, conferences... e.g. This is what Kant says in his Critique of pure reason / The piece of news published in the New York Times... / The journal Evolutionary Anthropology published... / As the author point in her web Looking for knowledge...

\subsection{Footnotes}

The indicative numbers for footnotes (which in any case will be placed at the end of the document, but at the end of each page) must meet after punctuation.

\subsection{References or Bibliography}

The complete references will be indicated (in alphabetic order of the name of the authors) at the end of the contribution, in a section entitled Bibliography or References. Should different publications of an author be edited in the same year, they will appear with subscript characters (1999a, 1999b).

Books

MORENO, Juan: Los retos actuales del darwinismo. ¿Una teoría en crisis?, Madrid, Síntesis, 2008.

DARWIN, C.: The Descent of Man and Selection in Relation to Sex, London, John Murray, 1871, $1882\left(2^{\mathrm{a}}\right.$ ed.).

: El origen del hombre y la selección en relación al sexo, translated by Julián Aguirre, Madrid, EDAF, 2006.

Book chapter

KINSBOURNE, Marcel: "Integrated field theory of consciousness", in MARCEL, A.; BISIACH, E. (eds.): Consciousness in Contemporary Science, Oxford, Oxford University Press, 1988, 35-78.

ROS VElASCO, J.: "Introduction", in: Feminism. Past, Present, and Future Perspectives, New York, Nova, 2017, 1-16. 
TINBERGEN, Nikolaas: "On aims and methods of Ethology", Zeitschrift für Tierpsychologie 20 (1963) 410-433.

MARTIN, S.: “Recepciones de la despersonalización”, Retos 12, 3 (2015) 103-115.

Internet resources

LEMOS RODRÍGUEZ, R.: "Conoce los beneficios del aburrimiento", La mente es maravillosa (Web), 2015, https://lamenteesmaravillosa.com/conoce-los-beneficios-del-aburrimiento/.

CAMPOS DÍEZ, Abigail: "Cómo vencer al aburrimiento sin moverse del sofá”, El país (online), 2015, https://elpais.com/elpais/2015/02/19/buenavida/1424345312_592437.html.

FLORES, Y.: “Aburrido. ¿Qué hacer contra el aburrimiento?”, El blog de Yes (Blog), 2017, http://www.elblogdeyes.com/aburrido-que-hacer-contra-el-aburrimiento/.

ARCHILA, Arturo: "El aburrimiento", Youtube (Videoclip), 2016, https://www.youtube.com/watch?v=0NXrkHpIFn4.

\section{$\underline{\text { 3. Revision }}$}

Each author will make sure that all indication of identity has been removed. In case of quotation of the author's own publications, the reference will be replaced by the sentence "[Reference removed to guarantee anonymous review]". The author will take care that the file does not include personal information within its digital properties.

\section{Sending}

Contibutions should be uploaded to:

https://ojs.uv.es/index.php/REK/

It is advisable that the authors review the previously published articles or use the provided template to better adaptation to the style rules. 